\title{
Rectal bleeding, a danger signal?
}

Citation for published version (APA):

Fijten, G. H. (1993). Rectal bleeding, a danger signal? [Doctoral Thesis, Maastricht University]. Thesis Publishers. https://doi.org/10.26481/dis.19931208gf

Document status and date:

Published: 01/01/1993

DOI:

10.26481/dis.19931208gf

Document Version:

Publisher's PDF, also known as Version of record

\section{Please check the document version of this publication:}

- A submitted manuscript is the version of the article upon submission and before peer-review. There can be important differences between the submitted version and the official published version of record.

People interested in the research are advised to contact the author for the final version of the publication, or visit the DOI to the publisher's website.

- The final author version and the galley proof are versions of the publication after peer review.

- The final published version features the final layout of the paper including the volume, issue and page numbers.

Link to publication

\footnotetext{
General rights rights.

- You may freely distribute the URL identifying the publication in the public portal. please follow below link for the End User Agreement:

www.umlib.nl/taverne-license

Take down policy

If you believe that this document breaches copyright please contact us at:

repository@maastrichtuniversity.nl

providing details and we will investigate your claim.
}

Copyright and moral rights for the publications made accessible in the public portal are retained by the authors and/or other copyright owners and it is a condition of accessing publications that users recognise and abide by the legal requirements associated with these

- Users may download and print one copy of any publication from the public portal for the purpose of private study or research.

- You may not further distribute the material or use it for any profit-making activity or commercial gain

If the publication is distributed under the terms of Article $25 \mathrm{fa}$ of the Dutch Copyright Act, indicated by the "Taverne" license above, 


\section{Rectal bleeding, a danger signal?}

Bloedverlies per anum, een alarmsignaal? 
Omslag: Guus van Rooy, RL Design 


\section{Rectal bleeding, a danger signal?}

\section{Proefschrift}

ter verkrijging van de graad van doctor aan de Rijksuniversiteit Limburg te Maastricht,

op gezag van de Rector Magnificus,

Prof. dr. H. Philipsen, volgens besluit van het College van Dekanen, in het openbaar te verdedigen op woensdag, 8 december 1993 om 16.00 uur

door

Gertrudis Hubertina Fijten

geboren te Maasbracht

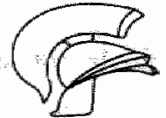


Promotores:

Prof. Dr. G.H. Blijham

Prof. Dr. J.A. Knottnerus

Beoordelingscommissie: Prof. Dr. P. Pop (voorzitter)

Dr. C.G.M.I. Baeten

Prof. Dr. D. Bruusgaard (Universiteit van Oslo,

Noorwegen)

Prof. Dr. C.A. de Geus

Prof. Dr. F. Sturmans

Dit onderzoek heeft plaats gewonden met financiële steun van het Ministerie van $\mathrm{O} \& \mathrm{~W}$ middels het Vernieuwingsfonds.

De uitgave van dit proefschrift kwam mede tot stand door een bijdrage van de firma $E$. Merck Nederland BV te Amsterdam. 
Aan mijn vader 


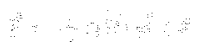

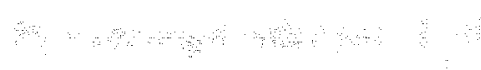
As?

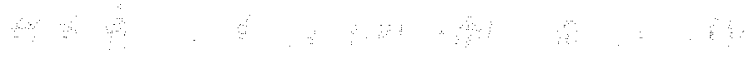

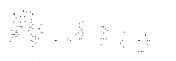

$+8$

4as: Wh: 


\section{Contents}

1. Introduction

2. The occurrence and significance of overt blood loss per rectum in the general population and in medical practice

3. Diagnostic approach of patients with rectal bleeding in general practice. State of the art

4. Methods of the empirical study

5. The incidence and outcome of rectal bleeding in general practice

6. Predictive value of signs and symptoms for colorectal cancer in patients with rectal bleeding in general practice

7. Predictive value of signs, symptoms and laboratory tests in patients with rectal bleeding in an outpatient clinic

8. General discussion

9. Summary

Samenvatting

Dankwoord

Curriculum vitae

Appendices

I Doctor's form, study A and study C

II Laboratory tests

III Patient's form

IV Doctor's form, study B

V Variables in relation to several diagnoses in study $A$ and in study $C$ 


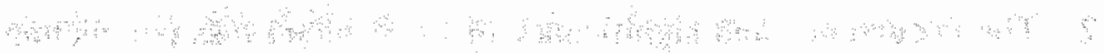

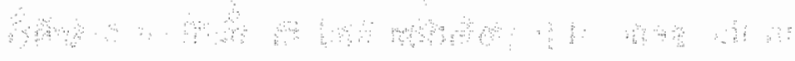

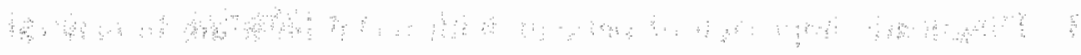




\section{Introduction}

Is overt blood loss per rectum (rectal bleeding) a danger signal?

According to public health education programmes aiming at early diagnosis of colorectal cancer and according to most medical literature, it is. Rectal bleeding is thought to be a symptom of early rather than late colorectal cancer ${ }^{1}$ and every instance of rectal bleeding, in particular in patients over 40 , demands careful clinical investigation by endoscopy, roentgenography and laboratory means. ${ }^{2-5}$ This can also be illustrated by a recent editorial in the Lancet saying that "rectal bleeding is always alarming, with the fear of cancer being uppermost in the patient's mind". "Only the foolhardy look no further: even when an obvious cause for bleeding is found initially, all too often another lesion lurks more proximally". ${ }^{6}$ Similarly, "patients with rectal bleeding must be considered as having a carcinoma until the opposite is proven" as was recently advised in a Dutch magazine?

However, voices have been raised cautioning against public education programmes designed to use rectal bleeding as a 'screening test' for colorectal cancer ${ }^{8}$ Rectal bleeding is not rare in healthy people and the incidence of cancer of the colon and rectum is relatively low with 0.5 cases per 1000 people per year.? The incidence of colon cancer is about 30 per 100,000 people per year, equally for men and women, and the incidence of rectum cancer is 22 for men and 14 for women per 100,000 per year. ${ }^{9}$ General practitioners (GPs), on the whole, consider invasive diagnostic investigations to be indicated only when there are reasons to suspect cancer. ${ }^{10,11}$

The general practitioner is used to facing patients who have a fear of cancer ${ }^{12}$, and he or she has to decide who can be reassured, and who should be further investigated. ${ }^{13}$ Estimates of probability are crucial in this diagnostic process. Intuitive probability assessments are susceptible to biases. ${ }^{14}$ The application of a clinical epidemiologic point of view can aid in rational clinical practice. ${ }^{15}$

Colorectal cancer is a major health problem with 2000 deaths each year in the Netherlands. ${ }^{16}$ 
The overall 5-year survival, according to 'Survival Epidemiology and End Results' (SEER) in the United States (1970-1983), was only 14\% for rectum cancer and $51 \%$ for colon cancer in the years 1973 to $1980^{17}$ and has shown little improvement recently despite the introduction of new surgical techniques and adjuvant chemotherapy. ${ }^{18}$ The reason mentioned for lack of improvement in survival is that in most cases the disease had already reached an advanced stage by time of diagnosis. ${ }^{18}$ However, it is not clear whether a delay in diagnosis in symptomatic patients, like those with overt rectal bleeding, is related to a worse prognosis ${ }^{19,20}$

In a time with growing investment in preventive and sereening activities it seems obvious that seeking a diagnosis as early as possible may do more good than harm. However, it becomes necessary to prevent unnecessary anxiety and medicalization among healthy people and to guard against overdiagnosis with excessive health care costs. ${ }^{21,22,23}$ Data to give decision making in general practice a scientific basis are not sufficiently on hand. ${ }^{24,25}$

\section{Aim of the study}

The main purpose of the present study was to collect quantitative data which will contribute to rational diagnosing of patients presenting with rectal bleeding in general practice. The main question in this study was: is it possible to discriminate effectively between patients with rectal bleeding who have colorectal cancer and those who do not; or at least to discriminate between those who need invasive investigations and those who do not?

The following questions relevant for clinical decision making were asked:

1. What is the incidence of rectal bleeding in general practice?

2. What is the prior probability of malignant disease in patients presenting with rectal bleeding in general practice? What are the frequencies of other sources of rectal bleeding?

3. What is the predictive value of (combinations of) signs, symptoms and simple laboratory tests for colorectal cancer in general practice? 
Another question of interest concerns the prior probability and predictive value in referred patients, which may be different from that in general practice and partly reflect the efficacy of the referral process. ${ }^{24-28}$ The opportunity to collect data in general internists' outpatient clinies was used to answer the following question.

4. What is the predictive value of (combinations of) signs, symptoms and simple laboratory tests for inflammatory bowel disease or neoplasm in an outpatient internal medicine clinic?

A study of this kind needs the participation of a large number of GPs since colorectal cancer is relatively rare. Such participation was expected to be possible in the area of Maastricht and the southern part of Limburg due to some favourable circumstances:

- A stimulation of extramural research by means of the "Innovation Funding" from the Dutch Ministry of Education and Science.

- The research interest in clinical epidemiology and rational diagnosis in the Department of General Practice of the University of Limburg.

- A positive attitude towards the improvement of rational diagnosis in primary care and better communication between GPs and medical specialists. Considerable stimulus for this is provided by the Diagnostic Coordinating Centre (DCC) Maastricht, which cooperates with all GPs in the Maastricht area, ${ }^{29}$ and also communicates with many other GPs in the region.

- The possibility to cooperate with a study on non-acute abdominall complaints in general practice and outpatient clinics, initiated by the Department of General Practice at the University of Limburg, funded by the Dutch Ministry of Welfare, Health and Cultural Affairs.

- The presence of a project with the aim of evaluating and improving rational diagnosing of patients referred for endoscopy of the upper intestinal tract, initiated by FJTE Vismans, internist. ${ }^{30}$

After initiation, the rectal bleeding study was allied to the non-acute abdominal complaints study. The latter study is presented separately in a thesis by JWM Muris and R Starmans. 


\section{Structure of this thesis}

The results of a literature search regarding the occurrence and significance of rectal bleeding in the general population and in general practice are found in Chapter 2.

In the literature the term rectal bleeding is usually applied to overt blood loss per anum or per rectum, but rectal bleeding in general may also mean occult blood loss. When 'rectal bleeding' is mentioned in this thesis this means overt ano-rectal blood loss seen by the patient.

In order to illuminate the location of the clinical aspects regarding patients with rectal bleeding in general practice in the Netherlands, the state of the art of the diagnostic approach is discussed in Chapter 3.

In Chapter 4 the methodology of the empirical part of the study is described.

In the following chapters the results are presented. Chapter 5 deals with the incidence and the diagnostic outcome of patients presenting with rectal bleeding in general practice. Chapter 6 deals with the predictive value of signs and symptoms in general practice. Chapter 7 reports about the predictive value of signs, symptoms and simple laboratory tests in patients presenting with rectal bleeding in an outpatient clinic.

Results are discussed in Chapter 8 and implications for the diagnostic process in general practice and recommendations for further studies are highlighted. The results are summarized in English and in Dutch in Chapter 9.

\section{References}

1. Raftery TL, Samson N. Carcinoma of the colon: a clinical correlation between presenting symptoms and survival. Am Surg 1980; 46: 600-6.

2. Gläser A, Weinert B. Fehldiagnosen bei Dickdarmkarzinomen. Zentralblatt ful Chirurgie 1976; 101(7): 418-21.

3. Graham J. Rectal bleeding. J Fam Pract 1978; 7: 169-76.

4. Bleiberg H. Gastrointestinale symptomen bij de diagnose van kanker. Patient Care (Dutch ed) 1982; 22-5.

5. Goulston KJ, Cook I, Dent OF. How irnportant is rectal bleeding in the diagnosis of bowel cancer and polyps? Lancet 1986; ii: 261-5. 
6. Editoral. Investigation of rectal bleeding. Lancet 1989; i: 195-7.

7. Havinga WH, Vismans FJFE, Sneller JP. Bloedverlies per anum: een carcinoom? Modern Medicine 1992; 16: 1068-71.

8. Chapuis $\mathrm{PH}$, Goulston $\mathrm{KJ}$, Dent $\mathrm{OF}$, Tait $\mathrm{AD}$. Predictive value of rectal bleeding in screening for rectal and sigmoid polyps. $\mathrm{Br}$ Med J 1985; 290: 1546-8.

9. Bakker D, Coebergh JWW, et al. (eds.). Cancer Incidence in The Netherlands: the southeastern part, 1978-1982. Eindhoven: Eindhoven Cancer Registry/IKZ, 1985 .

10. Melker RA de. Proctologie van de huisarts I. Huisarts Wet 1986; 29: 382-91.

11. Melker RA de. Proctologie van de huisarts II. Huisarts Wet 1987; 30:20-2.

12. Nylenna M. Fear of cancer among patients in general practice. Scand J Prim Health Care 1984; 2: 24-6.

13. Hodgkin K. Towards earlier diagnosis, $5^{\text {th }}$ edition. Edinburgh: Churchill Livingstone, 1985.

14. Slovic P, Fischhoff B, Lichtenstein S. Facts versus fears: understanding perceived risk. Chapter 33 in Kahneman D, Slovic P, Tyersky A. Judgement under uncertainty; heuristics and biases. Cambridge University Press, 1982.

15. Sackett DL, Haynes RB, Tugwell P. Clinical epidemiology. A basic science for clinical medicine. Boston: Little, Brown and Company, 1985.

16. Centraal Bureau voor de Statistiek. Vademecum of health statistics of the Netherlands. 's Gravenhage: SDU/uitgeverij/CBS-publicaties, 1991.

17. Stuurgroep Toekomstscenario's Gezondheidszorg. Kanker in Nederland. Scenario's over kanker 1985-2000. Deel 2, bijlagen. Urecht: Bohn, Scholtema \& Holkema BV, 1987.

18. Atkin WS, Cuzick J, Northover JMA, Whynes DK. Prevention of colorectal cancer by once-only sigmoidoscopy. Lancet 1993; 341: 736-40.

19. Chapuis PH, Dent OF, Fisher R, et al. A multivariate analysis of clinical and pathological variables in prognosis after resection of large bowel cancer. $\mathrm{Br} J$ Surg 1985; 72: 698-702.

20. Kyle SM, Isbister WH, Ling Yeong M. Presentation, duration of symptoms and staging of colorectal carcinoma. Austr N Z J Surg 1991; 61: 137-40.

21. Tijmstra $T$. The psychological and social implications of serum cholesterol screening. International J Risk \& Safety in Medicine 1990; 1: 29-44.

22. Tijmstra T. Iatrogene aspecten van screening. Practitioner (Durch ed.) 1991; 8: 57982.

23. Dunning AJ (chairman). Choices in Health Care. A Report by the Government Committee on Choices in Health Care, The Netherlands 1992. Distribution: Ministry of Welfare, Health and Cultural Affairs. 
24. Knottnerus IA. Interpretation of diagnostic data: an unexplored field in general practice. $J R$ Coll Gen Pract 1985; $35: 270-4$.

25. Knottnerus JA. The effects of disease verification and referral on the relationship between symptoms and diseases. Med Decis Making 1987, 7: 139-48.

26. Knottnerus JA, Knipschild PG, Sturmans F. Symptoms and selection bias: the influence of selection towards specialist care on the relationship between symptoms and diagnoses. Theoretical Medicine 1989, 10:67-81.

27. Knottnerus JA, Leffers P. The influence of referral patterns on the characteristics of diagnostic tests. $J$ Clin Epidemiol 1992, 45:1143-54.

28. Fijten $\mathrm{GH}, \mathrm{Blijham}$ GH, Unexplained lymphadenopathy in family practice: an evaluation of malignant causes and the effectiveness of physicians" workup. $J$ Fam Pract 1988; 27: 373-6.

29. Beusmans GHMI. Huisarts en Diagnostisch Centrum. Toepassing van werkafspraken door huisartsen. Proefschrift. Maastricht: Rijksuniversiteit Limburg, 1986.

30. Vismans FJTE, Adang RPR. De waarde van de anamnese bij dyspepsie. Medifo 1989; 5(2): 4-10, Utrecht: Bohn, Scheltema \& Holkema. 
2. The occurrence and significance of overt blood loss per rectum in the general population and in medical practice

Gerda H Fijten,, Geert H Blijham ${ }^{* *}$, J André Knottnerus ${ }^{* * *}$

* Diagnostic Coordinating Centre Maastricht

" Department of Internal Medicine, University Hospital, Utrecht

${ }^{* * *}$ Department of General Practice, University of Limburg, Maastricht

Accepted by the British Journal of General Practice for publication 


\section{ABSTRACT}

To determine the occurrence and significance of overt blood loss per rectum a Medline literature search was undertaken. The incidence of this symptom in the general population is reported to be about 20 per 100 people per year, the 'consultation incidence' in general practice is about 6 per 1000 and the incidence of referral to a medical specialist is estimated to be about 7 per 10000 per year. The clinical significance of the symptom varies within different populations: the predictive value of overt rectal blood loss for colorectal malignancy can be estimated to be less than 1 in 1000 in the general population, around 2 in 100 in general practice and up to 36 in 100 in the referred patients. How the manifestation of the bleeding (and other signs and symptoms) influence the care seeking and referral behaviour, leading to increasing prior probabilities, is unknown. 


\section{Introduction}

Overt blood loss per anum or per rectum (haematochezia) is common in general practice. Its aetiology is usually not serious but it may also be the first symptom of a colorectal malignant disorder. Although it is open to debate whether the prognosis of symptomatic colorectal malignant disease may be improved by earlier diagnosis, ${ }^{1-13}$ the finding of a carcinoma will often raise the question if it would have been possible to detect it earlier. ${ }^{14}$ Partly because of this there is considerable disagreement as to the optimal diagnostic management. Some advocate a full examination of every patient with blood loss per rectum (sigmoidoscopy in combination with barium enema or coloscopy) in order to rule out the possibility of a malignant tumour, ${ }^{15-28}$ whereas others favour a more conservative approach. ${ }^{11,29}$. The general practitioner is faced with the task to select patients in such a way that the costs and benefits of ancillary tests are reasonably balanced.

We conducted a literature study on the occurrence (i.e. the incidence and characteristic manifestations) of blood loss per rectum and its predictive value with respect to colorectal tumours in order to find data that may of use in this selection process.

\section{Method}

A literature study was undertaken by means of a Medline search (CD-ROM) in Index Medicus and Excerpta Medica and a manual search in the Family Medicine Literature Index (Famli). For the publication years 1984 to 1991 the following key words were used: "bleeding per rectum", "colorectal neoplasm" (Famli), "anal/rectal/colorectal bleeding", "anal/rectal/colorectal/gastrointestinal haemorrhage", "anal/rectal/colorectal blood loss". In some cases the search was restricted by adding the key words "colorectal polyps" and "colorectal carcinoma" (CD-ROM). Additional sources were traced on the basis of references. Also, handbooks and Dutch publications, among which those of several Dutch general practice registration projects, were consulted. 
The literature thus traced was assessed systematically on the following points:

- overt blood loss per rectum (nature of bleeding)

- the description of the population: age, sex, manner of selection

- the definition of blood loss used: in, on, or mixed with the stool, in the toilet or on the toilet paper, bright or dark red

- the period of time, the frequency, and the amount of blood loss

- the method of research: oral interview, written questionnaire, sample, population screening

- the country of origin

Altogether, 8617 references were found by CD-ROM. Studies discussing only occult blood loss or upper abdominal pathology were excluded. Also left out were studies dealing with blood loss as a side-effect of medication or surgery, with bleeding per rectum in children and with very specialistic diagnostic methods and therapeutic techniques. Approximately $2 \%$ of the studies seemed to be relevant within the scope of this study. The key word "rectal bleeding" yielded most of the references selected, and these were obtained from the Index Medicus. Excerpta Medica and Famli hardly added new references. Reports on the occurrence of overt blood loss were few as compared to those on occult blood loss. Even less in number were papers related to general practice: from CD-ROM and Famli only two references were found, and these turned out to be part of the same study.

\section{Results}

\section{General population}

\section{Incidence}

Nine studies were found relating to the general population. In these studies the occurrence of blood loss per rectum in "healthy" people, whose general practitioner was often not aware of the problem is reported (Table 1). 


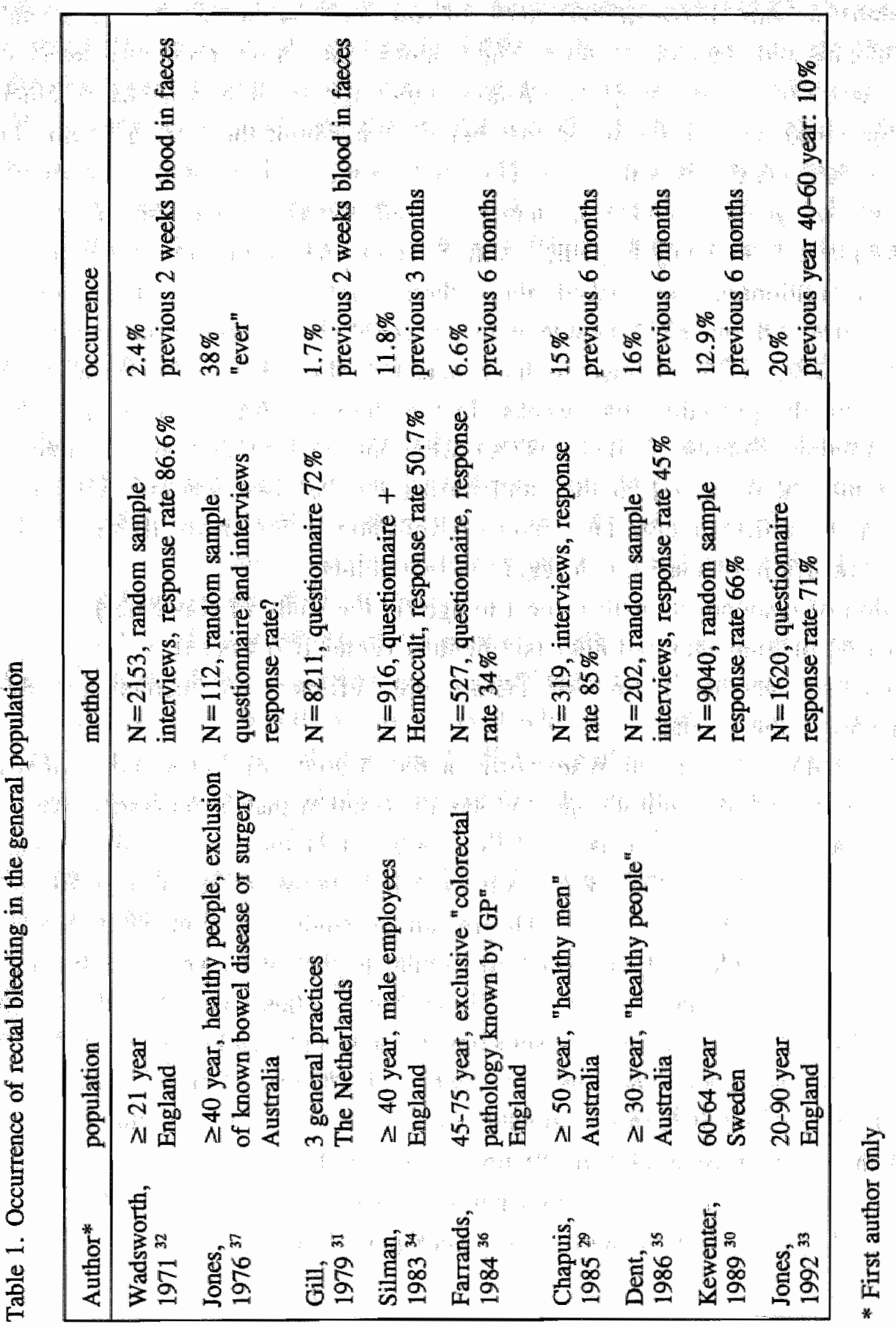


The largest study is that of Kewenter et al. ${ }^{30}$ It concerns a population screening in which persons between the ages of 60 and 64 were sent a postal questionnaire and Haemoccult tests. The response rate in the randomly selected sample was $66 \%$ ( 9040 subjects). Among other things, it was asked whether the subject had noticed any blood loss per rectum within the last half year. In $12.9 \%$ of subjects this was the case. This study is the only one with a follow-up period of two years, intended to identify any adenomas and carcinomas. In an almost equally large study by Gill, ${ }^{31}$ patients belonging to the practices of three general practitioners were asked about their stools by means of a written questionnaire. Of the 8211 people who answered the prestructured questions (response $72 \%$ ), $1.7 \%$ claimed to have detected blood in the faeces at least once during the preceding two weeks. In the study of Wadsworth et al 2153 adults (random sample, response $87 \%$ ) were interviewed and asked, among other things, about blood in the stool during the last two weeks. ${ }^{32}$ Of these $2.4 \%$ replied affirmatively. The study of Kewenter differs from those of Gill and Wadsworth particularly with regard to two points:

- selection of respondents with respect to age (in the study of Kewenter)

- the period of time enquired after (six months versus two weeks)

It is unclear whether these two factors are sufficient to account for the discrepancy in the results.

Like the studies of Gill and Wadsworth, a recent study of Jones and Lydeard concerns a population with an age and sex distribution that is representative of general practice. ${ }^{33}$ The conclusion of the study is that the prevalence of rectal blood loss amounts to $20 \%$ a year. Among people between the ages of 40 and 60 , the prevalence is lower: $10 \%$. The remaining studies, dealing with smaller numbers, yield incidence figures that are similar to that of Kewenter: Silman et al, ${ }^{34}$ Chapuis et al, ${ }^{29}$ and Dent et al. ${ }^{35}$ These three studies cover periods of 3-6 months. In the first two there is selection by age and gender: men of 40-50 years of age and older. The study of Dent et al involves men and women of over 30 years. Thus it seems reasonable to assume that $12-16 \%$ of the Western European and Australian adult population at large will affirm at any moment in time to have experienced blood loss per rectum in the past six months; for a year period, $20 \%$ will do so and for a 2 week period around $2 \%$. 
Farrands and Hardcastle ${ }^{36}$ and Jones ${ }^{37}$ present figures that deviate from the above percentages. In a study with a low response rate $(34 \%)$ Farrands and Hardcastle report rectal bleeding in $6.6 \%$ of the respondents during the last 6 months. In both studies, known intestinal disorders were an exclusion criterion. The percentages found may therefore have been higher if the total population had been considered, particularly in the study of Farrands where known haemorrhoids were possibly excluded as well. In the study of Jones ${ }^{37}$, the smallest of all, a frequency of $38 \%$ was found when the period of 6 months was extended to "ever".

Manifestation of blood lass

Only Jones reports on the frequency and volume of rectal bleeding. ${ }^{37}$ In approximately half of the cases the frequency of blood loss was more than five times; usually it was only a drop (79\%). In $21 \%$ there was medium $(18 \%)$ or heavy (3\%) bleeding. The blood was usually noticed "on the toilet paper" $(84 \%)$ and/or "on the stool" (63\%).

Other authors do not report on frequency, length of time, or amount of blood loss. In some instances the various manifestations of bleeding are mentioned. The occurrence of blood "in" or "mixed with the stool" varies widely: $100 \%$, $27 \%$, and $3 \%$ of reported bleeding. ${ }^{31,34,35}$ Two authors indicate that the blood is mostly "on the paper", "in the toilet" or "on the stool" (73\%-97\%). ${ }^{34,35}$ Usually the colour is bright red. In $23 \%-29 \%$ the blood is dark red. ${ }^{30,34}$ Finally, it is remarkable that many people $(19-43 \%)$ seldom or never inspect their faeces or the toilet paper..$^{31,35}$

\section{Diagnostic value}

The predictive value of blood loss per rectum for the presence of rectal or sigmoid neoplasms (adenomas and carcinomas), as reported in the various studies, is presented in Table 2; it varies from 3 to $8 \%$ for adenomas and from 0 to $0.95 \%$ for carcinomas. 
Table 2. Predictive value of rectal bleeding for adenomatous and malignant tumours in the rectum or sigmoid.

\begin{tabular}{|lcllc|}
\hline Author $^{*}$ & $\begin{array}{l}\text { predictive } \\
\text { value } \%\end{array}$ & comments & gold standard & $\begin{array}{l}\text { number of } \\
\text { patients }\end{array}$ \\
\hline $\begin{array}{l}\text { Silman, } \\
1983^{34}\end{array}$ & 6 & $\begin{array}{l}\text { adenoma } \geq 1 \mathrm{~cm} \\
\text { no malignancy }\end{array}$ & $\begin{array}{l}\text { flexible sigmoidoscopy } \\
\text { and barium enema }\end{array}$ & 108 \\
$\begin{array}{l}\text { Farrands, } \\
1984^{36}\end{array}$ & 3 & $\begin{array}{l}\text { adenoma } 0,5-1 \mathrm{~cm} \\
\text { no malignancy }\end{array}$ & $\begin{array}{l}\text { flexible sigmoidoscopy } \\
\text { and double contrast } \\
\text { X-ray of the colon }\end{array}$ & 35 \\
$\begin{array}{l}\text { Chapuis, } \\
1985^{29}\end{array}$ & 8 & $\begin{array}{l}\text { adenoma } \geq 1 \mathrm{~cm} \\
\text { no malignancy } \\
\text { Kewenter, }\end{array}$ & $\begin{array}{l}\text { flexible sigmoidoscopy } \\
(30 \mathrm{~cm})\end{array}$ & 48 \\
$1989^{30}$ & 4.3 & $\begin{array}{l}\text { adenoma } 3.3 \% \\
\text { malignancy } 0.95 \%\end{array}$ & $\begin{array}{l}\text { follow-up of 2 years. } \\
\text { if occult blood test } \\
\text { was positive: } \\
\text { sigmoidoscopy and } \\
\text { double contrast X-ray } \\
\text { of the colon. }\end{array}$ & 1164 \\
\hline
\end{tabular}

* First author only

In 346 people with dark red bleeding, Kewenter et al found three adenomas but no carcinomas (predictive value $0.9 \%$ ). ${ }^{30}$ In 818 people with bright red blood loss in the same study, 11 carcinomas and 35 adenomas were identified (predictive value $5.6 \%$ ). In contrast, Silman et al more frequently found an adenoma in patients with dark red $(16 \%, 4$ out of 25$)$ rather than bright red blood loss $(2.4 \%, 2$ out of 83$) .^{34}$ Chapuis et al screened 319 "healthy" men of over fifty years of age by means of sigmoidoscopy and an interview. ${ }^{29}$ They calculated that the sensitivity and specificity of rectal blood loss for rectal or sigmoid adenomas was $33 \%$ and $86 \%$, respectively (likelihood ratio for positive $\left(\mathrm{LR}^{+}\right)$or negative findings ( $\mathrm{LR}-$ ) 2.36 and 0.78 respectively). Silman et al obtained a sensitivity of $86 \%$ and a specificity of $89 \%$ for colorectal adenomas greater than $1 \mathrm{~cm}$ in diameter $\left(\mathrm{LR}^{+}=7.82, \mathrm{LR}^{-}=0.16\right){ }^{34}$ 


\section{General practice}

\section{Incidence}

The literature search yielded no references with respect to the incidence of overt blood loss per rectum in the general practice population. As a substitute we analysed the data from a number of registration projects carried out in Dutch general practices. Results are summarized in Table 3.

Table 3. Morbidity rates in Dutch general practices; incidence per 1000 persons in the population per year.

\begin{tabular}{|l|c|c|c|c|}
\hline \multirow{2}{*}{ Diagnoses } & \multicolumn{4}{|c|}{ Sources } \\
\cline { 2 - 5 } & $\begin{array}{c}\text { National } \\
\text { Study } \\
1991^{38} \\
\text { (symptoms) } \\
\text { diagnoses }\end{array}$ & $\begin{array}{c}\text { Transition } \\
\text { Project } \\
1991^{41} \\
\text { reasons } \\
\text { for } \\
\text { encounter }\end{array}$ & $\begin{array}{c}\text { Monitoring } \\
\text { Project } \\
1984 \\
\text { diagnoses }\end{array}$ & $\begin{array}{c}\text { CMR } \\
1985^{39} \\
\text { diagnoses }\end{array}$ \\
\hline $\begin{array}{l}\text { Rectal bleeding [Nos] } \\
\text { Haemorrhoid(s) }\end{array}$ & 0.4 & 4 & $0.6-0.9$ & - \\
Malignant colorectal neoplasm & $0.0^{*}$ & $0.0^{* *}$ & $0.2-1.1 *$ & 0.6 \\
Fissura ani, perianal abscess & 3.2 & 0.2 & 2.2 & 1.4 \\
Diverticulosis/-itis & 1.6 & 0 & 2.4 & 12.1 \\
Chronic enteritis/colitis & 0.8 & 0.1 & $0.5-0.2$ & \\
Others & 12.8 & 8.3 & $14.1-14.4$ & 16.1 \\
\hline $\begin{array}{l}\text { Total sum of rectal bleeding and } \\
\text { disorders where rectal bleeding } \\
\text { could be a symptom }\end{array}$ & & 4 & & $2.0^{\prime \prime}$ \\
\hline
\end{tabular}

Prevalence $=4$

** Malignant neoplasm intestine

"Others (a.o. diverticulosis, colitis) 
The National Study ${ }^{38}$ records diagnoses. In cases in which no diagnosis is made by the end of an illness episode, the symptom is registered. The incidence of "rectal blood loss, not other specified [NOS]" amounted to 0.4 per 1000 persons per year.

Moreover, a disorder in which rectal blood loss may have been a prominent symptom was diagnosed in 12.8 persons per 1000 per year. The Continuous Morbidity Registration of the Nijmegen Institute ${ }^{39}$ does not include "blood loss per rectum" as a separate category. However, a similar incidence of 16.1 per 1000 for diagnoses associated with this symptom was reported. The figures of ${ }^{\text {. }}$ the Monitoring Project ${ }^{40}$ are also in the same range. The Transition Project ${ }^{41}$ registers reasons for encounter rather than diagnoses. Consequently, the incidence of rectal blood loss as reason for encounter is higher in this study and the incidence of haemorrhoids is correspondingly lower.

We have become aware of data from partly unpublished studies regarding lower abdominal pathology in general practice, that may be of use to approximate the incidence of overt rectal blood loss. Bekker et $\mathrm{al}^{42}$ investigated the indications for proctoscopy and found an incidence of 4 per 1000 per year. Unpublished data of Fuller ${ }^{43}$ and of Nørrelund ${ }^{44}$ point to incidence rates of rectal bleeding of 8 per 1000 in England and 6 per 1000 in Denmark, respectively.

Taken together these data indicate that the incidence of rectal bleeding in general practice lies between 4 and 8 cases per 1000 per year.

\section{Manifestation and diagnostic value}

No epidemiologic data were found concerning the manifestation and the precise diagnostic value of rectal bleeding in general practice. Most registration projects lack not only a gold standard for diagnosis but also a diagnostic follow-up. An exception is the Transition project ${ }^{41}$ which gives an indication of the most frequent final diagnoses (top 5) made during subsequent visits. In illness episodes starting with "rectall bleeding" as reason for encounter, the following final diagnoses are made: in 30\% "haemorrhoids", in $26 \%$ "no cause 
found", in $18 \%$ "anal fissure or abscess", in $4 \%$ "constipation", and in $4 \%$ "other, nonspecific diagnoses". Colorectal carcinomas and adenomas are not given and therefore must have been found in less than $4 \%$ of cases of blood loss per rectum.

Hodgkin $^{45}$ indicated a ratio of $1: 20$ for the relationship between trivial and serious causes of blood loss per rectum. This would mean a predictive value of approximately $5 \%$ for "serious causes".

\section{Referred patients}

\section{Incidence}

Little has been reported on the incidence of blood loss per rectum in referred populations. Moreover, this will be highly dependent on the referral situation that is to be investigated: first or second referral centre, medical or surgical service, urban or rural populations. For the situation in the Netherlands Lamberts ${ }^{41}$ recorded a referral percentage for this complaint of $14 \%$. On the basis of this percentage, it can be calculated that around 0.56 patients per 1000 persons are referred per year because of blood loss per rectum $(14 \%$ of the incidence of 4 per 1000 per year in general practice). With an assumption of a higher incidence rate of rectal blood loss in general practice, for example 6 per 1000 , an estimation of an incidence of referred patients with rectal blood loss of is around 0.84 per 1000 per year.

\section{Diagnostic value}

Numerous reports have described the relative frequency of diagnoses in patients presenting with rectal blood loss. Again these results are partly dependent on the referral situation but may nevertheless be of use to obtain an impression of the efficacy and efficiency of the selection proces. Results of 26 reports are summarised in Table 4 . In the Australian studly, ${ }^{46}$ the predictive value of blood loss per rectum for the presence of tumours was $19 \%$ : for malignancy $11 \%$ and for adenomas $8 \%$. 


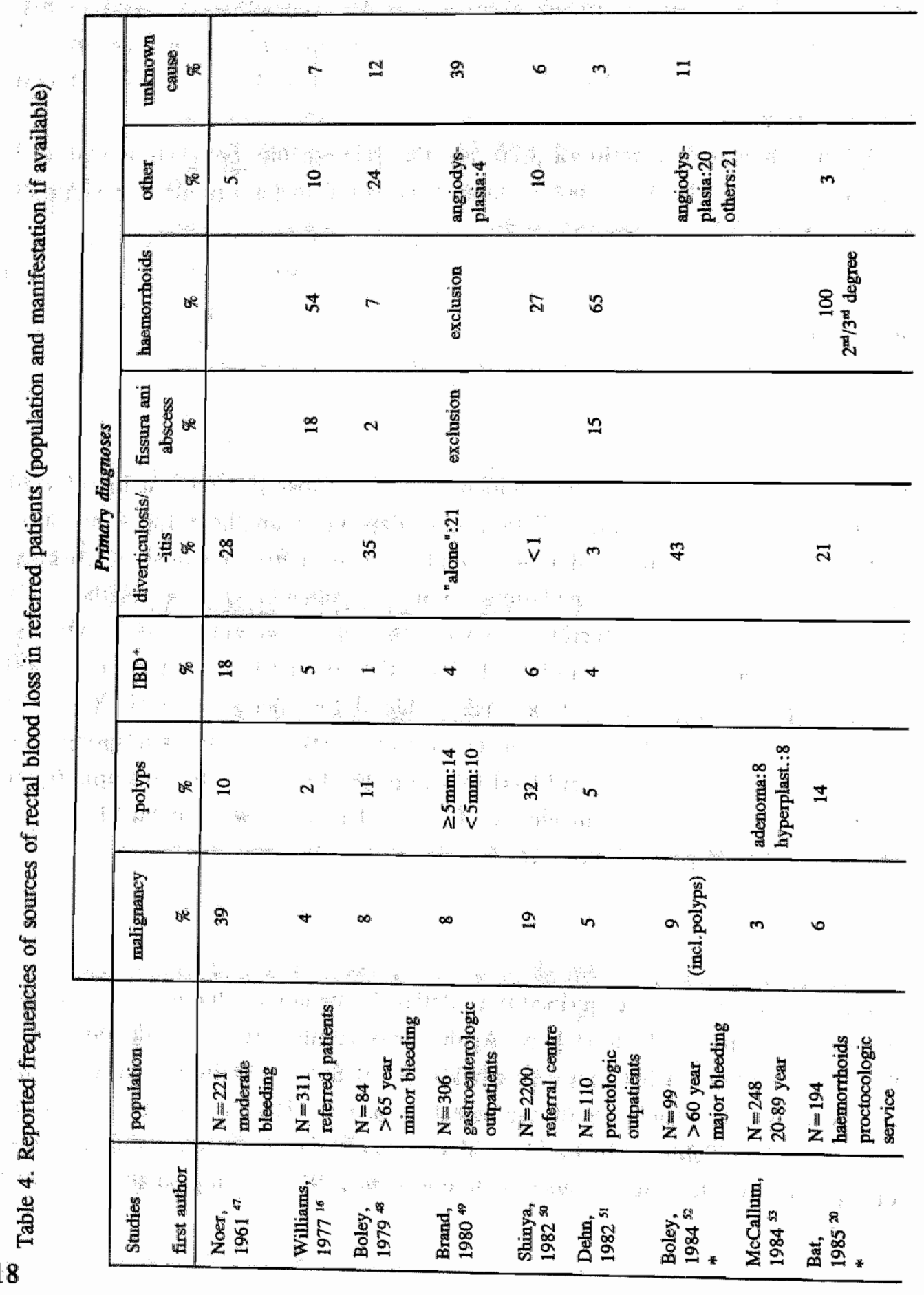




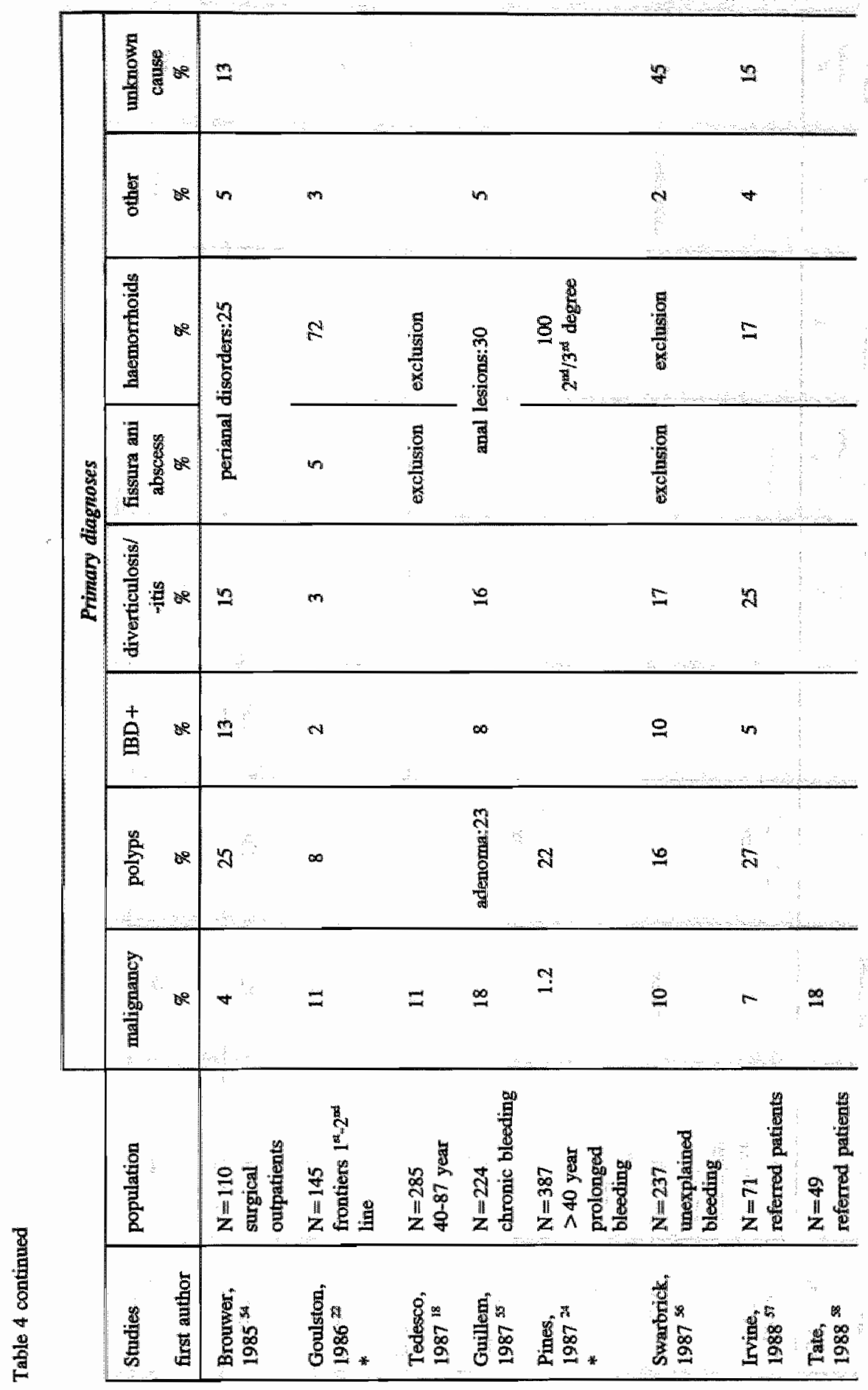




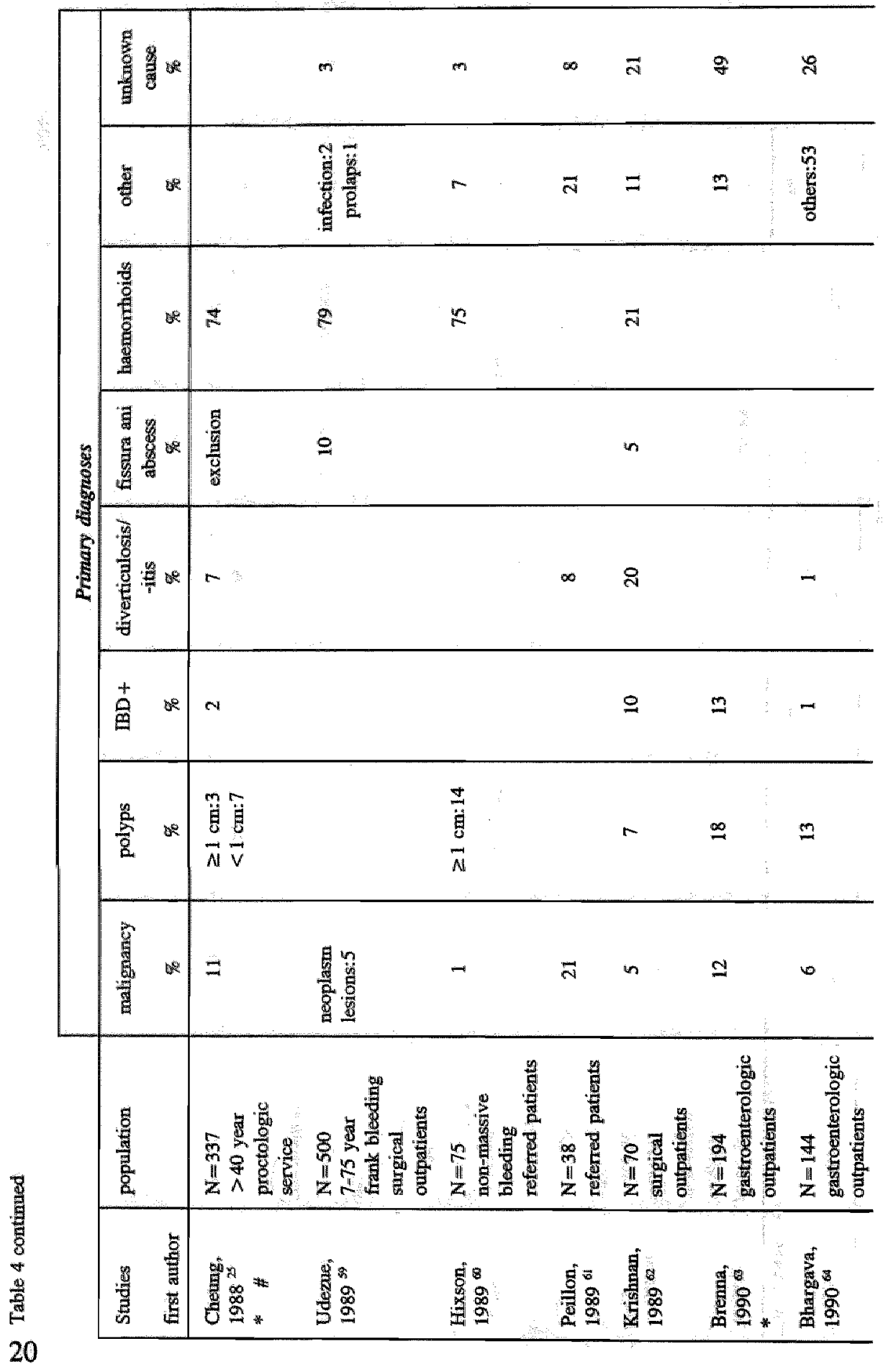




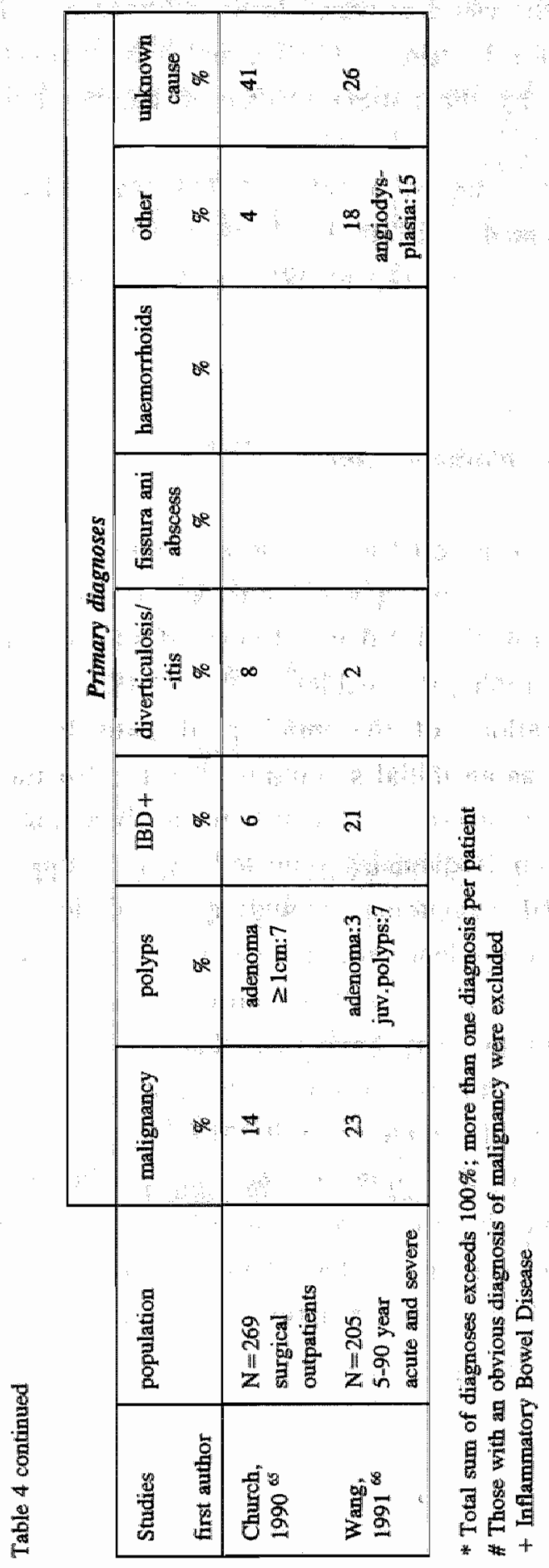


A colorectal tumour was found to be the cause of blood loss significantly more frequently in cases of "blood mixed with the faeces" (35\%), and less frequently in cases with anal protusion noticed by the patient $(10 \%)$ or haemorrhoids identified by general practitioner $(10 \%)$.

The results of the Australian study relate to a referred but less selected population than the other studies presented in Table $4 .{ }^{22}$ In these latter studies, often higher percentages of malignant tumours (up to $39 \%$ ) and adenomas (up to $32 \%$ ) were found.

\section{Predictive value of rectal bleeding for colorectal cancer}

The data presented can be used to obtain an estimate of the predictive value of overt rectal blood loss for the presence of a malignant colorectal tumour in the 3 situations described. For this we took the incidence figure of rectal blood loss as presented in the previous paragraphs, the incidence of colorectal cancer in the western world ${ }^{67}$ and 2 estimations of the number of patients with colorectal cancer and overt blood loss as an initial symptom. These estimations of between $10 \%$ and $50 \%$ of the occurrence of overt rectal bleeding in colorectal malignancy are derived from frequencies reported by retrospective studies that have recorded signs and symptoms, including blood loss, in patients in whom a colorectal tumour was identified. In one study "blood with stool" was an initial symptom in $10 \%$ of patients with a colorectal carcinoma. ${ }^{68}$ In other studies different initial symptoms may have been leading to further investigation for colorectal cancer with overt rectal blood loss having appeared in the course of time (may be not an initial symptom) in $40-80 \%, 69-74$

Results are presented in Table 5. Within the limits of uncertainly inherent to this type of analysis it can be seen that the predictive value of rectal bleeding for colorectal malignancy increases from probably less than 1 in 1000 in the general population to around 2 in 100 in general practice and to up to 36 in 100 in the practice of the medical specialist. 
Table 5. Estimation of predictive values of rectal blood loss for malignant colorectal tumours

\begin{tabular}{|c|c|c|c|}
\hline & $\begin{array}{l}\text { general } \\
\text { population }\end{array}$ & $\begin{array}{l}\text { general } \\
\text { practice }\end{array}$ & $\begin{array}{l}\text { referred } \\
\text { patients }\end{array}$ \\
\hline Incidence of rectal blood loss & $\begin{array}{c}20 \text { per } 100 \\
\text { per year }\end{array}$ & $\begin{array}{l}6 \text { per } 1000 \\
\text { per year }\end{array}$ & $\begin{array}{l}70 \text { per } 10^{5} \\
\text { per year }\end{array}$ \\
\hline $\begin{array}{l}\text { Expected number of people with } \\
\text { rectal blood loss per } 10^{5} \text { people } \\
\text { per year }\end{array}$ & 20,000 & 600 & 70 \\
\hline $\begin{array}{l}\text { Incidence colorectal malignant } \\
\text { tumours per } 10^{5} \text { per year } 67\end{array}$ & 50 & 50 & 50 \\
\hline $\begin{array}{l}\text { Number of colorectal malignancy } \\
\text { with rectal blood loss (in } 50 \% \text { or } \\
10 \% \text { of these) as a presenting } \\
\text { symptom per } 10^{5} \text { people per year }\end{array}$ & $25 \quad 5$ & 25 & $25 \quad 5$ \\
\hline $\begin{array}{l}\text { Predictive value of rectal blood } \\
\text { loss for colorectal malignancy }\end{array}$ & $0.12 \% \quad 0.02 \%$ & $4 \% \quad 0.8 \%$ & $36 \% \quad 7 \%$ \\
\hline
\end{tabular}

\section{Discussion}

Studies on the occurrence of blood loss per rectum in the general population can yield percentages that are either higher or lower than in reality is the case. There are various reasons for an underestimation. Rarely do people inspect their stool; in none of the studies the patients' report was controlled by inspection (validity); and the percentages reported nearly always concern "healthy" or even "more healthy than average" populations (exclusion of known intestinal disorders). Furthermore, it is not always easy for people to think, let alone speak about, diseases. Wadsworth et $\mathrm{al}^{32}$ offer three explanations for this: firstly, inadequate social acceptance (e.g. an interview about haemorrhoids is not readily accepted); secondly, fear or superstition that talking about a disease increases the likelihood of contracting it; and thirdly, a limited memory. The reported percentages can also be an overestimation. 
Therefore it seems useful to perform a prospective study on the incidence of rectal blood loss in this setting and to identify signs, symptoms, and risk factors that may contribute to effective and efficient diagnosis.

\section{References}

1. Keddie N, Hargreaves A. Symptoms of carcinoma of the colon and rectum. Lancet 1968; Oct: 749-50.

2. Clarke AM, Jones ISC. Diagnostic Accuracy and Diagnostic Delay in carcinoma of the Large Bowel. New Zeeland Med J 1970; 71: 341-7.

3. Irvin TI, Greaney MG. Duration of symptoms and prognosis of carcinoma of the colon and rectum. Surg Gyn Obstet 1977; 144: 883-6.

4. Clarke DN, Jones PF, Needham CD. Outcome in colorectal carcinoma: seven-year study of a population. Br Med J 1980; 431-5.

5. McDermott FT, Hughes ESR, Pihl E, Milne BJ, Price AB. Prognosis in relation to symptom duration in colon cancer. Br J Surg 1981; 68:846-9.

6. McDermott F, Hughes E, Pihl E, Milne BJ, Price A. Symptom duration and survival prospects in carcinoma of the rectum. Surg Gyn Obstet 1981; 153: 321-6.

7. Polissar L, Sim D, Francis A. Survival of Colorectal Cancer Patients in Relation to Duration of Symptoms and Other Prognostic Factors. Dis Colon Rectum 1981; 24: 3649.

8. Nilsson $E$, Bolin $S$, Sjödahl $R$. Carcinoma of the colon and rectum. Delay in diagnosis. Acta Chir Scand 1982; 148: 617-22.

9. Pescatori M, Maria G, Beltrani B, Mattana C. Site, emergency and duration of symptoms in the prognosis of colorectal cancer. Dis Colon Rectum 1982; 25; 33-40.

10. Dent OF, Chapuis PH, Goulston KJ. Relationship of survival to stage of the tumor and duration of symptoms in colorectal cancer. Med $J$ Aust 1983; 1: 274-5.

11. Chapuis PH, Dent OF, Fisher R, et al. A multivariate analysis of clinical and pathological variables in prognosis after resection of large bowel cancer. Br J Surg 1985; 72: 698-702.

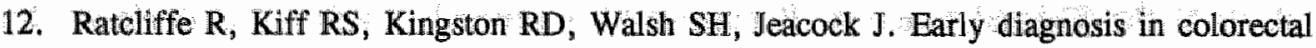
cancer. Still no benefit? J $R$ Coll Surg Edin 1989; 34: 152-5.

13. Kyle SM, Isbister WH, Ling Yeong M. Presentation, duration of symptoms and staging of colorectal carcinoma. Alustr NZ J Surg 1991; 61: 137-40.

14. Lisdonk EH van de, Bosch WJHM van den, Huygen FJA, Lagro-Janssen ALM. Ziekten in de huisartspraktijk. Utrecht: Wetenschappelijke Uitgeverij Bunge, 1990. 
15. Gläser A, Weinert B. Fehldiagnosen bei Dickdarmkarzinomen. Zentral blant für Chirurgie 1976; 101(7): 418-21.

16. Williams JT, Thomson JPS. Ano-rectal bleeding: a study of causes and investigate yields. Practitioner (English ed) 1977; 219; 327-31.

17. Graham J. Rectal bleeding. I Fam Pract 1978; 7: 169-76.

18. Tedesco JF, Wayne JD, Raskin JB, Morris SJ, Greenwald RA. Colonoscopic Evaluation of Rectal Bleeding. A study of 304 patients. Ann Intern Med 1987; 89: 9079.

19. Bleiberg H. Gastrointestinale symptomen bij de diagnose van kanker. Parient Care (Dutch ed) 1982; 22-5.

20. Bat L, Pines A, Rabau M, Niv Y, Shemesh E. Colonoscopic findings in patients with hemorrhoids rectal bleeding and normal rectoscopy. Isr J Med Sci 1985; 21(2): 139-41.

21. Bakaleinik M. Lower gastrointestinal hemorrhage pathologic physiology and surgical considerations. Milit Med 1985; 150: 303-8.

22. Goulston KJ, Cook I, Dent OF. How important is rectal bleeding in the diagnosis of bowel cancer and polyps? Lancer 1986; ii: 261-5.

23. Goulston $\mathrm{K}$, Dent $\mathrm{O}$. Rectal bleeding: when and how to investigate. Austr Fam Phys 1987; 4: 379-82.

24. Pines A, Shemesh E, Bat L. Prolonged rectal bleeding associated with hemorroids: the diagnostic contribution of colonoscopy. South Med J 1987; 80(3): 313-4.

25. Cheung PSY, Wong SKC, Boey J, Lai CK. Frank rectal bleeding: a prospective study of causes in patients over the age of 40. Postgrad Med J 1988; 64: 364-8.

26. Silverman AL, Desai TK, Dhar R, et al. Clinical Features, Evaluation, and Detection of Colorectal Cancer. Gastroenterol Clin North Am 1988; 17(4): 713-25.

27. Dent $\mathrm{OF}$, Goulston $\mathrm{KJ}$, Tennant $\mathrm{CC}$, et al. Rectal bleeding. Patient delay in presentation. Dis Colon Rectum 1990; 33: 851-7.

28. Vanhoof G. Proctologie - Symptomen en essentiële stappen bij het lichamelijk onderzoek. Patient Care (Dutch ed) 1990; Sept: 26-35.

29. Chapuis PH, Goulston KJ, Dent OF, Tait AD. Predictive value of rectal bleeding in screening for rectal and sigmoid polyps. Br Med I 1985; 290: 1546-8.

30. Kewenter J, Haglind E, Smith L. Value of a risk questionnaire in screening for colorectal neoplasm. Br J Surg 1989; 76(3): 280-3.

31. Gill K. De defaecatie van de mens. Een onderzoek in drie huisartspraktijken. Huisarts Wet 1979; 22: 186-91.

32. Wadsworth MEJ, Butterfield WJH, Blaney R. Health and Sickness. The choice of treatment. London: Pub Tavistock 1971.

33. Jones $\mathbf{R}$, Lydeard S. Irritable bowel syndrome in the general population. Br Med J 1992; 303: 87-90. 
34. Silman AJ, Mitchell $P$, Nicholls RJ, et al. Self-reported dark red bleeding as a marker comparable with occult blood testing in screening for large bowel neoplasma. Br J Surg 1983; 70: 721-4.

35. Dent $\mathrm{OF}$, Goulston KJ, Zubrzycki J, Chapuis PH. Bowel symptoms in an apparently well population. Dis Colon Rectum 1986; 29(4): 243-7.

36. Farrands PA, Hardcastle JD. Colorectal screening by self completion questionnaire. Gut 1984; $25: 445-7$.

37. Jones ISC. An analysis of bowel habit and its significance in the diagnosis of carcinoma of the colon. Am J Proctology 1976: 45-56.

38. Velden J wan der, Bakker DH de, Claessens AAMJ, Schellevis FG. Nationale studie naar ziekten en verichtingen in de huisartspraktijk. Basisrapport: Morbiditeit in de huisartspraktijk. Utrecht: Nivel, 1991.

39. Hoogen HJM van den, Huygen FJA, Schellekens JWG. Morbidity Figures from General Practice. Data from four general practices 1978-1982. Nijmegen: Nijmeegs Universitair Huisartsen Instituut, 1985.

40. Lamberts H. Morbidity in general practice. Utrecht: Huisartsenpers, 1984.

41. Lamberts $\mathrm{H}$. In het huis van de huisarts: Verslag van het Transitieproject. Lelystad: Meditekst, 1991.

42. Bekker JP, Berg van de FA, Dijkstra O. De proctoscoop, een nuttig instrument voor de huisarts. Huisarts Wet 1989; 32(11): 418-9.

43. Fuller JHS. [Personal communication]. Letter February 1987. University of London, England.

44. Nørrelund N. Trustrup, Denmark. [Personal communication]. Letter October 1991.

45. Hodgkin $\mathrm{K}$. Vroege diagnostiek in de eerste lijn. Hoofdstuk 2; 50. De Tijdstroom, 1984.

46. Mant A, Bokey EL, Chapuis PH, et al. Rectal bleeding. Do other symptoms aid in diagnosis? Dis Colon Rectum 1989; 32: 191-6.

47. Noer RJ, Hamilton JE, Williams DJ, Broughton DS. Rectal Hemorrhage: Moderate and Severe. Ann Surg 1962; 155: 749-805.

48. Boley SJ, DiBiase A, Brandt LJ, Sammartano BS. Lower intestinal bleeding in the elderly. Am J Surg 1979; 137: 57-64.

49. Brand EJ, Sullivan BH, Sivak MV, Rankin GB. Colonoscopy in the diagnosis of unexplained rectal bleeding. Ann Surg 1980; 192: 111-3.

50. Shinya $\mathrm{H}$, Cwern $\mathrm{M}$, Wolf $\mathrm{G}$. Colonoscopic diagnosis and management of rectal bleeding. Surg Clin North Am 1982; 62: 897-903.

51. Dehn T, McGinn FP. Causes of anorectal bleeding. Postgrad Med J 1982; 58: 92-3.

52. Boley SJ, Brandt LJ, Sumi M, Mitsudo SM. Vascular lesions of the colon. Yearbook Medical Publishers 1984; 301-26. 
53. McCallum RW, Meyer CT, Marignani DOP, Cane E, Contino C Flexible Sigmoidoscopy: Diagnostic Yield in 1015 Patients. Am $J$ Gastroenterol 1984, 79(6): 433-7.

54. Brouwer KJ Ervaringen met colonoscopy. Ned Tijdschr Geneeskd 1985; 129: 2266-9.

55. Guillem GJ, Forde KA, Treat MR, Neugut AI, Bodian CA. The impact of colonoscopy on the early detection of colonic neoplasms in patients with rectal bleeding. Ann Surg 1987; 206: 606-11.

56. Swarbrick ET, Fevre DI, Hunt RH, Thomas BM, Williams CB. Colonoscopy for unexplained rectal bleeding. $\mathrm{Br}$ Med $J$ 1987; 2; 1685-7.

57. Irvine EJ, O'Connor J, Frost RA, et al. Prospective comparison of double contrast barium enema plus flexible sigmoidoscopy vs colonoscopy in rectal bleeding: barium enema vs colonoscopy in rectal bleeding. Gut 1988; 29: 1188-93.

58. Tate JJT, Royle GT. Open access colonoscopy for suspected colonic neoplasia. Gut $1988 ; 29(10): 1322-5$.

59. Udezue NO. Five hundred consecutive sigmoidoscopie for frank rectal bleeding: an analysis. Surg Pract 1989; 19: 72-73.

60. Hixson $L J$, Sampliner RE, Chernin M, Amberg J, Kogan F. Limitations of Combined Flexible Sigmoidoscopy and Double Contrast Barium Enema in Patients with Rectal Bleeding. Eur J Radiol 1989; 9: 254-7.

61. Peillon $\mathrm{C}$, Steyaert $\mathrm{H}$, Delaunay $\mathrm{T}$, Lammens $\mathrm{B}$, Testart J. Les hémorragies digestives basses graves de l'adulte. $J$ Chir 1989; 126: 687-94.

62. Lawrence MA, Hooks VH, Bowden TA. Lower gastrointestinal bleeding. A systematic approach to classification and management. Postgrad Med 1989; 85: 89-100.

63. Brenna E, Skreden K, Waldum HL, Mårvik R. The benefit of colonoscopy. Scand J Gastroenterol 1990; 25: 81-8.

64. Bhargava DK, Rai RR, Chopra P. Colonoscopy for investigation of unexplained rectal bleeding in a tropical country. Gastroenterol Jpn 1990; 25: 781-5.

65. Church JM. Analysis of the colonoscopic findings in patients with rectal bleeding according to the pattern of their presenting symptoms. Dis Colon Rectum 1991; 34: $391-5$.

66. Wang CY, Won $\mathrm{CW}$, Shieh MJ. Aggressive colonoscopic approaches to lower intestinal bleeding. Gastroenterol Jpn 1991; 26: 125-8.

67. Bakker D, Coebergh JWW, et al. (eds.). Cancer Incidence in The Netherlands: the southeastern part, 1978-1982. Eindhoven: Eindhoven Cancer Registry/IKZ, 1985.

68. Månsson J. The diagnosis of colorectal cancer-Experiences from the community of Kungsbacka, Sweden. Scand J Prim Health Care 1990; 8: 31-5.

69. Aldridge $\mathrm{MC}$, Sim AJW. Colonoscopy findings in symptomatic patients without $\mathrm{X}$-Ray evidence of colonic neoplasms. Lancet 1986; ii: 833-4. 
70. Fujita $M$, sugiyama $M D$, Kumanishi $Y$, et al. Evaluation of effectiveness of mass screening for colorectal cancer. World J surg 1990; 14(5), 648-52.

71. Goh HS, Goh CR, Rauff A, Foong WC. Clinico-Pathological Prognostic Factors of large bowel cancer in Singapore: a multivariate analysis. Ann Acad Med 1987; 16: 43740.

72. Byrd RL, Boggs $\mathrm{HW}$, Slagle GW, Cole PA, et al. Reliability of colonoscopy. Dis Colon Rectum 1989; 32: 1023-5.

73. MacArthur $C_{*}$ Smith A. Factors associated with speed of diagnosis referral, and treatment in colorectal cancer. $J$ Epidemiol Community Health 1984; 38: 122-6.

74. Moore PA, Dillawari RA, Fidler WJ. Adenocarcinoma of the colon and rectum in patients less than 40 years of age. Am Surg 1984; 50: $10-4$.

75. Lisdonk EH van de. Ervaren en aangeboden morbiditeit in de huisartspraktijk. [Dissertation] Nijmegen, 1985: Hoofdstuk 7, 112. 
3. Diagnostic approach of patients with rectal bleeding in general practice. State of the Art

Fijten GH. Bloedverlies per anum. Diagnostiek in de huisartspraktijk. The Practitioner (Dutch ed.) 1992; 9: 509-12.

The current diagnostic approach of patients with rectal bleeding in general practice in the Netherlands is discussed in this chapter. The subject was previously published in Dutch and is translated in English with slightly adjustment for this thesis.

\section{ABSTRACT}

In an average general practitioner's population, yearly hundreds of people suffer from overt rectal blood loss and a dozen consult a doctor for this reason. General practitioners may be concerned overlooking cancer which does not present with an evident clinical picture. However, in the same patient population, colorectal cancer which results in rectal bleeding occurs probably less frequently than once every 2 years. A bleeding rectum carcinoma which can be palpated by means of a digital rectal examination only occurs approximately once every 10 years. Knowledge of the diagnostic value of other signs and symptoms in combination with rectal bleeding would be helpful to select patients for further diagnostic investigation. However, this knowledge is not yet available. 


\section{Introduction}

What does overt rectal blood loss indicate? Is it a sign of cancer? Is it reason to perform a digital rectal examination and/or to perform more invasive diagnostic examinations?

Rectal bleeding is a very broad term which can be distinguished into massive blood loss, minor overt blood loss and occult blood loss. Massive blood loss and occult blood loss are of a different order. A patient with massive rectal blood loss will generally be referred to a specialist immediately. Occult blood loss is particularly of interest as a screening test. It will only be dealt with in this paper in its relation to minor overt blood loss.

\section{Delay in treatment}

Among general practitioners as well as the general public, rectal bleeding is known as a signal for malignant colorectal tumours. Yet, patients often do not consider rectal bleeding a reason to consult their general practitioner, nor is it always reason for the general practitioner to conduct further examinations.

Literature has shown that the delay in treating colorectal tumours can be shortened. Graffner and Olsson found that $66 \%$ of the patients with tumours in the rectum or sigmoid had complaints for more than 3 months before consulting their general practitioner (patient delay). ${ }^{1}$ In general, these complaints are a change in bowel habit $(70 \%)$ or blood loss $(50 \%)$. A doctor's delay of more than 3 months between the first consultation and surgery occurs in $34 \%$ of the patients with rectal or sigmoid tumours. In many cases $(61 \%)$, an initial diagnosis of haemorrhoids is made. Occasionally (4\%), the delay results from a negative outcome for radiological examinations. Only $16 \%$ of the patients has a digital rectal examination during their first consultation, even though a tumour could be palpated in $44 \%$ of these patients. 
According to Dixon et al. approximately one quarter of the patients with rectal tumours do not undergo a digital rectal examination before being referred to a specialist. $^{2}$ In Dixon's report, the average referral delay is 16 weeks for carcinoma in the left half of the colon and 27 weeks for carcinoma in the right half of the colon.

Following digital rectal examination, further examinations such as colonoscopy, sigmoidoscopy and double contrast radiological examinations are often propagated for patients suffering from rectal blood loss. It is assumed that early detection of colorectal tumours (i.e. before complaints manifest themselves) will leadl to a better prognosis. However, it has not been unequivocally demonstrated that suffering a shorter period of blood loss has a positive effect on the duration of survival, or that waiting for further examinations is irresponsible. ${ }^{3}$ Overt rectal blood loss is a common occurrence and generally, in more than $90 \%$ of the new cases, it is not associated with more serious clinical conditions. The dilemma general practitioners often face is deciding whether to expose their patients to possibly unnecessary anxiety and costs, or whether to risk diagnosing a potentially malignant tumour too late or not at all. Considering the low prevalence of malignant causes for blood loss, it seems appropriate to select only those patients with an increased risk for malignant tumours for further invasive examinations.

\section{Symptoms and possible sources}

The case history and the development of the symptoms often determine the probable diagnosis and the diagnostic approach (Table 1). Pain, blood loss, mucous discharge, a change in bowel habit, diarrhoea, weight loss, nausea, tiredness and the development of these symptoms can be important indicators of a serious disorder. The most frequent initial symptom in patients with tumours in the descending colon is a change in bowel habit. This is often followed by rectal blood loss and abdominal pain. It is important to know which groups of patients with these symptoms are known to have a higher risk for colorectal tumours (Table 2). 
Table 1. Sources of rectal bleeding.

\section{Most frequent}

\section{Haemorrhoids}

Blood on the stool, after defaecation and on toilet paper. Feeling of prolaps, anal pain, anal itch are frequent. Trombose of haemorrhoids is painful. External haemorrhoids are seen by perianal inspection, internal haemorrhoids are seen by proctoscopy.

\section{Fissura ani}

Usually painful defaecation and bright red blood on the stool, after defaection and on toilet paper.

Seen by perianal inspection.

\section{Unknown source}

No source found even after follow-up.

\section{Less frequent or rare sources}

Fistula, abscess

Rarely rectal bleeding; seen by inspection.

Morbus Crohn, colitis ulcerosa

Recurrent rectal bleeding, abdominal pain, periods of diarrhoea, asthenia.

\section{Colitis}

After antibiotics, infections, ischaemia, irradiation.

\section{Proctitis}

After antibiotics, suppositoria, trauma, sexually transmitted infections, inflammatory; constipation, mucous discharge.

\section{Vascular-malformations, angiodysplasia}

Sometimes massive rectal bleeding.

\section{Rectum prolaps}

Inspection during straining.

\section{Diverticulosis}

Commonly present, rarely a source of bleeding, sometimes massive rectal bleeding.

\section{Solitary rectum ulcus}

Anal discharge, leakage of mucus, mucous discharge, constipation. 
Table 1 continued

\section{Polyps}

Polyps $>1 \mathrm{~cm}$ and localised in the rectum sigmoid may provoke complaints, little polyps in the rectum are usually hyperplastic (non-neoplastic) and without symptoms.

\section{Malignant colorectal tumours}

Change in bowel habit, blood mixed with stool, abdominal pain, sometimes weight loss, tiredness.

\section{Invagination}

Painful abdominal cramp in children.

Haemorrhagic disorders

Other than colorectal tumours

Endometriosis

Cyclic cramping pains in the rectum and cyclic bleeding.

Table 2. Risk factors for colorectal tumour.

- Previous history of colorectal neoplasm

- First degree family member(s) having colorectal malignant diseases

- Cancer of ovaria, endometrium, mammae

- Polyposis syndroms, families with polyposis

- Colitis ulcerosa: distal colon longer than 15 years, entire colon longer than 7 years

\section{The importance of digital rectal examination}

For patients with rectal blood loss, perianal inspection is a must. A number of common causes, such as a fissure or a prolaps, can be diagnosed. When the cause of the blood loss is a fissure, the general practitioner must carefully consider whether or not to perform a painful digital rectal examination. On the whole, however, performing a digital rectal examination after a perianal inspection can be of great value in diagnosing tumours, even though tumours are rarely found. This examination is also important for determining if there is faeces in the rectum before performing a proctoscopy. Finally, it is possible to examine the faeces on the glove for overt or occult blood. 
A proctoscopy can be a worthwhile additional procedure. Probable causes for blood loss such as haemorrhoids, proctitis and a rectum ulcus or tumour can be diagnosed with this procedure. In addition, it is possible to obtain samples for a culture or to treat haemorrhoids. Proctoscopy is not (yet) considered a basic skill for general practitioners. ${ }^{4}$

If haemorrhoilds, fissurae ani or other non-serious disorders are diagnosed, more serious proximal pathology (tumours, colitis ulcerosa or Morbus Crohn) must still be taken into consideration. A negative diagnosis based on a digital rectal examination does not exclude a malignant disorder. Even if a diagnosis of haemorrhoids or proctitis is made with the help of proctoscopy, possible malignancies higher in the colon must not be excluded, especially in patients older than 40-45 years of age. However, if patients have haemorrhoids (preferably diagnosed by means of proctoscopy) but lack other signs of malignancy, a regimen and follow-up check-up will often suffice.

If there is reason to suspect a malignant cause for rectal bleeding, then a sigmoidoscopy or a double contrast radiological examination of the colon is recommended in addition to a digital rectal examination (and a proctoscopy). When sigmoidoscopy shows no abnormalities in the rectum, sigmoid and distal colon, additional radiological examinations are advised for patients older than 40-45 years of age. ${ }^{5}$ Since these examinations do not provide a good image of the anal canal, digital rectal examination must still be performed.

There is insufficient scientific evidence to support the claim that digital rectal examinations must be performed on all patients suffering from rectal blood loss. Even though digital rectal examination is not a very demanding procedure, general practitioners are often reluctant to perform it. A study by Hennigan et al. names the following reasons: ${ }^{6}$

1. the reluctance and embarrassment of the patient;

2. the knowledge that the examination will be repeated after referral; and

3. the lack of time.

The general practitioner's embarrassment and doubts about the usefulness of the examination may also be reasons for not performing a digital rectal examination. 


\section{Epidemiological considerations}

From screening studies it appears that approximately $1.5 \%$ of the people questioned report rectal blood loss in the previous 2 weeks and approximately $13 \%-16 \%$ report blood loss in the previous 6 months or $20 \%$ in the previous year. ${ }^{711}$ Gill found that $19 \%$ of the people questioned never look at their own faeces. ${ }^{8}$ Only a small fraction of the people suffering from rectal blood loss consult a general practitioner. If everyone were to consult a general practitioner as a result of rectal blood loss, the general practitioner would see approximately 40 patients with this complaint each month and 500 patients each year. At present, the average general practitioner annually sees an estimated 10-15 patients whose primary complaint is rectal blood loss. New malignant tumours in the colon occur on average once every 1.5 years. Malignant tumours in the anus, rectum or sigmoid occur once every 6.5 years in an average practice. ${ }^{12}$ In approximately half of the cases of rectum carcinoma, rectal blood loss is the first symptom. Tumours located above the rectum or sigmoid result in overt blood loss less often (14\%).

It is estimated that general practitioners will come across a patient with a rectal tumour causing blood loss once every 13 years. Three quarters of these tumours can be reached with a finger during a digital rectal examination. With colon tumours, $55 \%$ is within reach of the rectoscope $(25 \mathrm{~cm})$. The incidence of malignant tumours increases with age. In people under 40 years of age, malignant tumours in the anal canal or rectum, recto-sigmoid junction occur very rarely-less than once per 100,000 people per year. The incidence of malignant tumours in people between 40 and 50 years of age is 6 per 100,000 people per year and between 50 and 60,24 per 100,000 . The incidence in people over 60 years of age is 100 per 100,000 people per year. ${ }^{13}$

Screening in Sweden has shown that for people between 60 and 65 years of age, the predictive value of bright red blood loss for a carcinoma is $1.3 \%$, and for an adenomatous polyp it is $0.9 \%$. It is remarkable that if there is a positive Haemoccult test as well as overt blood loss, the incidence of a carcinoma is $8.8 \%$ and the incidence of at least one adenomatous polyp is $27.5 \% .^{\circ}$ 
The data from this screening raises the question on which people in the age category 60-65 with bright red blood loss an examination of the colon should be performed, and for which people close observation of the development of the symptoms suffices. This question is even more relevant for younger people, in whom the incidence of malignancy is lower. Patients in a risk category (Table 2) should in any case be eligible for further examinations.

\section{The importance of further examinations}

When considering whether or not to perform one of the examinations (proctoscopy, rectosigmoidoscopy, colonoscopy, radiological examination), it is important to keep in mind that no examination offers a $100 \%$ assurance that a malignant disorder can be ruled out. Dealing with such uncertainty characterizes the work of the general practitioner. Knowing the patient, his/her background, the family, and the case history, and keeping an eye on the development of the symptoms are of great importance to an effective and efficient diagnosis. Knowing the limited value of an examination is as important as a competent performance of the examination.

When a patient suffers from rectal blood loss, a good case history must be made. In addition, a local examination, that is a perianal inspection ànd a digital rectal examination, must be performed. If there is an increased chance or suspicion of more serious pathology in the rectum or colon, further examinations should take place. Of course, the age of the patient plays an important role as well. An arbitrary, but generally accepted age limit is 45 . Colorectal malignancy rarely occurs at a younger age.

\section{The need for research}

Which other signs and symptoms increase or decrease the probability of colorectal cancer in patients with rectal bleeding in general practice and to what extent they influence this probability is yet unknown. 
We have initiated an empirical study to find the predictive value of signs and symptoms in combination with rectal bleeding. The study and the results will be presented in the following chapters.

\section{References}

1. Graffner $H$, Olsson S. Patient's and Doctor's delay in carcinoma of the colon and rectum. $J$ of Surg Oncology 1986; 31: 188-90.

2. Dixon AR, Thornton Holmes J, Cheetham NM. General practitioners' awareness of colorectal cancer: a 10 year review. Br Med J 1990; 301: 152-3.

3. Dent $\mathrm{OF}$, Chapuis PH, Goulston $\mathrm{K}$. Relationship of survival to stage of the tumour and duration of symptoms in colorectal cancer. Med J Austr 1983; 1: 274-5.

4. Bekker JP, Berg FA van de, Dijkstra O. De proctoscoop, een nuttig instrument voor de huisarts (The proctoscope, a useful instrument for general practitioners). Huisarts Wet 1989; 32: 418-9.

5. Fijten G, Pop P. Radiologisch en endoscopisch onderzoek van het colon op verzoek van de huisarts (Radiological and endoscopic examination on general practitioner's request). Practitioner (Dutch ed.) 1990; 7: 1161-7.

6. Hennigan TW, Franks PJ et al. Rectal examination in general practice. Br Med J 1990; 301: 478-80.

7. Fuller JHS. Ano-rectal bleeding. Practitioner (English ed.) 1984; 228: 825-8.

8. Gill K. Defaecatie van de mens. Een onderzoek in drie huisartspraktijken (Human defaecation. A study in three general practices). Huisarts Wet 1979; 2: 186-91.

9. Kewenter J, Haglind $E$, Smith L. Value of a risk questionnaire in screening for colorectal neoplasm. Br J Surg 1989; 76: 280-3.

10. Dent OF et al. Bowel Symptoms in an apparently well population. Dis Colon Rectum 1986; 29: 243-7.

11. Jones $\mathrm{R}$, Lydeard $\mathrm{S}$. Irritable bowel syndrome in the general population. Br Med $J$ 1992; 303: 87-90.

12. Bosch $\mathrm{W}$ van den. Epidemiologie van Kanker in de huisartspraktijk (The epidemiology of cancer in general practice). Practitioner (Dutch ed.) 1990; 7: 105-10.

13. Bakker D, Coebergh JWW, et al. (eds.). Cancer Incidence in The Netherlands: the southeastern part, 1978-1982. Eindhoven: Eindhoven Cancer Registry/IKZ, 1985. 


\section{Methods of the empirical study}

\section{Introduction}

This chapter gives a review of the general methodological aspects. The methodology sections in the following chapters give information on the specific methodology relevant for the subject of that chapter.

The study was carried out in cooperation with the Diagnostic Coordinating Centre (DCC) Mastricht, the Department of Internal Medicine at the University Hospital Maastricht and the Department of General Practice at the University of Limburg of Maastricht.

Patients were recruited from September 1988 to June 1990. Outcome data were gathered in 1991.

\section{Questions}

To answer the main question, "is it possible to discriminate effectively between patients with rectal bleeding who have colorectal cancer and those who do not?; or at least to discriminate between those who need invasive investigations and those who do not?", the following data are important.

1. The incidence of rectal bleeding, as an index of the inception cohort.

2. The prior probability of colorectal cancer and the other potential sources of bleeding, also as an index of the study population.

3. The predictive values of signs, symptoms and laboratory test results in general practice, providing the essential information for medical decision making. These data are used to construct a prediction model in general practice.

4. Determination of the predictive values in an outpatient clinic population. Since referred patients with rectal bleeding will almost always undergo further diagnostic investigations, including endoscopy or roentgenography, additional information compared to general practice might be gained. 
Knowledge of the differences in predictive values between general practice and the internal medicine clinic may be of use in improving the communication between general practitioners (GPs) and internists regarding patients with rectal bleeding.

In both general practice and the outpatient clinic the operationalized question was: to what extent do other (combinations of) symptoms enable the physician to confirm or rule out serious disease?

In general practice the focus was on colorectal cancer, since the prediction of the presence or absence of colorectal cancer is the main decision problem.

In the outpatient clinic the focus was on serious disease requiring further diagnostic investigation. Inflammatory bowel disease (IBD) and colorectal neoplasm (cancer and polyps) were taken together as serious disease.

\section{Design}

The design of the study can be defined as 'pseudo-follow-up' study, investigating a cross-sectional relationship between particular factors (signs, symptoms and simple laboratory test results) and a particular outcome (colorectal cancer, neoplasm or IBD), while the outcome can be only detected by follow-up. All diagnostic data available after a follow-up period of at least 1 year were used to establish the gold standard for the diagnostic outcome.

\section{Outcome}

After the follow-up period of at least 1 year the final diagnostic conclusion was determined. Three researchers (G Fijten, J Muris and R Starmans), blinded for the initial complaints and symptoms, abstracted all available diagnostic information from the medical records and established the diagnoses. Additionally, the final conclusion was presented to the patient's general practitioner who was asked for additional, not recorded, information or confirmation. 
The final diagnoses were classified in accordance with the International Classification of Primary Care (ICPC), defined on the basis of the criteria of the International Classification of Health Problems in Primary Care (ICHPPC2) ${ }^{1,2}$

In many general practice situations it is impossible to find a hard 'gold' standard because not all patients undergo colonoscopy or surgery. It was considered unethical (and very expensive) to submit such a protocol including endoscopy without preselecting 'serious bleeding'. It was assumed that a potentially malignant source of rectal bleeding would have been discovered within the follow-up period.

Endoscopy or roentgenography in all patients with rectal bleeding could yield some diagnoses, like diverticulosis and polyps, which would not necessarily be the source of bleeding.

Diverticulosis and polyps were classified as the outcome when these disorders were regarded as the source of bleeding. For a diagnosis of haemorrhoids proctoscopy was generally desired. But in cases where the complaints had been considered typical for haemorrhoids this was also accepted as the outcome after at least 1 year. Typical haemorrhoid signs and symptoms were: bright red blood dripping into the pan after bowel action and prolaps or one or more visible bleeding haemorrhoids.

For a diagnosis of IBD (proctitis and colitis) at least sigmoidoscopy was necessary.

Consensus of the three researchers and the general practitioner enabled the reference diagnosis to be established.

\section{Study populations}

Consecutive patients with rectal bleeding were recruited in general practice and general internists' outpatient clinics. Since it was noticed during the course of the study in general practice (study A) that the number of patients included in the study was less than expected and very variable, it was decided to do a complementary study (study B) with a modified protocol as described further on in this chapter and in Chapter 5. The aim of the study B was to assess a 
more accurate incidence rate. In summary there were three study populations.

Study A: Patients recruited by 83 GPs in Limburg, the southernmost province in the Netherlands. Initially 9 other GPs started with the study but they quit after some time without any of their patients included for the study.

Study B: Patients recruited by 10 GPs in the area of Maastricht during a threemonth period. Patients from $1 \mathrm{GP}$ had been excluded since it was uncertain if all eligible patients were included in the study.

Study C: Patients recruited in four general internists' outpatient clinics. There was no overlap of patients in study $A, B$ and $C$.

\section{Inclusion and exclusion criteria}

Inclusion: - All patients presenting to the doctor with overt blood loss per anum or rectum (rectal bleeding) seen by the patient within the previous three months. Rectal bleeding may be either the reason for encounter or be reported in the course of history taking.

Exclusion: - younger than 18 years of age, since children have a different spectrum of diagnoses and completing an extensive questionnaire might be difficult;

- older than 75 years of age, because during a pilot study it had appeared that older people had difficulties in completing the questionnaire;

- if the patient was known to have colorectal cancer or IBD;

- if urgent admission to a hospital was indicated, for example in cases of massive rectal bleeding, acute intestinal obstruction or perforation;

- if the patient was pregnant, since signs, symptoms and laboratory test results may be influenced by pregnancy.

As far as the outcome was concerned, patients were excluded if they were lost to follow-up. Moving to an unknown destination was the only accepted reason for loss to follow-up. For calculation of the incidence rate of rectal bleeding these patients have been included. 


\section{Instruments}

The data were collected through the following instruments.

1. A semi-structured questionnaire filled in by the doctor after the first consultation containing 70 variables: history, physical examination and initial management. This questionnaire is included in Appendix I (in Dutch). A complete physical examination was requested for all patients.

2. Low haemoglobin $(\mathrm{Hb})(<8.4 \mathrm{mmol} / 1$ in males and $<7.4 \mathrm{mmol} / 1$ in females) may be indicative for chronic bleeding. High erythrocyte sedimentation rate (ESR) has been found to have discriminating ability with respect to IBD and malignancies. ${ }^{3}$ The optimal upper limit was $12 \mathrm{~mm} / 1 \mathrm{hr}$ in men and $28 \mathrm{~mm} / 1 \mathrm{hr}$ in women, with no correction for age needed. Several cut-off points, for example $30 \mathrm{~mm} / 1 \mathrm{hr}$ for men and women, were tried in the search for an optimal point for discrimination. Leucocyte count has been reported to be an independent predictor for cancer and bacterial infections, but it has also been shown that high white blood cell count (WBC) is not a clinically interesting alternative to ESR. It was decided therefore to determine WBC $\left(>10^{9} / 1\right)$ in addition to ESR.

Faecal occult blood (FOB) testing in cases with overt rectal bleeding may additionally contribute to the diagnosis of colorectal neoplasm (cancer or polyps) especially in patients who have seen blood loss only once. Furthermore for patients with haemorrhoids the presence of occult blood in a central sample of the faeces may be indicative for colorectal pathology. In a screening study it has been shown that in patients, aged 60-64 years, the probability of neoplasm increased from $5.6 \%$ to $36.3 \%$ if FOB was positive. "The discriminatory value of the $\mathrm{FOB}$ was found to have been studied only in screening and case control settings. The literature on the diagnostic value of $F O B$ is large, but rather inconclusive about its usefulness. ${ }^{7,8}$ It was decided to determine FOB with the Haemoccult test in three subsequent portions of stool after a peroxidase and red meat-free diet. Carcinoembryonic antigen test (CEA) was not included in this study. It has shown to be valuable in assessing prognosis and early detection of metastases in colorectal cancer, but not in the detection of an undiagnosed tumour. ${ }^{7}$ 
The simple laboratory tests, $\mathrm{Hb}, \mathrm{WBC}$, ESR and Haemoccult (included in Appendix In, were assessed in the nearest hospital laboratories (which function for GPs use also). This was done to reduce the interpractice variation in assessment of these tests.

The laboratories had been informed about the study. The desirability of an unequivocal assessment among the laboratories was respected. More extensive and invasive diagnostic investigation was not prescribed by the study protocol. This was only done when the doctor considered it to be indicated.

3. A self-completion patient questionnaire containing 150 questions. Signs and symptoms mentioned in literature as having discriminatory value for the diagnostic outcome were used. ${ }^{9-13}$ A large section of the questionnaire contained questions relevant for patients with non-acute abdominal complaints. This section could be skipped when not applicable. The variables considered to be relevant for rectal bleeding are presented in Chapter 6 and 7.

Psycho-social factors may have an impact on the consulting behaviour of patients. Therefore 3 psychological scales were included: the VOEG, the Dutch version of the "Inventory for Subjective Health" (psychobiological stress), the subscales Self-esteem and Social Inadequacy of the Dutch Personality Inventory and the ZUNG questionnaire for depression. ${ }^{14-16}$

The patient questionnaire containing symptoms, (previous-)history, family history, medication consumption, social status and psychological scales is included in Appendix III (in Dutch).

\section{Pilot studies}

The instruments have been tested for rectal bleeding separately from non-acute abdominal complaints and for rectal bleeding combined with abdominal complaints. For rectal bleeding the pilot study was done in four practices during two months (18 patients). 
For the combined study a pilot study was done in one general practice, one health centre ( 50 patients in general practice) and in an internist's outpatient clinic in one hospital (50 patients).

The latter pilot study had revealed that the content of some psychological items provoked some resistance. It was therefore decided to restrict the questionnaire regarding the psychological scales to:

- the abbreviated VOEG for psychobiological stress (13 items)

- the NPV subscale for self-esteem (19 items)

- the NPV subscale for social inadequacy (15 items)

- the ZUNG scale for depression (20 items).

\section{Monitoring}

During the period of data collection the GPs, the internists and the registrars were frequently visited to stimulate them to be on the alert for including patients, to give feedback about their yield and to discuss potential problems arising. Stress was laid on avoiding selective inclusion regarding serious or harmless disorders. Special attention was paid to motivating patients to complete the questionnaire. Completion of digital rectal examination was encouraged.

Repeatedly newsletters were sent to the participating physicians to give information about the course of the study and to pay special attention to the problems which hadl arisen.

\section{Evaluation of potential inclusion}

Since during the course of the study it was noticed that fewer patients than expected were included, with a very variable frequency among doctors, special efforts were taken to evaluate the underdetection rate, the reasons for underdetection and the possibility of selective underdetection. 


\section{General practice}

Study B was initiated to find an accurate incidence rate of rectal bleeding. For this purpose daily controls of patient records were performed by practice assistants, who kept a notebook to gather data (age, gender, names) regarding all patients of whom rectal bleeding or abdominal complaints were recorded by the GP. Using this notebook, the doctors' questionnaires were checked for completeness of patients' recruitment.

The protocol was simplified by means of a single A4 format doctor's form (Appendix IV), by making the patient questionnaire not obligatory and by not prescribing laboratory tests. There was only one exclusion criterion, age less than 18 years.

The participation period was short (3 months, March till June 1990) and intensive.

In study A five GPs kept for a certain period a list with data and reasons for withdrawal (non-inclusion).

\section{Outpatient clinic}

An additional registration with epidemiologic data of referred patients with rectal bleeding derived from the University Hospital of Maastricht may serve as a map of the rectal bleeding presented in the general internist's outpatient clinic.

1. A retrospective analysis of patients' records of those who had been discharged from the hospital having a diagnosis of anal or colorectal malignancy in 1989 was done to find the frequency of patients with these malignancies and with rectal bleeding as a presenting symptom as well as the distribution of these patients among surgeons and internists.

2. Data from the Endoscopy Department at the University Hospital of Maastricht.

Results are presented in the general discussion, Chapter 8. 


\section{Data transport}

The questionnaires and laboratory results were checked for errors and missing answers by the researchers after each visit to the participating physicians.

The initial data were coded and imported into the VAX/VMS mainframe by the Data-entry service of the Department of Automation at the University of Limburg. The missing values and incorrect coding were checked using the BMDP-2D program and as much as possible corrected. The data of the followup assessment were coded and imported into a Personal Computer in a dBase program. After controlling for missing data and incorrect coding conversion with the software Kermit, entry into the mainframe was carried out.

Both sets of data were then combined on the mainframe and analysed with BMDP software. ${ }^{17}$

\section{Statistical analyses}

The data were analysed univariately first to detect incorrect coding for correction.

Second, the distribution of the results for the several items was assessed. For continuous variables several cut-off points were assessed for an optimal discriminatory cut-off point. Age was divided into age groups. Diagnostic outcome was divided in 9 groups: colorectal malignancy, polyps, colitis, proctitis, diverticulosis, infection, haemorrhoid(s), fissura ani (including fistula and abscess) and "no source of rectal bleeding found".

Most variables were transformed into dichotomous variables; with a cut-off point optimal for discrimination.

Loss of weight reported on the patients' form was derived by subtraction of the reported actual weight and earlier mean weight.

The psychological scales and the VOEG were recoded and summed up according to accepted guidelines.

In bivariate analysis the association between each variable with several outcome groups was assessed (Appendix V). Chi-square statistics were used to test 
statistical significance. From the cross tabulation (BMDP 4F) the sensitivity, the specificity, the positive predictive value $\left(\mathrm{PV}^{+}\right)$, the negative predictive value $\left(\mathrm{PV}^{-}\right)$and the odds ratios of the (independent) variables for the (dependent) diagnostic outcome were derived.

In study A the analysis was performed mainly with respect to colorectal malignancies versus all other diagnoses and, additionally, with respect to colorectal neoplasm (malignancies and polyps). In Appendix V, the association with the other diagnostic groups is presented. In study $\mathrm{C}$ the diagnostic outcome concerned colorectal neoplasm and IBD (colitis and proctitis),

The association with the other diagnostic groups is presented in Appendix V. Because of the quantity of data (small number of patients and not obligatory patients' questionnaire) such analysis was not done in study B.

All signs and symptoms can be considered as diagnostic tests and evaluated according to the rules for assessment of diagnostic tests. ${ }^{18}$

Sensitivity and specificity are classically considered the discriminatory characteristics of diagnostic tests but for clinical practice predictive values are more appropriate. These diagnostic indices are especially informative in studying one test. In a more complex situation, such as clinical practice, the adjusted odds ratio (OR) or regression coefficient (coef) (which allows calculation of the odds ratio: $O R=\mathrm{e}^{\text {covef }}$ ) are more suitable. $\mathrm{OR}=$ (true positive $\mathrm{x}$ true negative) : (false positive $\mathrm{x}$ false negative) or $\mathrm{OR}=\left(\mathrm{PV}^{+} \times \mathrm{PV}^{-}\right):\left(1-\mathrm{PV}^{+}\right)\left(1-\mathrm{PV}^{-}\right) .^{19}$

If bivariate odds ratios are presented with $95 \%$ Confidence Intervals (CI), these have been calculated using Epi Info on a personal computer ${ }^{20}$; if logistic regression coefficients are presented, both coefficients and $95 \% \mathrm{CI}$ were calculated by BMDP-LR on VAX/VMS mainframe.

The logistic regression coefficient determines the independent predictive value of a variable taking the other variables into account simultaneously. ${ }^{19.21}$

Forward stepwise multiple logistic regression analysis was used to obtain an adequate prediction model with a reduced number of variables. Variables which showed an association with the diagnostic outcome of choice with a p-value $<$ 0.1 were entered into multiple logistic regression. Entry and remove limits 
were applied for $\mathrm{p}$-values $<0.05$. So in the reduced model only variables which have independent statistically significant predictive values were included. The diagnostic value of the regression models were assessed by the goodness of fit test Hosmer Lemeshow ${ }^{22}$, the $\mathrm{PV}^{+}$and $\mathrm{PV}^{-}$for several cut-off points, the maximum sum of sensitivity and specificity and the Area Under the Curve (AUC) of a Receiver Operating Characteristic Curve (ROC)..$^{23-27}$ The AUC permits an overall impression of the discriminating performance of a model. An AUC of 1 or 0 discriminates perfectly and an AUC of 0.5 does not discriminate at all. The AUC was calculated with the aid of a software program by EP Brummelkamp, H Straatman and ALM Verbeek at the Catholic University in Nijmegen based on an article by Harley and McNeal. ${ }^{27}$

\section{References}

1. Lamberts $\mathrm{H}$, Wood $\mathrm{M}$ (eds.). ICPC International Classification of Primary Care. Oxford: Oxford University Press, 1987.

2. Classification Committee of WONCA. ICHPPC-2 defined. Inclusion criteria for the use of the rubrics of the Internal Classification of Health Problems in Primary Care. Oxford; Oxford University Press, 1983.

3. Dinant GJ, Knotnerus JA, Van Wersch JWJ. Discriminating ability of the erythrocyte sedimentation rate: a prospective study in general practice. BrJ Gen Pract 1991; 41: 365-70.

4. Grimm RH, Neaton JD, Ludwig W. Prognostic importance of the white blood cell count for coronary, cancer and all-cause mortality. JAMA 1985; 254: 1932-7.

5. Dinant GJ, Knottnerus A, Van Wersch J. Leucocyte count as an alternative to ESR in general practice? Scand J Prim Health Care 1991; 9; 281-4.

6. Kewenter J, Haglind E, Smith L. Value of a risk questionnaire in screening for colorectal neoplasm. Br J Surg 1989; 76: 280-3.

7. Beattle AD. Diagnostic tests in gastroenterology. London: Chapman and Hall Medical, 1992.

8. Starmans R, Muris JWM, Fijten GH, Pop P, Knottnerus JA, Crebolder HFJM. De diagnostische waarde van de testen op occult bloed in de faeces. Submitted.

9. Jones ISC, An analysis of bowel habit and its significance in the diagnosis of carcinoma of the colon, Am J Proctology 1976: 45-56.

10. Graham J. Rectal bleeding. J Fam Pract 1978; 7: 169-76. 
11. Silman AJ, Mitchell $P$, Nicholls RJ, et al. Self-reported dark red bleeding as a marker comparable with occult blood testing in screening for large bowel neoplasma. $B r J S u r g$ 1983; 70: 721-4.

12. Cheung PSY, Wong SKC, Boey J, Lai CK. Frank rectal bleeding: a prospective study of causes in patients over the age of 40. Postgrad Med $J$ 1988; 64: 364-8.

13. Isselbacher KJ, Amans RD, Braunwalt E, Petersdorf RG, Wilson JD (eds.). Harrison's Principles of Internal Medicine ( $9^{\text {h }}$ ed.). Toronto: McGraw-Hill, 1980.

14. Dirken JM. Arbeid en stress [Work and stress]. Groningen, The Netherlands: Wolters, 1969.

15. Luteijn F, Starren J, Dijk $H$ van. Nederlandse Persoonlijkheidsuragenlijst (NPV). [Dutch Personality Inventory] handleiding. Lisse, The Netherlands: Zwets \& Zeitlinger, 1980.

16. Zung WK. A self-rating depression scale. Archives of General Psychiatry 1965; 12:6370.

17. Dixon WK, Brown MB, Engelman L, Jennrich RI. BMDP statistical software manual, to accompany the 1990 release. Berkeley: University of California Press, 1990.

18. Sackett DL, Haynes RB, Tugwell P. Clinical epidemiology. A basic science for clinical medicine. Boston: Little, Brown and Company, 1985.

19. Kraemer HC. Evaluating medical tests. Objective and quantitative guidelines. Sage Publications: London, 1992.

20. Dean AG, Dean JA, Burton AH, Dicker RC. Epi Info, version 5.01b, a word processing, database and statistics program for epidemiology on microcomputers. Georgia: Stone Mountain, 1990.

21. Altman DG. Practical statistics for medical research. London: Chapman and Hall, 1991.

22. Hosmer DW, Lemeshow S. Assessing the fit of the model. In Applied logistic regression. 1st ed. New York: John Wiley and Sons, 1989.

23. Connell FA, Koepsell TD. Measures of gain in certainty from a diagnostic test. $A m I$ Epidemiol 1985; 121: 744-53.

24. Van der Schouw YT, Verbeek ALM, Ruijs JHJ. ROC curves for the initial assessment of new diagnostic tests. Fam Pract 1992; 9: 506-11.

25. Weinstein MC, Fineberg HV. Clinical decision analysis. Philadelphia: WB Saunders Company, 1980.

26. Knottnerus A. Interpretatie van diagnostische gegevens: theoretische en praktische bijdragen aan de diagnostische epidemiologie in de extramurale gezondheidszorg. [Thesis] Maastricht: Rijksuniversiteit Limburg, 1986.

27. Harley JA, McNeal BJ. The meaning and use of the area under a receiver operating characteristic (ROC) curve. Radiology 1982; 143: 29-36. 
5. The incidence and outcome of rectal bleeding in general practice

Gerda H Fijten, Jean WM Muris, ${ }^{* *}$ Richard Starmans, ${ }^{* *}$ Geert H Blijham, ${ }^{\text {*** }}$ J André Knottnerus," Theo FWA Krebber"

\footnotetext{
* Diagnostic Coordinating Centre Maastricht

** Department of General Practice, University of Limburg, Maastricht

*** Department of Internal Medicine, University Hospital, Utrecht
}

Accepted by Family Practice for publication in September 1993. 


\section{ABSTRACT}

The objective of the studies reported in this paper was to determine the incidence as well as the final diagnostic outcome of rectal bleeding presenting in general practice. Because of the wide variety observed in incidence rates among 83 GPs in the first study (A) an additional study (B) was undertaken. In study B with $10 \mathrm{GPs}$ special efforts were made to maximize the catchment rate. The mean 'consultation incidence rate' was 7 per 1000 people per year. A follow-up period of at least 1 year was applied to establish the final diagnostic conclusion. Occurrence of colorectal cancer was found in $3 \%$ of patients with rectal bleeding. This may represent an overestimation of the prior probability since there was a selection in favour of patients with clinically relevant rectal bleeding. In about $90 \%$ of the patients rectal bleeding was related to minor ailments or self-limiting disorders.

Further study on predictive values of (combinations of) others signs and symptoms is necessary to develop clinical recommendations. 


\section{Introduction}

Overt rectal bleeding is a common symptom. A recent study reports a prevalence of $20 \%$ in the general population. Only a small number of the people with rectal bleeding, however, consult a doctor. The ineidence of rectal bleeding in patients presenting in general practice can be roughly estimated to be at between 4 and 16 per 1000 people per year. ${ }^{23}$ Some of these patients will have colon or rectal cancer. The incidence of colorectal cancer is 44 per 100,000 inhabitants per year in The Netherlands and increases with age ${ }^{4}$ In less than half of the cases of colorectal cancer rectal bleeding is a presenting symptom. ${ }^{5,6}$ Therefore the prior probability of cancer in people with rectal bleeding can be estimated to be around $0.1 \%$. Empirically, there is little known about the prior probability of colorectal cancer in patients presenting with rectal bleeding to the general practitioner. A Medline search (CD ROM) in the literature, published between 1984 to 1992 , with "rectall bleeding" as one of the keywords, yielded only one study, twice referred to (by Goulston et al in $1986^{7}$ and by Mant et al in $1989^{8}$ ), in which patients were recruited in general practice. This Australian study gives a prior probability of $11 \%$ of cancer in patients presenting "rectal bleeding" as their clinical problem. In this study only patients older than 40 years of age were included. Furthermore, reports from study populations selected by referral to hospital are not useful for decision making in general practice. ${ }^{9}$ Depending on the selection before referral, the prior probability may be as high as $39 \% .^{10}$

The study reported here deals with the incidence and outcome of rectal bleeding in general practice.

\section{Methods}

\section{Design}

Consecutive patients with rectal bleeding were recruited by General Practitioners (GPs) in Limburg, the most southern province in the Netherlands, in a period from September 1988 to April 1990. 
The design of the study can be characterized 'pseudo follow-up'; patients are followed, for at least one year, to establish a final diagnosis.

This study was part of a larger study on rectal bleeding and non-acute abdominal pain.

\section{Patients}

All patients presenting to the doctor with overt rectal bleeding or a history of recent (i.e. within the last 3 months) rectal blood loss visible for the patient had to be included in the study.

Patients were excluded from the study if they met one of the following criteria: age younger than 18 years or older than 75 years, pregnancy and urgent admission to a hospital (massive bleeding or acute abdomen).

\section{Data collection}

Data were collected through the following:

1. A self-reported patient questionnaire containing 150 questions (somatic, social and psychological), A large section of questions required for abdominal pain can be skipped if not applicable.

2. A semi-structured questionnaire filled in by the doctor at the first consultation containing 70 variables: history, physical examination and initial management.

3. Laboratory tests: haemoglobin, erythrocyte sedimentation rate, white blood cell count and the Haemoccult test (3x, with a diet low of peroxidase and free of red meat).

The diagnostic items selected were those mentioned in literature as being relevant to discriminate between several diagnoses. ${ }^{8,11-13}$

The instruments were tested in a pilot study (for rectal bleeding only) in 4 practices during 2 months (18 patients) and in a pilot for the larger study in a health centre (50 patients). 


\section{Final diagnosis}

Outcome data were gathered in 1991. For this purpose the researchers (G Fijten, J Muris, R Starmans) reviewed the patient records in the practices after a follow-up period of at least one year. Any further diagnostic investigation (e.g. endoscopy) during this period was free to the decision of the GP. A final discussion with the GP completed the clinical follow-up. The follow-up procedure was blinded for the initial complaint(s) which could be rectal bleeding and/or non-acute abdominal complaints. The ICPC is used for the classification of diagnoses using the criteria of ICHPPC-2..$^{14.15}$

\section{Monitoring}

Action was taken to reduce the number of dropouts. Attention was paid to the problem of underregistration through regular personal contacts with the GPs (once a month) and via a newsletter circulated twice a year. The researchers were responsible for the contacts with the participating practices and for follow-up, each about one-third of the geographical area.

During the study performed according to this protocol (study A) it was noticed that the number of patients included was less than expected and very variable between practices. Therefore, in order to estimate possible underregistration by minimizing the number of dropouts, special efforts were taken by another 10 GPs using a modified protocol: study B.

\section{Study $B$}

This modified protocol was as follows:

- daily controls of patient records by the practice assistant (a notebook was kept to register data (age, gender, names) regarding all patients with rectal bleeding who visited the practice that day);

- very frequent (weekly) practice visits to check the questionnaires with the assistant's notebook;

- short intensive period of participation: 3 months (March till June 1990); 
- no exclusion criteria except $<18$ years of age;

- a simplified (one A4 format) doctors' form;

- the patient questionnaire not obligatory (but desired);

- no laboratory tests prescribed;

- outcome data collected in the same way as in study A.

\section{Data analysis}

Data were analysed on VAX-VMS mainframe using BMDP and on personal computer using Info Epi. ${ }^{16,17}$ The Chi-square test was used to assess the statistical significance of differences in contingency tables.

\section{Results}

Study A included 290 patients presenting with rectal bleeding in general practice according to the forms from 83 GPs. On average the duration of participation by the GPs was 11 months, with a range of 1 to 24 months. Standardized for participation time and part-time employment, the incidence of rectal bleeding in an average general practice (2200 persons per practice) was 2.15 per 1000 persons per year, with a inter-practice range of 1 to 8 .

In study B 48 patients were collected by 10 doctors in 3 months. Since in study $B$ special efforts have been taken to minimize the dropout rate (or, maximize the catchment rate) the incidence rate can be calculated more accurately, as is shown in Table 1.

The resulting incidence rate is 6.8 per 1000 per year, with an inter-practice range of 0 to 18.5 . On average this is three times as high as in study A. Only 3 GPs in study A yielded an incidence rate as high as the mean in study B. 
Table 1. Incidence rate of rectal bleeding presented in generall practice, per 1000 per year.

\begin{tabular}{|l|c|c|c|c|}
\hline Practice & $\begin{array}{c}\text { number } \\
(\mathrm{N})\end{array}$ & $\begin{array}{c}\text { weeks of registration } \\
(\mathrm{W})\end{array}$ & $\begin{array}{c}\text { practice size } \\
(\mathrm{S})\end{array}$ & $\begin{array}{c}\text { number per } 1000 \\
\text { per year }\end{array}$ \\
\hline A & 7 & 12 & 2800 & 10.8 \\
B & 3 & 12 & 2800 & 4.6 \\
C & 0 & 12 & 3100 & 0 \\
D & 3 & 11 & 2400 & 5.9 \\
B & 8 & 13 & 2500 & 12.8 \\
F & 4 & 13 & 2500 & 6.4 \\
G & 9 & 11 & 2300 & 18.5 \\
H & 9 & 13 & 3500 & 10.3 \\
I & 1 & 13 & 3200 & 1.25 \\
J & 4 & 11 & 2750 & 6.9 \\
\hline Total & 48 & & & 6.8 \\
\hline
\end{tabular}

Calculation of the mean of incidence rate $=\left(\sum_{A-J}\left(\frac{N \times 52}{W}\right) \times\left(\frac{1000}{S}\right)\right): 10$
Mean $=6.8$

Median $=6.6$

Range $=0-18.5$

Table 2 shows the age and gender distribution of patients in study A and B. In general no major difference was observed, although there were relatively more patients aged older than 55 years in study $A(p=0.07)$. The gender differences were not statistically significant.

Table 3 shows the diagnostic outcome in the two studies.

In study A 21 patients (7\%) were lost to follow-up, due to moving to an unknown destination. The mean follow-up period was 19.6 months, with a standard deviation of 4.9 and a range of 12 to 40 months.

In study B 4 patients ( $8 \%$ ) were lost to follow-up. The follow-up period varied from 12 to 15 months. 
Table 2. Age and gender distribution of patients in study $A$ and in study $B$.

\begin{tabular}{|l|cc|cc|}
\hline Age and gender & \multicolumn{2}{|c|}{ study A } & \multicolumn{2}{c|}{ study B } \\
\hline Age & number & $\%$ & number & \% \\
$18-39$ years & 144 & 49 & 24 & 50 \\
$40-44$ & 39 & 13 & 7 & 15 \\
$45-49$ & 19 & 7 & 5 & 10 \\
$50-54$ & 28 & 10 & 9 & 19 \\
$\geq 55$ & 60 & 21 & 3 & 6 \\
\hline Gender (1 missing) & & & & \\
female & 163 & 56 & 22 & 46 \\
male & 126 & 44 & 26 & 54 \\
\hline Total & 290 & 100 & 48 & 100 \\
\hline
\end{tabular}

Table 3. Final diagnoses related to rectal bleeding in study $A$ and study $B$.

\begin{tabular}{|l|c|c|}
\hline & study A & study B \\
Diagnosis & $\%$ & $\mathbf{N = 4 4}$ \\
\hline Unknown cause (but healthy) & 61 & 52 \\
Haemorrhoids & 16 & 30 \\
Fissura ani (fistel, abscess) & 7 & 9 \\
Infections & 2 & 2 \\
Diverticulosis & 1 & 0 \\
Proctitis & 4 & 0 \\
Colitis & 5 & 7 \\
Polyps & 2 & 2 \\
Cancer & 3 & 0 \\
\hline Total & $101^{*}$ & $102^{*}$ \\
\hline
\end{tabular}

- 6 patients with 2 diagnoses

* 1 patient with 2 diagnoses 
In both studies there was often $(61 \%$ and $52 \%)$ no specific diagnosis related th rectal bleeding found. These patients remained healthy within the follow-ü period. Minor ailments and selflimiting disorders like fissura ani anc haemorrhoids were frequently diagnosed with preponderance in study $B$ : ir $39 \%$ of patients in study $B$ and in $23 \%$ in patients in study $A$.

Haemorrhoids occurred twice as often in study B as in study A, but otherwise the two studies showed no major differences, Causes which can be considerec 'serious' (colitis, proctitis, polyps and cancer) occurred with a frequency of around $10 \%$ in both studies. The prior probability of cancer was $3 \%$ in study $A$ and 0 in sturdy $B$.

Study A patients were divided into 2 groups in order to evaluate differences in outcome between (1) those practices which participated at least 6 months with an incidence rate of rectal bleeding above the mean incidence rate and (2) those which participated only briefly or had an incidence rate below the mean (Table 4).

Age and gender were not statistically different but minor ailments (haemorrhoids, fissura ani, infection and diverticulosis) occurred more in the group with a higher incidence rate $(p=0.048)$. Different cut-off points for participation intensity (length of period and number of patients recruitment), for example 5 or 9 patients per practice, were applied with similar results.

\section{Discussion}

The incidence rate of rectal bleeding in general practice was found to be around 7 per 1000 people per year and varied among practices with a maximum incidence rate of 18 per 1000 per year. Study A concerns patients selected for the study according to the initial protocol, including laboratory tests and a patient questionnaire. There is probably an underregistration of rectal bleeding in this group especially regarding younger patients due to noncompliance of the registrating doctor. 
Table 4. Patients and outcome in two groups, related to the incidence rate of the practice and duration of participation of the GPs.

Group 1. GP participated $>6$ months and incidence rate $>2.15$ per 1000 per year.

Group 2, GP participated $<6$ months or incidence rate $<2.15$ per 1000 per year:

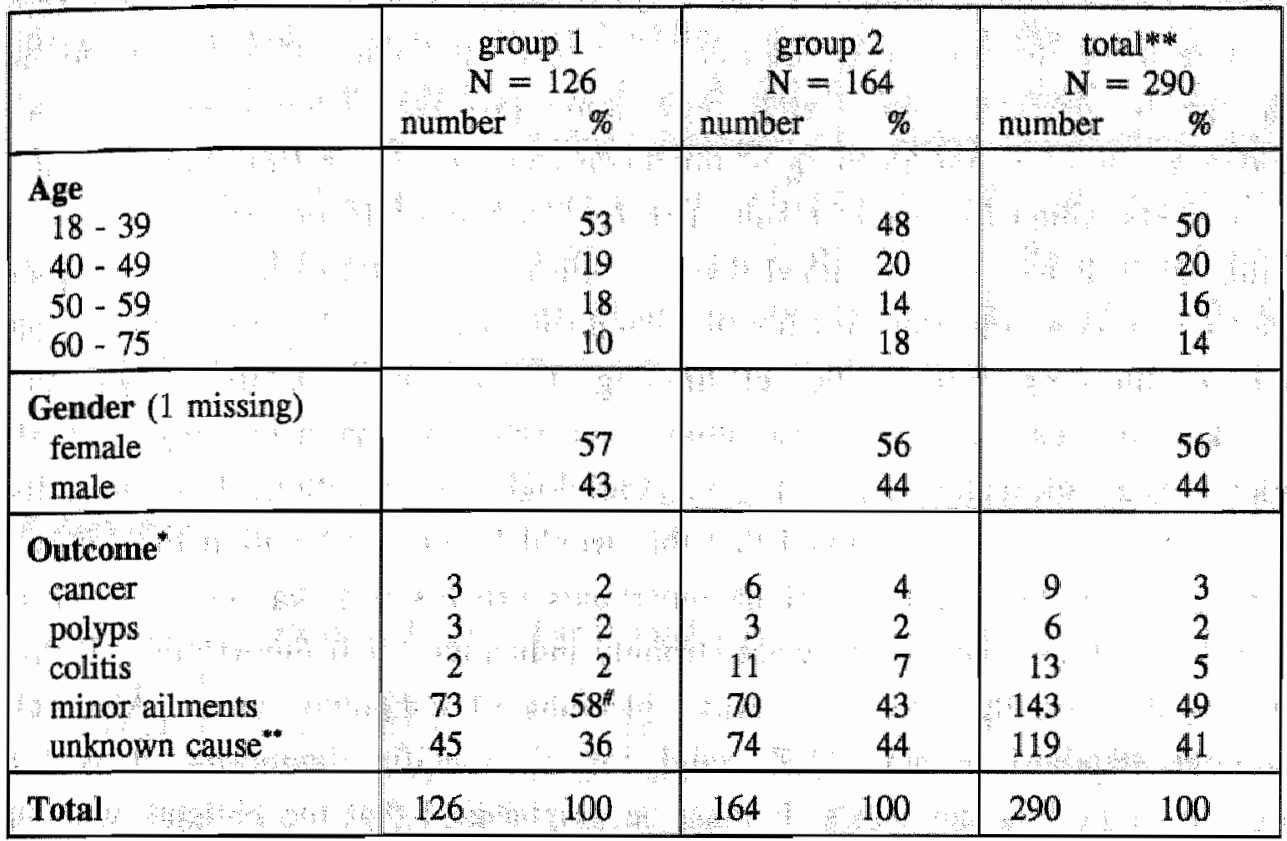

- diagnoses ranked according to severity

- lost to follow-up included

" $\mathrm{p}<0.05$

GPs in study A mentioned several reasons for not recruiting all patients who met the inclusion criteria. Most frequently it was "too much fuss for a simple and harmless complaint", often "lack of time" and sometimes the study was considered harmful for the patient because the possibility of inducing fear. Furthermore, the longer patients' questionnaires in study A might have caused some resistance among the GPs to motivate the patients with minor rectal bleeding, although the questionnaires had proved to be acceptable in a pilot study. However, this was done by a selected group of highly motivated GPs. In study $B$ special efforts had been taken to reduce underregistration. 
Laboratory test and patient questionnaires were not obligatory. At the same time there was a daily check of patient records. In study B the incidence of rectal bleeding was higher and there were relatively more younger patients. The incidence rate of around 7 per 1000 per year found in study B appears therefore to be the true incidence rate. This result is comparable to estimations that can be derived from Dutch registration projects. They have given an incidence rate of rectal bleeding of unknown cause of 4 per 1000 per year and of disorders which frequently result in rectal bleeding of 16 per $1000 .^{2,3}$

In this study it has been assumed that the follow-up period of at least one year is sufficient as a gold standard for the diagnosis of cancer. Usually a malignant cause of bleeding will not be self-limiting. For colitis, proctitis, polyps and diverticulosis, endoscopic or radiologic confirmation was necessary. Not all patients had colorectal endoscopy nor radiologic investigation. For clinically important colitis it was assumed that this would be detected within the followup period. For the diagnosis of haemorrhoids proctoscopy was desired unless clinical symptoms and history were strongly indicative for haemorrhoids. If this was not the case the conclusion was: 'bleeding of unknown cause'. Although the gold standard is not $100 \%$ valid for all specific diagnoses, it is for clinically important diagnoses. It must be emphasized that the patients without a specific diagnosis were healthy after a follow-up period of at least one year. Taking this in mind it can be concluded that serious disorders occurred in around $10 \%$. Malignant colorectal disease was diagnosed in $3 \%$ of patients in study A and in none in study B. The GPs of study A may have selected patients with respect to clinically relevant bleeding or age. This can result in a higher or overestimated prior probability of cancer. Although it should be noted that the size of study B and therefore the precision is smaller, the prior probability in a less preselected population is more likely to be less than $3 \%$. The Australian study had found a probability of cancer of $11 \%$ in patients older than 40 years with 'rectal bleeding as a clinical problem'. This different finding may be attributed to selection by age, but selection bias in favour of 'clinically relevant bleeding' cannot be excluded. These patients, of whom $42 \%$ were not available for analysis, were recruited in general practice but referred to a specialist for final diagnosis. 
We conclude that the incidence of 'rectal bleeding presented in general practice' is about 7 per 1000 per year. The initial study protocol, study A, yields a lower rate, 2 per 1000 , which is probably an underestimation of the real incidence but reflects rectal bleeding considered to be clinically relevant by the GPs. In patients with 'rectal bleeding presented in general practice' the prior probability of cancer is $3 \%$ or less. About $90 \%$ of the sources of bleeding are minor ailments or self-limiting disorders. In order to develop clinical recommendations for GPs for effective and efficient selection of patients (with a reasonably high prior probability of cancer) for invasive diagnostic workup, further study on predictive values of other signs and symptoms in combination with rectal bleeding is necessary.

\section{References}

1. Jones $\mathrm{R}$, Lydeard $\mathrm{S}$. Irritable bowel syndrome in the general population. $\mathrm{Br}$ Med $\mathrm{J}$ 1992; 303: 87-90.

2. Velden J van der, Bakker DH de, Claessens AAMJ, Schellevis FG. Nationale studie naar ziekten en verrichtingen in de huisartspraktijk. Basisrapport: Morbiditeit in de huisartspraktijk. Utrecht: Nivel, 1991.

3. Lamberts H. In het huis van de huisarts: Verslag van het Transitieproject. Lelystad: Meditekst, 1991.

4. Bakker D, Coebergh JWW, et al (eds.). Cancer Incidence in The Netherlands; the southeastern part, 1978-1982. Eindhoven: Eindhoven Cancer Registry/IKZ, 1985.

5. Månsson J. The diagnosis of colorectal cancer - Experiences from the community of Kungsbacka, Sweden. Scand J Prim Health Care. 1990; 8: 31-5.

6. Fujita M, Sugiyama MD, Kumanishi $\mathrm{Y}$, et al. Evaluation of effectiveness of mass screening for colorectal cancer. World J Surg 1990; 14: 648-52.

7. Goulston KJ, Cook I, Dent OF. How important is rectal bleeding in the diagnosis of bowel cancer and polyps? Lancet 1986; ii: 261-5.

8. Mant A, Bokey EL, Chapuis PH, et al. Rectal bleeding. Do other symptoms aid in diagnosis? Dis Colon Rectum 1989; 32: 191-6.

9. Knottnerus JA. Interpretation of diagnostic data: an unexplored field in general practice. $J$ R Coll Gen Pract 1985; 35: 270-4.

10. Noer RJ, Hamilton JE, Williams DJ, Broughton DS. Rectal Hemorrhage: Moderate and Severe. Ann Surg 1962; 155: 749-805. 


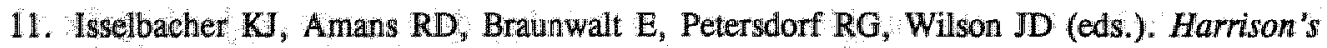
Principles of Internal Medicine ( $\varphi^{\text {h }}$ ed.). Toronto: McGraw-Hill, 1980.

12. Cheung PSY, Wong SKC. Boey J, Lai CK. Frank rectal bleeding: a prospective study of causes in patients over the age of 40. Postgrad Med J 1988; 64: 364-8.

13. Kewenter J, Haglind E, Smith L. Value of a risk questionnaire in screening for colorectal meoplasm. Br J Surg 1989; 76: 280-3.

14. Lamberts $\mathrm{H}$, Wood M (eds.). ICPC International Classification of Primary Care. Oxford: Oxford University Press, 1987.

15. Classification Committee of WONCA. ICHPPC-2 defined Inclusion criteria for the use of the rubrics of the Internal Classification of Health Problems in Primary Care. Oxford Oxford University Press, 1983.

16. Dixon WK, Brown MB, Engelman L, Jennrich RI. BMDP statistical software manual, to accompany the 1990 release. Berkeley: University of California Press, 1990.

17. Dean AG, Dean JA, Burton AH, Dicker RC. Epi Info "version 5.01b, a word processing, database and statistics program for epidemiology on microcomputers. Georgia: Stone Mountain, 1990. 
6. Predictive value of signs and symptoms for colorectal cancer in patients with rectal bleeding in general practice

Gerda H Fijten," Richard Starmans, ${ }^{* *}$ Jean WM Muris; ${ }^{* *}$ Hubert JA Schouten, ${ }^{* * *}$ Geert H Blijham, ${ }^{* * * *}$ J André Knottnerus**

*Diagnostic Coordinating Centre Maastricht

** Department of General Practice, University of Limburg, Maastricht

${ }^{* * *}$ Department of Methodology and Statistics, University of Limburg, Maastricht

${ }^{* * * *}$ Department of Internal Medicine, University Hospital, Utrecht

Submitted for publication 


\section{ABSTRACT}

Objective to determine the diagnostic value of (combinations of) signs, symptoms and simple laboratory test results for colorectal cancer in patients with rectal bleeding presenting in general practice.

Design

pseudo follow-up study; initial complaints and findings were compared with the final diagnoses which were independently assessed based on clinical follow-up established after at least 1 year.

Setting

: General Practices (83 GPs) in the South of the Netherlands.

Subjects

: 269 consecutive patients in the ages $18-75$ years presenting overt rectal bleeding to the general practitioner.

Outcome measure: sensitivity, specificity, predictive values, odds ratios and a prediction model derived from multiple logistic regression analysis.

Results

: age, change in bowel habit and blood mixed with or on stool show a statistically significant independent value in the discrimination between patients with a low and those with a high probability of colorectal cancer. The prediction model has a sensitivity of $100 \%$ and a specificity of $90 \%$ at a cut-off point (posterior probability) of 0.042 .

Conclusion : although the number of patients with colorectal cancer is small $(n=9)$ it was possible to identify three characteristics which can be helpful in the prediction of presence or absence of colorectal cancer in general practice. Application of the model presented might prevent $90 \%$ of 'unnecessary' invasive diagnostic procedures for patients with rectal bleeding who do not have colorectal cancer (true negative). Testing the performance of the model in other general practice populations is recommended. 


\section{Introduction}

Overt blood loss per anum or per rectum (haematochezia) is common in general practice. The incidence of patients in the ages of 18 to 76 years presenting this symptom to their general practitioner (GP) is 7 per 1000 people per year. Although its source is usually not serious it may also be the first symptom of a colorectal malignant disorder. ${ }^{1}$ It is open to debate whether the prognosis of symptomatic colorectal malignant disease may be improved by earlier diagnosis, ${ }^{2,3}$ but the finding of a carcinoma will often raise the question whether it would have been possible to detect it earlier. Partly because of this there is considerable disagreement as to the optimal diagnostic management. Some advocate a full examination of every patient with blood loss per rectum (sigmoidoscopy in combination with barium enema or colonoscopy) in order to rule out the possibility of a malignant tumour, ${ }^{4-6}$ whereas others favour a more conservative approach. ${ }^{7}$ The GP is faced with the task of selecting patients in such a way that the costs and benefits of ancillary tests are reasonably balanced.

Little is known about the diagnostic value of specific signs and symptoms useful in general practice. ${ }^{89}$ An early discrimination between patients with a low and those with a reasonably high probability for colorectal cancer could reduce the number of invasive investigations and prevent 'unnecessary' alarm.

The aim of the present study was firstly to determine the predictive value of patient characteristics, signs and symptoms for the presence of colorectal malignancy and secondly to identify important predictor variables contributing to a multivariate prediction model. Such a model could be helpful for GPs in deciding whether to proceed with further assessment.

\section{Methods}

\section{Design}

The design of the study can be characterized as 'pseudo follow-up': a crosssectional relationship between signs and symptoms and the diagnostic outcome is studied, while the outcome can be only detected by follow-up. 
All diagnostic information (medical records and information of the GP) available after a follow-up period of at least one year was used by three of the authors: (GF, JM, RS), blinded for the initial complaints, to establish the final diagnostic conclusion(s). Endoscopy or rontgenography was not obligatory and only performed when considered necessary by the GP. It was assumed that a potentially malignant source of rectal bleeding would have been discovered within the follow-up period. The International Classification of Primary Care ${ }^{10}$ was used for diagnostic classification. In cases with more than one diagnosis the severest is used in the analysis.

\section{Patients}

From September 1988 to June 1990,290 consecutive patients with rectal bleeding were recruited by 83 GPs in Limburg (the southernmost province of the Netherlands), with an average duration of participation of 11 months per doctor. Patients were included when overt rectal bleeding was the reason for encounter or when there was a history of recent (within the previous three months) rectal blood loss visible for the patient. Patients were excluded 1) if they were younger than 18 years or older than 75 years, 2) if they were pregnant, 3) if there was an urgent admission to a hospital (e.g. massive bleeding, acute abdominal pain or bowel obstruction) and 4) if follow-up data were not available.

\section{Variables}

The rectal bleeding study is part of a larger study on rectal bleeding and nonacute abdominal complaints. In compiling the questionnaires used in this study, items were selected which are reported in literature as being relevant for discrimination between the several diagnoses. ${ }^{11-15}$

The data were collected by the following means:

1. A semi-structured questionnaire filled in by the doctor after the first consultation, containing 70 variables; history, physical examination and initial management. 
2. A questionnaire filled in by the patient, containing 150 (somatic and psychological) questions.

3. Laboratory tests: haemoglobin $(\mathrm{Hb})$, erythrocyte sedimentation rate (ESR) (several cut-off points, including an optimal cut-off point according to Dinant et $\mathrm{al}^{16}$ ), white blood cell count (WBC) and occult blood in the faeces (FOB) (Haemoccult test, $3 \mathrm{x}$, with a diet low of peroxidase and free of red meat):

\section{Statistical analysis}

Data were analysed on VAX-VMS mainframe and personal computer, using BMDP and Epi Info (for odds ratios and $95 \%$ Confidence Intervals (CI) ${ }^{17,18}$ For significance testing the Chi-square test for independent proportions was used. ${ }^{19}$ The diagnostic values of variables (patient characteristics, signs and symptoms derived from the doctors" form together with some additional symptoms derived from the patients' form) were evaluated subsequently with bivariate and multivariable techniques. For variables showing an association (p-value $<0.1$ ) with cancer in bivariate analysis, sensitivity, specificity, predictive values $\left(\mathrm{PV}^{+}, \mathrm{PV}^{-}\right.$) and crude odds ratios were computed.

$\mathrm{PV}^{+}=$percentage of patients with the sign or symptom who have colorectal cancer.

$100 \%-\mathrm{PV}^{-}=$percentage of patients without the sign or symptom who have colorectal cancer.

Except for age, (continuous) variables were dichotomized (no or absence $=0$, and yes or presence $=1$ ). All dilagnostic variables, for which $p<0.1$, were entered into logistic regression analysis to find the 'independent' predictive value of each taking the other variables into account simultaneously. Forward stepwise logistic regression analysis was used to find a prediction model to predict the probability for colorectal cancer with a limited set of significantly contributing variables (reduced model). ${ }^{20}$ Enter and remove limits were applied for $p$-values $<0.05$. From the regression coefficients odds ratios (OR) can be calculated, $O R=e^{\text {coefficient }} . O R=$ (true positive $x$ true negative) : (fallse positive $\mathrm{x}$ false negative) or $\mathrm{OR}=\left(\mathrm{PV}^{+} \times \mathrm{PV}^{-}\right):\left(1-\mathrm{PV}^{+}\right)\left(1-\mathrm{PV}^{-}\right)$. 
If the coefficient is positive, the odds ratio is greater than 1 , which indicates that the variable is positively associated with cancer. If the coefficient is negative, the odds ratio is less than 1 , which indicates that the variable is negatively associated with cancer. ${ }^{21}$ The discriminatory power of the model was examined using the Area Under the Receiver Operating Characteristic (ROC) Curve (AUC). The AUC measures the discriminatory power of a test by simultaneously comparing its sensitivity and specificity at a range of cut-off points; a test that discriminates perfectly between disease and no disease has an AUC of 1 or 0 , a test without discriminatory power has an AUC of $0.5 .^{22,23}$ In addition, the regression results were evaluated by determining the cut-off points (posterior probabilities) associated with the maximum sum of sensitivity and specificity. ${ }^{24}$ In a second analysis the predictive values were determined after combining colorectal cancer and polyps into one group.

\section{Results}

Of 290 patients 21 were excluded since they were lost to follow-up (moved to an unknown destination). A total of 269 patients were studied, with a mean age of 42 years (range 18-75, standard deviation 15 years); $56 \%$ were females. Age and gender of the 21 excluded patients did not differ from the remaining 269 patients $(p \geq 0.1)$. The mean of follow-up time was 20 months with a standard deviation 5 months.

For $51 \%$ of the patients rectal bleeding was the reason for encounter: $49 \%$ had another reason, for example abdominal complaints, but blood loss per rectum was seen and mentioned by the patient. Eight patients used anticoagulants.

At the end of the initial consultation $8 \%$ of patients were referred to a medical specialist (5\% to an internist, $3 \%$ to a surgeon); endoscopy or roentgenography was requested for $14 \%$ and $10 \%$ of patients respectively. In the course of the follow-up period, after at least one year, a total of $24 \%$ of patients had been referred, $14 \%$ to an internist, $5 \%$ to a surgeon, $2 \%$ to another specialist and $3 \%$ to several specialists. A total of $31 \%$ had further investigations initiated by the GP by means of sigmoidoscopy ( $9 \%$ ), colon roentgenography $(9 \%)$, proctoscopy $(8 \%)$, sonography $(6 \%)$ and colonoscopy $(2 \%)$ (some patients underwent more than 1 investigation). 


\section{Diagnostic outcome}

The diagnostic outcome related to rectal bleeding of the study population of 269 patients is shown in Table 1 in relation to age and gender. The age distribution of the patients was not different for males and females (data not shown). The vast majority ( $95 \%$ ) of patients had diagnoses not related to neoplastic transformation: $75 \%$ of the patients in fact had haemorrhoids, or no bleeding cause could be identified in the follow-up period. None of the patients using anticoagulants had colorectal cancer nor polyps. Colorectal cancer was present in 9 patients $(3.3 \%, 95 \% \mathrm{CI} 1.2 \%-5.4 \%)$ with a strong preponderance in males ( 7 out of 9 ) and older individuals ( 8 out of 9 older than 60 ). The odds ratio (gender $x$ cancer) of males compared to females was $4.7 \quad(p=0,04)$.

Table 1. Frequency of colorectal carcinoma, polyps and other diagnoses according to age and gender. Row percentages per age or gender category (numbers in brackets).

\begin{tabular}{|l|c|c|c|c|}
\hline \multicolumn{5}{|c|}{ Diagnoses related to rectal bleeding } \\
\hline & $\begin{array}{c}\text { total number } \\
\mathrm{N}=269\end{array}$ & $\begin{array}{c}\text { cancer } \\
\mathrm{N}=9\end{array}$ & $\begin{array}{c}\text { polyp } \\
\mathrm{N}=6\end{array}$ & $\begin{array}{c}\text { others } \\
\mathrm{N}=254\end{array}$ \\
\hline & number & $\%$ & $\%$ & $\%$ \\
\hline Age & & 3 & 2 & 95 \\
$18-29$ years & $(62)$ & 0 & & \\
$30-39$ years & $(71)$ & 0 & 0 & 100 \\
$40-49$ years & $(55)$ & 0 & 0 & 100 \\
$50-59$ years & $(41)$ & 2 & 2 & 98 \\
$60-75$ years & $(40)$ & 20 & 5 & 91 \\
Gender & & & & 75 \\
femalle & $(151)$ & 1 & 1 & 98 \\
male & $(118)$ & 6 & 3 & 91 \\
\hline
\end{tabular}

gender $\mathrm{p}<0.05$ (Chi-square $2 \mathrm{df}$ ) age $\quad \mathrm{p}<0.01$ (Chi-square $8 \mathrm{df})$

Cancer : rectumcarcinoma (6), sigmoidcarcinoma (1) and coloncarcinoma (2)

Polyp : adenomatous polyp (3) and benign polyps not specified (3)

'Others : no cause of bleeding found (162), haemorrhoid(s) (41), fissura ani (18), infection (6), diverticulosis (2), proctitis (12) and colitis (13) 
We next determined the association between signs and symptoms (variables) and the diagnostic outcome, in particular colorectal cancer. Signs, symptoms and laboratory test results which did not have a statistically significant $(p \geq 0.1)$ association with colorectal cancer neoplasm are shown in Table 2.

Table 2. Variables without a statistically significant association with colorectal cancer.

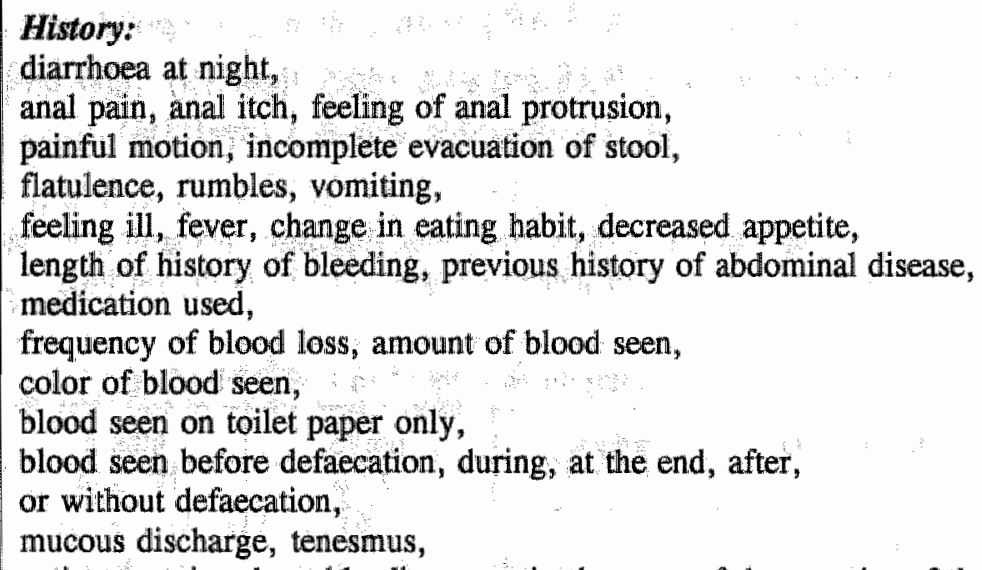

patient worries about bleeding, worries because of the severity of the complaints, patient considers cancer to be the source of bleeding, stressful period, history of abdominal surgery, visits abroad (tropical or Mediterranean countries), alcohol consumption ( $>2$ glasses/day), smoking.

\section{Physical examination:}

general impression, abdominal inspection, abdominal auscultation, palpation, percussion.

\section{Psychological tests:}

psychobiological stress (VOEG)

self-esteem, social inadequacy (Dutch Personality Inventory)

signs of depression (ZUNG). 
Variables with a significant association $(p<0.1)$ are listed in Table 3 together with their sensitivity, specificity, predictive value and odds ratio. In general practice the diagnostic value of a variable is highly determined by its predictive value for the absence of having a colorectal malignancy. Therefore of particular interest are those variables that have a very low (close to 0 ) positive predictive value $\left(\mathrm{PV}^{+}\right)$or a very low '100 minus negative predictive value $\left(\mathrm{PV}^{-}\right)^{\prime}$. The presence or absence of these respective variables indicates absence of colorectal cancer. In our analysis it appears that colorectal cancer is highly unlikely ( $1 \%$ or less) in patients who did not see blood on or mixed with stool, in patients who did see blood on the toilet paper and in patients without change in bowel habit, with pain at night, with a family history of abdominal disease or with a previous history of rectal bleeding. All other variables; although significantly associated with the outcome or having a reasonable sensitivity or specificity for the presence of colorectal cancer, were not useful for selection of patients with a very low probability of having malignant disease (that is for diagnosis by exclusion).

Rectal digital examination, although required by the protocol, was done only in $77 \%$ of patients. Results were generally negative and if positive mainly pointed to the presence of haemorrhoids. The association between abnormal prostate and colorectal cancer is an observation based on 2 patients (one with cancer). Proctoscopy was carried out at the first consultation by the GP in only $17 \%$ of patients. This subpopulation included only 2 patients with cancer.

Abdominal inspection, auscultation, percussion and palpation were carried out in $80-90 \%$ of all patients. None of these examinations contributed substantially to the probability of cancer. Anal fissurae were diagnosed in 29 patients, all without colorectal cancer. However, this negative association of fissurae with cancer was not significant $(\mathrm{p}>0.1)$.

Results of laboratory tests in relation to colorectal cancer are shown in Table 4. These data were available for 225 patients with a prior probability of cancer of $2.2 \%(5 / 225)$. As far as the diagnostic value for excluding colorectal cancer is concerned, patients with an ESR lower than $30 \mathrm{~mm} / 1 \mathrm{hr}$, a WBC below $10^{\circ} / 1$ or Haemoccult negative (three times) have a probability of colorectal cancer of $1 \%$ or less. 


\begin{tabular}{|c|c|c|c|c|c|c|c|c|c|c|c|}
\hline 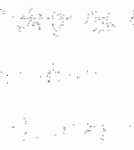 & $D_{1}$ & * * * & * & * & * & * & 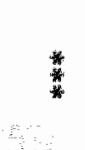 & * & & * & * \\
\hline 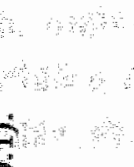 & 용 & givión & 3 & $\stackrel{+}{0}$ & 0 & 5 & $\ddot{0}$ & $\stackrel{0}{*}$ & 0 & 0 & r \\
\hline 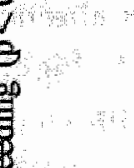 & $\begin{array}{l}1 \\
0 \\
8 \\
0\end{array}$ & monnc & + & $\ddot{2}$ & $m$ & $\nabla$ & + & $\leadsto$ & 0 & n & $m$ \\
\hline 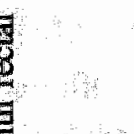 & 莡 & $\pm r-r$ & $N$ & $a$ & 0 & $\sim$ & $N$ & 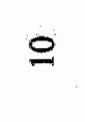 & 0 & 0 & $\Xi$ \\
\hline a & 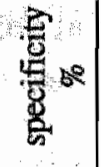 & มूล & $\infty$ & n & $\approx$ & \pm & I & 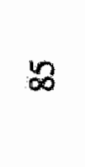 & 엉 & 8 & $\stackrel{\circ}{\circ}$ \\
\hline 4 & 蜜 & 워욕 & ते & $\infty$ & 0 & $\Rightarrow$ & $=$ & 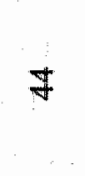 & 0 . & 0 & 9 \\
\hline & 岁 & 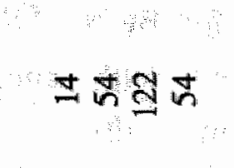 & $\stackrel{n}{n}$ & $\stackrel{\infty}{2}$ & 8 & ช & $\infty$ & F & 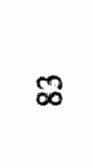 & ฉ̊ & 0 \\
\hline 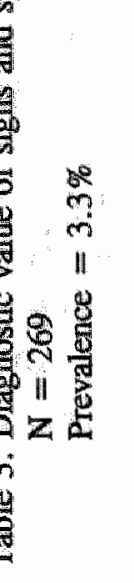 & 总 & 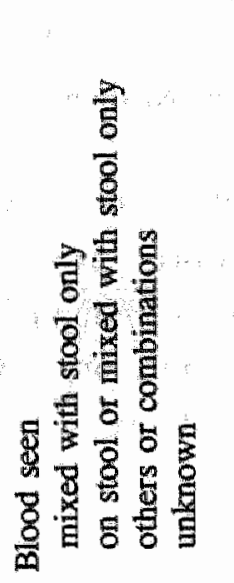 & 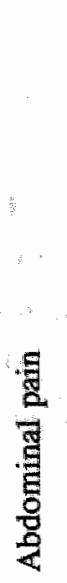 & 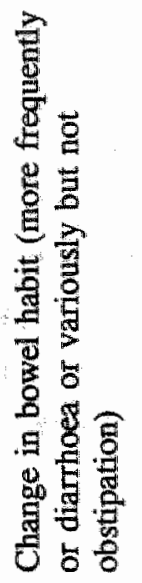 & 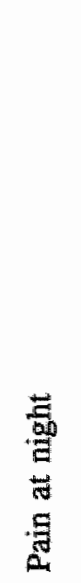 & 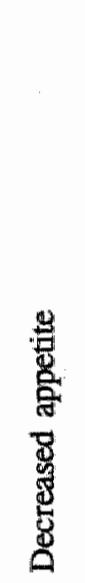 & $\begin{array}{l}\mathbb{8} \\
\stackrel{\mathscr{m}}{Z} \\
\text { Z }\end{array}$ & $\begin{array}{l}\frac{n}{0} \\
\frac{5}{50} \\
\frac{50}{2} \\
3\end{array}$ & 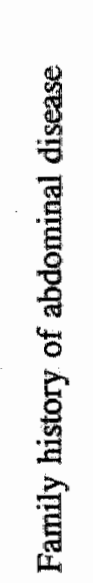 & 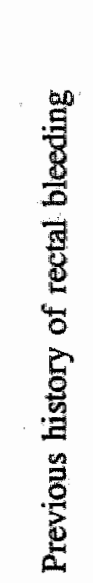 & 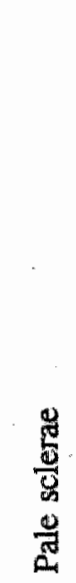 \\
\hline
\end{tabular}




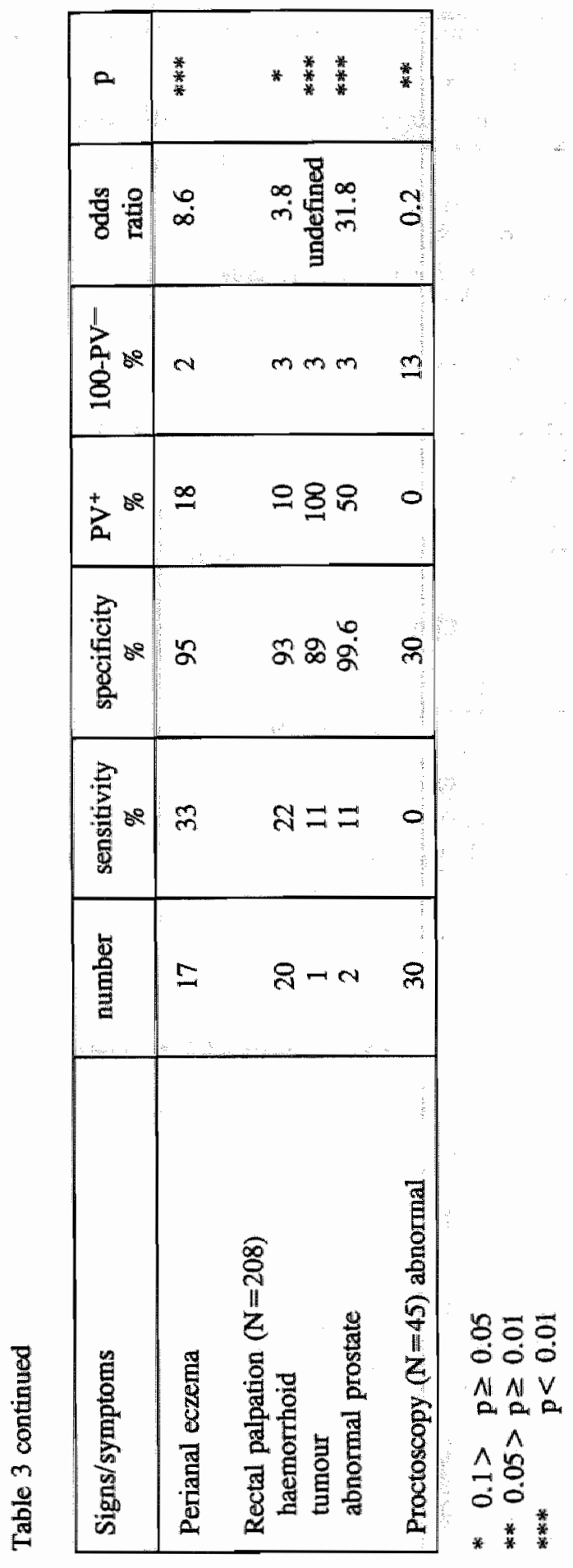




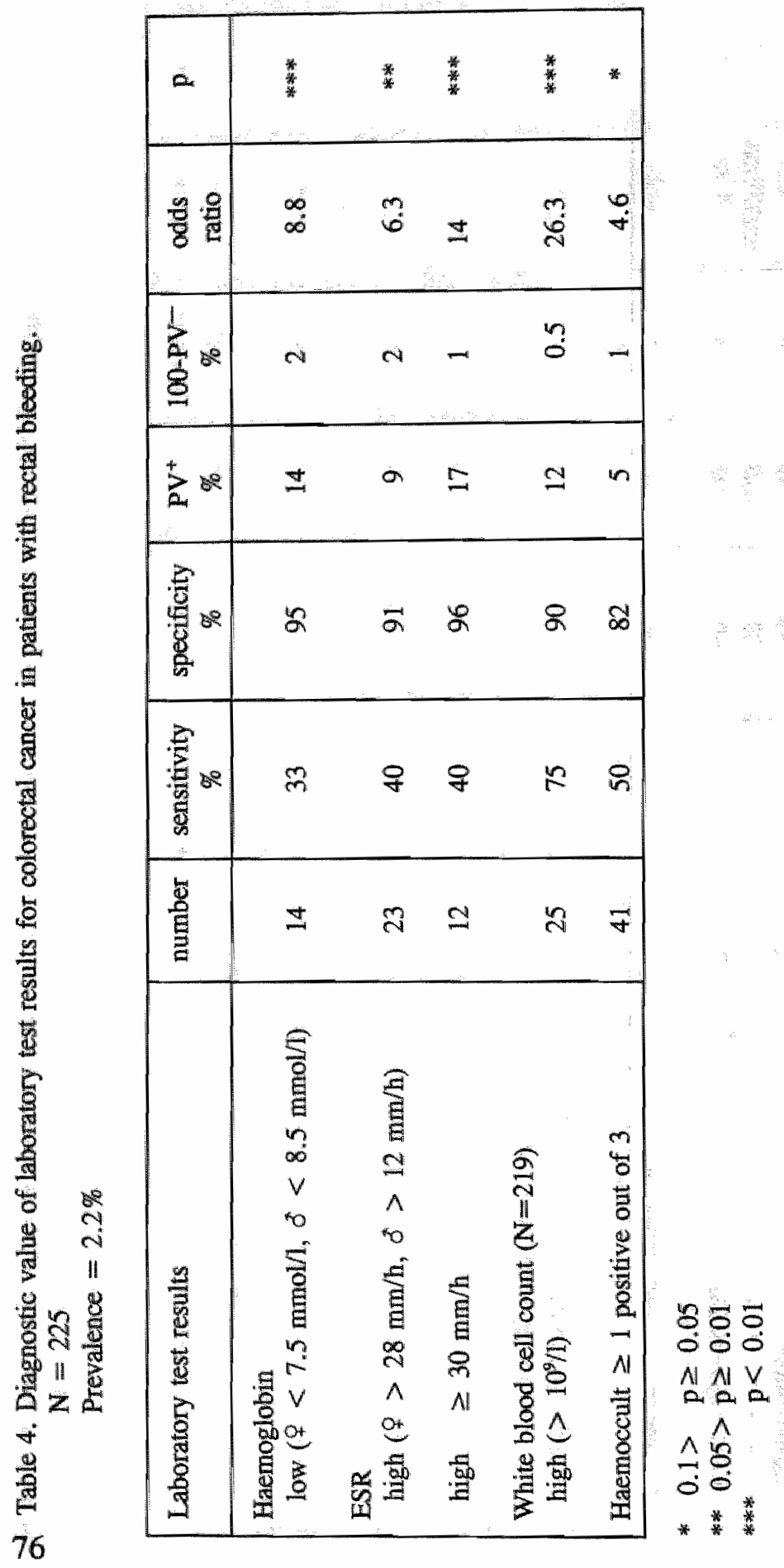




\section{Multiple logistic regression for cancer}

The diagnostic index resulting from forward stepwise logistic regression analysis is shown below Table 5 .

Table 5. Predicted probability of colorectal cancer according to multiple logistic regression analysis in patients with rectal bleeding.

Prior probability $=0.03$

Predicted (posterior) probability of colorectal cancer for patients with a changed bowel habit and/or blood mixed with or on stool in age categories.

\begin{tabular}{|l|c|c|c|c|}
\hline \multirow{3}{*}{ Age in years } & \multicolumn{4}{|c|}{ Change in bowel habit } \\
\cline { 2 - 5 } & \multicolumn{4}{|c|}{+} \\
\cline { 2 - 5 } & blood "mixed with" or "on" stool & blood "mixed with" or "on" stool \\
\cline { 2 - 5 } & + & - & + & - \\
\hline 30 & 0.002 & 0.0002 & 0.0002 & $1 \times 10^{-5}$ \\
40 & 0.01 & 0.002 & 0.001 & 0.0001 \\
50 & 0.10 & 0.01 & 0.01 & 0.001 \\
55 & 0.22 & 0.03 & 0.03 & 0.003 \\
60 & 0.44 & 0.09 & 0.07 & 0.009 \\
65 & 0.68 & 0.21 & 0.18 & 0.03 \\
70 & 0.86 & 0.43 & 0.38 & 0.07 \\
\hline
\end{tabular}

Above the optimal cut-off point for exclusion $(0.042)$ is in italic

Diagnostic index: logit $(p)=-6.7+2.1(($ Age-50)/10 $)+2.3$ if change in bowel habit + 2.1 if blood mixed with or on stool

Log likelihood $=-17.86$, Hosmer Lemeshow $\mathrm{p}=0.51$

Predicted (posterior) probability: $\frac{1}{1+e^{-\log _{0} i(p)}}$

Entered in logistic regression were: all history and physical examination variables with $p<0.1$, age (for statistical reasons transformed to (age-50)/10, i.e. decades bellow and above 50 years) and gender. Three variables remained significantly predictive: age $(O R=8)$, change in bowel habit $(O R=10)$ and blood mixed with stool or on stool ( $O R=8)$. The combination of these three could be assessed as a diagnostic test for the prediction of cancer. 
The area under the ROC curve (AUC) was 0.97 (Figure 1), which means a high discriminatory power.

\section{Figure 1}

ROC curve illustrating the relation between sensitivity and specificity of the prediction model (diagnostic index) for colorectal cancer.

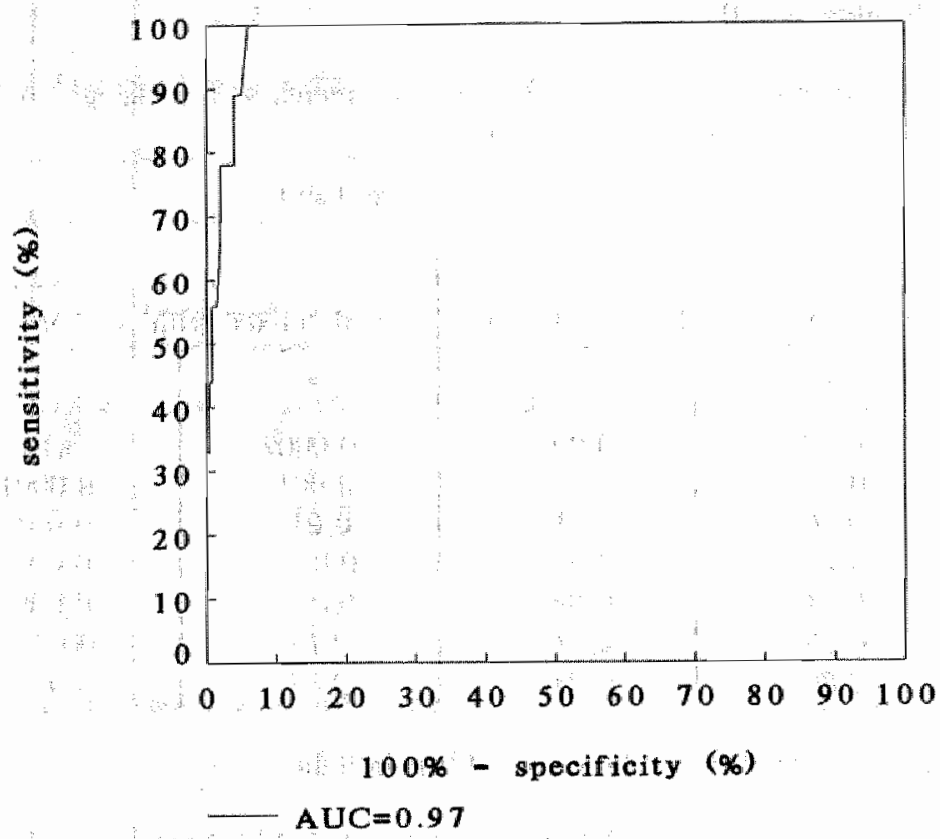

The maximum sum of sensitivity and specificity is achieved with a cut-off point of 0.042 , corresponding to a sensitivity of $100 \%$ and a specificity of $90 \%$. As stated before, we are particularly interested in accurately predicting the absence of malignancy.

Applying a posterior probability of 0.042 as the cut-off point, above which the test result is considered positive for cancer, results in $13 \%$ of patients $(n=35)$ classified as positive. This cut-off point corresponds to a $\mathrm{PV}^{+}$of $26 \%$. Below the cut-off point there were $87 \%$ of patients $(n=234)$. Those were 'truly' classified negative (no 'false negatives') with a $100 \%-\mathrm{PV}-$ being $0 \%$. 


\section{Polyps}

In 6 patients in our population polyps were detected and related to rectal bleeding: none of these was younger than 40 , but polyps occurred at somewhat younger age than cancer (Table 1). If polyps were added to cancer as the outcome parameter, the bivariate analysis showed fewer significant variables compared to cancer as the outcome (not significant: pain at night, decreased appetite, previous history of bleeding and Haemoccult) and did not show new significant variables. The logistic regression analysis resulted in a similar model, which can be described as follows: diagnostic index $=-4.8+1.4$ ((age-50)/10) +1.9 if change in bowel habit +2.1 if blood mixed with or on stool. (Hosmer Lemeshow $p=0.49$, log likelihood= -32.4 ). The AUC was 0.92 (Figure 2).

Figure 2

ROC curve illustrating the relation between sensitivity and specificity of the prediction model (diagnostic index) for cancer and polyps.

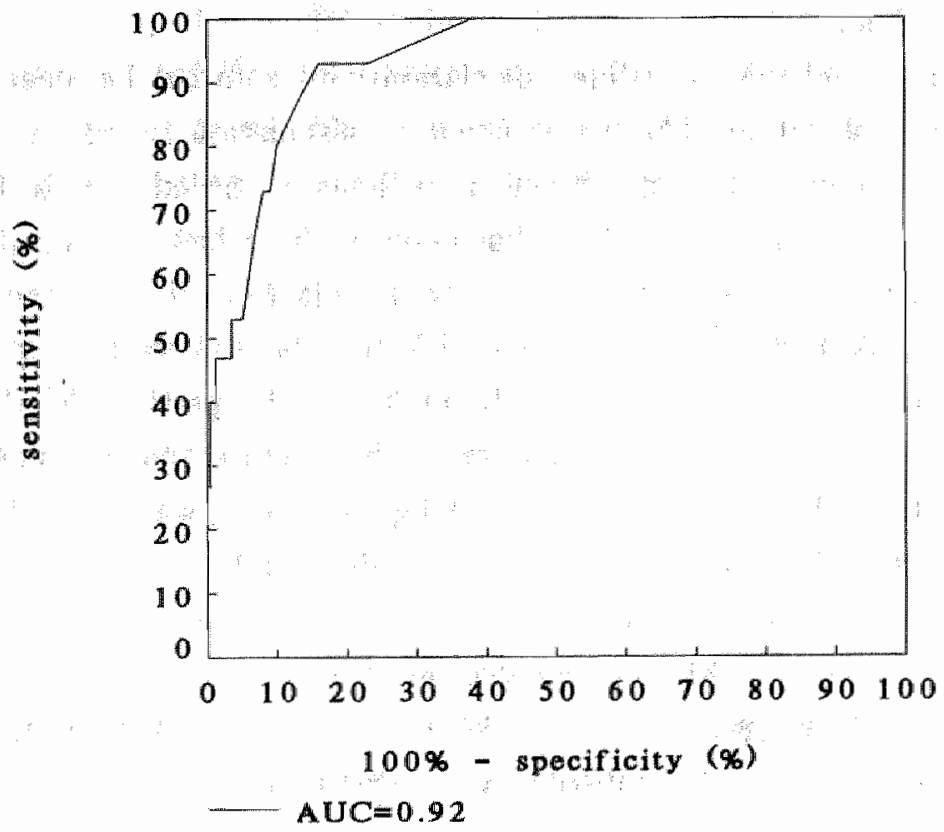


At a posterior probability of 0.058 the maximum sum of sensitivity (93\%) and specificity $(84 \%$ ) was $177 \%$. Applying this cut-off point $21 \%$ of patients were predicted positive for colorectal cancer or polyps with $\mathrm{PV}^{+}=25 \%$ and $79 \%$ predicted negative with $100 \%-\mathrm{PV}=0.5 \%$.

\section{Discussion}

This study showed a prior probability of rectal bleeding for colorectal cancer of $3.3 \%$ in general practice. For an effective selection of patients, resulting in either a very low probability or a reasonably high probability of cancer, knowledge of predictive values of other signs and symptoms in combination with rectal bleeding is desired.

Many single signs and symptoms did not show any discriminatory power. Some signs were statistically significantly associated with cancer but the discriminatory power was not strong, except for age and a palpable tumour. Patients above 60 years had a higher probability of cancer than younger patients. When a tumour is palpable, a very rare finding, there will not be a decision problem.

Some variables and their possible association with colorectal cancer need some comment or explanation. There was negative association found between family history of abdominal disease. Nineteen patients recorded that a first degree relative has an abdominal neoplasm but none of these had colorectal cancer (or polyps). This is remarkable since colorectal neoplasm in first degree relatives is known as a risk factor. ${ }^{25}$ The relative risk (of about 2 to 3 ) is probably too small to be found in our population. It might also be partly related to the fact that this question, both in questionnaires of the doctors and patients, was open (unstructured) and not specifically asking for the presence of colorectal neoplasm (rather than abdominal disease) in the family. The inclusion of FOB testing in the study may raise questions whether this is useful in cases with overt rectal bleeding. FOB was included since it may additionally contribute to the diagnosis of neoplasm as was shown in a screening study, where the probability of neoplasm for patients with overt rectal bleeding increased from 
$5.6 \%$ to $36.3 \%$ when $\mathrm{FOB}$ was positive ${ }^{26}$ Furthermore, FOB could be useful for patients who had seen blood loss only once. Laboratory tests were not entered into logistic regression because of the missing data. These missing data may be due to the resistance of the doctor to confront the patient with "unnecessary" investigations for a research protocol, when the patient is either highly suspected of having serious disease or when there is obviously a harmless cause.

Forward stepwise logistic regression analysis resulted in three variables significantly contributing to the prediction of presence or absence of cancer. With an optimal cut-off point for exclusion of cancer (maximum of negatives but no false negatives) $87 \%$ of all patients with rectal bleeding were correctly predicted as being negative for cancer and $90 \%$ of patients without cancer were predicted as being negative (a specificity of $90 \%$ ). Compared to recommendations for further assessment of all patients with rectal bleeding in order not miss cancer ${ }^{27}$, application of the regression model in the study population reduced the number of indications for further assessment by $87 \%$. Compared to a policy of further assessment of all patients aged older than 40 years (138 patients), the model reduced the number of eases of suspected cancer in all patients by $75 \%$ (for those without cancer by $80 \%$ ).

It would be interesting to see what symptoms and signs are associated with the presence of polyps, since polyps are considered to be precursors of cancer. Our study, however, was not designed to find definitive answers in this respect, since we did not ask for full colonic examination in all patients presenting with rectal bleeding. Therefore, even with a follow-up time of at least 1 year it remains possible that some polyps have been missed. The discussion about the relevance of early detection (before symptoms occur) of polyps is beyond the purpose of the present study. Non-bleeding polyps or self-limiting bleeding polyps were not detected but the prediction model can be applied for overtly bleeding polyps.

There were fewer patients included in the study than expected on the basis of the incidence rate of rectal bleeding in general practice of 7 per 1000 people per year. ${ }^{\prime}$ 
According to this rate we could have expected in a period of 11 months about 1200 patients with rectal bleeding by 83 GPs (about 2350 people per full-time GP; 6 partime GPs; population of 188,000 ). In the same period about 60 patients in the ages 18-75 should suffer from colorectal cancer. ${ }^{28}$ Of these patients probably between $10 \%$ and $50 \%$ should present with rectal bleeding. ${ }^{29,30}$ Taken into account that some of these would be urgently admitted to hospital (e.g. symptoms of bowel obstruction or perforation) and therefore not included in the study, our 9 patients with colorectal cancer are within the expected range. Information from the participating GPs confirmed our impression that patients with rectal bleeding who were not detected were especially those with minor ailments. ${ }^{1}$ Although special efforts had been taken to reduce the numbers of non-detected rectall bleeding patients and missing data through regular practice visits and via a newsletter, it was not feasible to gather all the data requested. Reasons mentioned for not including a patient were: "it is too much fuss for a simple and harmless complaint", or "lack of time" and sometimes the study was considered harmful for the patient because the possibility of inducing fear. We consider this data collection the maximum of what is possible in general practice research. Furthermore, the possible missing cases on both extremes of the spectrum, from obviously not serious to obviously serious (acute admission to hospital), suggest that the findings are based on and applicable to patients in whom rectal bleeding is likely to be a decision problem for GPs. The prior probability of colorectal cancer in the total group of patients with rectal bleeding (covering the whole spectrum) is probably less than $3 \%$. The 21 dropouts (lost to follow-up) were due to moving to an unknown destination without any reason to suspect selective dropout.

The small number of patients with cancer in the study may be a problem for statistical purposes, but in practice it means that the incidence and prevalence of some signs and symptoms in correlation with cancer is too low to be observed or to be shown statistically significant in about 83 'GP-years'. Although the number of colorectal cancer patients is small in our study, it must be recognized that this number will need three professional lifetimes of a GP to be diagnosed. Therefore, the clinical characteristics in our model deal with a large general practice population experience. 
For the following reasons the results cannot be considered as definitive evidence of diagnostic value: 1) the statistical test (likelihood ratio test) is less valid in samples with few cancer cases, 2 ) in view of the total number of variables, a type I error (falsely significant) may have occurred. Therefore, it is useful to test our model in a different but comparable population. It is worthwhile doing so since such a simple model would aid in effective and efficient diagnostic strategies.

In a previous study Mant et $\mathrm{al}^{31}$ concluded that signs and symptoms did not satisfactorily aid in deciding whether to proceed with full colonic investigation on the basis of a bivariate analysis. In their population, which was aged older than 40 years and derived from general practice but referred for diagnosis (according to study protocol), the only variables significantly associated with colorectal cancer and polyps were: blood mixed with faeces, anal protrusion noticed by the patient and the presence of haemorrhoids. The prior probability in their study was higher (11\% for malignancy and $8 \%$ for adenomas) than in our study ( $3 \%$ and $2 \%$ respectively). For patients older than 40 years in our study the prior probability of together cancer and polyps was $11 \%$, which is still somewhat less than the $19 \%$ in their study. The finding by Mant et al that the likelihood of colorectal cancer or polyps is higher among women contrasts with our findings. Logistic regression showed no significant additional contribution of gender to our model.

We did not find studies which present predictive values of combinations of signs and symptoms.

We conclude that in patients with rectal bleeding the predictive power of many signs and symptoms for colorectal cancer in general practice is low. The combination of age, change in bowel habit and blood seen mixed with or on stool can serve as a useful diagnostic tool for the prediction of colorectal carcinoma (or overtly bleeding polyps). This is the first reported model developed to discriminate between such patients with a very low (close to 0 ) probability of colorectal cancer (and overtly bleeding polyps) and those with a high probability. Although our model appears to do this quite successfully, testing its performance in other general practice populations is recommended. 


\section{References}

1. Fijten GH, Muris JWM, Starmans R, Knottnerus JA, Blijham GH, Krebber TFWA. The incidence and outcome of rectal bleeding in general practice. Fam Pract 1993 accepted for publication in September.

2. Chapuis PH, Dent OF, Fisher $R$, et al, A multivariare analysis of clinical and pathological variables in prognosis after resection of large bowel cancer, $B r J$ Surg 1985; 72: 698-702.

3. Kyle SM, Isbister WH, Ling Yeong $M$. Presentation, duration of symptoms and staging of colorectal carcinoma. Austr N Z J Surg 1991; 61: 137-40.

4. Goulston KJ, Cook I, Dent OF. How important is rectal bleeding in the diagnosis of bowel cancer and polyps? Lancet 1986; ii: 261-5.

5. Cheung PSY, Wong SKC, Boey J, Lai CK. Frank rectal bleeding: a prospective study of causes in patients over the age of 40. Postgrad Med $J$ 1988; 64: 364-8.

6. Silverman $A L$, Desai TK, Dhar $\mathbb{R}$, et al. Clinical Features, Evaluation, and Detection of Colorectal Cancer. Gastroenterol Clin North Am 1988; 17(4): 713-25.

7. Chapuis $\mathrm{PH}$, Goulston KJ, Dent OF, Tait AD. Predictive value of rectal bleeding in screening for rectal and sigmoid polyps. Br Med $J$ 1985; 290; 1546-8.

8. Knottnerus JA. The effects of disease verification and referral on the relationship between symptoms and diseases. Med Decis Making 1987; 7: 139-48.

9. Knottnerus JA, Leffers $P$. The influence of referral patterns on the characteristics of diagnostic tests. J Clin Epidemiol 1992; 45; 1143-54.

10. Lamberts H, Wood M. ICPC International Classification of Primary Care. Oxford: Oxford University Press, 1987.

11. Jones ISC. An analysis of bowel habit and its significance in the diagnosis of carcinoma of the colon. Am J Proctology 1976: 45-56.

12. Graham J. Rectal bleeding. J Fam Pract 1978; 7: 169-76.

13. Silman AJ, Mitchel. P. Nicholls RJ, et al. Self-reported dark red bleeding as a marker comparable with occult blood testing in screening for large bowel neoplasma. Br J Surg 1983; $70: 721-4$.

15. Isselbacher KJ, Amans RD, Braunwalt E, Petersdorf RG, Wilson JD (eds.). Harrison's Principles of Internal Medicine (9th ed.). Toronto: McGraw-Hill, 1980.

16. Dinant GJ, Knottnerus JA, Wersch JWJ van. Discriminating ability of the erythrocyte sedimentation rate: a prospective study in general practice. Br I Gen Pract 1991; 41: 365-70.

17. Dixon WK, Brown MB, Engelman L, Jennich RI. BMDP statistical software manual, to accompany the 1990 release. Berkeley: University of California Press, 1990. 
18. Dean AG, Dean JA, Burton AH, Dicker RC. Epi Info, version 5.01b, a word processing, database and statistics program for epidemiology on microcomputers. Georgia: Stone Mountain, 1990.

19. Haviland MG. Yates's correction for continuity and the analysis of $2 \times 2$ contingency tables. Statistics in Medicine 1990; 9: 363-83 (with discussion by others).

20. Altman DG. Practical staristics for medical research. London: Chapman and Hall, 1991.

21. Kraemer HC. Evaluating medical tests. Objective and quantitative guidelines. Sage Publications: London, 1992.

22. Van der Schouw YT, Verbeek ALM, Ruijs JHJ. ROC curves for the initial assessment of new diagnostic tests. Fam Pract 1992; 9: 506-11.

23. Weinstein MC, Fineberg HV. Clinical decision analysis. Philadelphia: WB Saunders Company, 1980.

24. Connell FA, Koepsell TD. Measures of gain in certainty from a diagnostic test. $A m J$ Epidemiol 1985; 121: 744-53.

25. Bonelli L, Martines H, Conio M, Bruzzi P, Aste H. Family history of colorectal cancer as a risk factor for benign and malignant tumours of the large bowel. A case-control study. Int $J$ Cancer 1988: 41: 513-7.

26. Kewenter J, Haglind E, Smith L. Value of a risk questionnaire in screening for colorectal neoplasm. Br J Surg 1989; 76: 280-3.

27. Guillem GJ, Forde KA, Treat MR, Neugut AI, Bodian CA. The impact of colonoscopy on the early detection of colonic neoplasms in patients with rectal bleeding. Ann Surg 1987; 206: 606-11.

28. Bakker D, Coebergh JWW, et al. (eds.) Cancer Incidence in The Netherlands: the southeastern part, 1978-1982. Eindhoven: Eindhoven Cancer Registry/IKZ, 1985.

29. Månsson J. The diagnosis of colorectal cancer-Experiences from the community of Kungsbacka, Sweden. Scand J Prim Health Care 1990; 8:31-5.

30. Fujita M, Sugiyama MD, Kumanishi $Y$, et al. Evaluation of effectiveness of mass screening for colorectall cancer. World J Surg 1990; 14: 648-52.

31. Mant A, Bokey EL, Chapuis PH, et al. Rectal bleeding. Do other symptoms aid in diagnosis? Dis Colon Rectum 1989; 32: 191-6. 
7. Predictive value of signs, symptoms and laboratory tests in patients with rectal bleeding in an outpatient clinic

Gerda H Fijten, Richard Starmans, "Jean WM Muris, " Peter Pop, Hubert JA Schouten, ${ }^{* * *}$ J André Knottnerus, ${ }^{* *}$ Geert H Blijham ${ }^{* * *}$

* Diagnostic Coordinating Centre Maastricht

* Department of General Practice, University of Limburg, Maastricht

*** Department of Methodology and Statistics, University of Limburg, Maastricht

${ }^{* * * *}$ Department of Internal Medicine, University Hospital, Utrecht

Submitted for publication 


\section{ABSTRACT}

Background : Diagnostic value of (combinations of) signs, symptoms and simple laboratory test results for Inflammatory. Bowel Disease (IBD) and colorectal neoplasm in patients with rectal bleeding was determined through predictive values, regression coefficients and probabilities.

Methods : : Pseudo follow-up study; initial complaints and findings were compared with the final diagnoses based on clinical follow-up, established after at least 1 year. Consecutive patients presenting overt rectal bleeding in General Internists' outpatient clinics were included in the study.

Results : In the study population with a prevalence of IBD of $26 \%$ and of neoplasm of $6 \%, 18$ variables have a statistically significant predictive value. Stepwise multiple logistic regression analysis showed 4 to 6 variables with an independent contribution to the discrimination between the presence and absence of IBD or neoplasm. The Receiver Operating Characteristic (ROC) of the regression model had an Area Under the Curve (AUC) of 0.92 . A model based on variables derived from history taking was able to predict IBD or neoplasm with a sensitivity of $100 \%$ and a specificity of $64 \%$.

Conclusions: Application of the model might prevent $43 \%$ of further invasive investigations in patients with rectal bleeding. Testing of the performance of the model in other outpatient clinic populations is recommended. 


\section{Introduction}

Overt rectal bleeding is a well-known alarming signal, with colorectal cancer and inflammatory bowel disease (IBD) being potential sources. However, little is known about the predictive value of the combination of this symptom with other signs, symptoms and simple laboratory tests for the presence or absence of these conditions. Several clinical features have been reported to be of some predictive value enabling discrimination between patients with a self-limiting or harmless (anal) source of bleeding and those with serious colorectal disease..$^{1-4}$ Most reports do not give quantitative information regarding the predictive values, except the study published by Mant et $\mathrm{al}^{4}$. These investigators concluded, on the basis of bivariate analyses, that in patients with rectal bleeding who consulted a general practitioner, most bowel symptoms and clinical features are not helpful in deciding whether to proceed to full colorectal assessment. The question arises whether the combination of several clinical features, in a prediction model determined by multiple logistic regression analysis, could be more helpful.

We are interested in the predictive values in patients presenting with rectal bleeding to a general internists' outpatient clinic, as part of a larger study about the incidence and medical management of patients with rectal bleeding.

In this paper we focus on (1) the determination of the predictive value of the patients' history, some psychological phenomena, results from physical examination and some simple laboratory test results for colorectal IBD or neoplasm and (2) the determination of the predictive value of a combination of these signs and symptoms. The aim is to find a prediction model which discriminates sufficiently to withhold patients without these lesions from invasive investigations. 


\section{Methods}

\section{Patients}

From September 1988 to April 1990105 consecutive patients having overt rectal bleeding and referred to the Departments of Internal Medicine at four hospitals in Limburg, in the South of the Netherlands, were recruited for the study. Patients were included in case overt rectal bleeding was the reason for consultation or when there was a history of recent (within the last three months) rectal blood loss visible for the patient while the patient was not already known to have IBD or neoplasm. Patients were excluded if their age was less than 18 years or more than 75 years or if there was an urgent admission to hospital (e.g, massive bleeding, acute intestinal obstruction or perforation).

\section{Data}

All patients entered into the study were asked to fill in a standard questionnaire with items reported in literature as being relevant for the discrimination between several anal and colorectal diagnoses. ${ }^{5-8}$ Patient's fear of cancer was reported to be an important predictor of a malignancy and psycho-social factors may have impact on the consulting behaviour of patients. Therefore, questions regarding anxiety and three psychological scales were included: the VOEG, the Dutch version of the "Inventory for Subjective Health" (psychobiological stress) ${ }^{10}$, the subscales Self-esteem and Social Inadequacy of the Dutch Personality Inventory ${ }^{11}$ and the Zung questionnaire for depression. ${ }^{12}$ Results of history taking and physical examination were registered by the internists. Basic laboratory tests were included: Haemoglobin (HB), White blood cell count (WBC), Erythrocyte Sedimentation Rate (ESR) and Haemoccult test for faecal occult blood (FOB) (3 times, with a diet low of peroxidase and free of red meat).

Further diagnostic investigation was done according to the choice of the physician. 
For ESR several cut-off points were evaluated.

In total 60 variables were analysed: age, gender, 4 laboratory tests, 32 variables derived from the doctor's questionnaire and 42 variables derived from the patient's form. Among variables represented both in the patient's and the doctor"s questionnaire $(n=20)$, those derived from the doctor were primarily chosen for further analysis.

\section{Outcome}

After a follow-up period of at least one year the final diagnostic conclusion was determined. Three of the authors (GF, JM, RS), blinded for the initial complaints, abstracted all available diagnostic information from the medical records and established the diagnoses. The final conclusion was presented to the patient's general practitioner (GP) who was asked for additional information or confirmation. The final diagnoses were classified according to the International Classification of Primary Care. ${ }^{13}$ In cases with more than one possible diagnosis the most severe is used in the analysis.

\section{Analysis}

Data were analysed on VAX-VMS mainframe using BMDP. ${ }^{14}$ Clinical data were initially analysed using bivariate techniques. The positive $\left(\mathrm{PV}^{+}\right)$and negative $\left(\mathrm{PV}^{-}\right.$) predictive values were computed, for both IBD (colitis or proctitis) and colorectal neoplasms (adenomatous polyp or carcinoma) versus anal sources (haemorrhoids, fissura ani), infections, diverticulosis or no source found at all.

All variables were dichotomous. For age also an interval scale was used. Variables showing a statistically significant association (Chi-square test for independent proportions $\mathrm{p}<0.1$ ) with a specific diagnosis group were entered into a forward stepwise logistic regression analysis to determine the 'indlependent' predictive value of each variable taking the other variables into account simultaneously. ${ }^{15-17}$ Enter and remove limits were applied for $\mathrm{p}$-values $<0.05$. 
From the regression coefficients odds ratios $(O R)$ can be calculated, $O R=$ $\mathrm{e}^{\text {coffficient }}$. $O R=$ (true positive $\mathrm{x}$ true negative) $:$ (false positive $\mathrm{x}$ false negative) or $\mathrm{OR}=\left(\mathrm{PV}^{+} \times \mathrm{PV}^{-}\right):\left(1-\mathrm{PV}^{+}\right)\left(1-\mathrm{PV}^{-}\right)$. If the coefficient is positive, the odds ratio is greater than 1 , which indicates that the variable is positively associated with IBD or neoplasm. If the coefficient is negative, the odds ratio is less than 1 , which indicates that the variable is negatively associated with IBD or neoplasm. ${ }^{16}$ The fit of resulting logistic models to the derived data set was assessed using the Hosmer Lemeshow test. ${ }^{18}$

The discriminatory power of the regression model (prediction model or diagnostic index) was examined using the Area Under the Receiver Operating Characteristic (ROC) curve (AUC). The AUC measures the discriminating power of a test by simultaneously plotting its sensitivity and specificity at a range of cut-off points (predicted or posterior probabilities). A test that discriminates perfectly between disease and non-disease has an AUC of 1 or 0 ; a test with an AUC of 0.5 does not discriminate at all..$^{19,20}$ In addition, the regression results were evaluated by determining the cut-off points (posterior probabilities) associated with the maximum sum of sensitivity and specificity. ${ }^{21}$

\section{Results}

\section{General}

A total of 104 patients were studied, with a mean age of 41 years (range 1871 , standard deviation 14 years), $52 \%$ were females. One patient was lost to follow-up. The mean of follow-up time was 25 months with a range of 12 to 36 months. Four patients in this population used anticoagulants, of whom one had IBD.

For $64 \%$ of the patients rectal bleeding was the reason for encounter: $36 \%$ had another reason, for example abdominal complaints, but blood loss per rectum was seen and mentioned by the patient.

During the follow-up period all patients were further investigated by endoscopy (84\%; proctoscopy $2 \%$, sigmoidoscopy $69 \%$, colonoscopy $13 \%$ ), or by roentgenography (21\%). 


\section{Diagnostic outcome}

The diagnostic outcome per age category is shown in Table 1.

Table 1. Frequencies of diagnoses related to rectal bleeding per age category, in 104 patients.

\begin{tabular}{|l|cc|cc|cc|cc|cc|}
\hline Age (years) & $\begin{array}{c}\text { no colorectal } \\
\text { source }\end{array}$ & IBD & \multicolumn{1}{c|}{$\begin{array}{c}\text { colorectal } \\
\text { neoplasm }\end{array}$} & \multicolumn{2}{|c|}{$\begin{array}{c}\text { other } \\
\text { colorectal } \\
\text { sources }\end{array}$} & total \\
\hline & $\mathrm{N}$ & $\%$ & $\mathrm{~N}$ & $\%$ & $\mathrm{~N}$ & $\%$ & $\mathrm{~N}$ & $\%$ & $\mathrm{~N}$ & $\%$ \\
\hline $18-29$ & 13 & 21 & 9 & 33 & 1 & 17 & 1 & 10 & 24 & 23 \\
$30-39$ & 20 & 31 & 8 & 30 & 1 & 17 & 1 & 10 & 30 & 30 \\
$40-49$ & 12 & 21 & 6 & 22 & 0 & 0 & 1 & 10 & 19 & 18 \\
$50-59$ & 9 & 14 & 0 & 0 & 2 & 33 & 4 & 40 & 15 & 14 \\
$\geq 60$ & 7 & 13 & 4 & 15 & 2 & 33 & 3 & 30 & 16 & 15 \\
\hline Total & 61 & 100 & 27 & 100 & 6 & 100 & 10 & 100 & 104 & 100 \\
\hline
\end{tabular}

" anal source (19), no source found (42)

*ancer (3) and polyps (3)

* rectum ulcus (1), rectum prolaps (1), infection (4), diverticulosis (4)

Colorectal sources (rectum prolaps, rectum ulcus, infection, diverticulosis, proctitis, colitis, polyp or carcinoma), judged to be related to rectal bleeding, were found in $41 \%$ of patients. In this population IBD (proctitis $(n=8)$ and colitis $(n=19))$ is the most frequent source. Three patients had an adenomatous polyp as the probable source of rectal bleeding. Three cancers were found: two in the rectum and one in the rectum/sigmoid. One patient with cancer was relatively young at 38 years of age. Among younger patients ( $<50$ years) the prevallence of IBD was higher than among older patients, $32 \%$ versus $13 \%$ $(\mathrm{p}=0.05)$. Among older patients neoplasms were more prevalent, $13 \%$ versus $3 \%(\mathrm{p}=0.04)$. There was a slight preponderance of females regarding colorectal sources, $44 \%$ compared to $38 \%$ for males $(p=0.14)$. In $59 \%$ of cases $(\mathrm{n}=61)$ no colorectal source of rectal bleeding was found within the follow-up period. Anal sources were found in $18 \%(\mathrm{n}=19)$ of cases; no source of bleeding was found in $40 \% \quad(n=42)$. In the category "no bleeding source found" $45 \%$ fulfilled the criteria of the Irritable Bowel Syndrome $(n=19)$. 


\section{Diagnostic value}

Signs, symptoms and laboratory test results which did not have a statistically significant $(\mathrm{p} \geq 0.1)$ association with IBD or neoplasm are shown in Table 2 .

Table 2. Variables without a statistically significant association with IBD or neoplasm.

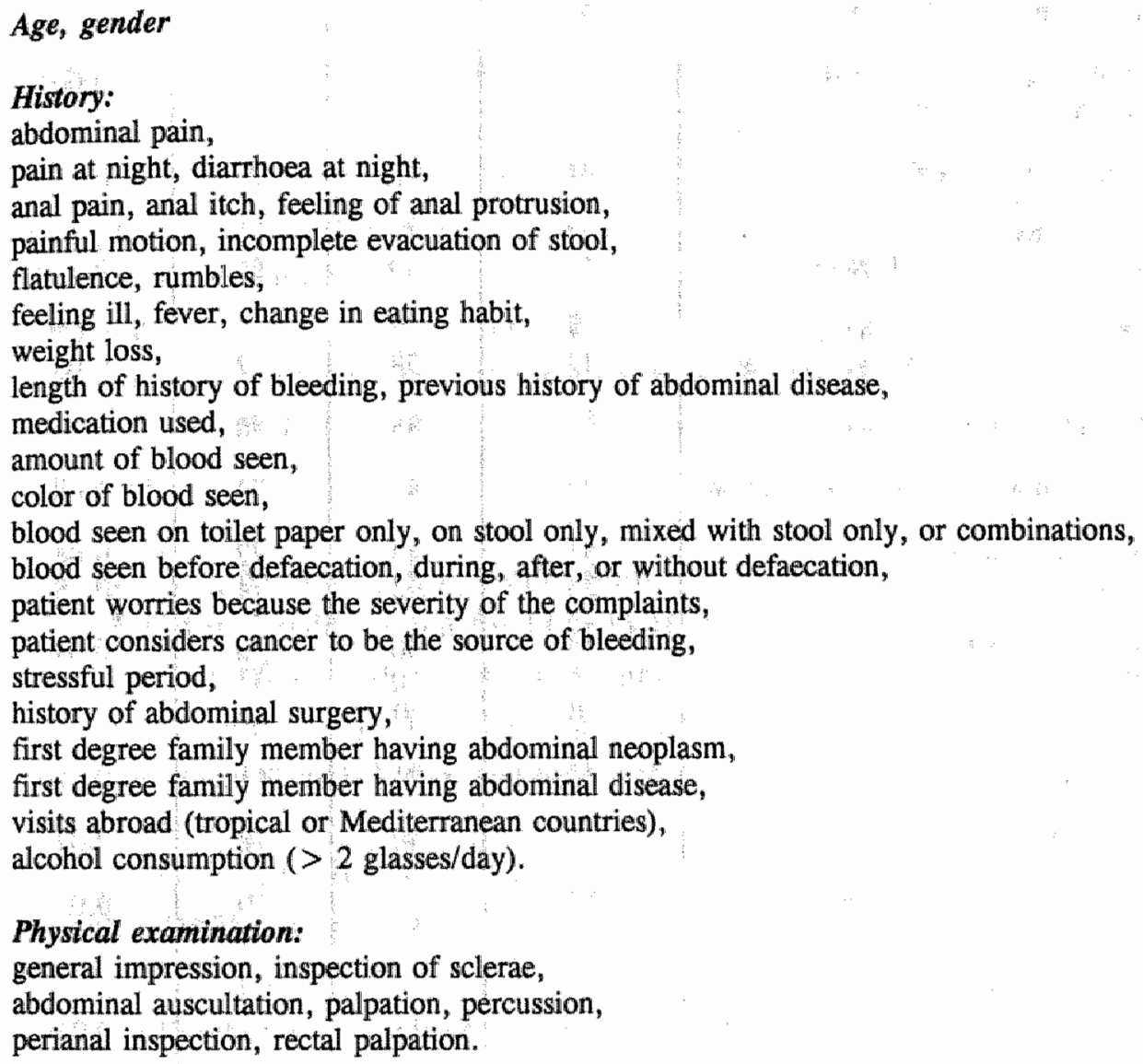

\section{Physical examination:}

general impression, inspection of sclerae, abdominal auscultation, palpation, percussion, perianal inspection, rectal palpation.

\section{Laboratory tests}

haemoglobin $\left(q<7.5 \mathrm{mmol} / \mathrm{l}, \mathrm{o}^{*}<8.5 \mathrm{mmol} / \mathrm{l}\right)$,

WBC $\left(>10^{\%} / 1\right)$.

\section{Psychological tests:}

self-esteem, social inadequacy (Dutch Personality Inventory). 
Significant associations were found for the variables shown in Table 3.

Table 3. Predictive values of signs, symptoms and laboratory test for IBD or neoplasm in 104 patients presenting rectal bleeding, with p-values $<0.1$. Prevalence $=32 \%$.

\begin{tabular}{|c|c|c|c|c|}
\hline+5 & $\begin{array}{c}\text { frequency } \\
(\%)\end{array}$ & $\begin{array}{l}\mathrm{PV}^{+} \\
(\%)\end{array}$ & $\begin{array}{l}\mathrm{PV}^{-} \\
(\%)\end{array}$ & $\mathrm{p}$ \\
\hline $\begin{array}{l}\text { History } \\
\text { Abdominal pain }>2 \text { weeks }\end{array}$ & 70 & 25 & 52 & 0.03 \\
\hline $\begin{array}{l}\text { Previous period with rectal } \\
\text { bleeding }>1 \text { year ago }\end{array}$ & 31 & 55 & 75 & 0.004 \\
\hline $\begin{array}{l}\text { Change in bowel habit } \\
\text { Bowel frequency }\end{array}$ & 41 & 46 & 79 & 0.007 \\
\hline $\begin{array}{l}\text { a) } \geq 22 / \text { week } \\
\text { b) increase in bowel frequency }\end{array}$ & $\begin{array}{l}27 \\
50\end{array}$ & 42 & $\begin{array}{l}67 \\
86\end{array}$ & $\begin{array}{l}0.008 \\
0.0002\end{array}$ \\
\hline $\begin{aligned} \text { Aspect of faeces: very hard } \\
\text { watery, diarrhoea }\end{aligned}$ & $\begin{array}{r}7 \\
12\end{array}$ & $\begin{array}{r}0 \\
58\end{array}$ & $\begin{array}{l}67 \\
72\end{array}$ & $\begin{array}{l}0,07 \\
0.03\end{array}$ \\
\hline Blood seen more than once & 67 & 45 & 90 & 0.007 \\
\hline Blood seen at the end of defaecation & 32 & 47 & 73 & 0.06 \\
\hline $\begin{array}{l}\text { Mucous discharge } \\
\text { Tenesmus }\end{array}$ & $\begin{array}{l}51 \\
34\end{array}$ & $\begin{array}{l}43 \\
43\end{array}$ & 77 & $\begin{array}{l}0.04 \\
0.08\end{array}$ \\
\hline $\begin{array}{l}\text { Decreased appetite } \\
\text { Nausea } \\
\text { Vomiting }\end{array}$ & $\begin{array}{r}14 \\
55 \\
8\end{array}$ & $\begin{array}{r}50 \\
20 \\
0\end{array}$ & $\begin{array}{l}76 \\
53 \\
66\end{array}$ & $\begin{array}{l}0.05 \\
0.004 \\
0.05\end{array}$ \\
\hline Smoking & 42 & 21 & 61 & 0,06 \\
\hline Anxiety because of bleeding & 66 & 40 & 78 & 0.07 \\
\hline $\begin{array}{l}\text { VOEG }>3 \text { (psychobiological stress) } \\
\text { ZUNG }>40 \text { (signs of depression) }\end{array}$ & $\begin{array}{l}80 \\
22\end{array}$ & 27 & $\begin{array}{l}50 \\
64\end{array}$ & $\begin{array}{l}0.05 \\
0.03\end{array}$ \\
\hline $\begin{array}{l}\text { Physical examination } \\
\text { Abdominal inspection abnormalities } \\
\text { (including distension and scars) }\end{array}$ & 25 & 15 & 62 & 0.04 \\
\hline $\begin{array}{l}\text { Laboratory tests } \\
\text { ESR }(9>28, \delta>12 \mathrm{~mm} / \mathrm{hr}) \\
\text { Haemoccult } \geq 1 \text { pos. result(s) out of } 3\end{array}$ & $\begin{array}{l}16 \\
33 \\
\end{array}$ & $\begin{array}{l}56 \\
72 \\
\end{array}$ & $\begin{array}{l}71 \\
88 \\
\end{array}$ & $\begin{array}{l}0.03 \\
0.000 \\
\end{array}$ \\
\hline
\end{tabular}

$\mathrm{PV}^{+}=\%$ pts with the sign, symptom or a positive test result who have IBD or neoplasm
$\mathrm{PV}=\%$ of patients without the sign $\mathrm{PV}^{-}=\%$ of patients without the sign, symptom or positive test result who do not have IBD
or neoplasm 
Regarding the variable change in bowel habit (more frequent defaecation or diarrhoea or variously normal stool and diarrhoea, excluding constipation), the information derived from both the doctors' forms and the patients forms (increased bowel frequency) was analysed. Since there may be a different perception of change in bowel habit between doctors and patients, both items are shown and entered into the multiple logistic regression analysis to find the strongest predictor.

Psychological variables, in particular the presence of psychobiological stress (VOEG) and signs of depression (ZUNG) were significantly related to the absence of neoplasm or $\mathbb{B B D}$. Anxiety because of the bleeding was related to the presence of these diseases.

Except for abdominal inspection, physical examination did not show a significant association with a positive diagnosis. Neither did digital rectal examination, although in one patient a palpable tumour was diagnosed. It must be noted here that there were only 3 rectum/sigmoid tumours in the study population.

Data regarding laboratory test results were missing for $\mathrm{WBC}$ in 7 patients, for ESR and HB in 5 patients and for FOB in 16 patients. ESR with a cut-off point of $30 \mathrm{~mm}$ per hour did not show a significant association with a positive diagnosis, but with a cut-off point, reported to be optimal by Dinant et al ${ }^{22}$, of $28 \mathrm{~mm}$ for females and $12 \mathrm{~mm}$ for males the ESR significantly correllated with serious disease.

For a meaningful clinical application of these variables, their ability to correctly identify patients with a very low probability of colorectal neoplasm or IBD is most important. The use of the variable should lead to the exclusion of patients without these diseases, in other words the $\mathrm{PV}^{+}$should be very low (e.g. $<10 \%$ ) or the $\mathrm{PV}^{-}$should be very high (e.g. $>90 \%$ ). As can be seen in Table 3, very few variables appeared to be useful in this respect; the presence of very hard faeces or vomiting and the fact that blood was seen only once virtually exclude the presence of colorectal neoplasm or IBD. 


\section{Logistic regression}

Results of logistic regression analysis are shown in Table 4.

Table 4. Prediction models, resulting from forward stepwise multiple logistic regression analysis, with IBD and neoplasm as the dependent variable.

Model 1: history taking

Model 2: history taking, physical examination and FOB test

\begin{tabular}{|c|c|c|c|}
\hline 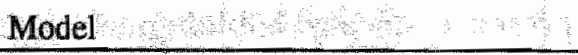 & $\cdots$ & & ses \\
\hline Variables & coefficient & se & coefficient se \\
\hline $\begin{array}{l}\text { Abdominal pain }>2 \text { weeks } \\
\text { Change in bowel habit } \\
\text { Blood seen more than once } \\
\text { Blood seen at the end of defaecation } \\
\text { Tenesmus } \\
\text { Nausea } \\
\text { Signs of depression (ZUNG) } \\
\text { Inspection (distension, scar) } \\
\text { Haemoccult } \geq 1 \text { pos. result(s) out of } 3\end{array}$ & $\begin{array}{r} \\
+2.9 \\
+3.9 \\
+2.5 \\
+2.3 \\
-3.0 \\
-2.7\end{array}$ & $\begin{array}{l}1 \\
0.8 \\
1.0 \\
1.8 \\
0.8 \\
0.8 \\
1.0\end{array}$ & $\begin{array}{cc}-2.9 & 0.9 \\
+2.1 & 0.7 \\
& \\
& \\
-3.3 & \\
+4.8 & 1.1 \\
\end{array}$ \\
\hline Constant & -4.9 & 1.2 & -1.0 \\
\hline $\begin{array}{l}\text { Log likelihood } \\
\text { Hosmer Lemeshow p }\end{array}$ & $\begin{array}{r}-33 \\
0 \\
\end{array}$ & & $\begin{array}{r}-32.2 \\
0.8 \\
\end{array}$ \\
\hline AUC & & & 0.91 \\
\hline
\end{tabular}

se: standard error

Model 1. Diagnostic index, $\operatorname{logit}(p)=-4.9$

-2.7 if signs of depression

+2.5 if blood is seen at the end of defaecation

+3.9 if blood is seen more than once

+2.3 if tenesmus is reported

-3.0 if nausea is reported

Model 2. Diagnostic index, logit $(p)=1.0$

+2.9 if change in bowel habit is reported

+4.8 if haemoccult is positive

- 3.3 if abdominal distension or scars by inspection

-2.9 if abdominal pain of more than 2 weeks duration

+2.1 if change in bowel habit (except obstipation)

In model 1,18 items derived from history taking were entered, Six items appeared to have an independent statistically significant contribution to the prediction of IBD or neoplasm. 
If the patient had a changed bowel habit $(O R=18)$, if blood was seen more than once $(O R=49)$, if blood was seen at the end of defaecation $(O R=12)$ and if tenesmus was present $(O R=10)$, the probability of a positive test result (posterior probability of IBD or neoplasm) was very high. If the patient had signs of depression $(O R=0.07)$ or reported nausea $(O R=0.05)$, the posterior probability was very low. For the several combinations predicted probabilities can be calculated with the formula below Table 5 . In model 2 three variables derived from physical examination and laboratory tests were added to model 1. Inspection $(O R=0.04)$ and $F O B(O R=121)$ were stronger predictors than most items from model 1 . These items, in combination with abdominal pain of more than two weeks of duration $(O R=0.06)$ and change in bowel habit $(\mathrm{OR}=8)$, resulted in a well-fitting prediction model.

Both models 1 and 2 scored satisfactorily for the goodness-of-fit test, the Hosmer Lemeshow test, as well as for the AUC. The diagnostic values of the models are shown in Table 5 and the ROC curves in Figures 1 and 2. The maximum sum of sensitivity and specificity is equal, $168 \%$, for both models.

Figure 1

ROC curve of prediction model 1 : history variables

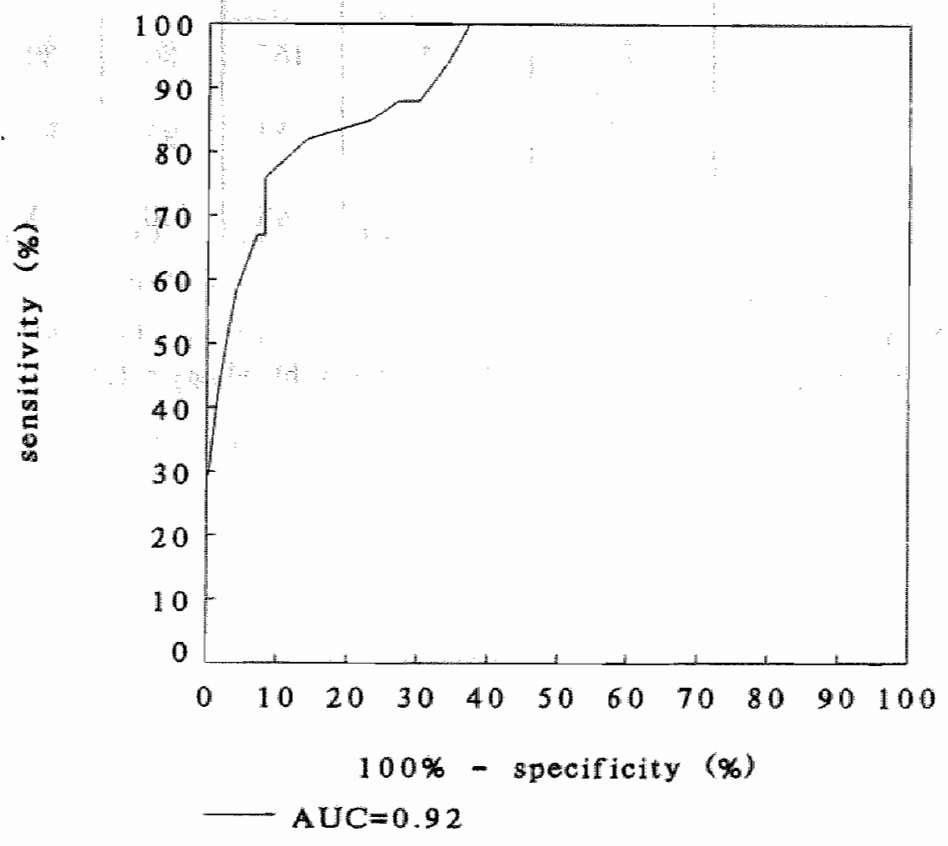


Table 5. Diagnostic value of the logistic regression model for IBD or neoplasm at different cut-off points (predicted probabilities).

\begin{tabular}{|l|c|c|c|c|c|c|}
\hline $\begin{array}{l}\text { Cut-off point for predicted } \\
\text { probability }\end{array}$ & sensitivity & $\begin{array}{c}\text { Mpecificity } \\
\%\end{array}$ & $\begin{array}{c}\Sigma \\
\%\end{array}$ & $\begin{array}{c}\mathrm{PV}^{+} \\
\%\end{array}$ & $\begin{array}{c}\text { PV- } \\
\%\end{array}$ & $\begin{array}{c}\text { TN } \\
\%\end{array}$ \\
\hline 0.10 & 100 & 60 & 160 & 54 & 100 & 42 \\
0.14 & 100 & 64 & 164 & 56 & 100 & 43 \\
0.30 & 82 & 86 & $168^{*}$ & 73 & 91 & 59 \\
0.50 & 76 & 92 & $168^{*}$ & 81 & 89 & 63 \\
0.70 & 67 & 93 & 160 & 81 & 86 & 64 \\
0.90 & 27 & 100 & 127 & 100 & 75 & 68 \\
\hline 0.08 & & Model 2 & & & \\
\hline 0.10 & 100 & 17 & 117 & 34 & 100 & 10 \\
0.30 & 94 & 55 & 149 & 49 & 95 & 38 \\
0.50 & 76 & 92 & $168^{*}$ & 81 & 89 & 63 \\
0.70 & 73 & 94 & 167 & 86 & 88 & 64 \\
0.90 & 64 & 99 & 163 & 95 & 85 & 67 \\
\hline
\end{tabular}

$\Sigma \quad=$ sum of sensitivity + specificity

* maximal $\Sigma$

TN $\%=$ (number of true negative/104 patients with rectal bleeding) $\times 100$

Predicted probability $=\frac{1}{1+e^{-\log i(t)}}$ 
Figure 2

ROC curve of prediction model 2: history variables, abdominal inspection and FOB

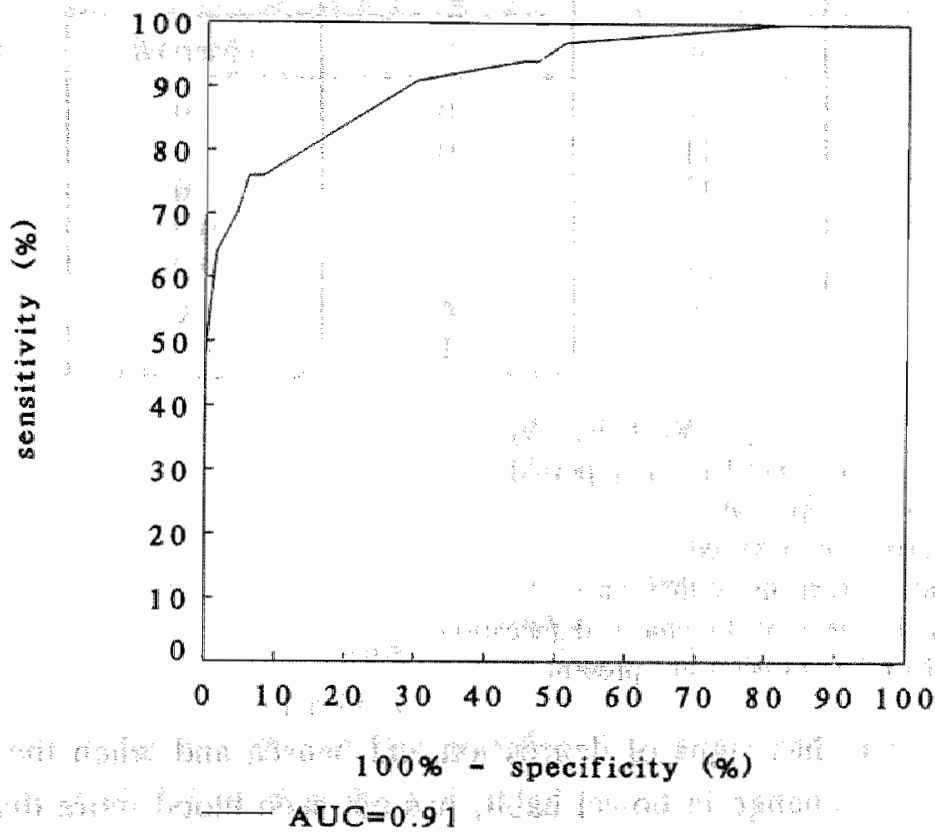

Let us illustrate how such a model can be used in clinical practice with an example of a simplified sumscore. Regression model 1 is simplified to an additive score where the six characteristics, with comparable regression coefficients, are weighted as one point. The sumscore is the sum of the points for each patient. This sumscore (considered as an interval variable) is entered into logistic regression analysis to find the predicted probabilities at the several scores. The results are shown in Table 6 . 
Table 6. Observed and predicted probability of IBD or neoplasm for sumscores.

\begin{tabular}{|l|c|c|c|c|}
\hline & $\begin{array}{c}\text { Model 1 } \\
\text { with score }\end{array}$ & $\begin{array}{c}\text { LBD or } \\
\text { neoplasm }\end{array}$ & \multicolumn{2}{|c|}{ proportion of IBD or neoplasm } \\
\hline Sumscore & $\mathrm{n}$ & $\mathrm{n}$ & observed & predicted \\
\hline-2 & 2 & 0 & 0 & 0.0001 \\
-1 & 11 & 0 & 0 & 0.001 \\
0 & 19 & 0 & 0 & 0.014 \\
1 & 38 & 7 & 0.2 & 0.167 \\
2 & 29 & 21 & 0.7 & 0.741 \\
3 & 4 & 4 & 1.0 & 0.976 \\
4 & 1 & 1 & 1.0 & 0.998 \\
\hline
\end{tabular}

sumscore $=V_{1}-V_{2}+V_{3}+V_{4}+V_{5}-V_{6}$

$V_{1}=1$ if change in bowel habit is reported

$V_{2}=1$ if nausea is reported

$V_{3}=1$ if tenesmus is reported

$V_{4}=1$ if blood is seen more than once

$V_{5}=1$ if blood is seen at the end of defaecation

$V_{6}=1$ if signs of depression are present

When the patient has signs of depression and nausea and when the patient has no tenesmus, no change in bowel habit, has not seen blood more than once and has not seen it at the end of defaecation the sumscore is minus 2 . In the study population none of these patients had IBD or a neoplasm. Applying a cut-off point of $\leq 0$, for example, a patient with 2 symptoms scoring negative and with 2 or less than 2 other 'positive' items is considered as having a very low probability of IBD or neoplasm.

The predicted probabilities according to the sumscore are very close to the observed probabilities in the study population. The correlation between the predicted probability by the regression model and the sumscore was high, $\mathrm{R}=$ 0.97. The sumscore is a simplification of the model and is somewhat less accurate. The AUC is 0.89 (Figure 3) and the Hosmer Lemeshow $p=0.49$. With a similar optimal cut-off point, $\leq 0$ (100\% sensitivity), the sumscore results in $31 \%(n=32)$ true negatives, whereas model 1 results in $43 \%(n=45)$ true negatives. 
Figure 3

ROC curve of sumscore: history variables

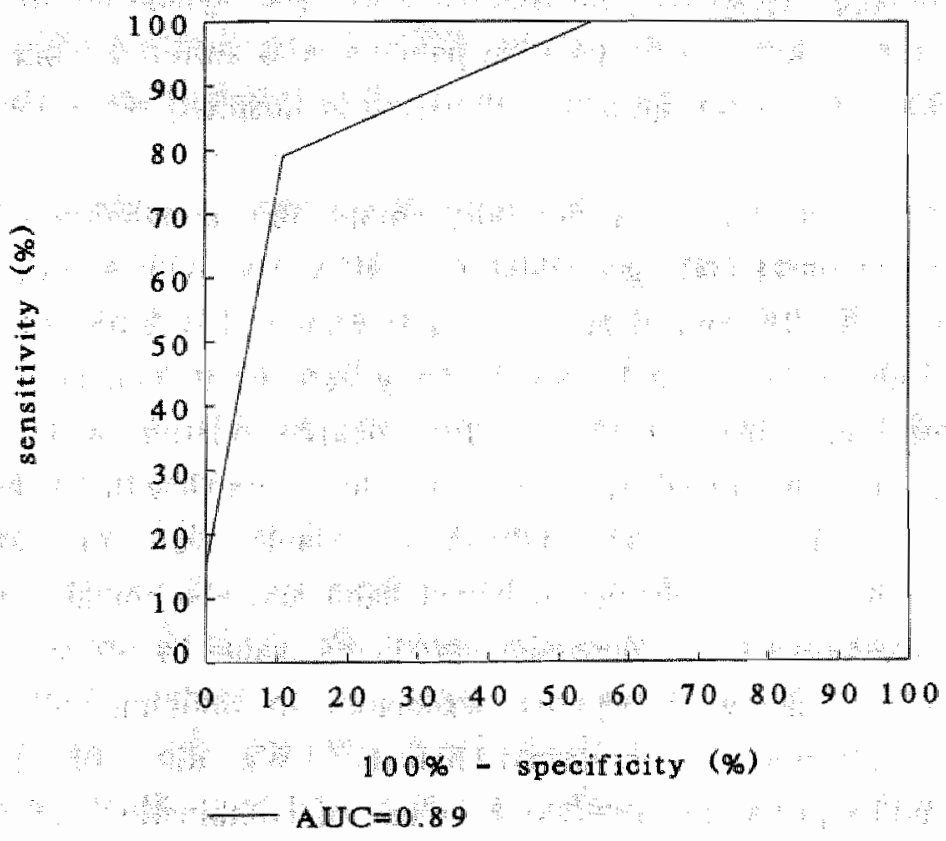

\section{Discussion}

A patient with rectal bleeding may confront physicians with a decision problem: invasive investigation (endoscopy or roentgenography) for further assessment or not. For this clinical reason IBD and neoplasm together were chosen as the dependent variable.

In decision analytic terms, the clinical problem in this patient population can be defined as 'exclusion diagnosis'; to find a subpopulation that almost certainly does not have IBD or cancer and can be spared from further more invasive tests. This means that only variables with a $\mathrm{PV}^{+}$of close to zero or a $\mathrm{PV}^{-}$of close to $100 \%$ are clinicaliy relevant. One of the main findings of our analysis is that many of the numerous items regularly used in clinical practice for their presumed importance in predicting the presence or absence of colorectal disease did not have statistically significant predictive values in our bivariate analysis. For those which showed a predictive vallue this was almost never 
sufficient to exclude the probability of IBD or neoplasm; only the presence of hard faeces, womiting and having seen blood loss only once allowed exclusion of IBD or neoplasm. However, the frequency of these symptoms in the study population was very low, partly because patients who suffered from vomiting caused by bowel obstruction (an acute admission to hospital) were not included in this study.

In the study by Mant et al, in a not fully comparable population with rectal bleeding of recent onset and aged older than 40 years, with a probability of colorectal cancer of $19 \%$ and of any colorectal source of bleeding of $29 \%$, the investigators found some variables significantly associated with any colorectal source of bleeding: female gender, a first degree relative with colorectal cancer, anal protrusion noticed by the patient, blood mixed with faeces and the presence of haemorrhoids: ${ }^{4}$ In our study these variables were not significantly discriminatory. In contrast, change in bowel habit and abdominal pain lasting longer than 2 weeks were of independent predictive value in our study but not predictive in Mant's study. A negative association of smoking with IBD is a widely known phenomenon reviewed before. ${ }^{23}$ We did not find other comparable studies presenting predictive values of combinations of signs and symptoms in patients with rectal bleeding.

Studying the influence of the diagnostic variables simultaneously in a stepwise multiple logistic regression analysis, only 6 of the 16 variables entered in model 1 (history variables) were found to contribute independently to the prediction of IBD or neoplasm. Nausea and signs of depression were independent predictors for the absence of IBD or neoplasm. It is important to make a critical decision regarding invasive diagnostic investigations, especially for patients without serious disease but with psychosomatic complaints or psychological problems, in order to prevent somatic fixation.

Of the 19 variables entered into model 2 (including history, abdominal inspection and FOB) only 4 were found to contribute independently to the prediction of IBD or neoplasm. Model 1 and model 2 are equally good regarding the measured discriminatory power (AUC), the goodness of fit and the maximum sensitivity and specificity. 
However, regarding clinically important parameters model 1 is better. Applying the model with an optimal cut-off point for exclusion of serious disease (maximum negative rate but without false negatives, i.e. an optimal specificity and a sensitivity of $100 \%$ ), model 1 leads to a negative rate of $43 \%$ $(n=45)$ and consequently $43 \%$ of invasive investigations could be avoided, while all IBD and neoplasm were identified. Sixty-four percent of patients without these diseases were predicted negative (specificity). With model 2 , for the same purpose (exclusion of true negatives), the specificity was $17 \%$, and only $10 \%(n=12)$ patients could possibly profit from applying the model. It can therefore be accepted, with some reserve, because of the missing data, that the laboratory tests did not provide additional contribution to the diagnosis of absence of IBD or neoplasm.

The inclusion of FOB testing in the study may raise questions whether this is useful in cases with overt rectal bleeding. FOB was included since it may additionally contribute to the diagnosis of neoplasm as was shown in a screening study, where the probability of neoplasm for patients with overt rectal bleeding increased from $5.6 \%$ to $36.3 \%$ when FOB was positive. ${ }^{24}$ Furthermore, FOB could be useful for patients who had seen blood loss only once.

Interpretation of the results is not possible without consideration of the study population. The incidence rates of colorectal diseases may be different in other clinical situations.

Furthermore selection before referral can influence the diagnostic values. ${ }^{25-27}$ In the Netherlands before consulting a specialist patients have to be seen by the GP. Many GPs have a service for proctosigmoidoscopy and roentgenography at their disposal without referring the patient to an outpatient clinic. For colonoscopy patients usually are referred either to a Surgery Department or to an Internal Medicine Department. Patients obviously having, or very likely to have, haemorrhoids or colorectal cancer are more often referred to surgeons. Patients with rectal bleeding of unknown origin are more often referred to internists.

The model here presented indicates that some variables are important and others unimportant predictors in the study population. It was not considered 
useful to split our study population at random, into a 'study population' and a 'test population'. This would not provide information about the external clinical validity, but only about the random sample variability. ${ }^{27}$ Moreover, splitting the limited study population would decrease the statistical precision considerably. Replication of our study and testing the performance of the model independently in another, comparable, population seems useful. Preferably the study size should be large in order to decrease the standard errors and, consequently, to find more precise estimations.

We conclude that a prediction model based on variables resulting from history taking can be useful in selecting patients who really do not need sigmoidoscopy or colonoscopy and to prevent 'unnecessary' investigations and alarm. It is recommended to test the performance of the model based on history taking in other populations.

\section{References}

1. Cheung PSY, Wong SKC, Boey J, Lai CK. Frank rectal bleeding: a prospective study of causes in patients over the age of 40. Postgrad Med J 1988; 64: 364-8.

2. Church JM. Analysis of the colonoscopic findings in patients with rectal bleeding according to the pattern of their presenting symptoms. Dis Colon Rectum 1991; 34: 391-5.

3. Newstead GL. Logical clinical decisions in the investigation and management of non urgent rectal bleeding. Gastroenterol Jpn 1991; 26(3): 107-10.

4. Mant A, Bokey EL, Chapuis PH, et al. Rectal bleeding. Do other symptoms aid in diagnosis? Dis Colon Recum 1989; 32: 191-6.

5. Jones ISC. An analysis of bowel habit and its significance in the diagnosis of carcinoma of the colon. Am J Proctology 1976: 45-56.

6. Graham J. Rectal bleeding. I Fam Pract 1978; 7: 169-76.

7. Silman AJ, Mitchell P, Nicholls RJ, et al. Self-reported dark red bleeding as a marker comparable with occult blood testing in screening for large bowel neoplasma. Br J Surg 1983; 70: 721-4.

8. Isselbacher KJ, Amans RD, Braunwalt E, Petersdorf RG, Wilson JD (eds.). Harrison's Principles of Internal Medicine $\left(9^{4}\right.$ ed.). Toronto: McGraw-Hill, 1980.

9. Nylenna $\mathrm{M}$. Diagnosing cancer in general practice: from suspicion to certainty. $\mathrm{Br} \mathrm{Med}$ $J$ 1986; 293: 314-7. 
10. Dirken JM. Arbeid en stress [Work and stress]. Wolters: Groningen, The Netherlands, 1969.

11. Luteijn F, Starren J, Dijk H van. Nederlandse Persoonlijkheiddsvragenlijst (NPV). [Dutch Personality Inventory] handleiding. Zwets \& Zeilinger: Lisse, The Netherlands, 1980.

12. Zung WK. A self-rating depression scale. Arch Gen Psychiatry 1965; 12: 63-70.

13. Lamberts $\mathrm{H}$, Wood $\mathrm{M}$ (eds). ICPC International Classification of Primary Care. Oxford: Oxford University Press, 1987.

14. Dixon WK, Brown MB, Engelman L, Jennrich RI. BMDP statistical software mantal, to accompany the 1990 release. Berkeley: University of Califomia Press, 1981.

15. Haviland MG. Yates"s correction for continuity and the analysis of $2 \times 2$ contingency tables. Statistics in Medicine 1990; 9: 363-83 (with discussion by others).

16. Kraemer HC. Evaluating medical tests. Objective and quantitative guidelines. London: Sage Publications, 1992.

17. Altman DG. Practical statistics for medical research. London: Chapman and Hall, 1991.

18. Hosmer DW, Lemeshow S. Assessing the fit of the model. In Applied logistic regression. 1st ed. New York; John Wiley and Sons, 1989.

19. Van der Schouw XT, Verbeek ALM, Rujjs JHJ. ROC curves for the initial assessment of new diagnostic tests. Fam Pract 1992; 9: 506-11.

19. Weinstein MC, Fineberg HV. Clinical decision analysis. Philadelphia: WB Saunders Company, 1980.

20. Connell FA, Koepsell TD. Measures of gain in certainty from a diagnostic test. $A m J$ Epidemiol 1985, 121: 744-53.

21. Dinant GJ, Knottnerus JA, Van Wersch JWJ. Discriminating ability of the erythrocyte sedimentation rate: a prospective study in general practice. Br J Gen Pract 1991; 41: 365-70.

23. Calkins BM. A meta-analysis of the role of smoking in inflammatory bowel disease. Dig Dis Sci 1989; 34: 1841-53.

24. Kewenter J, Haglind E, Smith L. Value of a risk questionnaire in screening for colorectal neoplasm. Br J Surg 1989; 76(3): 280-3.

25. Knottnerus JA. The effects of disease verification and referral on the relationship between symptoms and diseases. Med Decis Making 1987; 7: 139-48.

26. Knottnerus JA, Leffers P. The influence of referral patterns on the characteristics of diagnostic tests. J Clin Epidemiol 1992; 45: 1143-54.

27. Knottnerus JA. Prediction rules: statistical reproducibility and clinical similarity. Med Decis Making 1992; 12: 286-7. 


\section{General discussion}

\section{Introduction}

In this chapter, the main findings of the study will be reviewed and some practical aspects, the strengths and limitations of the methodology will be discussed. After a short review of our findings in relation to the literature, practical implications and recommendations with regard to research will be given.

\section{Main findings}

In general practice it appears possible to discriminate effectively between rectal bleeding patients who do not have cancer and those who have a reasonably high probability of colorectal cancer (who need invasive diagnostic investigation). In the study population it is possible to identify $87 \%$ of patients as truly negative for colorectal cancer (those who do not need invasive diagnostic investigation for colorectal cancer).

Also in the internists' outpatient population it appears possible to discriminate effectively between patients who do not have serious bowel disease and those who have a reasonably high probability. In this population $43 \%$ are truly classified negative.

1. The incidence of patients consulting the general practitioner (GP) with overt ano-rectal blood loss (rectal bleeding) in the ages 18-75 years is about 7 per 1000 people per year. The initial study protocol, study A, yielded a lower rate, 2 per 1000 , which is probably an underestimation of the real incidence but may reflect the incidence of rectal bleeding considered to be clinically relevant (likely to be a decision problem) by the GPs.

2. In rectal bleeding patients in the ages 18-75 years presenting in general practice the prior probability of colorectal cancer is $3 \%$ or less. The prior probability increases with age. About $90 \%$ of the sources of bleeding are minor ailments or self-limiting disorders. 
3. In general practice as well as in the internist outpatient clinic, many signs, symptoms, results of physical examination and simple diagnostic tests usually considered to be of diagnostic value (60 variables are analysed), do not contribute significantly in the discrimination between the presence and absence of serious disease (in general practice colorectal cancer (and polyps), in the outpatient clinic colorectal neoplasm and IBD), Variables which have shown to be statistically significant associated with the diagnostic outcome in bivariate analysis, often do not show a statistically significant association in multivariable analysis.

Forward stepwise logistic regression analysis was used to obtain a prediction model with a reduced number of significant variables. The logistic regression coeffient determines the independent predictive value of a variable taking the other variables into account simultaniously. From the regression coefficients odds ratios (OR) can be calculated, $\mathrm{OR}=\mathrm{e}^{\text {coefficient }} . \mathrm{OR}=$ (true positive $\mathrm{x}$ true negative) : (false positive $\mathrm{x}$ false negative) or

$\mathrm{OR}=\left(\mathrm{PV}^{+} \mathrm{X} \mathrm{PV}-\right):\left(1-\mathrm{PV}^{+}\right)\left(1-\mathrm{PV}^{-}\right)$. If the coefficient is positive, the odds ratio is greater than 1 , which indicates that the variable is positively associated with the diagnostic outcome. If the coefficient is negative, the odds ratio is less than 1 , which indicates that the variable is negatively associated with the diagnostic outcome.

4. For the general practice population, forward stepwise logistic regression analysis resulted in three variables significantly contributing to the prediction of presence or absence of colorectal cancer: age ([age - 50]: 10) $(\mathrm{OR}=8)$, change in bowel habit (more frequent, diarrhoea or variously normal stool and diarrhoea but not obstipation) $(\mathrm{OR}=10)$ and blood seen mixed with or on stool $(O R=8)$. With a cut-off point optimal for exclusion of cancer (with a sensitivity of $100 \%$ no false negatives, so $\mathrm{PV}^{-}=100 \%$ ) a maximum of specificity of $90 \%$ was reached. This means that $87 \%$ of all patients with rectal bleeding were predicted (correctly) negative and $90 \%$ of those without cancer were predicted negative.

According to the presented prediction model (Chapter 6, Table 5) a rectal bleeding patient is suspected for colorectall cancer in the following cases: if 
the patient is older than 70 years; if the patient is older than 60 years and suffers from at least one of the two symptoms: a changed bowel habit (with exclusion of constipation) and blood mixed with or on stool; if the patient is older than 50 years and has both the above mentioned symptoms. Patients younger than 50 years have a very low probability of colorectal cancer (close to $0 \%$ ). This probability decreases in absence of the mentioned symptoms and with younger age. It must be remembered that colorectal cancer although relatively rarely does occur at younger age.

If overtly bleeding polyps were added to cancer as the outcome parameter, the logistic regression analysis resulted in a similar model. However, the maximum sensitivity was not $100 \%$ but $93 \%$ (1 patient had an undetected polyp).

5. In an internists' outpatient clinic population the analysis was done regarding colorectal neoplasm (cancer and polyps) taken together with Inflammatory Bowel Disease (IBD), including proctitis and colitis. The prior probability of these 'serious bowel diseases' is $32 \%$ in the study population.

Forward stepwise logistic regression analysis found a set of six signs and symptoms, derived from history taking, significantly predicting serious disease, namely: change in bowel habit (with exclusion of constipation) (OR $=18)$, blood seen more than once $(O R=49)$, blood seen at the end of defaecation ( $O R=12)$, tenesmus $(O R=10)$, nausea ( $O R=0.05$ ), signs of depression ( $O R=0.07$ ). A set of four variables was found when physical examination and laboratory test results were also taken into account: change in bowel habit $(O R=8)$, abdominal pain less of than 2 weeks of duration $(O R=0.06)$, abnormal findings with abdominal inspection $(O R=0.04)$, and at least one positive Haemoccult test out of three tests $(O R=121)$. The regression model derived from only history findings was more useful for diagnosis by exclusion. Application of this model might spare $43 \%$ of all patients with rectal bleeding and $64 \%$ of those patients without IBD and neoplasm from invasive diagnostic procedures. 


\section{Methodology}

\section{Practical aspects}

\section{Practical problems and the study protocol}

Research in general practice and especially a multipractice study has some pitfalls. ${ }^{1,2}$ "It is always important to be aware that individual GPs differ in the way they interpret the definitions used in a research project and in the way the research record will be completed. Also, in the hurly-burly of general practice it can be very difficult to ensure that all patients available for the study are included. When under pressure, the doctor may wish to excuse himself from undertaking extra work or may simply forget to include the patient in the study. ${ }^{\text {1 }}$ Morrell relates some pitfalls to the fact that few GPs have been taught how to undertake a research project. Other pitfalls are related to the fact that GPs have a very special relationship with their patients, often spanning years of repeated contact which offers unique opportunities but carries with it serious responsibilities. The fact that the average consultation in general practice lasts just a few minutes and collecting complex research data is difficult in this setting is yet another pifall. ${ }^{-1}$ Dambsbo and Olsen concluded that the quality of multipractice studies depends crucially on whether the recording period is not too long, whether the forms to be filled in are as simple as possible, and whether the participating doctors are motivated for the study. ${ }^{2}$ Aware of these practical problems we have tried to optimalize the participation of the doctors. They were informed about the expected practical consequences before they agreed to participate in our study. Those who agreed can be considered as motivated. Action was taken to keep them motivated and involved in the study, for example, through regular personal contacts and via a newsletter. The workload per patient varied between doctors from 10 to 20 minutes and seemed quite acceptable (doctor's questionnaire and laboratory test are enclosed in Appendices I and II). However, one of the problems the participating GPs most frequently mentioned regarding the compliance to the study was lack of time. Other reasons were "too much fuss for a simple and harmless complaint" and "a possibility of inducing fear and harm for the patient". Furthermore, the long 
patient's questionnaires (Appendix III) might have caused some resistance among the GPS to motivate the patients with minor rectal bleeding, although the questionnaires had proved to be acceptable in a pilot study.

Because general practice is an unexplored field regarding our questions it was not possible to design a short and simple form. Because of the very low prior probability of colorectal cancer a quite long recording period was necessary.

In evaluating the experience with studies A (initial protocol) and B (modified protocol) there are advantages and disadvantages in both. Study B with a simplified doctor's questionnaire (Appendix IV) and a short registration period was more reliable regarding the incidence rate of rectal bleeding than study $\mathrm{A}$. But the availability of other data of interest in order to determine predictive values of signs and symptoms, i.e. answers to questions in doctors' forms and answers in patients' forms, is less. The simplified doctor's form was completed less accurately and answers to open questions were sometimes hardly readable or not clearly interpretable. Patients' questionnaires were not obligatory (but desired) and therefore only available for $66 \%$ of the patients with rectal bleeding in study B (in study A for $90 \%$ ). Moreover, the available patient questionnaires in study B were often not completed satisfactorily resulting in much missing data. Patients with minor ailments and complaints of only short duration may have been less motivated to fill in the questionnaire. Laboratory tests were not available (not included in the study protocol).

Because of the small number of patients, the absence of patients with colorectal cancer and the large amount of missing data, we did not analyse the study $B$ data. For GPs in study B the workload per patient was less than in study A, but study B yielded a larger number of patients per unit of time counterbalancing the first advantage.

The variation in incidence rates did not influence the prior probabilities of the several diagnoses very much while cancer did not occur in study B. The conclusion that cancer is a relatively rare cause of rectal bleeding remains, for the 'selected' and even more for the 'unselected' general practice population. The prior probability of colorectal cancer in an 'unselected' general practice population will probably be even lower than we found in our study population. 
The cooperation with a study on non-acute abdominal complaints in general practice and outpatient clinics; initiated by the Department of General Practice at the University of Limburg, made it possible to find and manage a large number of physicians ready to participate. However, a complicating factor might have resulted from the combination of two entry complaints, rectal bleeding' or 'non-acute abdominal complaints', for three possible reasons. First, the inclusion criteria might not have been quite clear in the beginning. The 'non-acute abdominal complaints' should have been lasting longer than two weeks while this restriction was not desired regarding rectal bleeding. Second, the long patients' questionnaires might have caused some resistance among the GPs regarding the patients with minor rectal bleeding, although many questions could be skipped in cases without abdominal pain and although the questionnaires had been demonstrated to be acceptable in a pilot study. Finally, some doctors may have been more interested in and focused on chronic abdominal complaints and less alert to including patients with rectal bleeding, while the reverse may have been also true.

\section{Strength of the methodology}

This study encompasses the general practice experience of 83 GPs with an average duration of participation of 11 months (study A) and 10 GPs with 3 months' participation (study B). To find a similar database about three professional lifetimes of GPs are needed.

Study B was initiated to function as a reference group with an optimal incidence rate. Comparing the two studies confirmed that in study A patients with "minor ailments" were more likely not to be included in the study. We consider this data collection about the maximum of what is possible in general practice research. The possible missing cases on both extremes of the spectrum, from obviously not serious to obviously serious (acute admission to hospital), means that our findings are based on and applicable to patients in whom rectal bleeding is likely to be a decision problem for GPs. 
The gold standard of diagnoses is described in Chapter 4. It was assumed that clinically relevant and potentially serious sources of rectal bleeding would have been discovered within the follow-up period of at least 1 year. Endoscopy or roentgenography of all patients could have yielded some diagnoses, like diverticulosis and polyps, which were not necessarily the source of bleeding. Diverticulosis and polyps were classified as the outcome only when these disorders were regarded as the source of bleeding.

A hospital outpatient population may provide more detailed information regarding some diagnostic outcomes because of a generally more extensive investigation. Therefore, we did an analysis in internist outpatients clinics similar to that in general practice. These patients were comparable to the general practice population regarding age and gender (Table 1 ).

Table 1. Age and gender distribution of patients with rectal bleeding in internists' outpatient clinics (OP) and in general practice (GP)

\begin{tabular}{|l|cc|ccc|}
\hline Age (years) & \multicolumn{3}{|c|}{ OP } & GP & GP \\
& number & number & $(\%)$ \\
\hline $18-39$ & 55 & $(53)$ & 144 & $(50)$ \\
$40-49$ & 19 & $(18)$ & 58 & $(20)$ \\
$50-59$ & 15 & $(14)$ & 46 & $(16)$ \\
$\geq 60$ & 16 & $(15)$ & 42 & $(14)$ \\
& & & & \\
Gender & 55 & $(52)$ & 164 & $(56)$ \\
Female & 50 & $(48)$ & 126 & $(44)$ \\
Male & 105 & $(100)$ & 290 & $(100)$ \\
\hline Total & & & & \\
\hline
\end{tabular}

In the outpatient population all patients had further diagnostic investigation during the follow-up period, while in the general practice population only $48 \%$ had any further colorectal examinations by means of endoscopy or roentgenography initiated by the GP (31\%) and/or by referral (25\%) (Table 2).

However, rates of colorectal cancer and polyps were equal in the two populations (Table 3). This supports the assumption that the length of the follow-up period and therefore our gold standard could be regarded as appropriate for our purpose. 
Table 2. Further diagnostic investigations in the internists outpatient population (OP) and general practice population (GP) through the time of follow-up

\begin{tabular}{|l|cc|cc|}
\hline & \multicolumn{2}{|c|}{ OP } & \multicolumn{2}{c|}{ GP } \\
& $N=104$ & $(\%)$ & $N=269$ & $(\%)$ \\
\hline Endoscopy & & & & \\
proctoscopy & 2 & $(2)$ & 21 & $(8)$ \\
sigmoidoscopy & 72 & $(69)$ & 23 & $(9)$ \\
colonoscopy & 14 & $(13)$ & 6 & $(2)$ \\
Roentgenogram of lower bowel & 22 & $(21)$ & 23 & $(9)$ \\
abdomen & 10 & $(10)$ & 15 & $(6)$ \\
No further investigation initiated by the & 0 & & & \\
doctor participating in the study & & & 186 & $(69)$ \\
& & & & \\
Referral total & & $(11)$ & 67 & $(25)$ \\
surgery & & $(8)$ & 41 & $(15)$ \\
internal medicine (other internist) & 11 & $(3)$ & 14 & $(5)$ \\
gynaecology & 3 & & 3 & $(1)$ \\
psychology & 0 & & 2 & $(1)$ \\
more than 1 discipline & 0 & & 7 & $(3)$ \\
No referral nor further investigation & 0 & & 140 & $(52)$ \\
\hline
\end{tabular}

Table 3. Diagnoses related to rectal bleeding in the outpatient population (OP) and general practice (GP)

\begin{tabular}{|l|cc|cc|}
\hline & \multicolumn{2}{|c|}{ OP } & \multicolumn{2}{c|}{ GP } \\
& $\mathrm{N}=104$ & $(\%)$ & $\mathrm{N}=269$ & $(\%)$ \\
\hline Unknown cause & 44 & $(42)$ & 162 & $(61)$ \\
Haemornoid(s) & 14 & $(13)$ & 43 & $(16)$ \\
Fissura ani, abscess & 8 & $(8)$ & 19 & $(7)$ \\
Infection & 4 & $(4)$ & 6 & $(2)$ \\
Diverticulosis/itis & 4 & $(4)$ & 2 & $(1)$ \\
Proctitis & 8 & $(8)$ & 12 & $(4)$ \\
Colitis & 19 & $(18)$ & 13 & $(5)$ \\
Polyps & 3 & $(3)$ & 6 & $(2)$ \\
Colorectal carcinoma & 3 & $(3)$ & 9 & $(3)$ \\
\hline Total & $107^{*}$ & $(103)^{*}$ & $272^{*}$ & $(101)^{*}$ \\
\hline
\end{tabular}

- 3 patients had 2 diagnoses 


\section{Limitations of the methodology}

\section{Representativeness of the population}

The specific Dutch Health Care situation with open access to general practice for all patients, with a fixed list of patients per GP and a 'gate-keeper' function of GPs will have a positive influence the representativeness of our findings.

Of course, the local situation within the Netherlands may vary. Some practices will have access to endoscopy facilities while others have to refer the patient to an internist or surgeon for this.

Rectal bleeding was recorded and included in the study without systematically all consulting asking patients whether they had seen blood loss per rectum. Inter-doctor variation in alertness for rectal bleeding and selection of inclusion of patients in the study was not measured.

\section{General practice results}

Although special efforts had been taken to reduce the numbers of 'not-included' (undetected) rectal bleeding patients in the study through regular practice visits and via a newsletter, it was not possible to gather all the data requested. Information from the participating GPs indicated that patients with rectal bleeding who were not included in the study were especially those with minor ailments. This was supported by the results of study B (Chapter 5). In order to evaluate the extent of underregistration and the extent of selective underregistration with its possible influence on the prior probability of colorectal cancer, the following figures of expected numbers of patients can be given. On the basis of the results of study B, in study A about 1200 patients had to be included by 80 full-time GPs (77 full-time GPs and 6 part-time GPs, and a population of $\pm 80 \times 2350=188,000$ people) in a period of 11 months. In study A, however, only 290 patients with rectal bleeding (269 analysed) were accrued. In this population and among the expected 1200 patients with rectal bleeding, between 5 and 25 patients would be expected to suffer from colorectal cancer as illustrated in Chapter $2^{*}$. Of these a proportion would have been urgently referred to hospital and would therefore not be included in our study. So, the number of not-included cancer patients is probably very small. This conclusion is confirmed by the following deduction. According to data of a recent Dutch retrospective study of patients with colorectal cancer, GPs

\footnotetext{
- The incidence rates as deseribed in Chapter 2 were corrected for the fact that 75 years was the upper age limit for inclusion in our study. According to registrations in England $42 \%$ of patients with colorectal cancer are aged older than 75 years."
} 
referred $43 \%$ of these patients to hospital within one week after presentation because of a palpable tumour, acute abdominal complaints or massive bleeding. ${ }^{4}$ Since these patients are probably urgently referred, they would have been excluded from our study. In $35 \%$ of the remaining patients in the retrospective study the GP reported that the patient had overt rectal bleeding. On the basis of the data in this latter study and assuming that about $30 \%$ of patients with colorectal cancer are older than 75 years $^{5}$, we could expect 9 patients to be suffering from colorectal cancer in our study population. In fact 9 patients in our study did have colorectal cancer. So, the number of 'notincluded cancer patients', in contrast to the number of 'not-included rectal bleeding patients with minor ailments', is probably very low.

Combining the results of studies $\mathrm{A}$ and $\mathrm{B}$, the prior probability of colorectal cancer in patients with rectal bleeding in general practice, younger than 76 years of age, would be $0.8 \%$ ( 9 (study A) per 1200 (expected number in study A)). We found a prior probability of $3.3 \%$. Even if some patients with colorectal cancer were missed in study A, which is not very likely as shown above, the maximum prior probability according to the above mentioned maximum expectation of 25 patients, would be $2.1 \%$. This illustrates that GPs have selected patients with rectal bleeding having a slighty increased probability of cancer for inclusion in the study. It has to be remembered that this study population represents those patients that confront GPs with a decision problem.

\section{Outpatient clinic}

The study population recruited in the internists' outpatient clinic is a selected population, of which the preselection is determined by regional circumstances. The findings are therefore not generally representative for patients referred for rectal bleeding in general. In other areas and other countries the prevalences of the several diagnoses related to rectal bleeding may be different. The prior probability of colorectal cancer in our population was remarkably low. Two additional registrations, with linked epidemiologic data of rectal bleeding patients referred to the University Hospital of Maastricht, may serve as a map of the diagnostic route of those patients, via internists' outpatient clinics, via acute admissions or via surgeons. The internist of this hospital delivered a major part of outpatients for our study ( $50 \%$ versus $50 \%$ by the other three hospitals). 
1. A retrospective analysis of patient records of those who had been discharged from the hospital having a diagnosis of anal or colorectal malignancy in 1989 was done to find the expected number of patients with these malignancies for inclusion in our study (Table 4). We found only 3 such patients presenting with rectal bleeding who were not urgently admitted and had initially consulted an internist.

Table 4. A retrospective analysis of patients with colorectal carcinoma diagnosed in 1989.

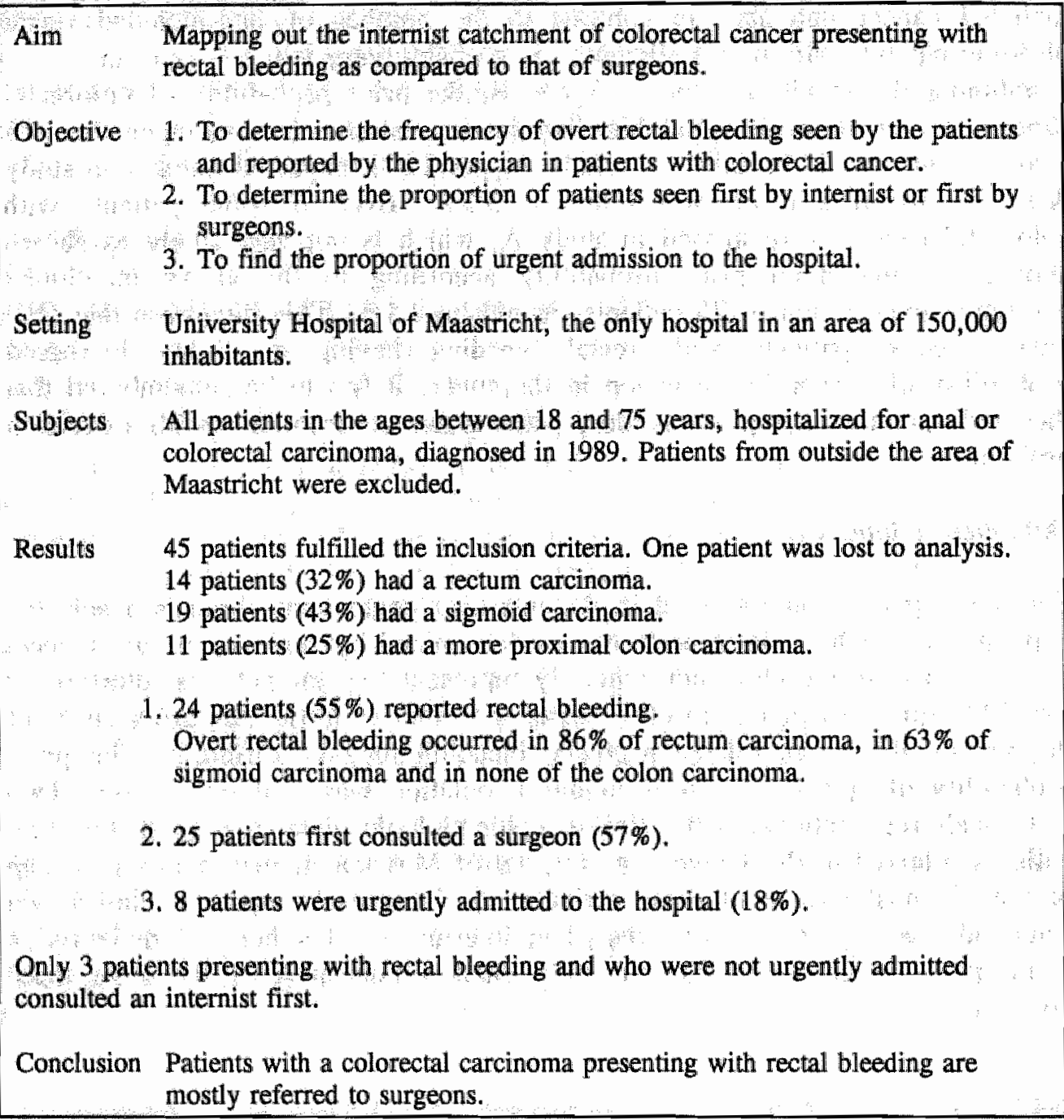


2. Data regarding patients referred for proctoscopy, sigmoidoscopy or colonoscopy to the Endoscopy Department in University Hospital of Maastricht (Table 5) were checked. These data also support the conclusion that patients with colorectal carcinoma presenting with rectal bleeding were more frequently referred to surgeons.

Table 5. Endoscopy unit data, RP Adang et al., January 1989-October 1990: 22 months

Total number of endoscopies of the lower gastrointestinal tract: $2270^{\circ}$

on the indication of rectal bleeding: $1052(47 \%)$

Endoscopic diagnosis of Neoplasm (without histologic confirmation) $\mathrm{N}=440$ adenomatous polyp ( $\mathrm{n}=326)$, with rectal bleeding: $156(48 \%)$

rectumcarcinoma $(n=48)$, " $\quad$ *: $27(56 \%)$

coloncarcinoma $\quad(n=66), \quad ", "$ " $\quad " \quad: 29(44 \%)$

Rectal bleeding $\mathbf{N}=1052$

adenomatous polyp $15 \%$

rectumcarcinoma $3 \%$

coloncarcinoma $\quad 3 \%$

Neoplasm $N=440$

referred by general practitioner $25 \%$

referred by surgeon $46 \%$

referred by internist $\quad 29 \%$

Expected number of patients with a neoplasm and rectal bleeding referred for endoscopy per year by internists:

adenomatous polyp: $12 / 22 \times 0.29$ (proportion internist) $\times 156=25 /$ year rectumcarcinoma: $\quad 12 / 22 \times 0.29$ (proportion internist) $\times 27=4 /$ year coloncarcinoma: $\quad 12 / 22 \times 0.29$ (proportion internist) $\times 29=5 /$ year

Included are patients older than 75 years of age and acute admissions (exclusion criterion for the study).

* Repeated investigations not included

The data in Table 5 include patients older than 75 and also acute admissions (both exclusion criteria in our study). When this is taken into account, internists in our area are shown to have relatively few patients with a colorectal carcinoma available to include in the study. 
Regarding the predictive values of signs and symptoms in patients referred to internists' outpatient clinics, it is shown that even in this referred population if was possible to identify a subpopulation, on the basis of history findings, with a very low probability of serious disease.

\section{Instruments}

The signs and symptoms are 'soft' data. To validate these data it would be necessary for all patients to be seen by several doctors in a comparable situation (reproducibility) and that a gold standard for all symptoms was applied. This was, of course, not feasible.

We have selected the doctors' registration as the starting-point for analysis. The patient's questionnaire was used for additional information. Some questions and answers were only available in the patient's form, for example, the detailed questions about the manifestation of the blood seen and the extensive psychosocial questions, including the Zung self-rating scale.

When patients' questionnaires are compared to doctors' questionnaires it appears that some symptoms are more frequently reported in the patients' questionnaires than in the doctors' questionnaires. Remarkable examples are: nausea being reported in 105 patients' forms and only present in 68 patients according to the doctors' forms; tenesmus in 93 and 59 patients respectively; and abdominal pain in 152 and 135 respectively (Appendix V). Although in the patients' forms more missing data occur regarding these symptoms (28 for nausea and 40 for tenesmus) than in the doctors' forms ( 3 and 4 respectively) the occurrence is higher according these patients forms. Since it was beyond the scope of our research, we did not determine the agreement between patients and doctors. Although there may be differences in the interpretation of the questions between doctors and patients, among doctors (inter-doctor variation) and among patients (inter-patient variation), this database is considered to reflect usual daily general practice very well. 


\section{Statistics}

The exact predicted probabilities derived from logistic regression may be not fully reliable due to the small number of patients with cancer (and polyps), $N=9(+6)$, in the study population. Fewer than 10 outcome events per independent variable in the model may result in "overfitting" the data, ${ }^{6,7}$ For statistical purposes this is a problem but in practice it means that the incidence and prevalence of some signs and symptoms in correlation with cancer is too low to be observed or to be shown statistically significant in about 83 'GPyears'.

\section{Interpretation of signs of depression}

Signs of depression, in our study defined as a Zung score of $>40$, were present in $22 \%$ of outpatients and in $28 \%$ of patients with rectal bleeding in the general practice population. The Zung Self-Rating Depression Scale is accepted as a useful screening instrument for depression. ${ }^{8}$ With application of a frequently used cut-off point for depression of $>50$, depression was present in $8 \%$ in the outpatient population and in $6 \%$ in general practice. This is comparable to the prevalence of depression in the primary care setting which has been reported in the range from $6 \%$ to $17 \%$ ?

Only in the outpatient population were signs of depression significantly predictive for the absence of 'IBD or neoplasm'. This may support the presence of a phenomenon described by Zung that patients with depression are frequently referred to specialists for additional medical workups; they are subjected to unnecessary, potentially harmful and costly diagnostic tests. ${ }^{9}$

Three symptoms which indicate depression are included both in the Zung questionnaire and in our gastroenterologic questions: decreased appetite, weight loss and constipation. These symptoms frequently occur in patients with gastroenterologic complaints. Constipation was present in $7 \%$ of our outpatients and was significantly associated with the absence of 'IBD or neoplasm', but decreased appetite (present in $14 \%$ of patients) was associated with the presence of 'IBD or neoplasm'. Weight loss (present in $27 \%$ ) did not show a 
significantly association with these diagnoses in this population.

Further study is necessary to evaluate the validity of the Zung questionnaire for diagnosing depression in patients with gastroenterologic complaints. In the outpatient population constipation may falsely increase an association between signs of depression and the absence of serious disease, whereas decreased appetite and weight loss tend to decrease such an association.

\section{Findings in relation to the literature}

Compared to the findings reported by Lamberts $^{10}$, the incidence of rectal bleeding in general practice of 4 per 1000 per year, the percentages of further diagnostic investigation (radiology/imaging: 1\%) and referral to a medical specialist linked to rectal bleeding as a reason for encounter (14\%), our findings in study A show a lower incidence (2 per 1000) and higher percentages of further diagnostic investigation $(31 \%)$ and referral $(25 \%)$. This may confirm our earlier illustrated conclusion that the general practitioners in study $A$ have selected patients that are more likely to confront GPs with a diagnostic decision problem.

Our data represent a first analysis of the predictive value of rectal bleeding in combination with other signs and symptoms. It is only partially possible to compare our results with reports of common symptoms of serious disease or predictive values on the basis of bivariate analyses.

Holtedahl has shown that a single symptom known as a warning signal of cancer, with bleeding as one of the seven warning signals, is rarely a sufficient basis for decisions related to the diagnosis of cancer in general practice. "The quantitative data in the booklet by Holtedahl, aiming at early diagnosis of cancer in general practice, do not provide all the required diagnostic values of symptoms for clinical decision making. ${ }^{12}$ He summarized some common symptoms of colorectal cancer in addition to rectal bleeding: change in bowel habit (that included constipation), mucous discharge from the rectum and anaemia. In our study mucous discharge is not significantly associated with cancer and none of our cancer patients had constipation. 
Nylenna reported that no single symptom recorded in his study seems to be a very useful guide for an increased awareness of cancer. ${ }^{13}$ The most important indicator was fear of cancer. "The chance of having a cancer reported within two years was four times as high in patients expressing fear of cancer as in those who did not." Change in bowel habit was also mentioned in this study as having predictive value for cancer $\left(\mathrm{PV}^{+}\right.$of $7 \%$ ) but without a more detailed risk quantification.

Mant et al reported significant associations with colorectal cancer and polyps of blood mixed with stool (positive association), of anal protrusion and of haemorrhoids identified by the general practitioner (both negative associations)..$^{14}$

None of these reports provided information sufficient to exclude the probability of colorectal cancer in general practice.

Three studies reported common reasons for suspecting serious disorders in outpatients. These are the occurrence of at least one of the following on presentation: blood mixed with stool, tenesmus, change in bowel habit and a positive family history of colorectal neoplasm. ${ }^{15-17}$ In addition, each study reported other distinctive characteristics. Firstly, a neoplasm is, in addition to the above symptoms, considered by Cheung et al when there is leakage of mucous per rectum, weight loss, abdominal pain, and a palpable tumour. ${ }^{15}$ In the study by Church, other suspected symptoms are: dark red blood and leakage of mucous. ${ }^{16}$ Non-suspect symptoms in this study are: bright red blood during or after defaecation, on the paper or in the toilet. Finally, Newstead considered abdominal pain and age above 40 years to be additional reasons to perform colonoscopy in patients with rectal bleeding. ${ }^{17}$ Most of these reported symptoms showed more or less diagnostic value either in our general practice population or in the outpatient population. However, according to our findings, abdominal pain and dark red blood are, on the contrary, associated with the absence of serious disease. 


\section{Practical implications}

One of the main purposes of this study was to find ways to improve the diagnostic practice in relation to patients with rectal bleeding in general practice. Therefore, at the end of this work, we may try to answer the question: is improvement really necessary and how can this be accomplished? As far as the early diagnosis of patients with colorectal cancer concerns we did not find a reason to change the current diagnostic strategies. A profile of the patients with colorectal cancer is given in Table 6. Doctors' delay was defined as the period between the first consultation for rectal bleeding and action taken by the GP in order to confirm or rule out colorectal cancer, by either referral or further investigation. From this table it appears that most patients with colorectal cancer were referred or investigated further within 4 weeks, with one patient having a doctor's delay of 8 weeks.

In contrast, the diagnostic strategies of the GPs leave room for further improvement regarding the selection of patients who do not benefit from further diagnostic investigation. Of the 269 patients presenting with rectal bleeding only $18 \%$ had a diagnosis requiring further investigation (cancer, polyp, colitis, proctitis, infection, diverticulosis) whereas $48 \%$ in actual practice underwent further diagnostic investigation.

Neoplasms are the most difficult diagnoses for GPs because they usually do not present with an evident clinical picture and because GPs are concerned about the possibility of overlooking cancer. Polyps although in general being more prevalent than colorectal cancer seem to be less frequently related to rectal bleeding than cancer. The discussion about the relevance of early detection of polyps (before symptoms occur) is beyond the purpose of the present study. Diverticulosis is not an important differential diagnosis. It is a frequent finding when, especially in older patients, endoscopy or roentgenography is performed but it is rarely a cause for blood loss. ${ }^{18}$ Patients with bleeding caused by diverticular disease are characterized by a sudden urge to defaecate followed by the passage of a large bloody stool. ${ }^{\Downarrow 9}$ Colitis, proctitis and infections are usually easier to diagnose. 


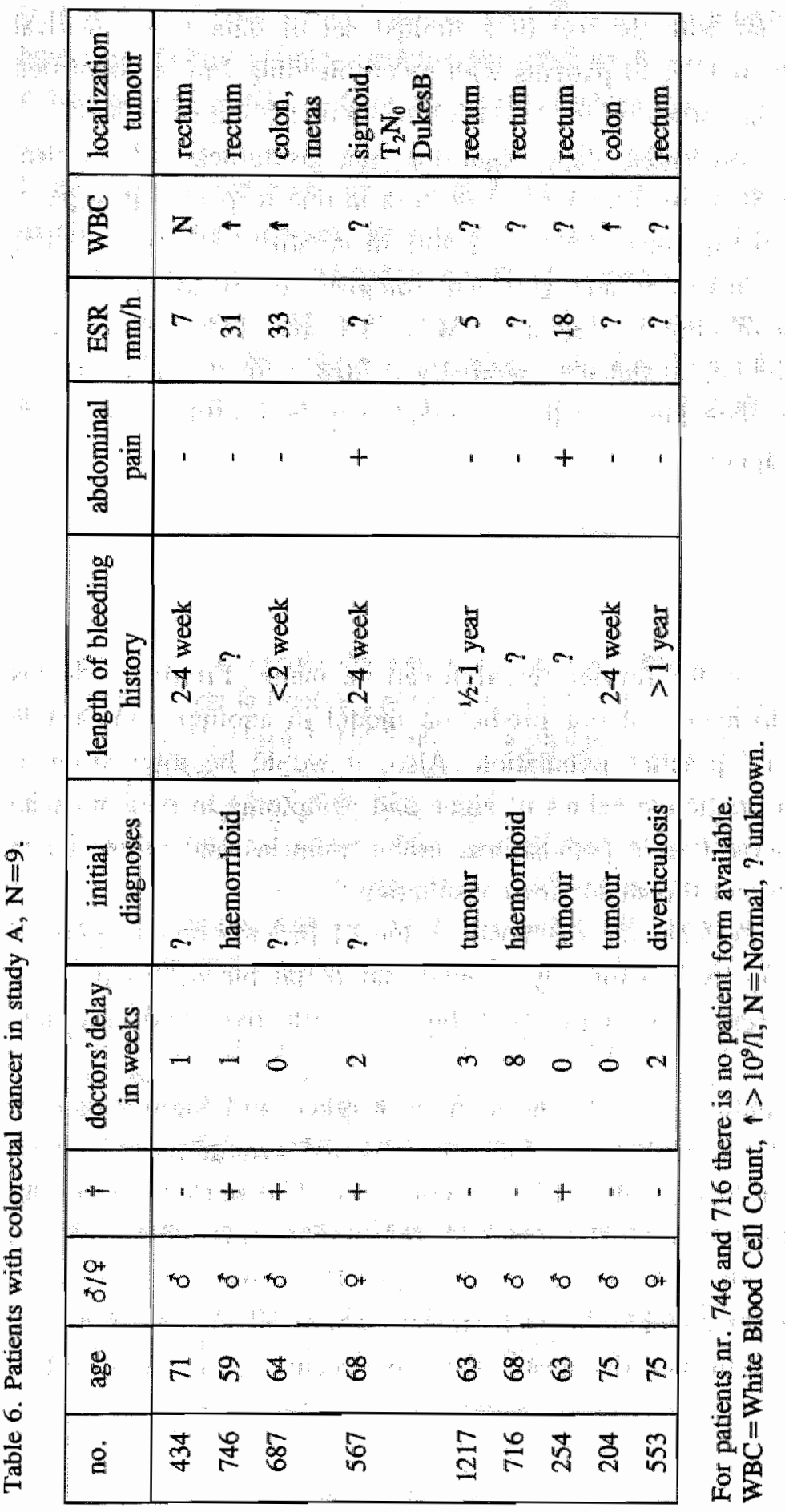


Our results indicate that with the use of a limited set of data from medical history, a considerable number of patients with rectal bleeding can be identified as not needing further investigation for exclusion or confirmation of cancer. Goulston et al have presented data regarding the usefulness of clinical assessments (before further investigation) of doctors in this respect. ${ }^{20}$ It appears that of the patients without cancer GPs were able to identify $64 \%$ (specificity). correctly by elinical assessment and gastroenterologists to do so in $80 \%$ of cases. The sensitivity of clinical assessment was $75 \%$ and $87 \%$ respectively. With the application of our model the specificity is $90 \%$ with the maintenance of a $100 \%$ sensitivity, indicating that this approach may be useful to overcome the problem of overdiagnosis.

\section{Future research}

General recommendations for further research can be made. Firstly, it seems useful to test the performance of our prediction model in another comparable and even larger general practice population. Also, it would be interesting to analyse differences in predictive values of signs and symptoms in patients with rectal bleeding in other different populations, other countries and other health care systems with different thresholds for consultation.

It is recommended to evaluate the diagnostic value of proctoscopy in general practice. Demonstration by proctoscopy of anal and rectal bleeding causes in combination with other signs may contribute to effective and efficient diagnostic strategies.

For a better understanding of differences in occurrence and significance of rectal bleeding and of the predictive values of signs and symptoms in general practice compared to referred patients it is recommended to perform a similar study in a referred population which include all referred patients within a given area. This could be feasible in an Endoscopy Department, perhaps in combination with a Roentgenography Department, where all patients within a certain area who need further diagnostic workup because of rectal bleeding could be identified. 
It is further recommended to analyse differences in interpretations of symptoms between healthy people, patients and doctors in order to provide adequate and more focused public, patient and medical education.

Finally, our findings may contribute to the development of criteria for diagnostic investigation including referral and criteria for the extent of investigation (rectal examination, blood sample, proctoscopy, sigmoidoscopy, colonoscopy or roentgenography). Such criteria may be useful in daily practice in order to improve the effectiveness and efficiency of the diagnostic process and to improve the communication between GPs and patients and between GPs and specialists as well.

\section{References}

1. Morrell D. Common pits and how to avoid falling into them. In: Morrell D (ed.). Epidemiology in General Practice. Oxford: Oxford University Press, 1988.

2. Dambsbo $\mathrm{N}$, Olsen J. Difficulties in a multipractice study. Scand J Prim Health Care $1983 ; 1 ; 135-42$.

3. Office of Population Censuses and Surveys. Cancer statistics. Registrations. Cases of diagnosed cancer registered in England and Wales, 1987. London: HM Stationery Office, 1993. Series MBI No. 20.

4. Berg van de FA, Coebergh JWW, Damhuis RAM, Geul KW, Does van de E. Patiënten met colorectaal carcinoom: wat vond en deed de huisarts? Huisarts Wet 1993; 36 (8): 242-6.

5. Bakker D, Coebergh JWW, et al. (eds.) Cancer Incidence in The Netherlands: the southeastern part, 1978-1982. Eindhoven: Eindhoven Cancer Registry/IKZ, 1985.

6. Concato J, Feinstein AR, Holford TR. The risk of determining risk with multivariable methods. Ann Int Med 1993; 118: 201-10.

7. Harrell FE, Lee KL, Matchar DB, Reichert TA. Regression models for prognostic prediction: advantages problems, and suggested solutions. Cancer Treat Rep 1985; 69: 1071-7.

8. Wilkin D, Hallam L, Doggett M. Measures of Need and Outcome for Primary Health Care. Oxford: Oxford University Press, 1992. 
9. Zung WWK. The role of rating scales in the identification and management of the depressed patient in the primary care setting. J Clin Psychiatry 1990; $51[6$, suppl]: 726.

10. Lamberts H. In het huis wan de huisarts: Verslag van het Transitieproject. Lelystad: Meditekst. 1991.

11. Holtedahl KA, A method of calculating diagnostic indexes for possible cancer symptoms in general practice. Allgemeinmedizin 1990;74-9.

12. Holtedahl KA. Early diagnosis of cancer in general practice: a manual. Berlin Heidelberg, Springer Verlag, 1990.

13. Nylenna M. Diagnosing cancer in general practice: from suspicion to certainty. $B r$ Med J 1986; 293: 314-7.

14. Mant A, Bokey EL, Chapuis PH, et al. Rectal bleeding. Do other symptoms aid in diagnosis? Dis Colon Rectum 1989; 32: 191-6.

15. Cheung PSY, Wong SKC, Boey J, Lai CK. Frank rectal bleeding: a prospective study of causes in patients over the age of 40. Postgrad Med $J$ 1988; 64: 364-8.

16. Church JM. Analysis of the colonoscopic findings in patients with rectal bleeding according to the pattern of their presenting symptoms. Dis Colon Rectum 1991; 34: $391-5$.

17. Newstead GL, Logical clinical decisions in the investigation and management of non urgent rectal bleeding. Gastroenterol Jpn 1991; 26(3): 107-10.

18. Boley SJ, DiBiase A, Brandt LJ, Sammartano BS. Lower intestinal bleeding in the elderly. Am J Surg 1979, 137: 57-64.

19. Jones DJ. Diverticular disease. Br Med J 1992; 304: $1435-7$.

20. Goulston KJ, Cook I, Dent OF. How important is rectal bleeding the diagnosis of bowel cancer and polyps? Lancet 1986; ii: 261-577. 


\section{Summary}

\section{Introduction}

Overt ano-rectal bleeding is known as a danger signal. Knowledge of the predictive value of this sign in combination with other signs and symptoms is hardly available but desired for rational clinical practice. The main purpose of the present study was to collect quantitative data for the use in general practice. The main question in this study was whether it is possible to discriminate effectively between patients with rectal bleeding who have colorectal cancer and those who do not; or at least to discriminate between those who need invasive investigations and those who do not.

We tried to answer the following questions:

1. What is the incidence of rectal bleeding in general practice?

2. What is the prior probability of malignant disease in patients presenting with rectal bleeding in general practice? What are the frequencies of other sources of rectal bleeding?

3. What is the predictive value of (combinations of) signs, symptoms and simple laboratory tests a. for colorectal cancer in general practice?

b. for serious bowel disease in outpatients?

\section{Literature}

To determine the occurrence and significance of overt blood loss per anorectum a Medline literature search was undertaken. The incidence of this symptom in the general population is reported in literature to be about 20 per 100 people per year, the 'consultation incidence' in general practice is reported to be about 6 per 1000 per year and the incidence of referral to a medical specialist is estimated to be about 7 per 10,000 per year. The clinical significance of the symptom varies within different populations: the predictive value of overt rectal blood loss for colorectal malignancy was estimated to be about 1 in 1000 or even less in the general population, around 2 in 100 in general practice and up to 36 in 100 in the referred patients. It is unknown how the manifestation of the bleeding (and other signs and symptoms) influence the care seeking and referral behaviour, leading to increased prior probabilities. 


\section{Current Dutch situation}

The current diagnostic approach of patients with rectal bleeding in general practice in the Netherlands is discussed in Chapter 3. General practitioners often face a dilemma: deciding whether to expose the patient to possibly unnecessary anxiety and costs, or whether to risk diagnosing a potentially malignant tumour too late or not at all. General practitioners are concerned about the possibility of overlooking cancer which does not present with an evident clinical picture. Knowledge of the diagnostic value of other signs and symptoms in combination with rectal bleeding could be helpful.

\section{Research protocol}

Chapter 4 gives a review of the general methodological aspects of our empirical study. In both general practice and the outpatient clinic the question was operationalized as: to what extent do other (combinations of) symptoms enable the physician to confirm or rule out serious disease?

In general practice the focus is on colorectal cancer, since the prediction of the presence or absence of colorectal cancer is the main decision problem. In the outpatient clinic the focus is on serious disease requiring further diagnostic investigation. Inflammatory bowel disease (IBD) and colorectal neoplasm (cancer and polyps) were taken together as serious disease.

The design of the study can be defined as 'pseudo-follow-up' study, investigating a cross-sectional relationship between particular factors (signs, symptoms and simple laboratory test results) and a particular outcome (colorectal cancer, neoplasm or IBD), while the outcome can be only detected by follow-up. All diagnostic data available after a follow-up period of at least 1 year were used to establish the final diagnostic outcome (gold standard). It was assumed that a potentially malignant source of rectal bleeding would have been discovered within the follow-up period. Since referred patients with rectal bleeding will almost always undergo further diagnostic investigations, including endoscopy or roentgenography, additional information regarding the frequencies of possibly missed diagnoses of polyps and malignancies in the general practice population could be gained by analysing outcome data in a outpatient population. 


\section{Population}

Consecutive patients in the ages 18-75 years with rectal bleeding were recruited in general practice (study A and B) and general internists' outpatient clinics (study C). Since it was noticed during the course of the study in general practice (study A) that the number of patients included in the study was less than expected and very variable, it was decided to conduct a complementary study (study B) with a modified protocol and special efforts to maximize the catchment rate. The aim of the study $B$ was to assess a more accurate incidence rate. For this there were during a three months' period daily controls of patient records by practice assistants.

\section{Data}

The data were collected through a semi-structured questionnaire filled in by the doctor after the first consultation (history, physical examination and initial management); some simple laboratory tests: erythrocyte sedimentation rate, haemoglobin, white blood cell count and faecal occult blood; and a selfcompletion patient questionnaire (history, signs and symptoms).

\section{Results}

The incidence as well as the final diagnostic outcome of rectal bleeding presenting in general practice both in the initial study A (83 GPs, 11 months, $\mathrm{N}=290$ ) and in study B with a modified protocol ( $10 \mathrm{GPs}, 3$ months, $\mathrm{N}=48$ ) are presented in Chapter 5. In study B the mean 'consultation incidence rate' (of patients in the ages 18-75 years) is 7 per 1000 per year, in study $A$ this is 2 per 1000 . The study $A$ data are further analysed. Follow-up data were available for 269 patients, with a mean follow-up period of 20 months (standard deviation 5 months).

Occurrence of colorectal cancer was found in 9 patients with rectal bleeding in study A $(3.3 \%, 95 \% \mathrm{CI} 1.2 \%-5.4 \%)$. In about $90 \%$ of the patients rectal bleeding was related to minor ailments or self-limiting disorders. A prior probability of $3.3 \%$ may represent an overestimation of the real prior probability since there was a selection in favour of patients who are more likely to be a decision problem for the GP. 
Patients with obviously harmless rectal bleeding were less likely to be included in the study than patients which are more likely to confront the GP with a decision problem.

\section{Predictive values in general practice}

In Chapter 6 the predictive values of signs and symptoms in rectal bleeding patients for colorectal cancer are presented. In bivariate analysis most variables did not show statistically significant predictive value (chi-square $p \geq 0,10$ ) (Table 2). The diagnostic value of signs, symptoms and simple laboratory test results is determined by the sensitivity, specificity, predictive values and odds ratios. The diagnostic values regarding bivariately significant variables are given in Tables 3 and 4 . All significant variables were entered into forward stepwise logistic regression analysis to find the 'independent' predictive value of each variable taking the other variables into account simultaneously. Although the number of patients with colorectal cancer is small $(n=9)$ it was possible to identify three characteristics significantly and independently contributing to the diagnosis: age, change in bowel habit (with exclusion of constipation) and blood only mixed with or on stool. Constipation, blood on toilet paper, blood in lavatory bowl, other or unknown presentations and combinations of presentations did not show predictive value. For statistical reasons age is transformed into decades above and below 50 years ((age - 50): 10). The prior probability of cancer increases with age above 50 years and equally decreases with age below 50 years.

According to the prediction model (Table 5) with the application of a cut-off point optimal for exclusion (no false negatives and a minimal number of false positives) in the study population, a rectal bleeding patient is suspected for colorectal cancer in the following cases: if the patient is older than 70 years; if the patient is older than 60 years and suffers from at least one of the two symptoms: a changed bowel habit and blood mixed with or on stool; if the patient is older than 50 years and has both the above mentioned symptoms. Patients younger than 50 years have a very low probability of colorectal cancer (close to $0 \%$ ). It must be remembered that colorectal cancer although relatively rarely does occur at younger age. 
A prediction model containing the combination of these three signs can be assessed as a diagnostic test for the prediction of cancer.

The Area Under the Receiver Operating Characteristic (ROC) curve (AUC) is 0.97 , which means a high discriminatory power. The maximum sum of sensitivity and specificity is achieved with a cut-off point of 0.042 (posterior probability), corresponding to a sensitivity of $100 \%$ and a specificity of $90 \%$. For accurately predicting the absence of malignancy in our study population, application of this cut-off point is suitable At this point $13 \%$ of patients $(n=35)$ are classified as positive for cancer with a positive predictive value $\left(\mathrm{PV}^{+}\right)$of $26 \%$, while $87 \%$ of patients $(\mathrm{n}=234)$ are truly classified as negative $\left(\mathrm{PV}^{-}=100 \%\right.$ ). Application of the prediction model presented might prevent $90 \%$ of 'unnecessary' invasive diagnostic procedures for patients with rectal bleeding who do not have colorectal cancer.

If polyps, which were deteeted and related to rectal bleeding in 6 patients in our population, are added to cancer as the outcome parameter the logistic regression analysis results in a similar model. However, the diseriminatory power is slightly less with an AUC of 0.92 . The maximum sum of sensitivity $(93 \%)$ and specificity $(84 \%)$ is $177 \%$. Applying the model in our study population with a cut-off point optimal for exclusion of cancer and polyps, $21 \%$ of patients are predicted positive for colorectal cancer or polyps with a $\mathrm{PV}^{+}$of $25 \%$ and a PV- of $99.5 \%$. It is concluded that in patients with rectal bleeding the predictive power of many signs and symptoms for colorectal cancer in general practice is low.

The answer on our main question in the study is: yes, it appears possible to discriminate in rectal bleeding patients between those who do not have colorectal cancer and those who have a rather high probability of cancer. Therefore, it appears possible to discriminate effectively and efficiently patients for invasive diagnostic investigations.

This is the first reported model developed to discriminate between such patients with a very low (close to 0 ) probability of colorectal cancer (and overtly bleeding polyps) and those with a high probability. Although our model appears to do this quite successfully, testing its performance in other general practice populations is recommended. 


\section{Predictive values in the outpatient population}

In the study outpatient population the prior probability (prevalence) of serious bowel disease is $32 \%$ : $26 \%$ inflammatory bowel disease (IBD: colitis or proctitis) and $6 \%$ neoplasm (colorectal cancer or polyps). The 18 variables with a statistically significant predictive value on the basis of a bivariate analysis are given in Chapter 7 .

Forward stepwise multiple logistic regression analysis shows 4 to 6 variables with an independent contribution to the discrimination between the presence and absence of IBD or neoplasm. The AUC of the two models is 0.92 and 0.91 . Model 1 is based on variables derived from history taking and contains six items: a changed bowel habit (except constipation), blood seen more than once, blood seen at the end of defaecation, tenesmus, (absence of) nausea and (absence of) signs of depression. Model 2 is based on history: change in bowel habit (except constipation) and (absence of) abdominal pain of more than two weeks of duration; physical examination: (absence of) abnormalities (scars and distension) by abdominal inspection; and laboratory tests results: at least one positive result of three faecal occult blood tests.

Model 1 is more useful regarding exclusion of serious disease than model 2. Applying model 1 in the study population with a cut-off point optimal for exclusion, $43 \%$ of patients are truly classified negative for IBD or neoplasm, with a sensitivity of $100 \%$ and a specificity of $64 \%, \mathbf{P V}^{+}=\mathbf{5 6 \%}$ and $\mathbf{P V}^{-}=$ $100 \%$. With model 2 , only $10 \%$ of patients ean profit by being classified negative (sensitivity $=100 \%$, specificity $=17 \%, \mathrm{PV}^{+}=34 \%, \mathrm{PV}^{-}=$ $100 \%$ ). Testing of the performance of the model in other outpatient clinic populations is recommended. It can be accepted with some reserve because of the missing data, that the laboratory tests do not provide additional contribution to the diagnosis of absence of IBD or neoplasm.

\section{Study yield}

Although research in general practice and especially a multipractice study has some pitfalls (described in Chapter 8 ), this is the only possible way to find predictive values of signs and symptoms in combination with rectal bleeding 
for colorectal cancer in general practice. It appears possible to discriminate effectively and efficiently between patients who need invasive diagnostic investigation because of a reasonably high probabillity of colorectal cancer and those for whom this is not indicated because of a very low probability.

To find a similar database about three professional lifetimes of GPs would be needed.

Combining the results of studies A and B in general practice, the prior probability of colorectal cancer in rectal bleeding patients in the ages 18-75 years is $0.8 \%$ ( 9 per 1200). In our study population, however, which is representing patients that may be more likely to confront $G P_{S}$ with a decision problem, the prior probability is $3.3 \%$. It is illustrated that GPs have selected patients with rectal bleeding and a somewhat higher than average probability of cancer for inclusion in the study.

The study population recruited in the internists' outpatient clinic is a selected population, of which the preselection is determined by regional circumstances. The findings are therefore not generally representative for patients referred for rectal bleeding in general. The prior probability of colorectal cancer in our outpatient population is remarkably low. Two additional registrations, with linked epidemiologic data of rectal bleeding patients referred to the University Hospital of Maastricht, serving as a map of the diagnostic route of those patients, via internists' outpatient clinics, via acute admissions or via surgeons show that internists in our area have see relatively few patients with colorectal carcinoma available who meet the inclusion criteria of the study. It is shown that even in this referred population it is possible to identify a subpopulation, on the basis of history findings, with a very low probability of serious bowel disease. It is recommended for the future to test the performance of our prediction models in another comparable general practice population and in another comparable outpatient population.

Studying a population older than 75 years can provide additional information regarding predictive values in these patients who probably have a high prior probability of cancer (,polyps and diverticulosis). It would also be interesting to analyse differences in predictive values of signs and symptoms in patients with rectal bleeding in both other different general practice populations and referred populations. 
Furthermore, it is recommended to evaluate the diagnostic value of proctoscopy in general practice. Demonstration of anal and rectal bleeding causes in combination with other signs may contribute to more effective and efficient diagnostic strategies.

It is further recommended to analyse differences in interpretations of symptoms between healthy people, patients and doctors in order to provide adequate and more focused public, patient and medical education.

Finally, our findings may contribute to the development of criteria for diagnostic investigation including referral and criteria for the extent of investigation. 


\section{Samenvatting}

\section{Inleiding, vraagstelling}

Zichtbaar bloedverlies per anum wordt gezien als waarschuwingssignaal voor darmkanker. Een belangrijke taak van de huisarts bij een patiënt met bloedverlies per anum is om deze patiënt weloverwogen onder te brengen bij de groep met een minimale kans op darmkanker (en de patiënt daarmee onnodig onderzoek te besparen) of wel bij de groep met een redelijk grote kans (en daarmee een procedure met invasief onderzoek in gang te zetten).

Kennis van de predictieve waarde van bloedverlies per anum in combinatie met andere symptomen en bevindingen bij lichamelijk onderzoek ten aanzien van darmkanker en andere ziektenbeelden is nauwelijks beschikbaar maar wel noodzakelijk om rationele diagnostiek te bevorderen.

Het beschreven onderzoek beoogt deze kennis te vermeerderen en uiteindelijk een antwoord te zoeken op de volgende vraag: "is het mogelijk in een gedefiniëerde groep patiënten met bloedverlies per anum effectief en efficiënt onderscheid te maken tussen degene die wel en degene die geen darmkanker hebben?; ofwel is het mogelijk onderscheid te maken tussen patiënten bij wie al dan niet invasieve onderzoeken geïndiceerd zijn?" Getracht is de volgende vragen te beantwoorden:

1. Wat is de incidentie van bloedverlies per anum in de huisartspraktijk?

2. Wat is in deze populatie met bloedverlies per anum de a priori kans voor darmkanker? In welke frequentie komen andere oorzaken van bloedverlies voor?

3. Wat is de voorspellende waarde van (de combinatie van) andere symptomen en bevindingen in a. de huisartsenpopulatie voor darmkanker;

b. een poliklinische populatie voor ernstige darmaandoeningen.

\section{Literatuur gegevens}

Om een beeld te krijgen van het vóorkomen en de betekenis van zichtbaar bloedverlies per anum werd een literatuurstudie via Medline verricht.

De incidentie van dit symptoom in de algemene bevolking is ongeveer 20 per 100 volwassenen per jaar. De "consultatie-incidentie" in de huisartspraktijk 
ongeveer 6 per 1000 mensen per jaar en de incidentie van "verwezen" naar een medisch specialist wordt geschat op ongeveer 7 per 10.000 mensen per jaar.

De klinische (diagnostische en prognostische) betekenis van bloedverlies per anum varieert binnen verschillende populaties: de voorspellende waarde voor darmkanker wordt geschat rond 1 per 1000 of minder in de algemene populatie, rond 2 per 100 of minder in de huisartspraktijk en tot 36 per 100 in de verwezen patientenpopulatie. Het is niet bekend, in hoeverre de presentatie (de aard) van het bloedverlies en van andere bijkomende symptomen van invloed is op het om hulp vragen van mensen en op het verwijsgedrag van huisartsen, en daarmee op een toename van a priori kansen.

\section{Huidige nederlandse situatie}

De huidige diagnostische benadering van patiënten met bloedverlies per anum in de huisartspraktijk wordt in hoofdstuk 3 beschreven.

Er bestaat vaak een dilemma voor de huisarts: aanvullend onderzoek met mogelijk onnodige angst, ongemak en onkosten voor de patiënt, of geen onderzoek met het risico een mogelijke kwaadaardige tumor (te)laat op te sporen. Huisartsen zijn terecht bevreesd om kanker over het hoofd te zien te meer in situaties waarin een duidelijk klinisch beeld ontbreekt. Kennis van de diagnostische waarde van bloedverlies in combinatie met andere symptomen is nodig om het diagnostisch handelen van huisartsen beter te onderbouwen dan nu het geval is.

\section{Onderzoeksopzet}

In hoofdstuk 4 wordt een overzicht gegeven van de methodologische aspecten van de empirische studie. Zowel in de huisartspraktijk als in de algemeen internistische polikliniek was de vraagstelling: "in welke mate maken andere (combinaties van) symptomen het mogelijk om ernstige ziekten te bevestigen of uit te sluiten?"

In de huisartspraktijken beperken we ons tot darmkanker omdat hier het voorspellen van aan- of afwezigheid van deze ziekte het belangrijkste besliskundige probleem vormt.

In de internistische polikliniek richten we ons op een aantal mogelijke ernstige aandoeningen die om invasief onderzoek vragen: inflammatoire aandoeningen 
(IBD: colitis en proctitis) en colorectale neoplasmata (kanker en poliepen). Het design van de studie zou men "pseudo follow-up" kunnen noemen. Een cross-sectionele relatie tussen bepaalde factoren (symptomen, bevindingen bij lichamelijk onderzoek en uitslagen van eenvoudige laboratoriumtests) en een bepaalde uitkomst (diagnose) wordt onderzocht terwijl die uitkomst slechts via een follow-up vastgesteld kan worden. Alle klinische en diagnostische gegevens die beschikbaar zijn na een follow-up periode van minstens één jaar dragen bij aan het vaststellen van de uiteindelijke diagnose (gouden standaard). Er wordt vanuitgegaan dat ernstige ziekten die het bloedverlies veroorzaken niet selflimiting zijn en met een hoge mate van waarschijnlijkheid binnen één jaar manifest zijn.

Omdat verwezen (poliklinische) patiënten vrijwel altijd invasieve diagnostische onderzoeken, zoals endoscopie of röntgenonderzoek ondergaan, is het te verwachten dat de analyse van de diagnostische resultaten in deze populatie enige informatie zal kunnen verschaffen ten aanzien de mate waarin belangrijke diagnosen (zoals maligniteiten en poliepen) gemist zouden kunnen zijn in de huisartsenpopulatie (waar deze onderzoeken vaak niet plaats vinden).

\section{Onderzoekspopulatie}

Patiënten in de leeftijdscategorie 18-75 jaar bij wie sprake is van zichtbaar bloedverlies per anum, als reden van komst of gemeld tijdens een anamnese, werden in de studie opgenomen. Patiënten die acuut verwezen werden (bijv. wegens massaal bloedverlies of klachten verdacht voor darmobstructie of perforatie) evenals zwangeren werden uitgesloten. Omdat gedurende het verloop van de oorspronkelijke studie in de huisartspraktijk (studie A) bleek dat het aantal in het onderzoek opgenomen patiënten lager was dan verwacht en het aantal tevens sterk varieerde tussen de huisartsen onderling, werd besloten om een complementaire studie (studie B) met een aangepast protocol uit te voeren. Het hoofddoel van studie B was het vinden van de werkelijke incidentie van bloedverlies per anum in de huisartspraktijk. Hiertoe werden ondermeer gedurende 3 maanden dagelijks de patientenkaarten door de praktijkassistentes gecontroleerd op aanwijzingen voor bloedverlies per anum.

Studie C betreft de patiënten van de polikliniek Interne Geneeskunde. 


\section{Data}

Gegevens werden verzameld met behulp van:

- een semi-gestructureerd vragenformulier dat door de arts na het eerst consult werd ingevuld (anamnese, lichamelijk onderzoek en beleid);

- enkele eenvoudige laboratoriumtests: bezinkingssnelheid der erytrocyte (ESR), hemoglobine-gehalte ( $\mathrm{Hb})$, aantal leucocyten (WBC) en een test voo occult bloed in de faeces (FOB);

- een uitgebreide door de patiënt zelf in te vullen vragenlijst (uitgebreider anamnese en psychologische tests).

In totaal werden 60 variabelen geanalyseerd. De vragenlijsten zijn als bijlag toegevoegd. De percentages van voorkomen van diverse diagnosen pe variabele zijn eveneens in de bijlagen vermeld.

\section{Resultaten}

De incidentie van bloedverlies per anum en de uiteindelijke diagnosen in dt huisartsenpopulatie zijn weergegeven in hoofdstuk 5 . In studie $A$ (8: huisartsen, gemiddelde registratieduur 11 maanden, $N=290$ ) werd eer incidentie vastgesteld van 2 patiënten (in de leeftijd van 18-75 jaar) per 1000 per jaar en in studie $B$ (10 huisartsen, 3 maanden, $N=48$ ) van 7 per 1000 per jaar. In studie A was follow-up mogelijk bij 269 patiënten met een gemiddelde follow-up duur van 20 maanden (standaard deviatie 5 maanden). De gegevens van de studie A patiënten zijn verder geanalyseerd.

Bij 9 patiënten $(3,3 \%, 95 \% \mathrm{CI} 1,2 \%-5,4 \%)$ werd darmkanker vastgesteld. In ongeveer $90 \%$ van de patiënten was het bloedverlies gerelateerd aan onschuldige aandoeningen. De gevonden a priori kans van darmkanker van $3,3 \%$ is mogelijk een overschatting van de werkelijke a priori kans omdat er een selectie bestond ten gunste van patiënten bij wie het bloedverlies vaker een besliskundig probleem vormt ten aanzien van eventueel te verrichten aanvullende diagnostiek. Patiënten bij wie vrijwel zeker sprake is van een onschuldige andoening werden minder vaak in het onderzoek betrokken. 


\section{Predictieve waarden in de huisartspraktijk}

In hoofdstuk 6 worden de voorspellende waarden van symptomen en bevindingen bij patiënten met bloedverlies per anum voor darmkanker gepresenteerd. In de bivariate analyse bleken de meeste variabelen bleken geen statistisch significante (chi kwadraat, $\mathrm{p} \geq 0,10$ ) voorspellende waarde te hebben (tabel 2).

De diagnostische waarde van symptomen en bevindingen wordt evenals die van laboratoriumtests bepaald door de sensitiviteit, de specificiteit, de voorspellende waarde en odds ratio. Van de variabelen die in de bivariate analyse statistisch significant discriminerend bleken, zijn de genoemde diagnostische waarden gegeven (tabel 3 en 4). Al deze variabelen werden ingebracht in een logistische regressie analyse (forward stepwise) om de "onafhankelijke" predictieve waarde van elke van deze variabelen te bepalen waarbij gelijktijdig rekening werd gehouden met de overige variabelen.

Hoewel het aantal patiënten met darmkanker klein is $(\mathrm{N}=9)$ bleek het mogelijk drie factoren te identificeren die onafhankelijk en statistisch significant bijdragen aan de diagnose: leeftijd, een veranderd defaecatie patroon (behalve obstipatie) en bloed alleen of vermengd met of op de ontlasting. Aan obstipatie, bloed op het toiletpapier, bloed in de pot, bloed anderszins of met een onbekende presentatie evenals van de diverse combinaties van presentaties van bloedverlies kon geen onafhankelijke predictieve waarde worden toegekend. $\mathrm{Om}$ statistische redenen werd leeftijd getransformeerd tot decades onder en boven 50 jaar ((leeftijd-50):10). Boven de 50 jaar neemt de kans op darmkanker toe met het stijgen van de leeftijd (in decaden) en beneden de 50 jaar neemt deze kans in gelijke mate af met het dalen van de leeftijd.

Bij toepassing van het gepresenteerde predictiemodel (tabel 5) in de studiepopulatie met een gekozen afkappunt welk optimaal is voor uitsluitingsdiagnostiek (geen fout-negatieven en een minimaal aantal foutpositieven), wordt een patiënt in de volgende gevallen als positief (verhoogde kans op kanker) geclassificeerd: indien deze ouder is dan 70 jaar; indien deze ouder is dan 60 jaar en minstens één van de twee symptomen ('veranderd defaecatiepatroon' en 'bloed vermengd met of op de ontlasting') heeft; of indien de patiënt ouder is dan $\mathbf{5 0}$ jaar en beide eerder genoemde symptomen 
heeft. Patiënten jonger dan 50 jaar hebben een erg kleine a priori kans op kanker. Opgemerkt moet echter worden dat ook bij jongere patiënten, hoewel relatief zeldzaam, darmkanker voorkomt.

Het predictiemodel kan beoordeeld worden als een diagnostische test voor kanker. Deze test heeft een hoog onderscheidend vermogen (oppervlakte onder ROC curve (AUC) is 0,97). Bij het optimale afkappunt voor uitsluiting van kanker is de sensitiviteit $100 \%$ en de specificiteit $90 \%$. In de studiepopulatie wordt dan $13 \%$ als positief geclassificeerd met een positief voorspellende waarde $\left(\mathrm{PV}^{+}\right)$van $26 \%$ en $87 \%$ als negatief met een negatief voorspellende waarde (PV) van 100\%. Toepassing van dit model zou aldus $87 \%$ "onnodige" invasieve diagnostische procedures kunnen besparen (bij patiënten zonder kanker in $90 \%$ van de gevallen). Indien poliepen, welke gerelateerd werden aan het bloedverlies $(\mathrm{N}=6)$, toegevoegd worden aan kanker als de uitkomstparameter dan resulteert de logistische regressie-analyse in nagenoeg hetzelfde model. Het onderscheidend vermogen is iets minder met een AUC van 0,92 . De maximale sensitiviteit is $93 \%$ bij een specificiteit van $84 \%$. Bij een afkappunt optimaal voor exclusie van 'bloedende poliepen en kanker' wordt $79 \%$ als negatief geclassificeerd met $\mathrm{PV}^{+}=25 \%$ en $\mathrm{PV}^{-}=99,5 \%$. Er kan geconcludeerd worden dat de predictieve warden van de overige gebruikelijke en diagnostisch belangrijk geachte symptomen en bevindingen erg beperkt zijn. De uiteindelijke onderzoeksvraag kan grotendeels bevestigend worden beantwoord. Het is mogelijk gebleken te onderscheiden tussen patiënten die geen darmkanker hebben en degene die een verhoogde kans hebben. Daarmee is het mogelijk effectief en efficiēnt onderscheid te maken tussen patiènten bij wie invasiefonderzoek geïndiceerd is vanwege een hoge kans op darmkanker en patiënten bij wie dit niet het geval is vanwege een zeer lage kans op kanker (vrijwel $0 \%$ ).

Hoewel deze eerste beschrijving van een predictiemodel voor het onderscheiden tussen patiënten met een zeer lage kans op kanker en een nogal hoge kans bruikbaar lijkt wordt aanbevolen on de uitkomsten in een identieke onderzoekspopulatie in andere huisartspraktijken te toetsen. 


\section{Predictieve waarden in poliklinische populatie}

In de internistische polikliniekpopulatie (study C) is de a priori kans (prevalentie) van ernstige aandoeningen 32\%: IBD 26\% en colorectale neoplasmata $6 \%$ (hoofdstuk 7 ).

Een bivariate analyse levert 18 variabelen op die statistisch significante predictieve waarde hebben voor deze aandoeningen.

Logistische regressie analyse (forward stepwise) resulteert in twee modellen met 4 tot 6 variabelen welke een onafhankelijke bijdrage leveren aan het onderscheiden van de aan- of afwezigheid van IBD of neoplasmata. Beide modellen hebben een goed onderscheidend vermogen met een AUC van 0,92 en 0,91 .

Het eerste model is gebaseerd op 6 variabelen, afgeleid van alleen anamnestische gegevens: een veranderd defaecatie patroon (behalve obstipatie), bloed per anum frequenter aanwexig dan slechts énmaal, bloed waargenomen op het einde van de defaecatie, loze aandrang, (afwezigheid van) misselijkheid en (afwezigheid van) tekenen van depressie. $\mathrm{Bij}$ het tweede model zijn tevens het lichamelijk onderzoek en de laboratoriumtests betrokken: een veranderd defaecatiepatroon, (afwezigheid van) buikpijn die langer dan twee weken bestaat, (afwezigheid van) abnormale bevindingen (littekens, opgezette buik) bij inspectie van het abdomen en ten minste eén positieve van drie hemocculttests. Het eerste model is beter in het uitsluiten van ernstige ziekte dan het tweede. Bij toepassing van het eerste model met een afkappunt optimaal voor exclusie is de sensitiviteit $100 \%$, de specificiteit $64 \%$ en wordt $43 \%$ terecht als negatief geclassificeerd, met $\mathrm{PV}^{+}=56 \%$ en $\mathrm{PV}^{-}=100 \%$. Bij toepassing van het tweede model voor eenzelfde doel wordt slechts $10 \%$ terecht als negatief geclassificeerd (sensitiviteit 100\%, specificiteit $17 \%, \mathrm{PV}^{+}=34 \%, \mathrm{PV}^{-}=$ $100 \%)$ waardoor dus minder patiënten "onnodige" invasieve diagnostische procedures bespaard blijven dan bij het eerste model. Ook de resultaten met deze modellen moeten in een identieke populatie uit andere praktijken getoetst worden. Met enige reserve, vanwege een aantal gemiste testuitslagen, kan geconcludeerd worden dat eenvoudige laboratoriumtests geen predictieve waarde toevoegen aan de anamnese voor het uitsluiten van IBD of neoplasmata. 


\section{Opbrengst van het onderzoek}

Onderzoek in de huisartspraktijk en vooral in een "multipraktijk-setting" hee beperkingen en valkuilen (beschreven in hoofdstuk 8). Desalniettemin is dit $d$ enige manier om voor de huisarts bruikbare informatie te verkrijge betreffende predictieve waarden van symptomen in combinatie met bloedverlie per anum. Het bleek mogelijk om effectief en efficiënt onderscheid te make tussen patiënten bij wie invasief onderzoek geïndiceerd is vanwege een hog kans op darmkanker en patiënten bij wie dit niet geïndiceerd is. On vergelijkbare gegevens te verzamelen zijn ongeveer drie professionel loopbanen van huisartsen nodig.

Uit de combinatie van de resultaten van studie A en B kan afgeleid worden da in de huisartspraktijk de a priori kans op darmkanker voor patiënten me bloedverlies per anum in de leeftijd van 18-75 jaar en zonder reden voor acut verwijzing $0,8 \%$ ( 9 per 1200 ) zal zijn.

In studie $\mathrm{A}$ is deze kans $3,3 \%$ en betreft een groep patiënten die waarschijnlijl vaker een beslissingsprobleem voor de huisarts vormt. Patiënten met eviden onschuldige aandoeningen werden immers vaak niet in de studie opgenomer terwijl dit waarschijnlijk nauwelijks het geval was voor patiënten mel darmkanker.

De internistische polikliniekpopulatie is een geselecteerde populatie waarbij de preselectie mede door regionale omstandigheden bepaald is. De bevindingen zijn daarom niet representatief voor verwezen patiënten met bloedverlies per anum in het algemeen. Opvallend is dat in de verwezen populatie van deze studie de a priori kans op darmkanker (3\%) erg laag is. De evaluatie van additionele gegevens verzameld in het Academisch Ziekenhuis Maastricht (de grootste leverancier voor studie C: $50 \%$ van de totale studiepopulatie), bestaande uit een retrospectieve analyse van patiënten met maligne colorectale tumoren en een analyse van endoscopiegegevens, leidt tot de conclusie dat in onze regio internisten relatief weinig patiënten zien met darmkanker die voldoen aan de studiecriteria. Er werd aangetoond dat het zelfs in de verwezen populatie mogelijk is op basis van anamnestische gegevens een subpopulatie te identificeren die een zeer kleine kans heeft op een ernstige darmaandoening. Aanbevolen wordt om in de toekomst het onderscheidend vermogen van de gepresenteerde modellen in identieke populaties uit andere praktijken te toetsen. 
Onderzoek binnen een populatie ouder dan 75 jaar zal waarschijnlijk resulteren in een hogere a priori kans op darmkanker (en tevens op poliepen en diverticulose) dan in onze populatie en informatie kunnen verschaffen over de voorspellende waarden van de diverse variabelen in de oudere populatie. Verder zou het interessant zijn om verschillen in predictieve waarde van symptomen en bevindingen tussen een huisartsenpopulatie en een omvangrijkere 'verwezen populatie' te evalueren.

Ook wordt aanbevolen de diagnostische waarde van proctoscopie voor gebruik in de huisartspraktijk verder te onderzoeken. Het aantonen van anale en rectale oorzaken van bloedverlies in combinatie met andere symptomen en bevindingen kan bijdragen aan meer effectieve en efficiënte diagnostische strategieën.

Evenzeer is het aanbevelingswaardig verschillen in interpretaties van symptomen tussen gezonde mensen, patiënten en artsen te analyseren ter bevordering van zowel adequate en gerichte bevolkings- en patiëntenvoorlichting als het onderwijs an medici.

Tenslotte zouden de resultaten van ons onderzoek kunnen bijdragen aan de ontwikkeling van criteria voor de aanvraag van (al dan niet uitgebreid) diagnostisch onderzoek en criteria voor verwijzing van patienten met bloedverlies per anum. 


\section{Dankwoord}

Op deze plaats een woord van dank aan de mensen die aan dit onderzoek hebben bijgedragen en degenen die mij anderszins hebben gesteund.

Dr. Jon Vismans, internist, heeft destijds een aanzet voor deze studie gegeven. Van zijn eerste projectaanvraag (interface project) heb ik dankbaar gebruik gemaakt.

Zonder de bereidwilligheid en inspanningen van de artsen, de assistentes en de patiënten was dit onderzoek niet mogelijk geweest.

De volgende huisartspraktijken hebben deelgenomen: Baarlo: J Hoefnagels, G Stemkens; Bocholtz: E Mom; Born: P van Galen, J Flos; Brunssum: H Drost, D van Geel, C Hoogervorst, W Nieuwdorp, A de Nooy, A Roos, J Tullens, J van Wanrooy; Bunde: J Swaans; Eindhoven: $M$ Klomp, S van Rijn; Eijsden: $\mathrm{H}$ Ausems; Elsloo: J Boesten, H Jochems, J Koppes; St. Geertruid: H Habets; Geleen: M Dirckx, T Hellemons; Gronsveld: W Boersma; Gulpen: M Hendrickx; Heerlen: P van Aubel, P Bots, E Campman, J Dolhain, A Haas, M Hundscheid, $\mathrm{H}$ Logister $\uparrow, \mathrm{J}$ Luger $\dagger$, A Nurmohamed, A Schlösser, A Sijstermans, B van der Werf, F Zwanikken; Hoensbroek: R Brouwers, P van de Voort, F Willemsen; Horn: G Saes; Hulsberg: C Kroes, J Nijhof; Kerkrade: E Hubbers, F Soomers; Maastricht: R Croughs, J Dejong, R Heijnen, R de Jong, Th Krebber, R Lauw, A Leenen, J Meijers, P Muyrers, L Nicolai, C Phaff, H Reinink, J van Rooij, J Theunissen, $P$ Vaissier, F Verhaegh, R van Well, P Wielders, G Wolfs, R Zonneveld, J Zuidweg, V Zwietering; Mechelen: $\mathrm{H}$ Huyben; Mheer: $\mathrm{G}$ van Buchem; Neerbeek: $\mathrm{M}$ Muris, Y van Leeuwen; Nuth: F Donders, G Wagenaar; Obbicht: $\mathrm{M}$ Link; Roermond: P van Esser, A de Vries, G Sampers; Schin op Geul: M Huyts; Schimmert: P Aarts; Sittard: M Brassee, P Freens, E Pustjens, P Ruers; Stein: A van den Berg, C Vincentie; Tegelen: W Beurskens, $\mathrm{K}$ Bloemen, $\mathrm{T}$ Mangnus, P Nijskens; Vaals: S Gerbers, P Heynen, J Meindersma; Valkenburg: P van der Ploeg, C Straus; Venlo: H Crebolder, H van Dam, R van der Grinten, R Heida, A van Kessel, G de Koning, J Muris, J Vlek; Voerendaal: R Panhuysen, P Hulshof. 
Aan de pilotstudie namen deel: G Beusmans (Maastricht), J Boesten (Elsloo), R Ubachs (Nieuwstadt), L Nicolail (Maastricht) en huisartsen Gezondheidscentrum Withuis (Venlo).

Enkele huisartsen leverden extra inspanningen middels het zeer consequent noteren van van uitvallers c.q. weigeraars, waarbij de reden van 'niet in de studie opgenomen' werd vastgelegd: J Boesten, H Jochems, C Phaff, P Wielders en C Vincentie.

De volgende internisten en internisten in opleiding hebben geparticipeerd: Academisch Ziekenhuis Maastricht: R Brummer, C van Deursen, P Kingma, R Loffeld, J le Noble, P Pop, A Saleh, W Tan, J Vismans, R Zeyen; Maasland Ziekenhuis, Sittard/Geleen: L Bos, L Engels, B Looij; St. Josefziekenhuis, Kerkrade: J Goedhard; St. Gregorius de Grote Ziekenhuis, Brunssum: W Venekamp, J Wals.

De afdeling Klinische Chemie van het Wever Ziekenhuis te Heerlen (prof. dr. P Brombacher heeft waardevolle adviezen ten aanzien van het laboratoriumonderzoek gegeven.

Dank aan de medewerkers van de medische archieven en van de poliklinieken van bovengenoemde ziekenhuizen, die het mogelijk maakten de follow-up gegevens van de 'internisten-patiënten' te verkrijgen. Dank ook aan huisartsen die verdere follow-up gegevens van deze "internisten-patiënten" verstrekt hebben.

Het medisch archief $\mathrm{van}$ het azM heeft extra diensten verleend ter verkrijging van gegevens betreffende patiënten met "maligne colorectale tumoren" van zowel internisten als chirurgen.

Dankzij Rob Adang, internist in opleiding, was het mogelijk te beschikken over gegevens betreffende patiënten die een endoscopie van de onderste tractus digestivus hebben ondergaan. 
Sommige mensen hielpen in meer praktische zin: Mevr. G Wijnands en medewerkers van de afdeling Data-entry van het MEMIC; mevr. P Lemaire, de VAX-operator; Trudie Seegers en Paula Rinkens hebben beiden, in noodgevallen, geholpen bij de dataverwerking; Yvonne Daemen en Anjes Schreurs, boden kortdurend secretariële hulp, Mariëlle van Rijn, Caroline Gortemakers en Hilda Grooters, waren ijverige wetenschapsstagiaires; David Warndorff en Brenda Swaak hielpen bij de vertaling van twee hoofdstukken in het engels; Bob Wilkinson heeft uiteindelijk correcties op het engels taalgebruik van het hele manuscript verzorgd.

De medewerkers van het Diagnostisch Coördinerend Centrum (DCC) Maastricht leverden op velerlei wijze steun en werkplezier.

Isi Vos-Loverix, secretaresse DCC, heeft in momenten van nood en tijdens de laatste afwerkingsfase hand en span diensten verleend. Dankzij haar ijver en nauwgezetheid is de lay-out van de inhoud van dit manuscript tot stand gekomen.

Ron Winkens, je deur van je werkkamer stond vaak voor mij open. Voor de gedachten-wisselingen en je commentaar op de voorlaatste versie van dit manuscript ben ik je dankbaar.

De projectgroep "Bloedverlies per anum": Geert Blijham (hoogleraar Oncologie), André Knottnerus (hoogleraar Huisartsgeneeskunde), Jean Muris (huisarts-onderzoeker), Peter Pop (hoogleraar Transmurale Geneeskundige Zorg, coördinator DCC), Richard Starmans (huisarts-onderzoeker), Hubert Schouten (statisticus), dank ik voor de goede samenwerking.

Jos Hamers en Tonnie Kleynen zijn achtereenvolgens research-assistent geweest. Hun dagelijkse ondersteuning op de werkvloer was onmisbaar.

Pieter Leffers (epidemioloog) will ik bedanken voor zijn commentaar op de vragenlijsten en belangrijke adviezen in de beginfase van dit project.

Een speciaal woord van dank aan Dr. Theo Krebber, huisarts te Maastricht, die met zijn enthiousiasme en ervaring een belangrijke bijdrage aan de complementaire studie (studie B) heeft geleverd, Door zijn toedoen werden 11 huisartsen in Maastricht bereid gevonden kortdurend intensief te participeren. 
Van drie mensen heb ik bijzonder veel geleerd:

Peter Pop, jouw inzet ter verbetering van rationele diagnostiek en samenwerking tussen huisartsen en specialisten zijn voor mij steeds een inspirerend voorbeeld geweest.

André Knottnerus, je was een stimulerende leermeester en tevens een sublieme begeleider.

Geert Blijham, je stond aan de wieg van mijn onderzoekersbestaan. Jouw aanwezigheid, humor en wijsheid hebben me veel goed gedaan.

Tenslotte ben ik een ieder dank verschuldigd die mij gedurende deze rit heeft bijgestaan.

Mijn ouders die het mij mogelijk maakten te studeren. Overige familieleden en vrienden, jullie boden de broodnodige afleiding en ontspanning. De vriendschap met verschillende mensen is voor mij op verschillende momenten van grote waarde geweest. Enkelen wil ik hier noemen: Herman Muller, Marjo Boumans en Leon Laeven, Anja Wijckmans en René Erckens, Yvonne Winants, Agnes Jonkman, Christine Rouneau, Gène Janssen, Gianluigi Passerini (multo grazie Gigi) en Piet Portegijs.

Het is een bekend gegeven dat de vrouw van een promovendus offers brengt. Jan, ik had je eenzelfde lot als partner van een promovenda willen besparen. Te vaak ging dit werk ten koste van onze spaarzame tijd samen. De manier waarop je me steunde waardeer ik zeer. 


\section{Curriculum vitae}

Gerda Fijten was born on November $1{ }^{\text {st }}$, 1957 in Maasbracht, the Netherlands. A miller's daughter and the third child of five, she grew up in the village Born. She finished her secondary education, Gymnasium beta, at the Serviam Lyceum in Sittard in 1976. In 1977 she matriculated ("propaedeuse") in Psychology in Tilburg. She studied Medicine at the University of Limburg in Maastricht, where she graduated in 1983. In 1984 she completed her general practitioner training at the University of Limburg. From 1985 to 1986 she attended the one-year Research Training for General Practitioners at the same University.

From September 1986 until September 1992 she worked as a general practitioner investigator at the Diagnostic Coordinating Centre Maastricht, where she carried out the study presented here. Since 1992 she has participated in the SGO (Stimuleringsprogramma Gezondheidszorg Onderzoek/ Health Services Research) Core Training for General Practitioners at the Department of General Practice of the University of Limburg.

In the period from 1983 to 1992 she was also part-time general practitioner in several practices, rural and urban, in the Netherlands. Since 1987 she has been involved in postgraduate education for general practitioners as a member of the WDH (Werkgroep Deskundigheidsbevordering Huisartsen). Since 1991 she has been a member of the Board of the European General Practice Research Workshop (EGPRW). 
Appendix

I. Doctor's form, study A and study C

II. Laboratory tests

III. Patient's form

IV. Doctor's form, study B

V. Variables in relation to the several diagnoses 
Appendix 1. Doctor"s form, study A

\title{
Diagnostisch Centrum Rijksuniversiteit Limburg
}

\author{
Onderzoek
}

BUIKKLACHTEN

Artsenformulier

Artsnr.:

PBRSOMULIA:

War Voond BrTteres:

CREDORTRDATUN 
Kartnr.

$1.1 \quad 5$

Artenr.

1. I. 1 7.

$1 / 129$

$1.1 .110-12$

(deze klachten perlode):

sinds:

REHAITE HET WAALTIJDEN:

$$
\begin{array}{ll}
\text { - hongerpijn } & \text { nee/ja } \\
\text { - na het eten erger nee/ja } & \text { nee/ja } \\
\text { - anders } &
\end{array}
$$$$
\text { - na het eten erger nee/ja }
$$$$
\text { nee/ja, nl. }
$$

NACANELIJTE RIJNEW:

nee/ja

UTTSTRALING :

nee/ja flank/rug/bovenbeen

$\begin{array}{ll}1 & 13 \\ 11 & 14\end{array}$

$115-16$

$1 \leq 1 \quad-17$

PHats van pijn:

$\square \mathrm{n}, v_{i}, \mathrm{t}$.

$\square$ rond navel

$\square$ rechts boven

$\square$ aldden boven

$\square]$ links boven

E rechts onder

D links onder

$\square$ midden onder

VERERGERDAE PACTOREA:

- voorover butken nee/ja

- Mgen

nere/ $j a$

- andiere

nee/ja nl.

TRACrus (deze klachtenperiode)

\section{Bet Itust}

Hisselifk

Bloed braken

opboeren

Gelelatht

GEYTCAT:

ONILASTIMG:

[ gevtyzigd defaecatiepatroon, $\mathrm{dl}$.

$\square$ bloed per anum

- $11 \mathrm{j}$ per anua

$$
\text { loze aandrang }
$$

HICTIE AFUIJKEND:

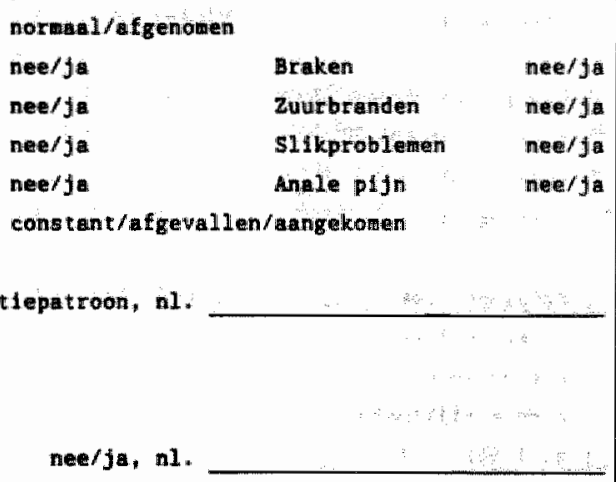

1.126

$1.127 \quad 1,128$

1. $29: \quad 1.130$

$1.32 \quad 1,12$

1.1 $33 \quad 1.34$

1.15

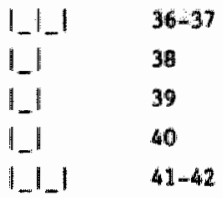




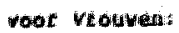

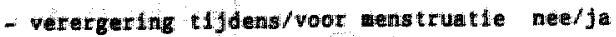

1143

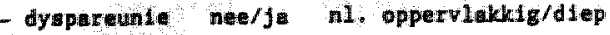

$111 \quad 44-45$

- vrvloed me ma

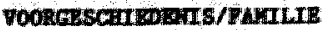

- bakend at bulkandoening nee/ fa. nil.

- bulkoperettes neerja: nil.

- butkandoeningen in fawille

neerja, nl.

- earder blowdverlites per anum nee/je

- undere releviante gegevens

\section{PSTCRO SOCHALS MUALESE}

- werkprobliemen onbekend/nee/ja

- relatleprobleiben onbekend/nee/ja

- andere relevante problewen nee/ja, nl.

\begin{tabular}{|c|c|c|}
\hline REDTCANGaifin & nee/ja nl. & $\therefore$ \\
\hline $\begin{array}{l}\text { ROKEN } \\
\text { MCOHOL }\end{array}$ & $\begin{array}{l}\text { nee/ ja nl. } \\
\text { nee/ja nl. }\end{array}$ & $\begin{array}{l}\text { per dag } \\
\text { per dag }\end{array}$ \\
\hline
\end{tabular}

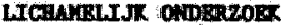

Sclerae, conjunctl vae

Stenting

t normaal / bileek / rood / greel

: normad / angetig / depressief

BUIKOHDERZOER:
- Inspectie

- percussde

$\square$ opgezet
$\square$ idt tekens nd.

$\square$ andere, mil.

$\square$ geen afuljkingen

[ niet verricht

- avsultatie

$\square$ rustige periscalt tek

0 hyper preristalitek

$\square$ andere, nl.

D niet werricht
Q dempingen (abn.) ni. Local1satile:

[ vergote lever

$\square$ percusste pijn

$\square$ geen afvijkingen

$\square$ niet verricht
$1-1$

I I 65

$1--1$

$9-60$

I-I

$61-62$

$1 I_{-}$

$63-6.4$

$I^{-}$

$1-1$

$\mid 1$ I_

$68-69$

$70-71$

$\|$

72

$1 \ldots 113-74$

$11: 75$

1 1_1 76.77 


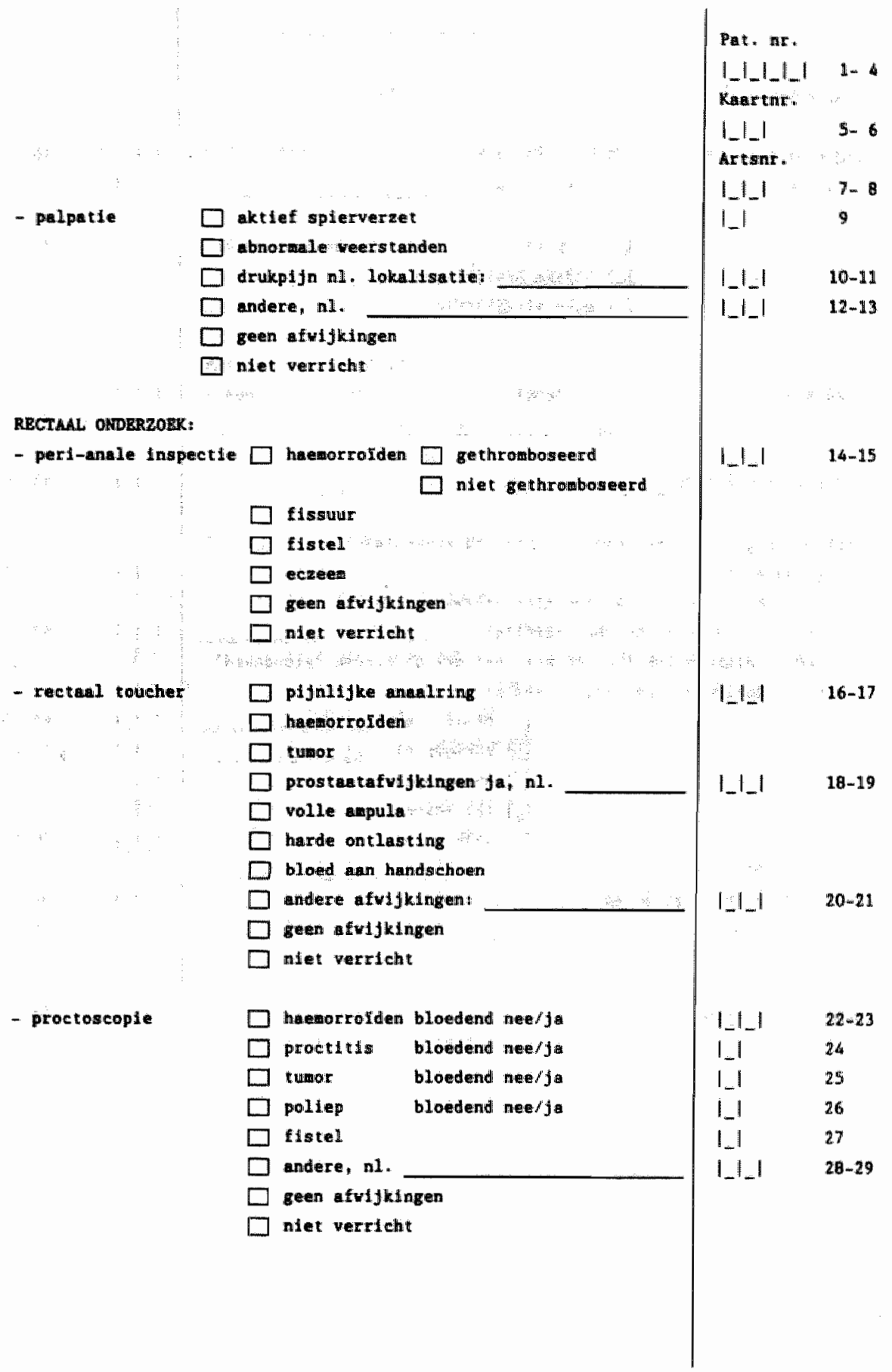


Dook reow ant

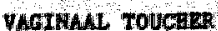

- utinasus niet werricht

vergroot nil.

$\square$ drukpifn

$\square$ andere afvijkingen

] gen afviflkingen
.
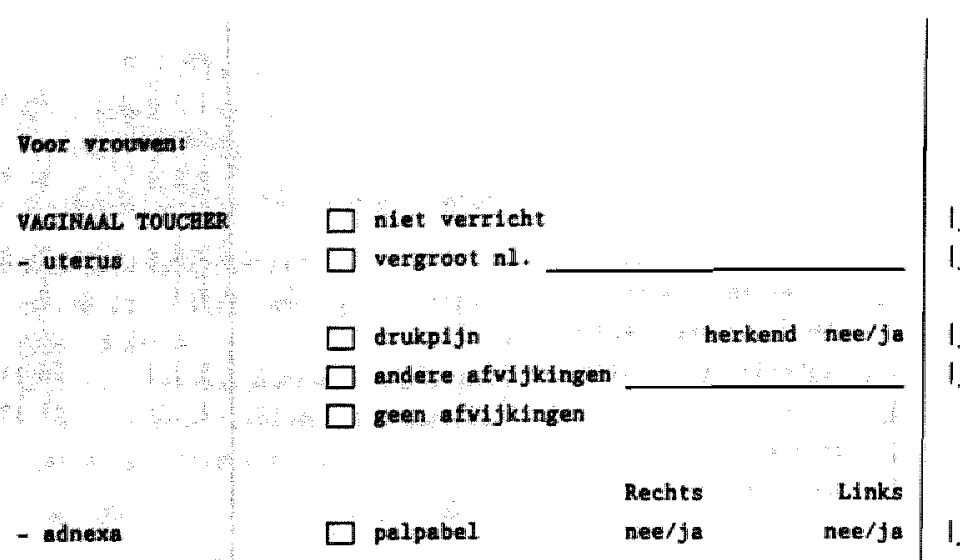

\section{VoOnLOPICS DLCONSE}

plpabel
I_I

I. I_ I

I_I

I.I.

33

34-35

$36-37$

ILI I

Limks

nee/ja

BRLBID (desgevenat meer dan fén antwoord ankiulisen)

\section{[ Eerustgesteld}

$\square$ terugkowen als de klechten miet atnewen

$\square$ coritrole-consult, op velk terwifn?

$\square$ nadere diagnostiek (butiten het voor dit onderzack "standaard" IaboratorIu-onderzoek), te veten:

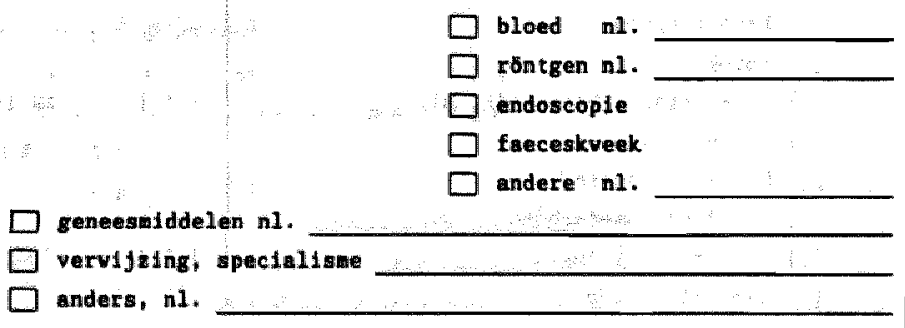

\begin{tabular}{|c|c|}
\hline $1 I_{-} \mid$ & $44-45$ \\
\hline$|1| 1 \mid$ & $46-47$ \\
\hline I.1 & 48 \\
\hline I_ & 49 \\
\hline I_I_I & $50-51$ \\
\hline $1 \_1$ & $52-53$ \\
\hline $1.1 \ldots$ & $54-55$ \\
\hline $1,1 \ldots$ & $56-57$ \\
\hline
\end{tabular}

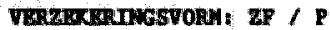


Appendix II. Laboratory test

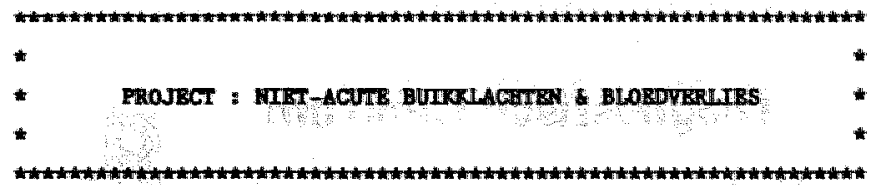

\section{Pattint}

Arts

Geboortedatur

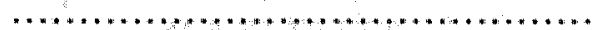

Geslacht

Datum consult

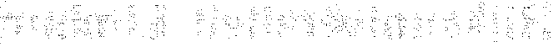

Pat. nx.

$1 \ldots 1 \ldots 1 \ldots 1-4$

Kartar.

$|-| \mid$

5- 6

Artsnr.

$1=1.1$ 7-8

$9 \quad 14$

|_l_l_l_l_l_

1115

1621

$1-1,1 \ldots 1 \ldots 1$

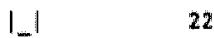

23

28

Da tum laboratorium onderzoelk

I_LI_LI_LIII I

$\mathrm{BSE}$

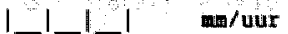

$1 / 11$

$29-31$

Aspect

1. $\mathrm{g} \cdot \mathrm{b}$.

I_I

2. gesluterd

3. ........ (0.a. geel)

$1 \ldots 1 \ldots 1 \quad 33-35$

the

$1 \ldots 1 \ldots 1 \quad \operatorname{mog} 1 / 1$

at

$1 \ldots+11 / 1$

I_I_I 36-38

Ery's

$1-1 \ldots 1 \quad 39-41$

wev

$1+1+1$ II

HCH

$1 \ldots 1 \ldots 1 \quad$ fmol

NCEIC

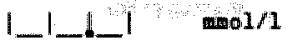

Leuco's

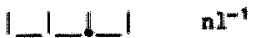

$1.1101 \quad 42-44$

$1 \ldots 1 \ldots 1 \quad 45-47$

$1 \ldots 1.1 \quad 48-50$

$1 l_{-} \|_{-} \mid$

Decultbloed le keer nes. - pos.

$1 \ldots 1$

2e keer neg. - pos.

3e keer meg. - pos.

$1+1 \quad 55$

$1.1 \quad 56$ 
Appendix III. Patient's form

\title{
Diagnostisch Centrum \\ Rijksuniversiteit Limburg
}

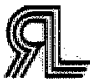

\author{
Onderzoek
}

BUIKKLACHTEN

\author{
Vragenlijst
}

Stempel arts:

BgRsonalla:

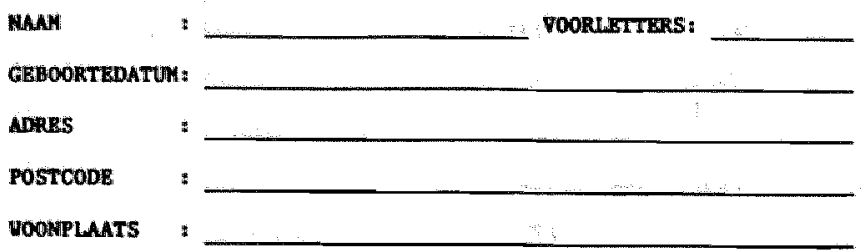


Geachte Hevrouw, Wij aheer,

Bij Uw zojulst afgelegde bezoek an de arts kvaw 0.6. ter sprake, dat U last had van buthlachten of bloed bij de ontlasting.

Aan de Rifksuniverstrelt Limburs en thet Dignostisch centrum Mastrich wordt vetenschappelij|k onderzoek getlaan naar deze klachten. 0ok vy arts woet mee an dit onderzoek.

Het doel van dit onderzoek is Ww arts in de toekows te helpen bIf het behandelen van deze klachten. Wf vragen dazvoor UN medeverking.

v zult werken dat onze wragend1jst lang 1 . Vele vragen stellen wl om vetenschappelithe redenen, niet ofdat ve vervachten dat leand daarvan nu extra veel last heeft. Somige vragen zullen al door Uw arts gesteld zijn. Toch vragen vif $U$ on ze nog en keer schriftelljk te beantuoorden. Mocht U het woetllfk vinden deze vragen te beantvoorden, dan kun $U$ abin urts of de assistente vragen $U$ histif te helpen.

Van Uv arts krijgen ve, nadat $U$ Uw toesteming voor deelname aan het onderzoek gegeven hebt, de resultaten tan het Ilchamelljk onderzoel laborator Ium-onderzoek en de uiteindelljke dIagnoge.

Uv gegevens vallen onder het mediach geheln.

VIf zullen ze zorgruldig ververken, varbij ow nasa en andere persoonlifke gegevens gehetw biljwen roor but tenstanders.

Oa het verloop van $\mathrm{Ww}$ klachten te vervolgen vilien vij over gen $\mathbf{j a a r}$ nog eens contact wet $u$ opnemen.

Net vriendelijke groet, ande namens the arts

Digmost Isch Centrum Misisticht, A f kusun iversit telt Limburg Wevr. Drs. G. Fitten, hidedis Drs. J. Murls, hulsarts Drs. R. Starmans, arts 


\section{TORLICATIN:}

- Sehriff alleen in het gedeelte links van de vertikale $14 \mathrm{j} n$. De kolom rechts van de pagfina Is nodig woor de verwerking. MIIt $U$ bler niet sehrifiven.

- Probeer alle vigaten te beantwoorden, behalve vannever is aangegeven dat U cen antal. vragen woet overslaan wet blfroorbeeld "ga door narar vragg $20^{m}$.

- Beantwoord de vragen In de aangegeven volgorde, dan kunt 0 geen vragen vergeteri.

- 4 kunt kilezen ut de voorgedrukte antwoorden; slechts fén keuze woge 1 th, tenz 11 anders angegeven vordt.

- Geef het door II gekozen antwoord aan door het exbijt behorende holkje wet cifferr an te krulsen.

Noorbield Dafa

2. nee

- Irdien er een 1 Ifn achter een door $U$ gekozen antwoord stat kunt $U$ daniop Un antwoard toellchten.

Yoarbegeld:

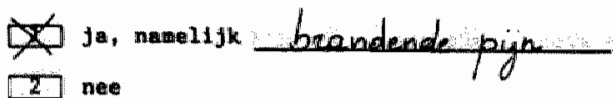

- Uw Informet wordt strikt vertrouwelifk behandeld. 


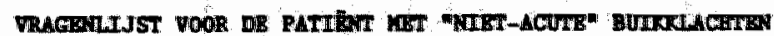

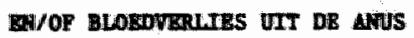

1

Algewene gegevens.

1. Vat is uw geboor tedatun?

Dag: waand:

jana:

2. Op velke datu vult I deme vragenligst in?

Dag: raend: jatr:

3. Dat is the geslacht?

D v rouw

2 man

4. Bent U:

II gehuwd of samenwomend

2] alleenstaand $n 1$ :

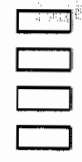

noolt gehurd of samenvonend geveest gescheiden

weduwe/veduwar

anders:

5. VRRRSITUATIE: w11t $U$ aangewen wat op $U$ van toepassing is.

(U kunt desgewenst meer dan één antwoord aankrutisen)

I Ik heb nu een valledige baan.

2] ik heb nu een part-time baan voor .. uren per veak.

3] Ik bem nu verkloos

[4 It ben met penstoen/vur

5 ik ben nu atbeidsongetchikt

$01 \mathrm{k}$ volg ean opleiding

7 Mk ben hudsan, hutis rouw

B. anders " name11jk:

6. Mat was de reden van dit bezoek aan de arta? (omschrisf Uw klachten)
Pat. mr.

$1.1-1 \ldots 1$ - $1-4$

Kaserine.

$|.| . \mid$

5. 6

Artanr.

$1.111-8$

$9 \quad 14$

$1,1 \ldots 1,1 \ldots 1$

15

$1,1,1,1 \ldots 1$

1.1

21

1

22

1.1

23

1. 1

$24-25$

IIII

26-27

1.1 .1

$20-29$

$|1$.

$30-31$

1.1

$32-33$ 
Indien $y$ geth bloedverlies ult de mus heeft gehad, doorgaan bij III vrasg 19.

Dit gedeelte gat over bloedverlies uit de anus.

7. Howlang hef $\mathrm{a}$ nu bloedwerlles wit de anus? sinds

B. If dit de eerste keer (of eerste periode) in ov leven dat $v$ bloed verllies ut de anus heeft?

$11 \mathrm{fa}$

2 nee, holang geleden voor de allereerste keer:

$11 \quad 37$

$111 \quad 38-40$

I. veet ik niet ineer

9. Makike Uf zich ongerust over het bloedverlies voordat $\mathrm{u}$ naar de hull serts kwan?

$\square$ ja, omdat

2 nee

10. Aan velke borzak dacht $U$ zelf toen t naar de arts ging?

(U kunt desgewenst meer mogelijkheden ankruisen)

I. mambelen

2 scheurtje in de anus (bv. kloofje)

3 onts teklng, darminfectle

4 uitsulpingen in de darmwand (bvi divertikels)

5 darmpoliep

6 darmkanker

10 andere dan bovengenoemde, namellth:

11. Hoe wank 18 er de lantste veken bloedverlies uft de anus geveest? (sleshts ten vakje inwullen)

Du slechts ben keer of zelden

ta keer per dag (antal inwullen)

W.. keer per week (aantal Inwilien)

0 keex per mand (aantal inwullen)

$1+1 \_1 \quad 48-50$

$1-1.1$ 1 51-53

$1 \ldots 1-1$-1 54-56

$1 \ldots 1.1 \quad 57-59$

12. Koat ex val eens bloed zonder ontlasting?

$1 \mathrm{ja}$

[2] nee 
13. Hoe Is het bloed bij de ontlasting amentg?

(meer dan één antwoord sankrúsen mag)

I het bloed at op of rondom de ontlasting

2 het bloed is verwengd wet de ontlasting

3 het bloed at op het tolletpapler

4 veet $1 \mathrm{k}$ niet

5 anders, namellyk:

14. Danneer kont bet bloed?

(weer dan één antvoora ankirutsen mag)

$\square$ vớr de ontlasting

2 Ujdens de ontliasting

3 op het einde ran de ontlasting

4 na de ontlasting

5 zonder ontlasting

6 veet ik ntet

15. Hoeveel bloedveriles is er meestal per heer?

(het best passende antwoord ankrulsen)

1 een streepje

2 enkele druppelitjes

3 een vingerhoedfe

4 een kopje

3 meer dan een kapje

16. Wat is de kleur van het bloed?

1 helder rood

2 donker rood

3 visselend helder/donker rood

17. Meeft $U$ de lantste veken ronelingen In de butlik gehad?

II doorlopend

2 ledere dag. maar niet doorlopend

[ vaak (1-5 dagen per veek)

L af en roe (ainder dan één dag per veek)

5 nooit

10. Is tw bulk de lasts te veken opgezet?

I doorlopend

2 iedere dag, maar niet doorlopend

3 vaak (1-5 tagen per week)

$\square$ af en toe (minder dan eén dag per week)

5 noost 
29. Wordt to "s achts valker we pijot

[I] (bugne elke nacht

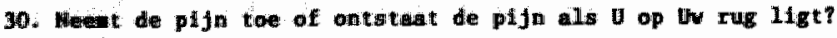

I.

2 nee

31. Weent de pign toe of ontstant de pijin al $\mathrm{U}$ op th linkerzij Migt?

Da

2 net

32. Weverit de pufn toe of ontatant de pljn als $u$ op uv rechterzis 1 gt?

II ja

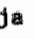

2 nete

33. Neewt de pijn toe of ontsteat de pijn vlak vófr het eten?

[1] Ja, ongeveer. . vinuten voór het eten

Le ne?

34. Weent de pljn toe of amtstant de pifn ma het eten?

DI ja, ongeveer .. Ginuten na het eten.

2 nee

35. Is koffle van invlloed op de pijn?

I de plyn ontstaat of neent toe na koffite

2] de pilfn vordt alinder of verduignt na koffie

(3) kotfie heeft geen Invloed op de plifn

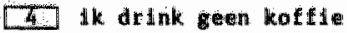

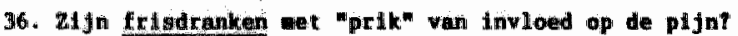

[I de pijn ontstant of neest toe na frisdranken at prik

[2 de pijn vordt inder of verdvijat na frisdranken met prik

3 frisdranken pet prik hebben geen invloed op de pijn

[4] IK drink geen frisdranken wet prik

37. Zi In nleoholhowdende dranken van invloed op de pijn?

II de pijn ontstat of neeat: toe nal alcoholhoudende dranken

[2] de pilin vordt ainder of verdwifnt no alcoholhoudende dranken 
38. 2ijin nelk of andere elkprodukten van lavloed op de pija?

I] de pijn ontstaat of neest toe as het drinker van velk

2 de pifn wordt ainder af verdulint no het drinken ven welk

[3] wellk heeft geen invloed op de plifn

4 1k drink geen welk

39. Is sterk gekruid eten van Invloed op de pifn?

1 de pifn ontstaat of neemt toe na sterk gekruid eten

2 de pijn neemt af of verdwijnt na sterk gekruid eten

3 sterk gekruid eten heeft geen Invloed op de pijn

$\square$ ik eet geen sterk gekruld eten

40. Is vet eten van invloed op de pijin?

$1]$ de pljn ontstat of neemt toe na vet eten

2 de pijn wordt minder of verdusjnt na vet eten

3 vet ten heeft geen invloed op de piln

4 ik eet geen vet eten

41. zijn koolsoorten (bv. spruitjes, vitte kool) ven invloed op de pijn?

I de pifo ontstaet of neevt toe na het eten van bepaalide koolsoorten

2 de pijn vordt minder of verduljnt na het eten van bepaalde koolsoorten

[3] het eten van koolsoorten heeft geen Invloed op de pljn

4 Ik get gen koolsoorten

42. Is "rauvkost" (bv. groenten, fruit) van Invloed op de plifnt

1 de pijn ontstaat of neemt toe ma het eten van bepalde rauwhost

2 de plijn wordt winder of verdvifnt na het eten van bepalde rauvkost

3 het eten van rauvkost heeft geen Invloed op de pijn

4 Ik eet geen raurkost

43. Zijn er undere voedingsinfiddelen varardoor de pijn in de bulk ontstant of toeneest?

I ja, nameldjk:

2 nee

44. Zijn er andere voedingsaiddelen vaardoor de pijn vernindert of verdvifnt?

D ja, nawelifk: 


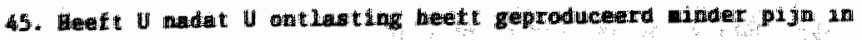
Whath bet

D ja, wat

2. Ja, soin:

X nat nooit

46. Beeft to btj het begin van de pIjn last van dunne ontlasting?

CI Ja, nestid

2] ja, sols

3 nee, moolt

47. Whet $\mathrm{U}$ bij het begin van de pijo vaker ontlasting produceren?

I. ja meestal

3 nee, noolt

48. Heeft 0 als kind bulkpijn gehad?

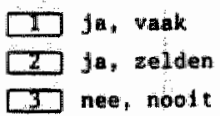

Nu volgen nog enkele vragen over ww ontlasting. Bet gat er danrbif o. onderscheid te alken tusisen de periode dat pijin of andere blachten (bv, bloedverilies, veranderde ontlasting) had en de periode dat if gén klachten had. N11t inaro belde kolomen invulien

\section{RLACIIEY PERTODB}

49. Hoe vaak heeft $U$ dan gealddeld ont lasting?

D \#k hel ... keer per dag ont lest ing

[1] heb. ". keer per verk ont lastling

50. MiJn ontlasting Is dan:

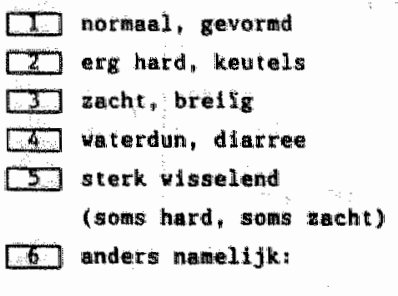

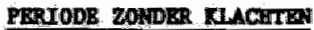

Hoe vaak heeft $U$ dan gentddelld ontlasting?

D ik heb ... keer per dag ontlasting

[2] Ik heb ... keer per reek ontlasting

1.1

71

Pat . int.

1 I_L_l_ 1 $1-4$ Kanttne.

1

5- 6

Artone.

1.1.1 $7-8$

9

10

1.1

$1-12$

1

$13-14$

|_. I.

Mign ontlasting is dan

$15-16$

17-18

I norma i, gevormd

I.I I
2 erg hard, keutels

3 zach t bres $1 \mathrm{~g}$

4 vaterdun, diarre

5. sterk wsselend

(soms hard, sows zache)

6 anders namelifk:
$19-20$

$21-22$ 
De volgende vragen gann veer over de periode dat andere klachten heeft.

51. Aankruiaen wat bIJ U voorkont

( $U$ mag desgewenst weer mogelij)kheden eankrui sen)

[I] silfo bil de ontlasting

2 slijw ult de anus zonder ontlasting

$1 \ldots 1 \ldots 1.23-25$

[3 duldelijk herkenbare voedselresten bif de ontlasting

4 pijn bij het praduceren van ontlasting

5 rowimelingen in de bulk

6 veel last van vinden laten

7 een gevoel dat nog niet alle ontlasting is als $U$ maar het tollet bent geveest

$\square$ "s nachts last van dfarree

9 het gevoel naer het tollet te moeten zonder dat er ontlasting kont

52. Heeft $U$ de lantste veken teerzyarte ontlasting gehad?

I. Ja, de laatiste maal is ... dagen geleden

2 nee (ga door met punt 7 , wraag 54)

26

$11-27-28$

I.I 29

I_l 30-31

1.1

32

1.1

$33-34$

1,1

$35-36$ 


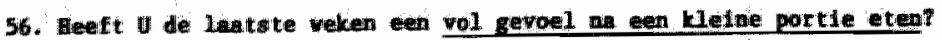

तI je

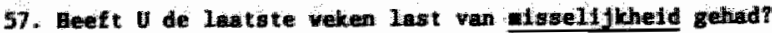

In Ja, daar heb ik wak las wan

[2] Je, daet heb ik of en woe last van

Inee

58. Heaft $\mathrm{d}$ de lagt te veken soeten overgeven (braken)?

I] Jo, dare heb Ik valk Last van

2 ja, daar heb $1 \mathrm{k}$ af en toe last van

3 nee

59. Heeft 0 oolt een aurr gevoel (of zure vloalstof) dat o-hoog kont In wo nond na het eten of drinken?

II Ja, vaak

2 ja, sows

3 noce

60. Beeft probienen wet het doorsilkken van eten of drinkent (1) kunt desgevenst weer antwoorden aankruisen)

$\square$ ja, eten blijft steken

2. ja, drinken bHoft steken

3 Ja, doet pijn

4 nee, helemal niet

5 anders namelijk:

61. Heeft I regelnatig een brandiend gevoel in de borst, achter het bore tbeen?

TI Ja, bis het eten

[2] Ja, bij bukker/11ggem

[3]

4. nee, zelden af noolt

62. Heef $U$ de lasiste veken last van opboieren?

[I] ja, waak

DI nee, nooit 
63. Heeft tu de latste veken gen gevoll of tw bull opgeret is?

T ja, vasik

2] ja, solss

64. Beeft 0 de lantste veken last van:

(meer dain én antroord invullen mas)

D. pijn bij de anus

2 jeuk bij de anus

3 een gevoel dat er jets uit de anus pullt

4 nee, ik heb geen van deze klachten

65. Voelt U zich ziek?

I ja

66. Heeft $\mathrm{U}$ zelf Uw eetgewoontes veranderd vanwege Uw klachten?

$\square$ ja, namel1jk:

2 nee

67. Hat was th gevicht 4 weken geleden en hoeveel vergt $U$ op dit mowent?

$\square$ weken geleden voog ik ongeverer ..... k110

$1-1 \quad 57-59$

$1 \ldots 1 \ldots 1 \quad 60-62$

618. Eeeft U teaperatuurverhogdmg gehad gedurende de lastste veken?

प Ja - hoevell bedroeg de temperatuur? in. $\mathrm{C}$

[3 weet ik nlet of tenperatuur niet genetun

69. Gebrulkt $\mathrm{u}$ geneesinddelen (ook zetplllem)?

(U kunt desgevenst weer antwoorden aankruisen)

I ja, mididen voor mag of darmen, naam:

[2 ja, laxeermididelen, laxeerthee, nasm

1.1. $1.1 \quad 67-68$

1.1.1 69-70

I_I I $11-72$

3 ja, antistolling (blowedverdunner) naam

1. 1.1

4. andere iniddelen,

กมอมที 
70. Wowk v atgaretten, shag pijp of algarent (U kunt desgewenst weer antwoorden ankrulsen)

I Ja, ongeverer.... stgaretren per dag

2 Ja; ongever $\ldots$ sigaren per dag

3 Ja, ongeveer ..... pljpen per dig

Hit nes

72. Hewt $\mathbf{u}$ het de Iatste weken drubler gebad den andersit

II ja

73. Heeft $\mathbf{U}$ de lawitste veken een woell Ifhe perlode doorgenabt (afgexien von U klachten) of varen er altuatles die marar op de magr lagen"?

(I)

74. Wenen de Wiachten toe blj stress of spaningea?

D Jis; navelijk bil

75. Heaft $\mathrm{U}$ wet tw huidige klachten de latste veken nilet kunnen verken? [T jai $\ldots$... verkdagen niet kuninen werken in de lastste 3 veken

1] Nerk niet

76. Heft $\mathbf{u}$ bulkoperat les onderganit

DI ja, nawelljk: (hier operaties vermelden) jaar: Jasr: 
77. Deeft ten wan on ouders wak Moulklachten" gehad?

1 Ja

2. nete

3] weet ik niet

78. Is bdy ten wan the ouders oolt bif een ondersoelk wan bulk af dareen een afvijuing gevondent?

1 ja, nawel1jk:

2] nee

3 veet ik niet

79. Heeft een of weer van th broers of zussen valk buikdiechten gehad?

[1]

1

45

2 nee

3 veet ik int

4. Ik heb geen broers of zussen (ga door met vrang al)

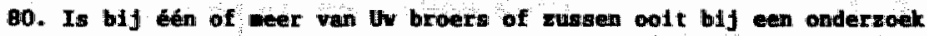
wan butk of darnen een afwiking gevonden?

I $\mathrm{ja}$, nawellyk:

1.1 $\quad 46$

2 nee

1. 1 - $\quad 47-48$

\$ weet Ik nlet

81. Heeft $\mathbf{U}$ kinderen?

I ja, hoeveel ...

2 nee, (g door met vraag 83 )

82. Is bif Gétin of neer van th indnderen oolt bif onderzoelk van butk of darsen afwijking gevonden?

1 ja, namelijk:

3] wet $1 \mathrm{k}$ niet

83. Bent $\mathrm{d}$ in het afgelopen jaar buiten Buropa of In landen anin de Hiddellandse zee geveest?

D ja, velke(e) land(en) 
111. It haud van atie.

112. Ix ba djn gowoonten gevalikelifh veranderes.

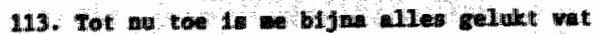
It Hide.

114. In ees groep vamon houd it ne liever op de anthererond:

15. Feranderingen ta bet veex habben velatg Itriogd op $\mathrm{dy}$.

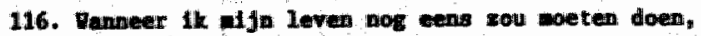
gon in het wet to dow.

117. Alleen bil wangen die ik good trem, woel ik HJ op ajn oralk.

114. Ik han in korte tIJd veel verik doen.

119. Op wadere Emaen theb ik velpis invlow.

120. Ik verk lifwer Dlean dan bet oen wantal bangen easean.

121. 41. Ik of rela sal gavin, voll ik be on tapanian.

122. Ik verk graag anel.

123. Ih beb woor veel dingen belaggratelling.

124. Ik tran goed tegew en graple.

125. As It lets wil berelkea, set: ik neestal dwor.

126. It ban evestal ergens wee besig.

127. Il beb veinig behoefte aid hontakt net andere nensen.

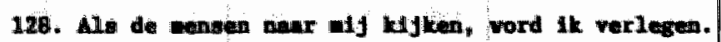

129. Ik doe wijn verk neeted at plexier.

130. Ik hav alju problemen alf wal wan.

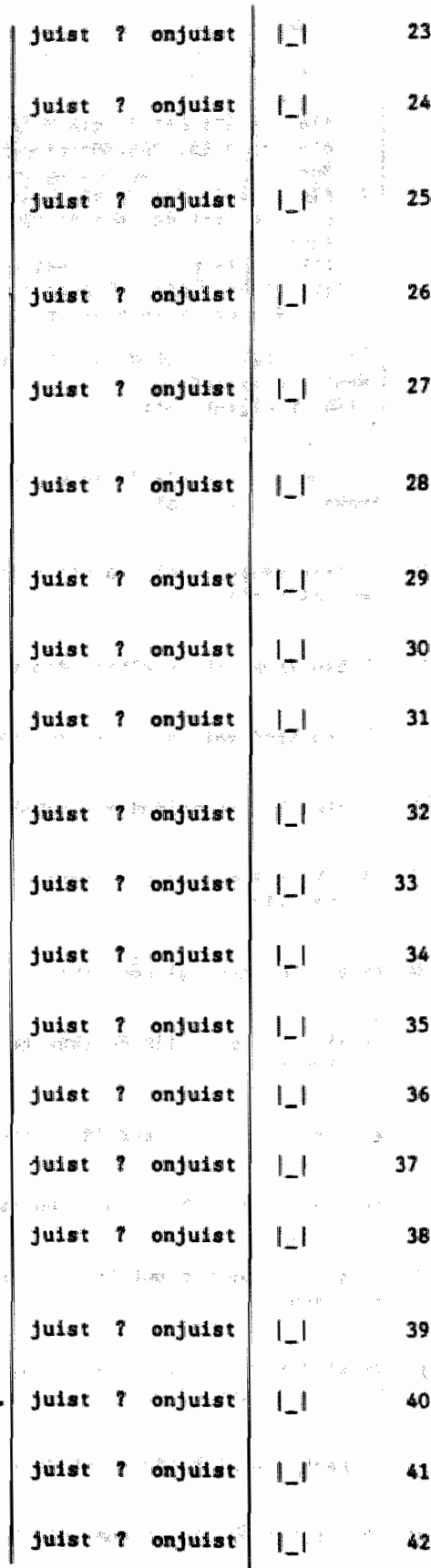




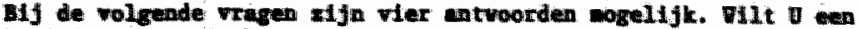
hrulaje acten in hat bokje dat op 0 van topassing is.

131. In woell ne neersiachilg en Donber.

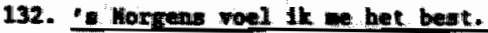

133. I. heb thullbulea of bet gevoli dat ik deder noment vel in huiler houn ult tareten.

134. Ir bab woel te eot whapes.

135. I heb evenmeel etlunt als en thde selienden.

136. Ir find kifkea noer, anen sijn of preteon cet ean avtrelvkel1jke man of roon leuk.

137. Ik heb hex pervell dat it magerder norid.

138. If hab Iast vo rerstopptar.

139. H1ju hart clopt meller din norimeil.

140. It rank pan bet allaste vernold.

141. Hifa godachtea ifo even belder lis vroeser.

142. Ik vind bet genakellyk on alles te doen vat it rroeger nolk dewd.

143. Il ben rauteloog on onsedurd

144. It bem hooprol gettend over de concosts

145. Ik ben prikkelbasarder dun Twoog IILL.

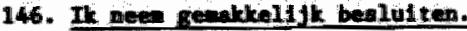

147. Ik gelloof det $1 k$ mattig on nodig bian.

148. It vind atja leven boulend.

149. Ik denk tot bet beter nou aljo ils It dood ins.

150. In doe alle gebratkellfte dingen mot net pleater.

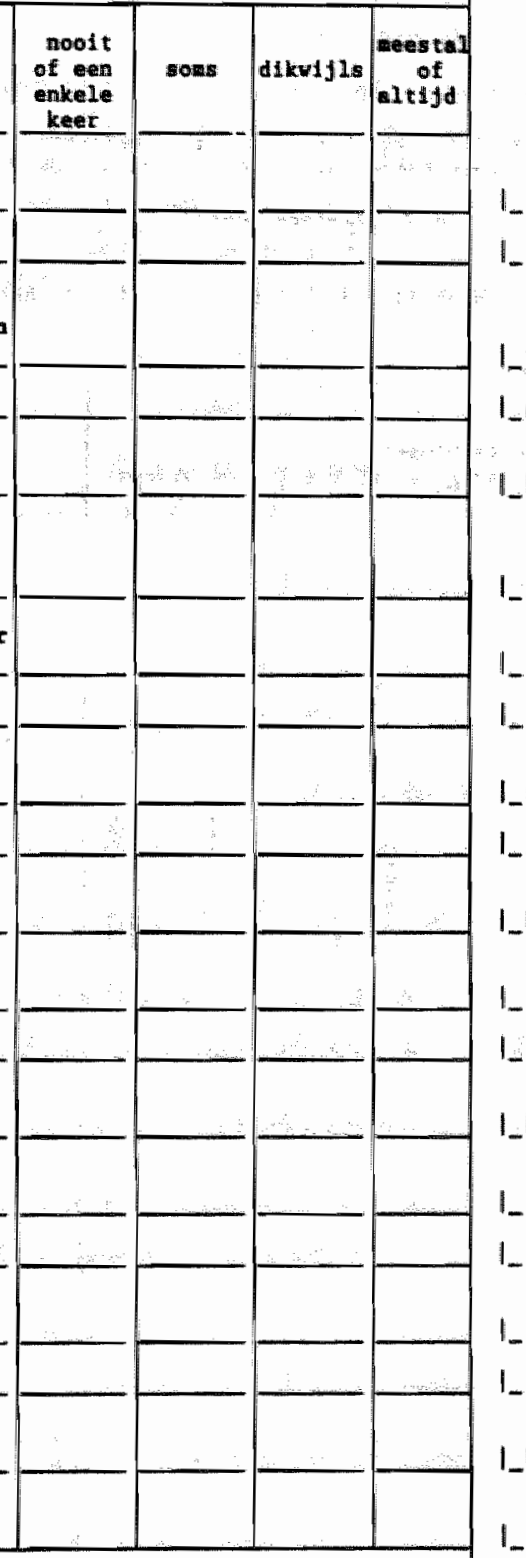


Dt we de Latgta wroug:

Befe U alle yregen beentwooth

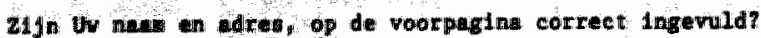

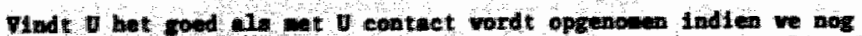

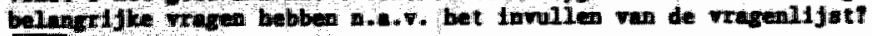
I $1 \mathrm{a}$

2o jo wat is the telefoonnumer?

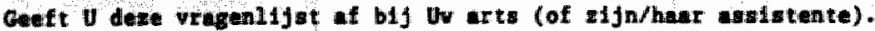

\section{Aurmitu Dun.}

Rulate voor opmerkingen

(werweidt to nodls hat numar van de vrang): 


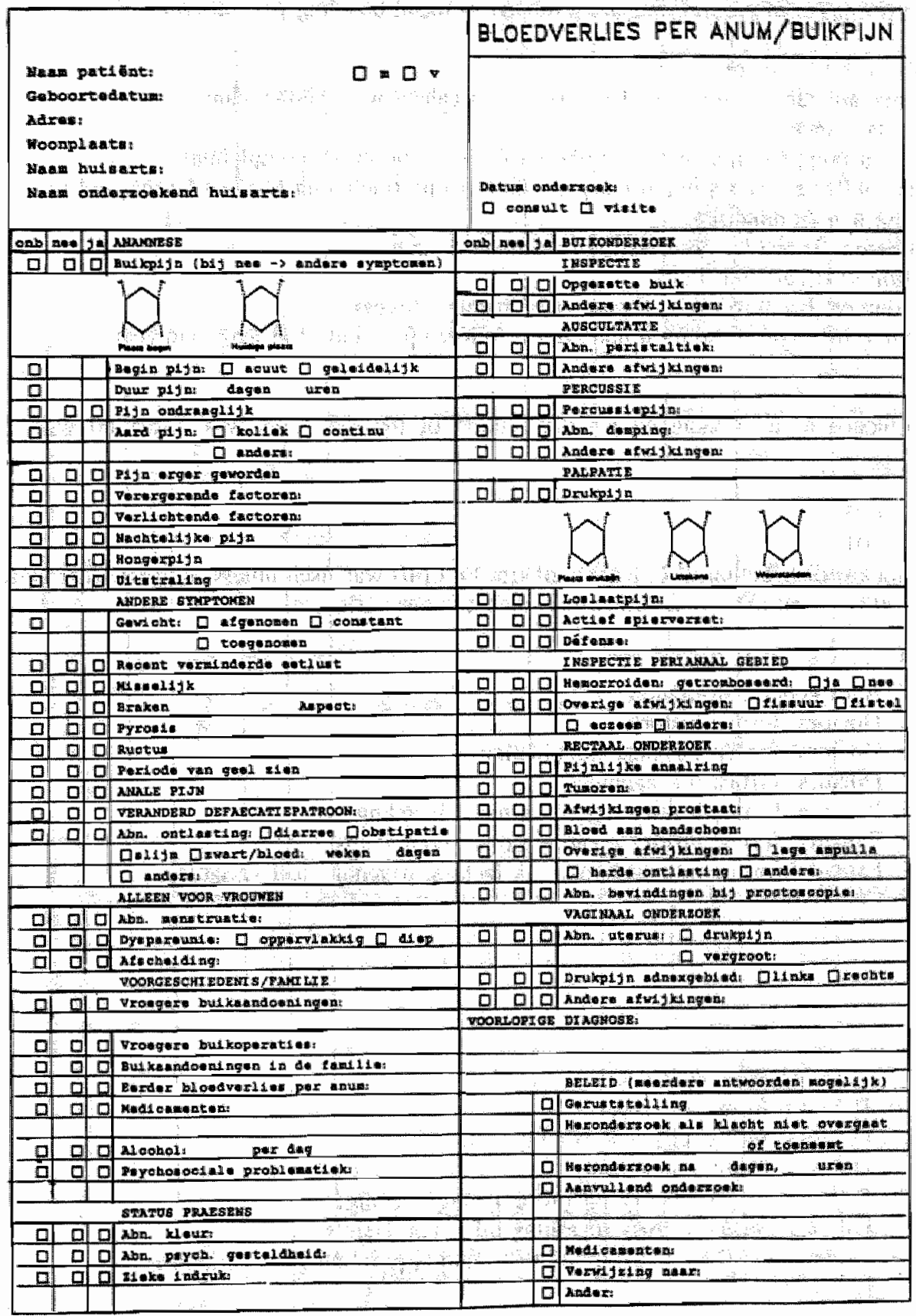




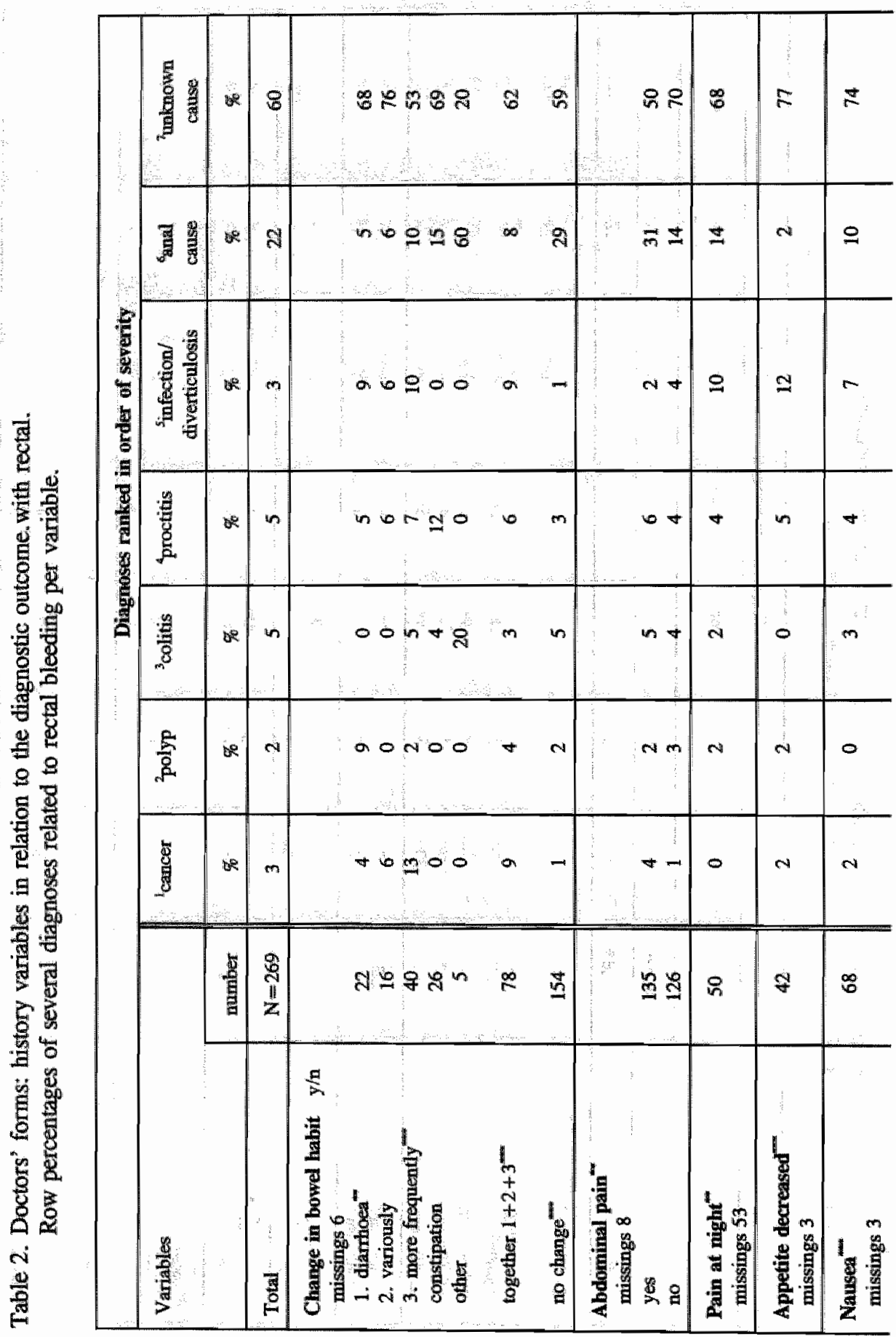




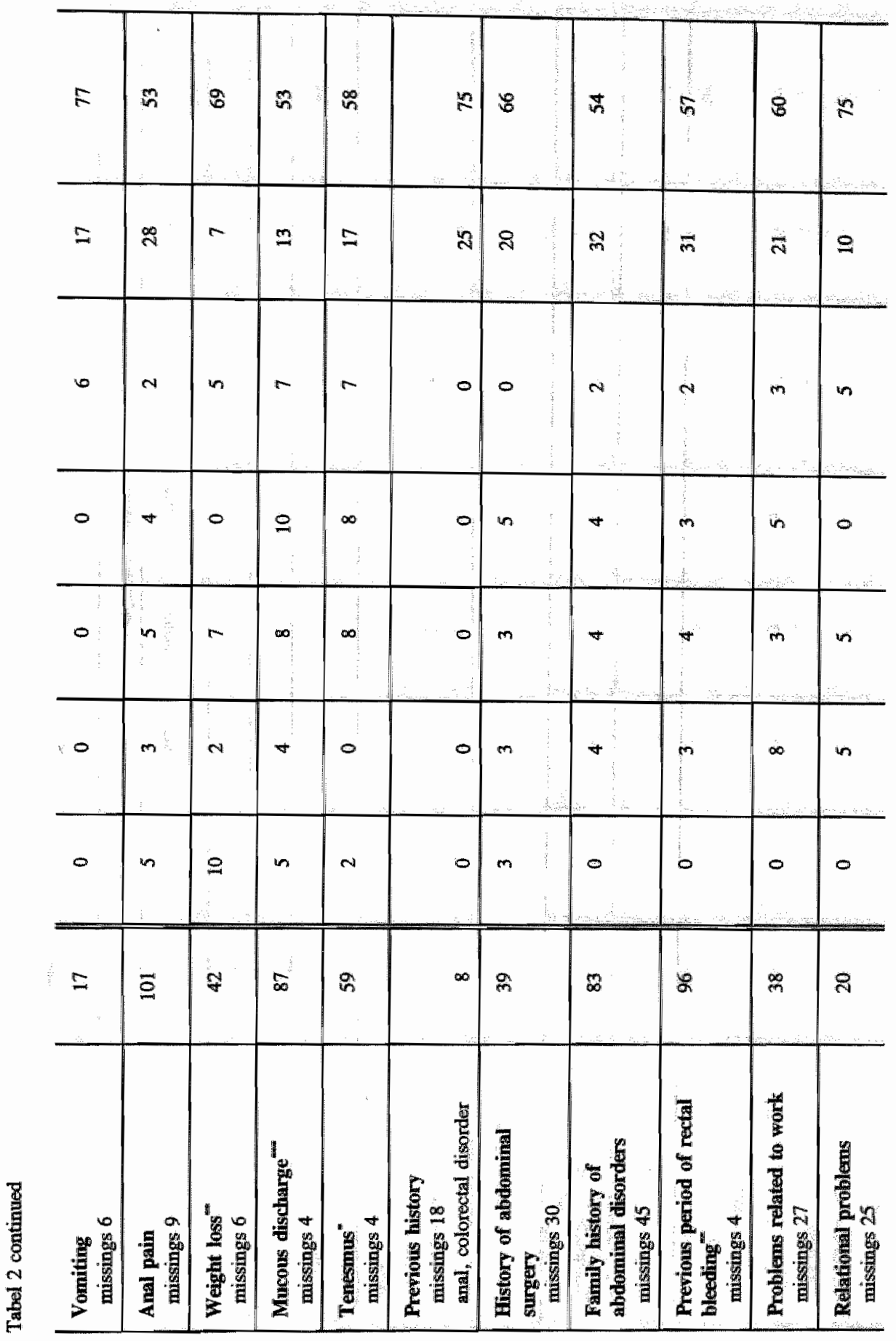




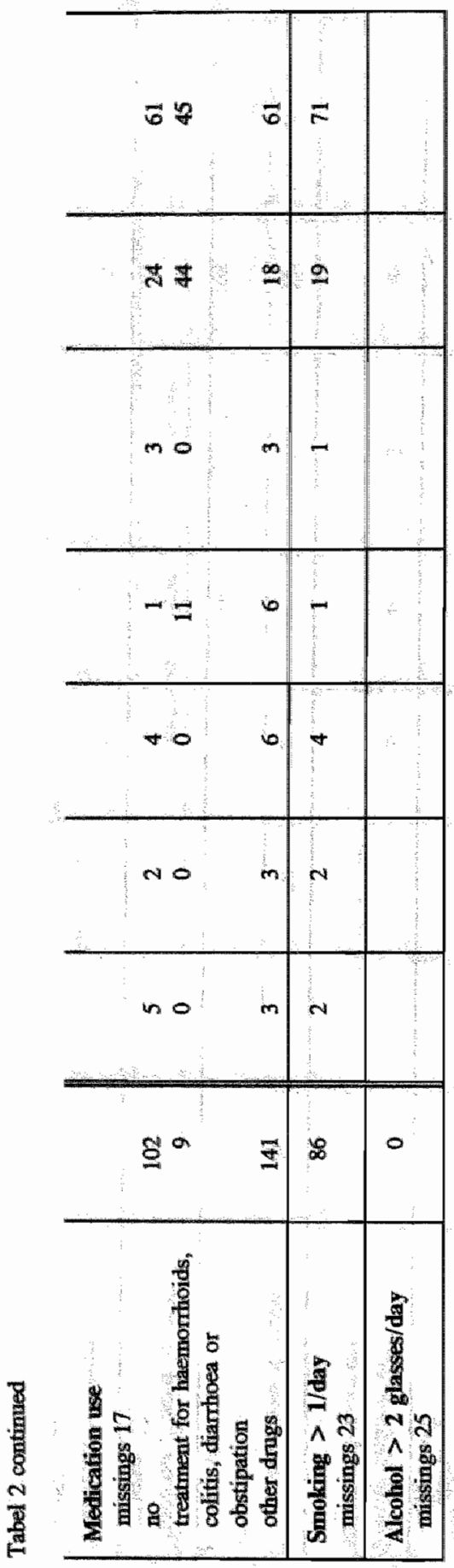




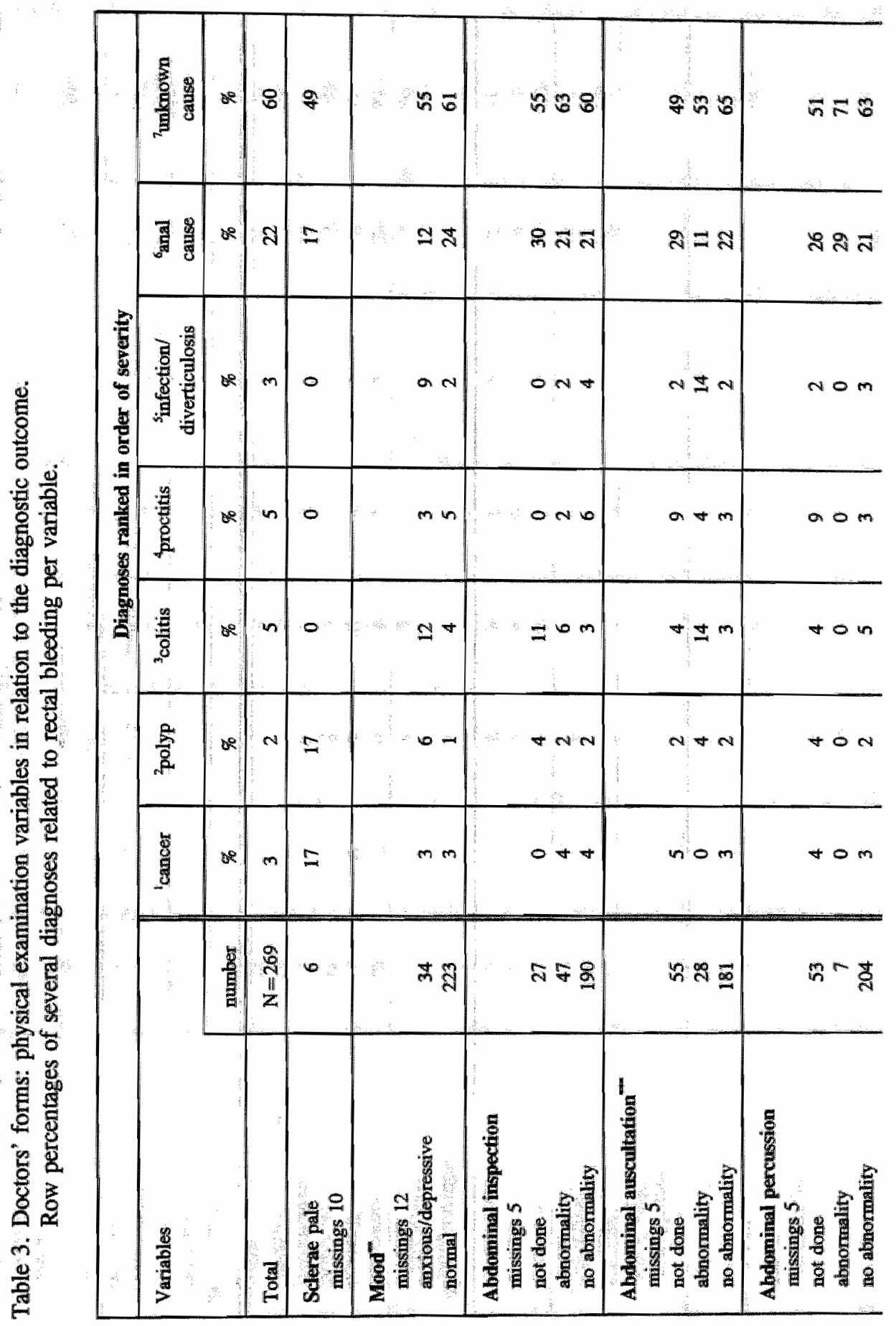




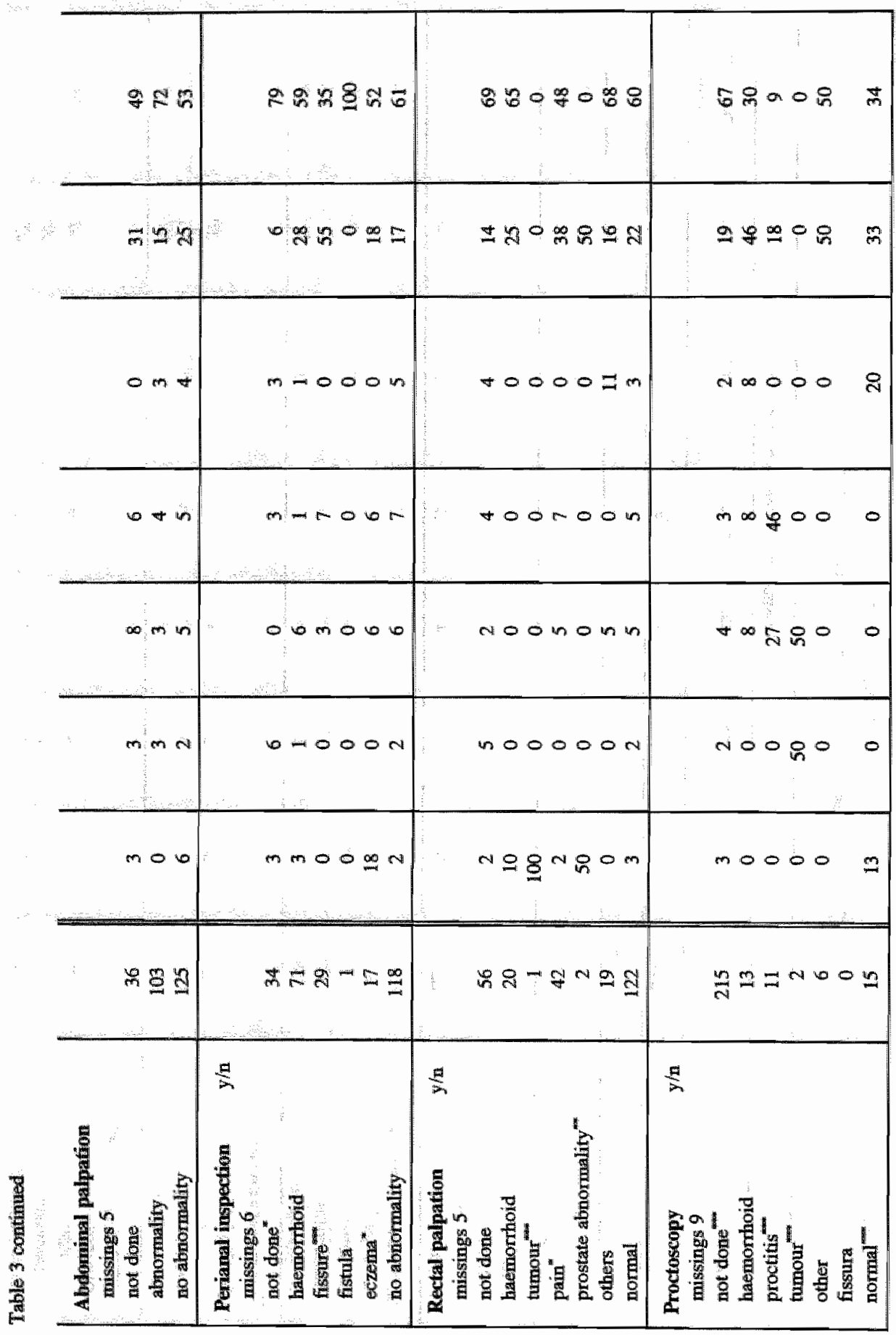




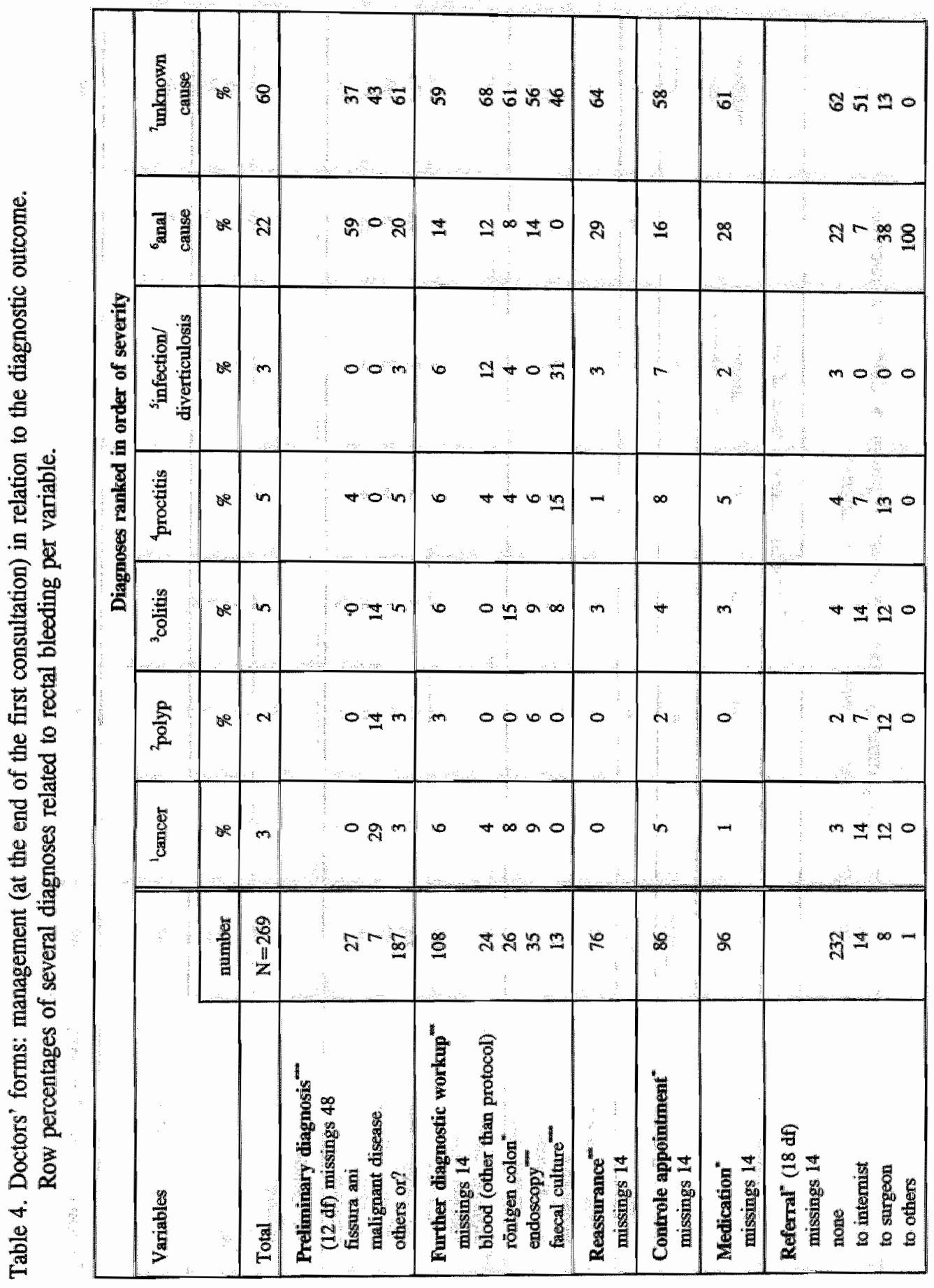




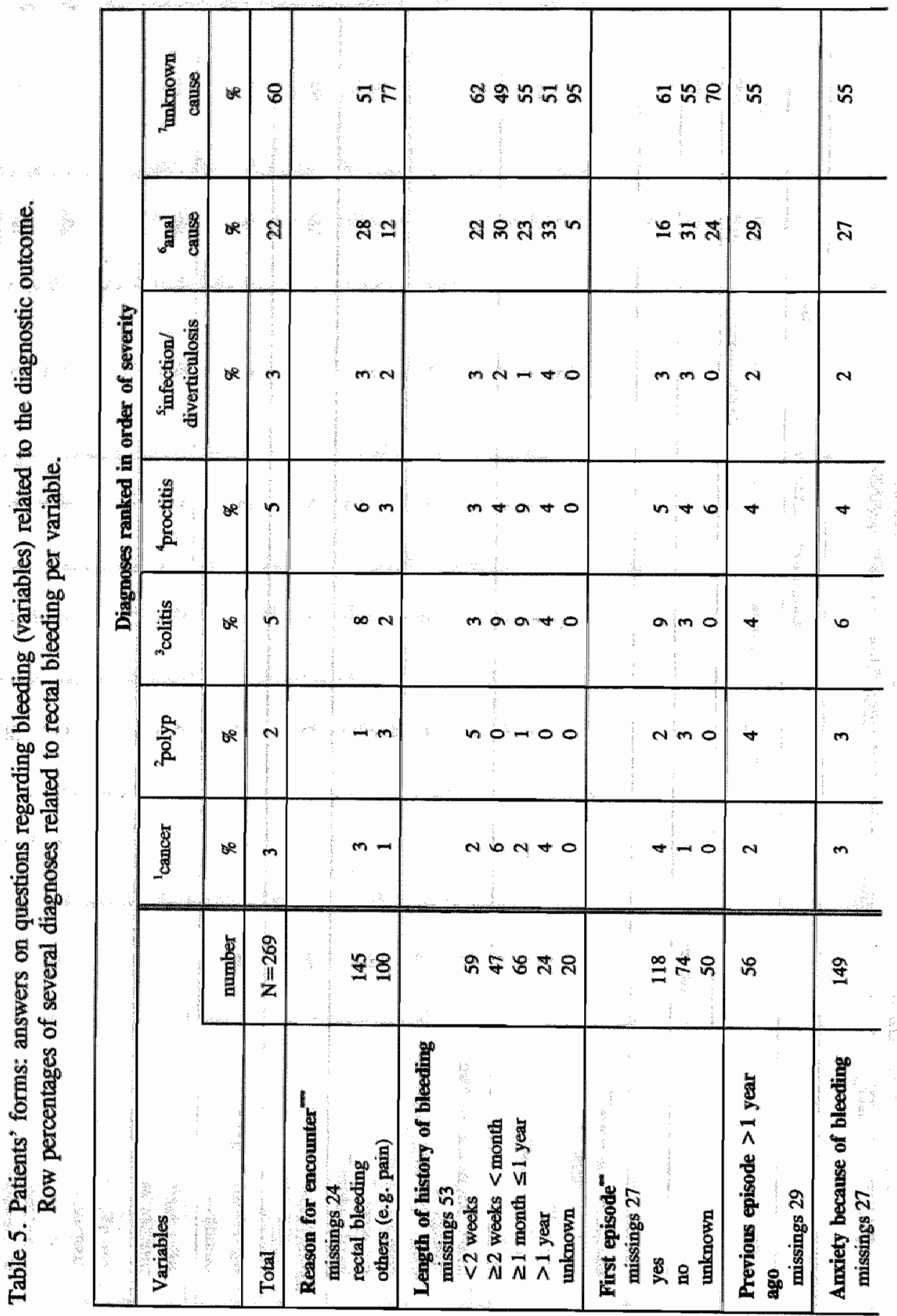




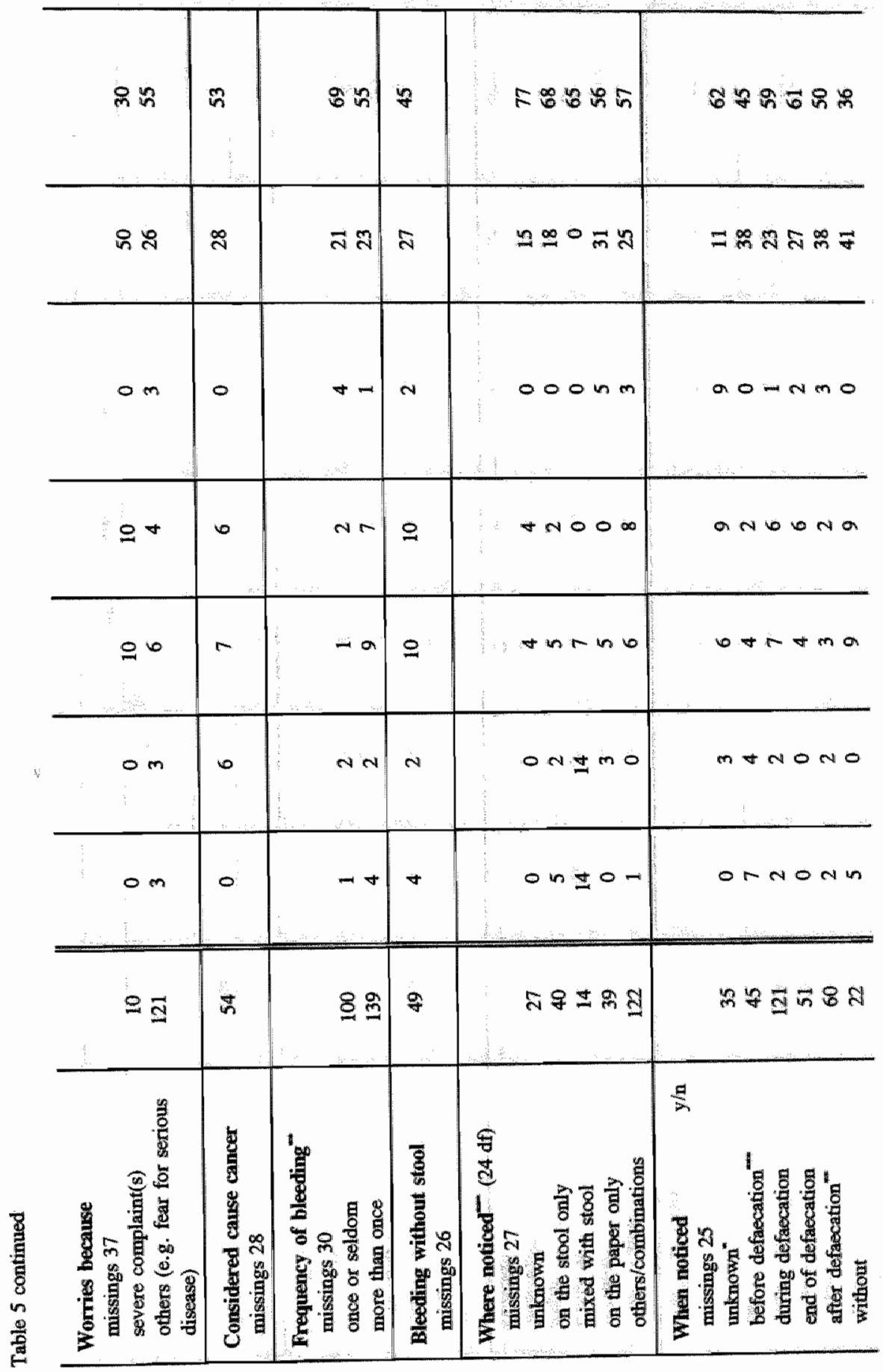




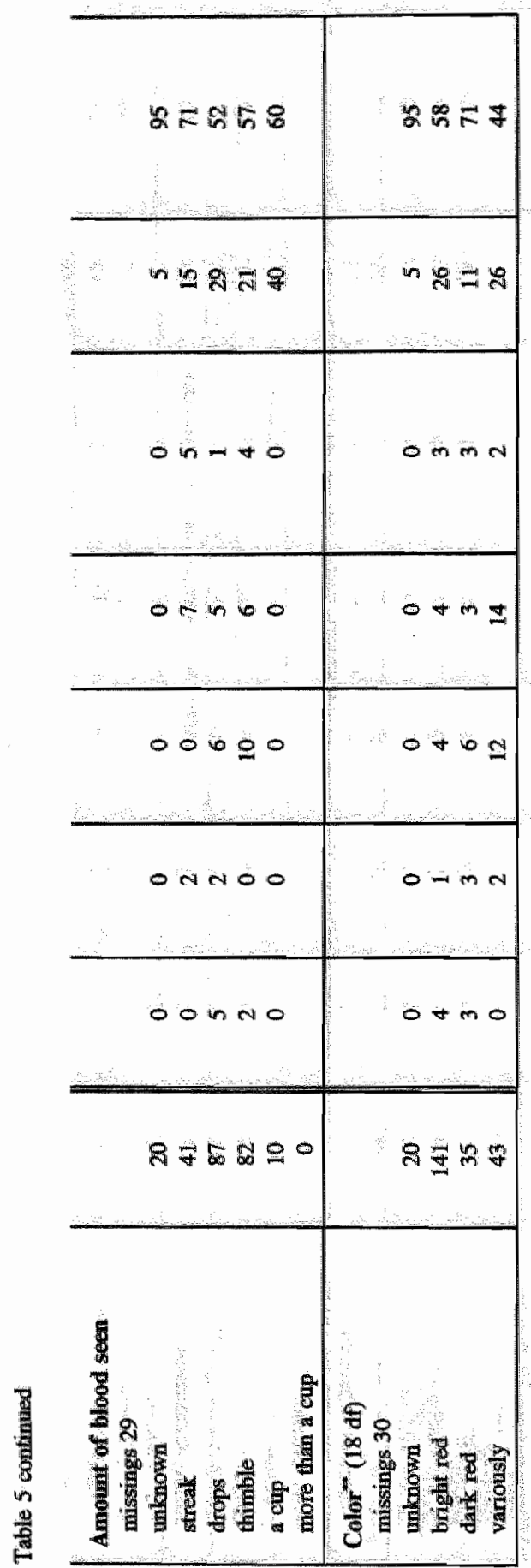




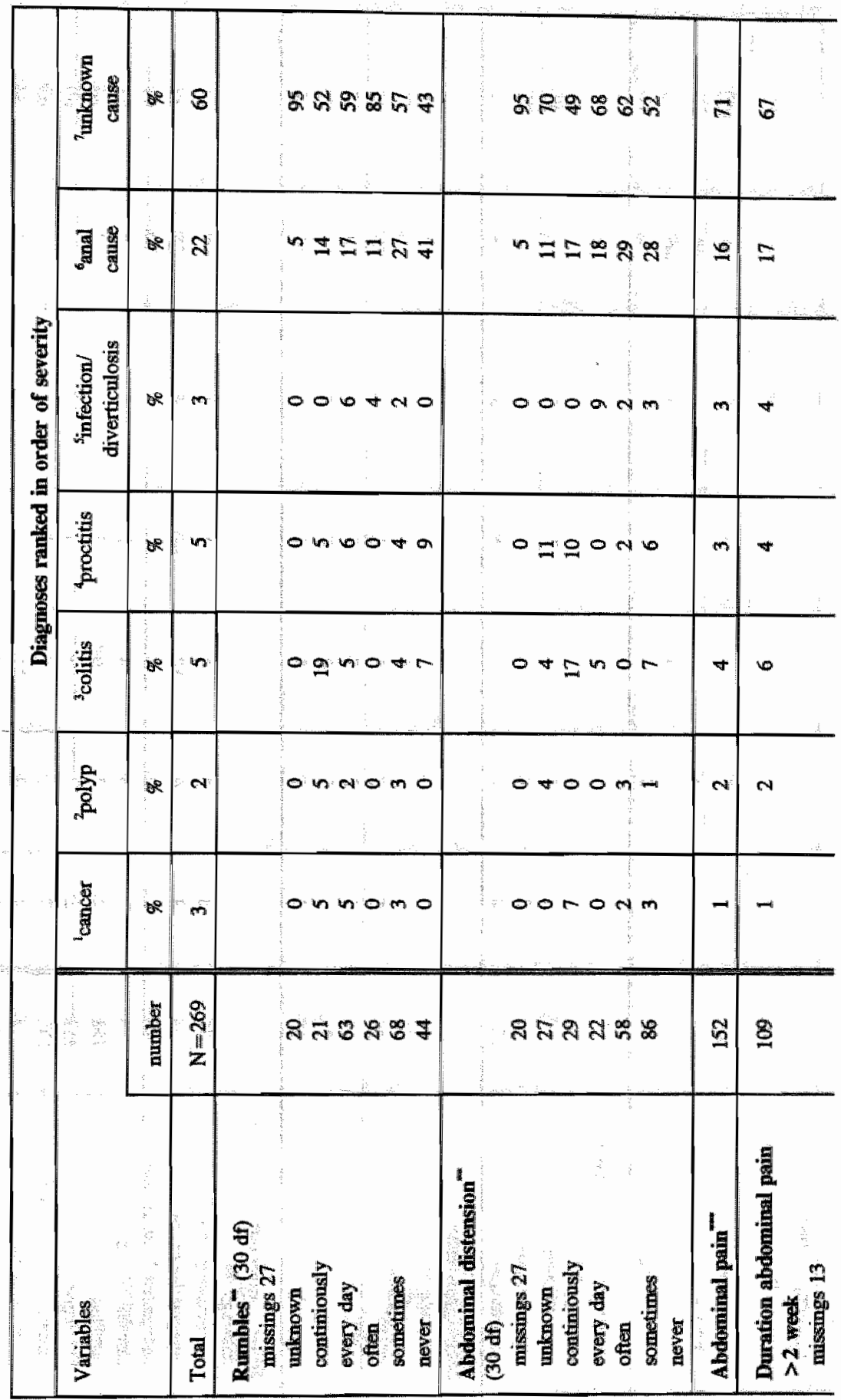




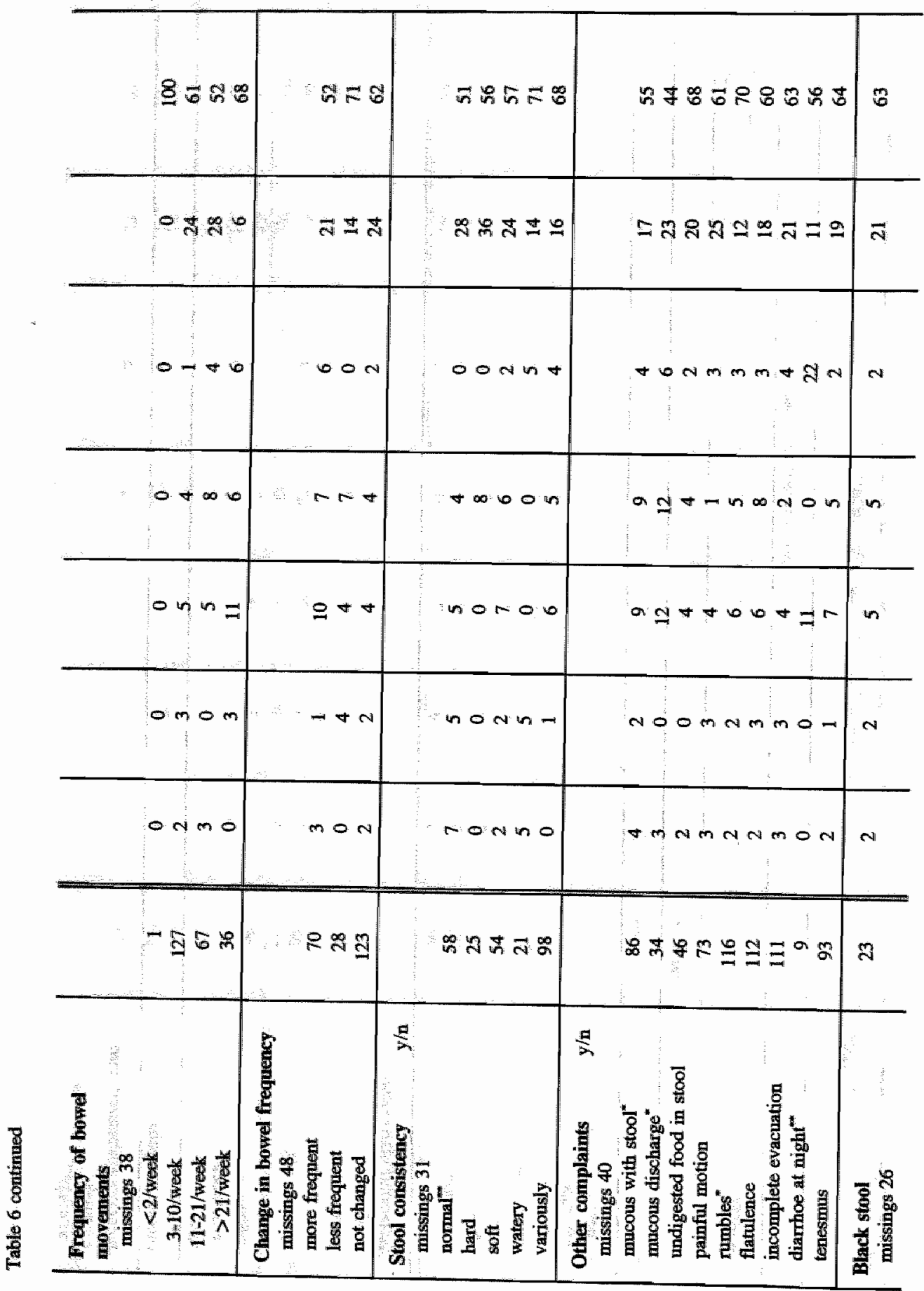




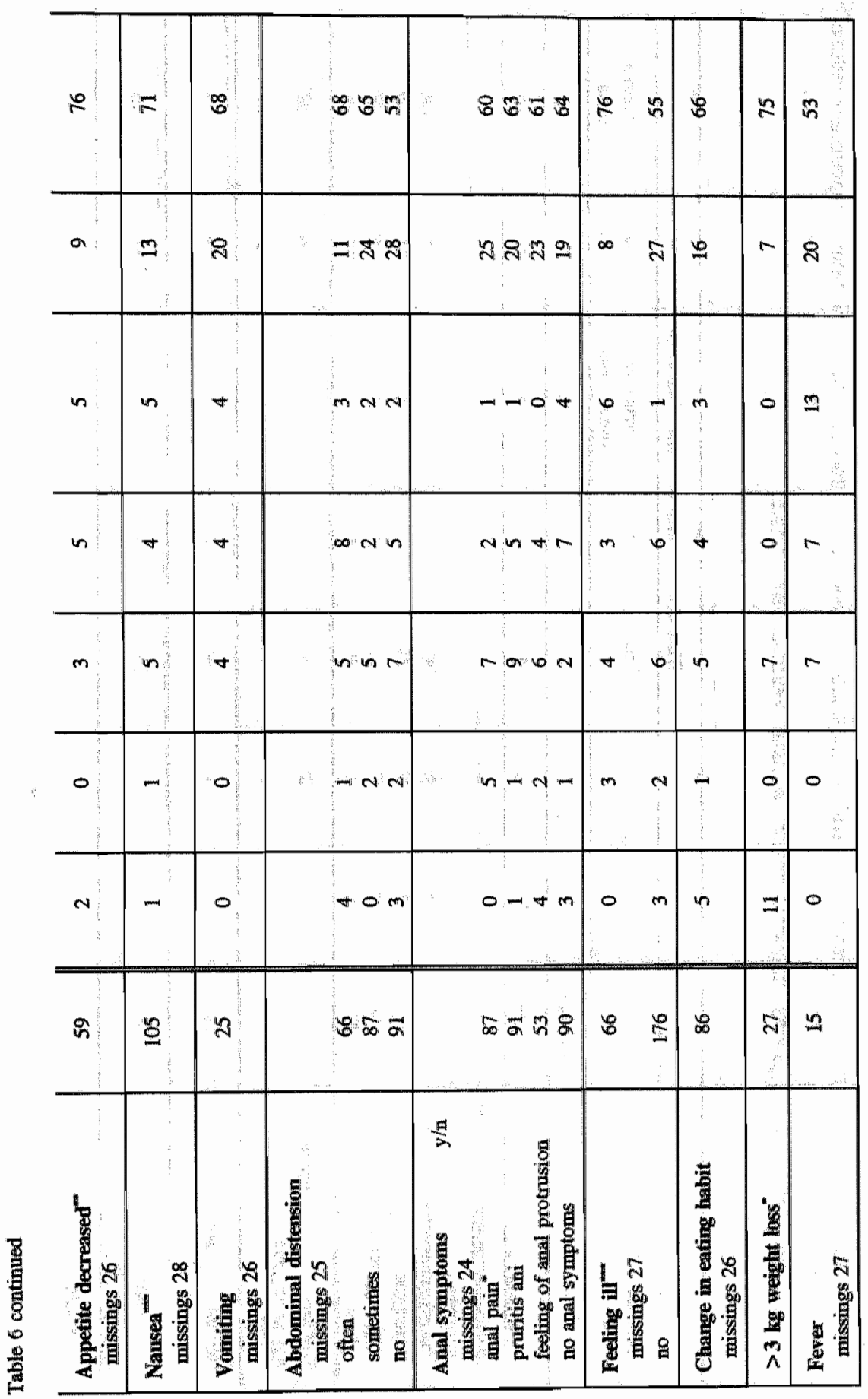




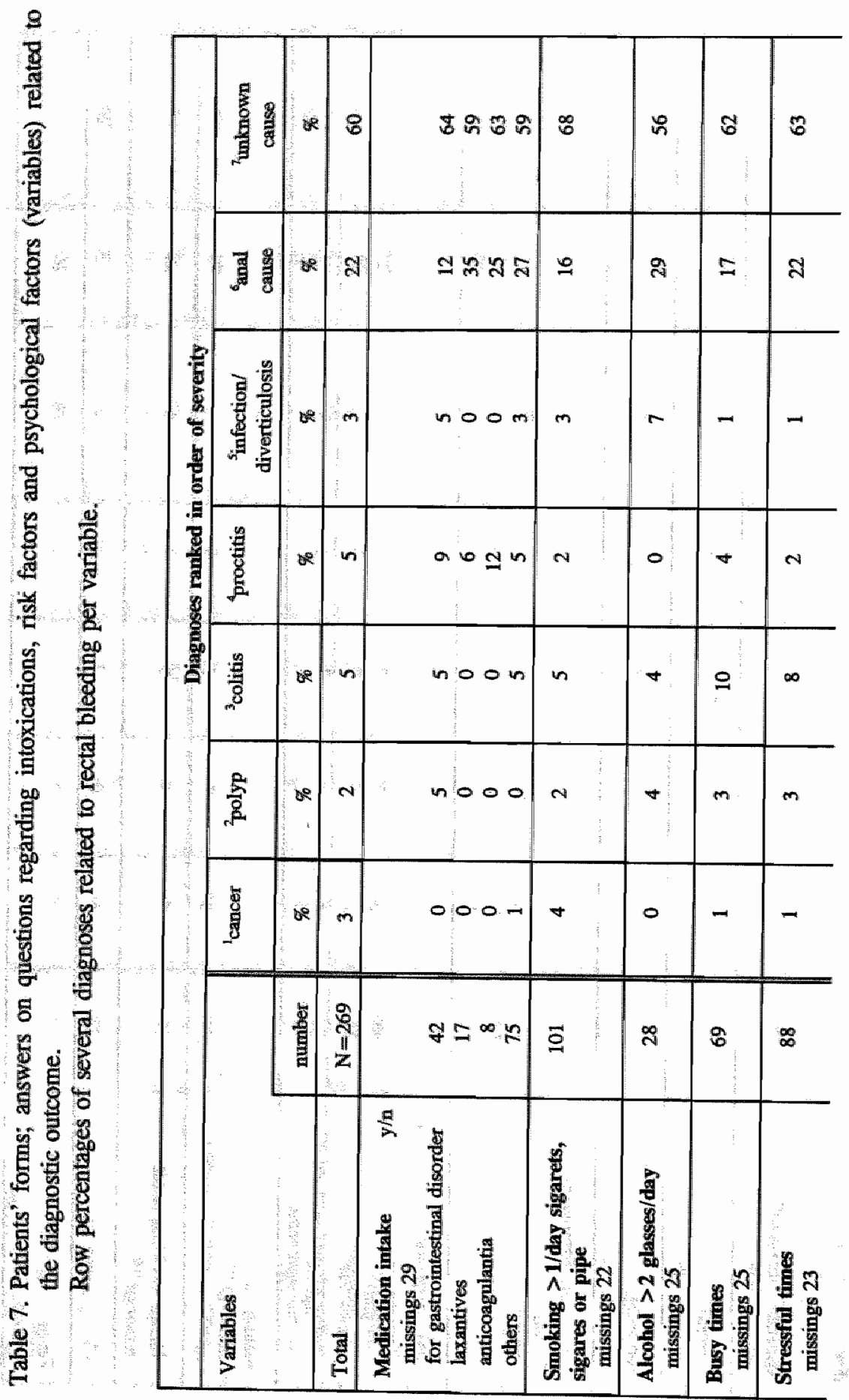




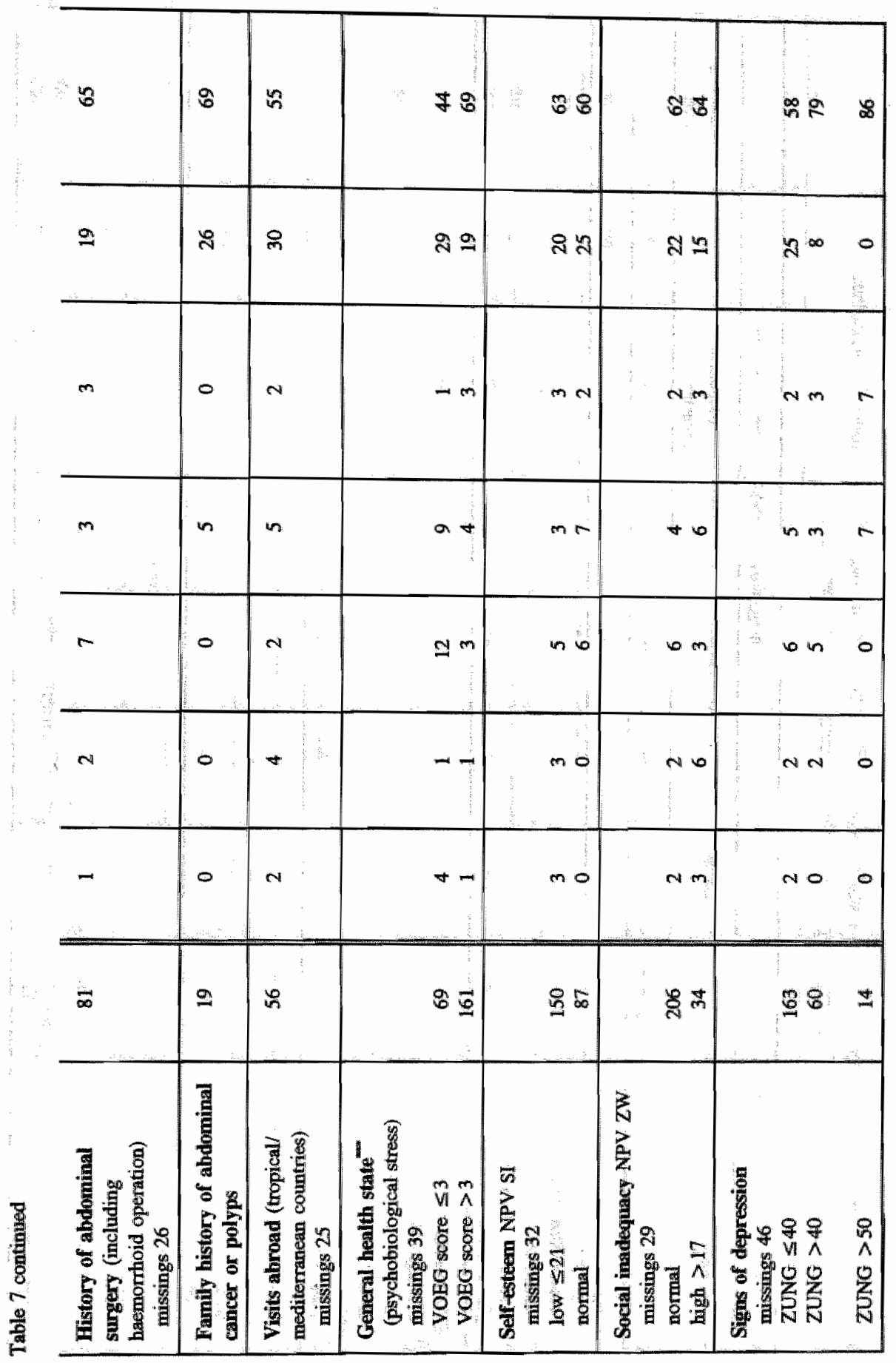




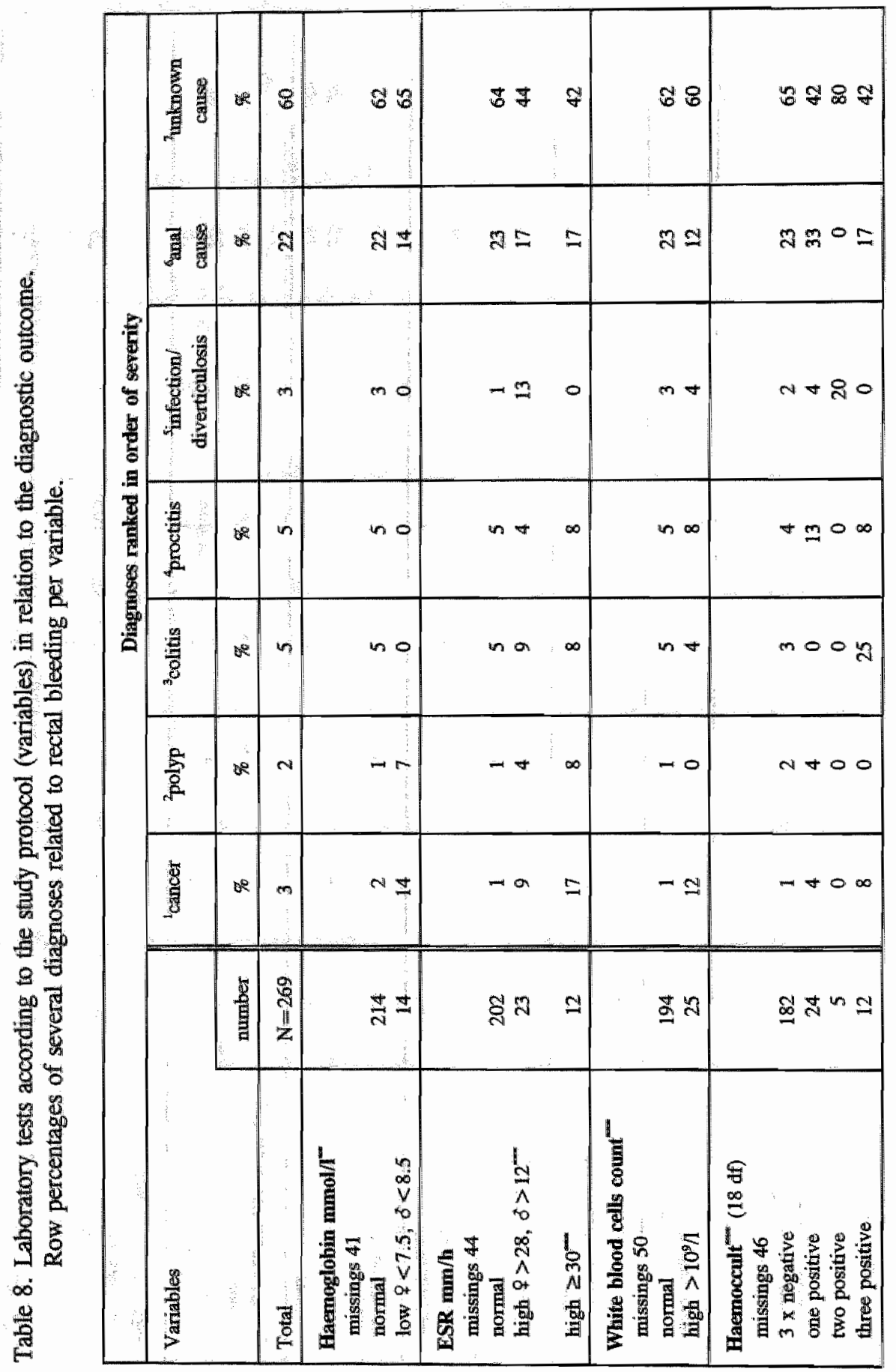




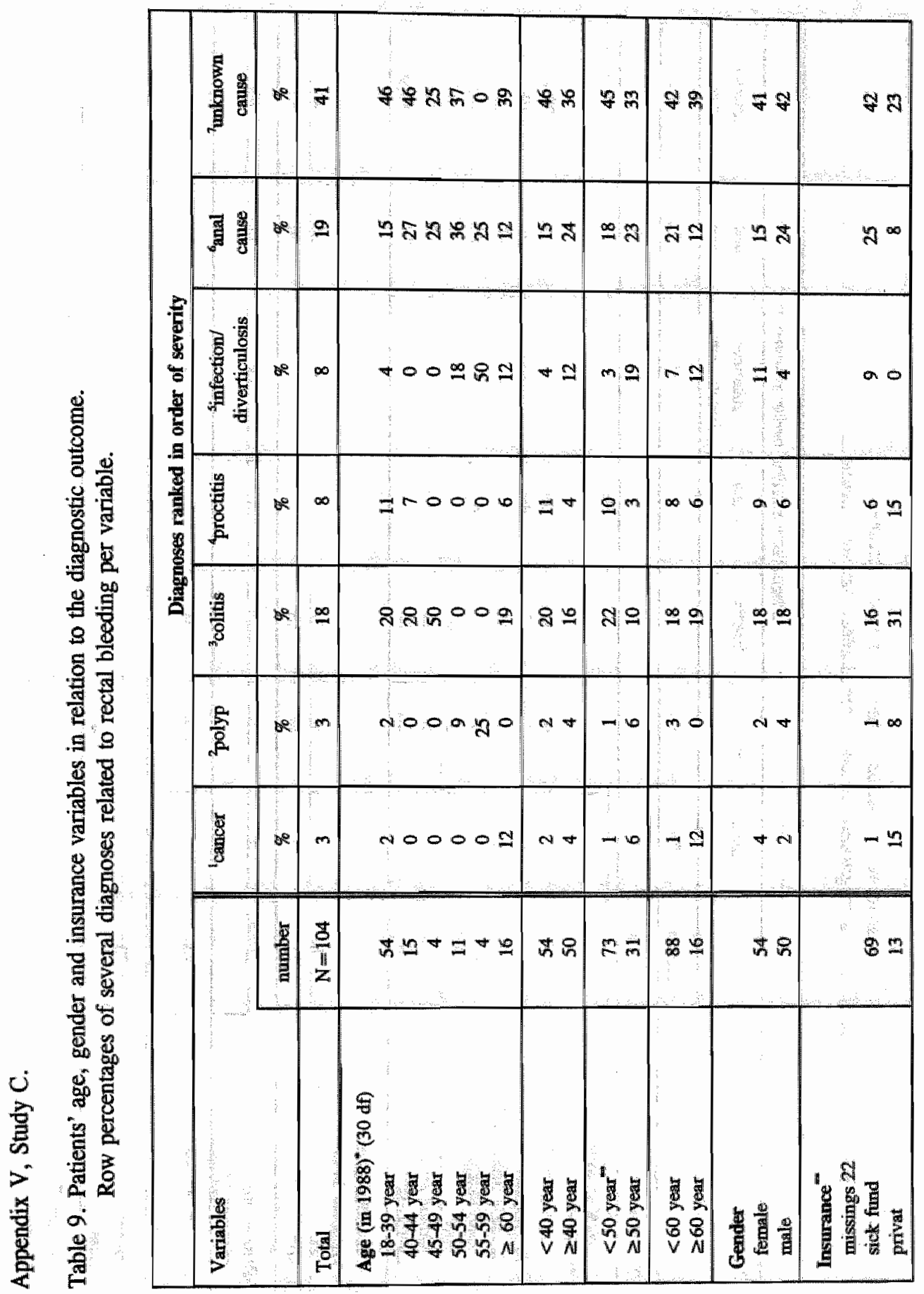




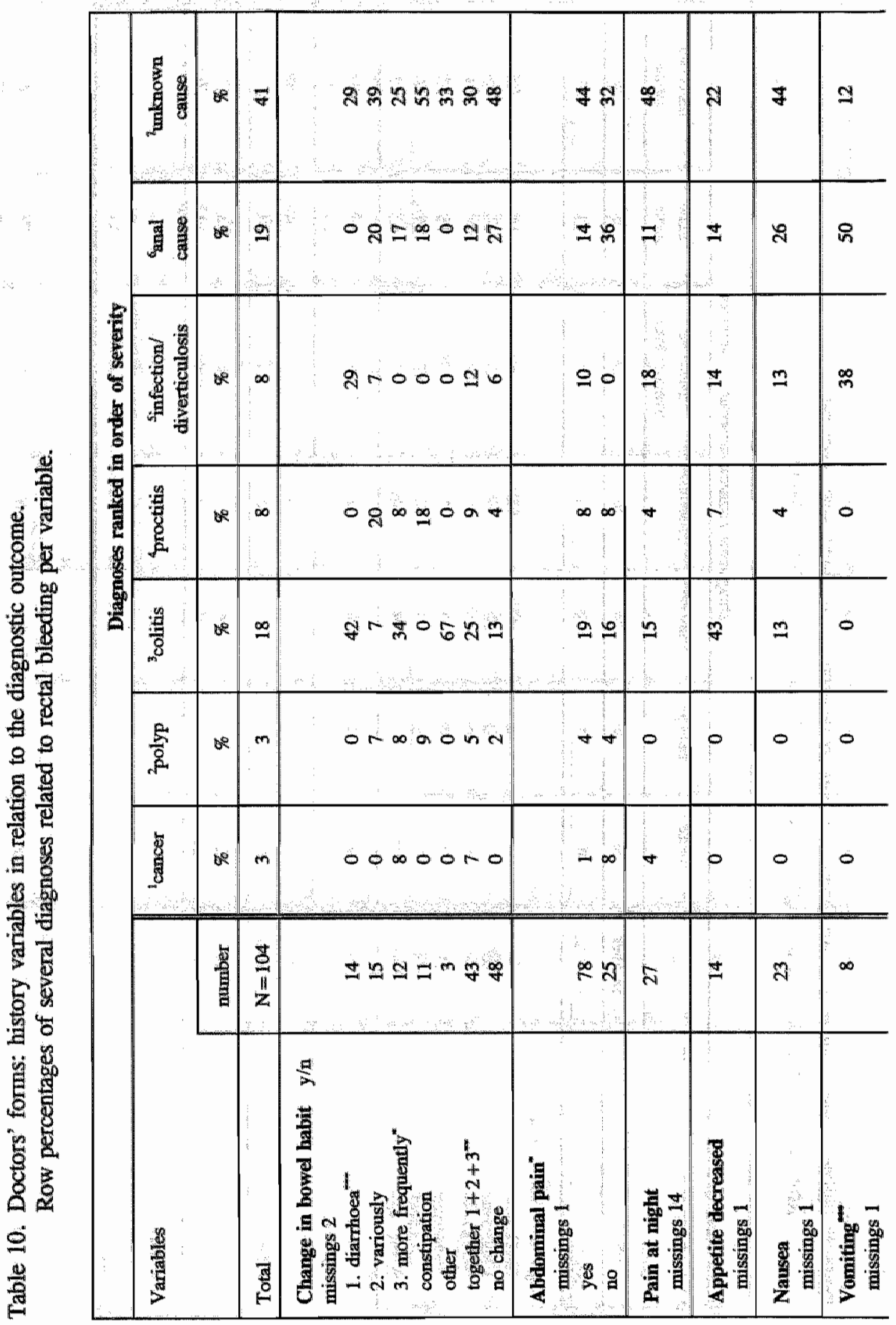




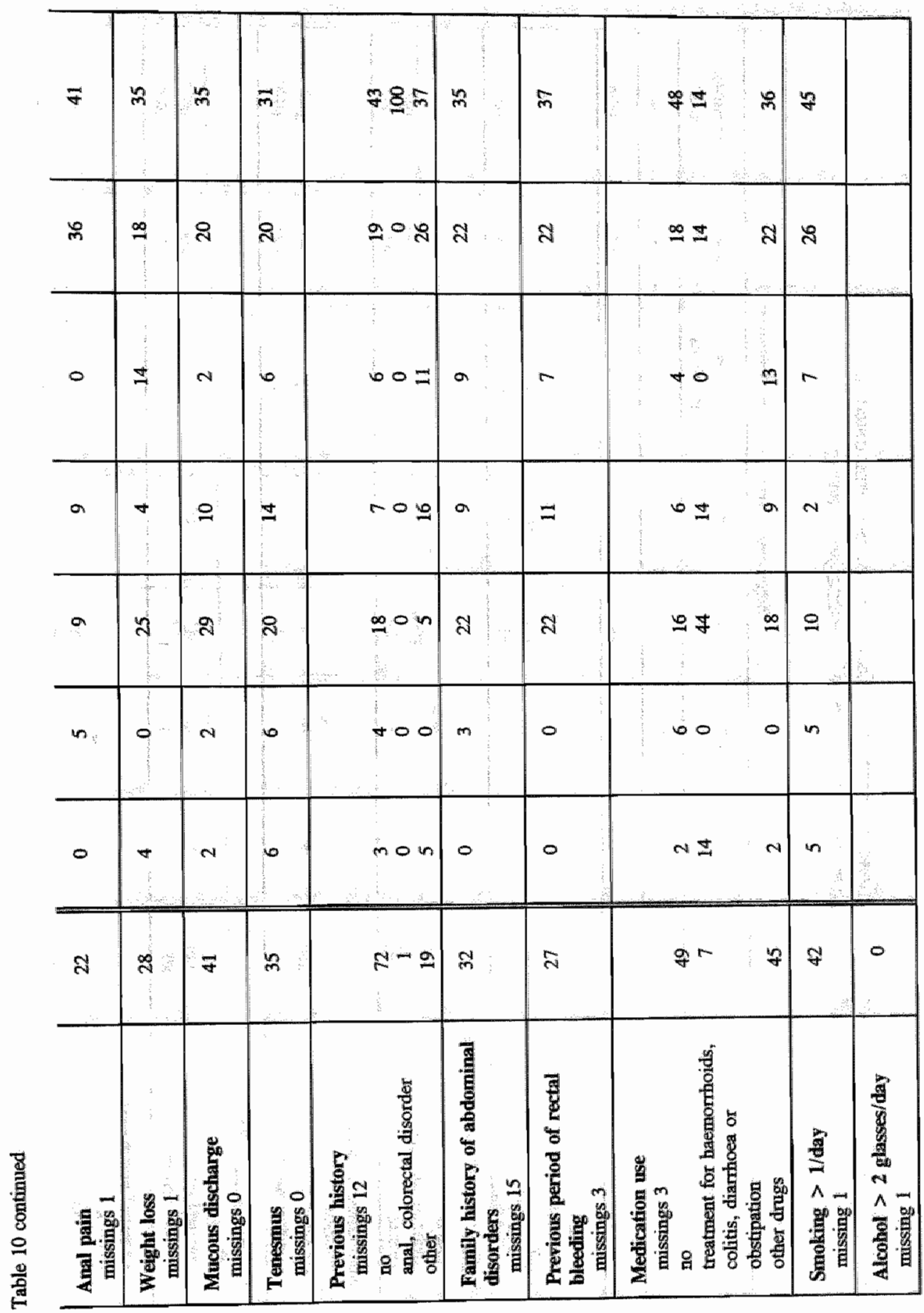




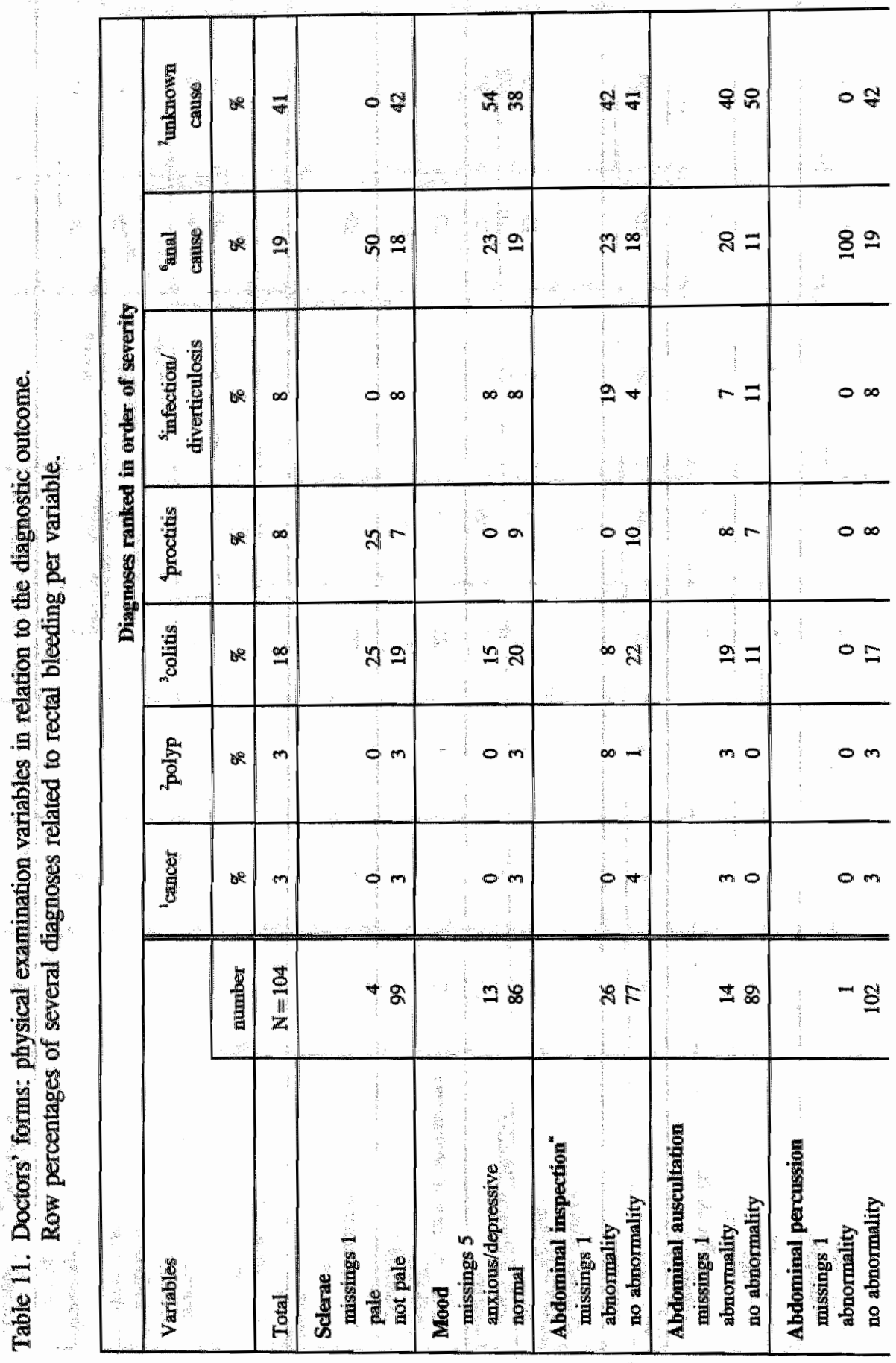




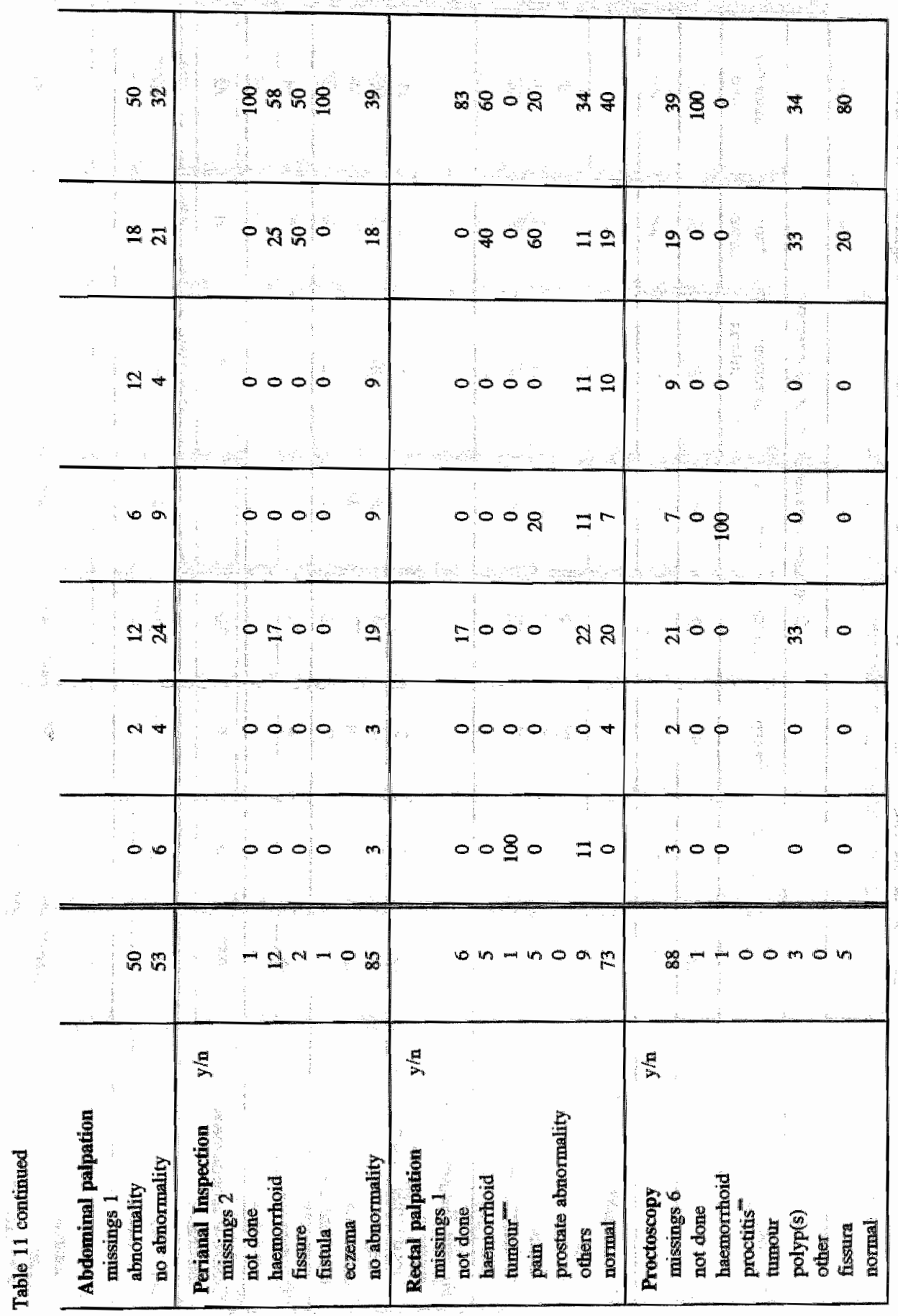




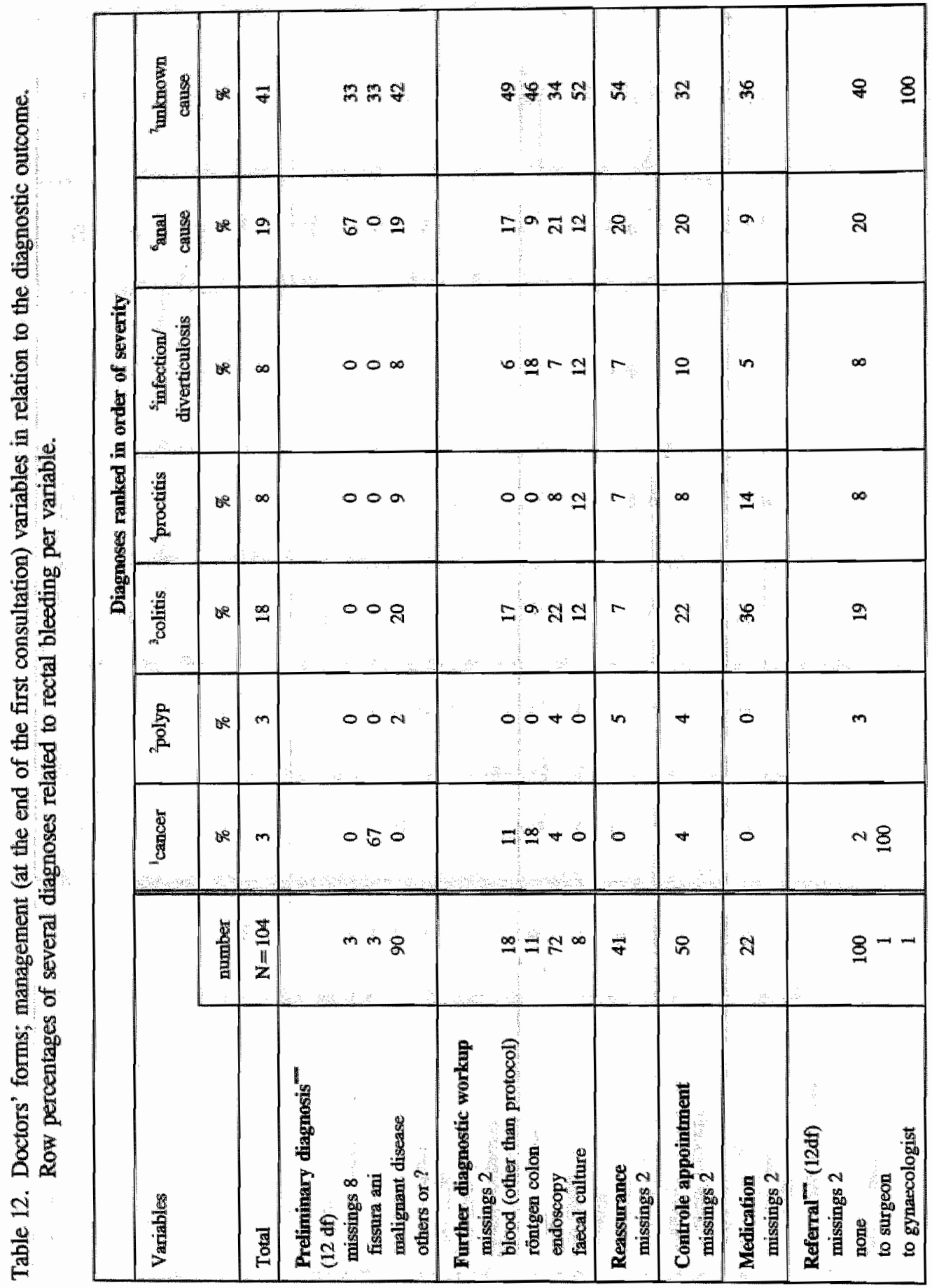




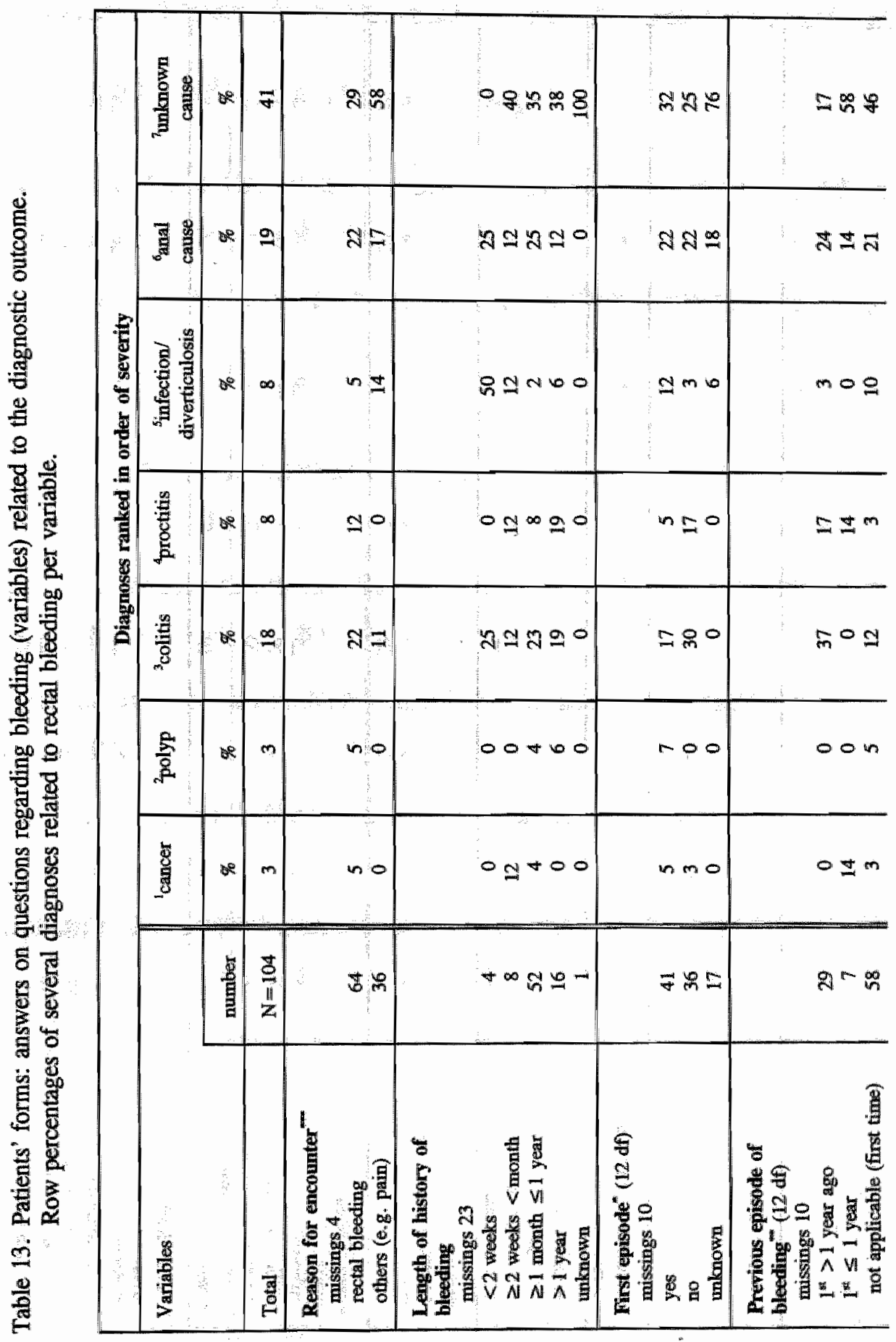




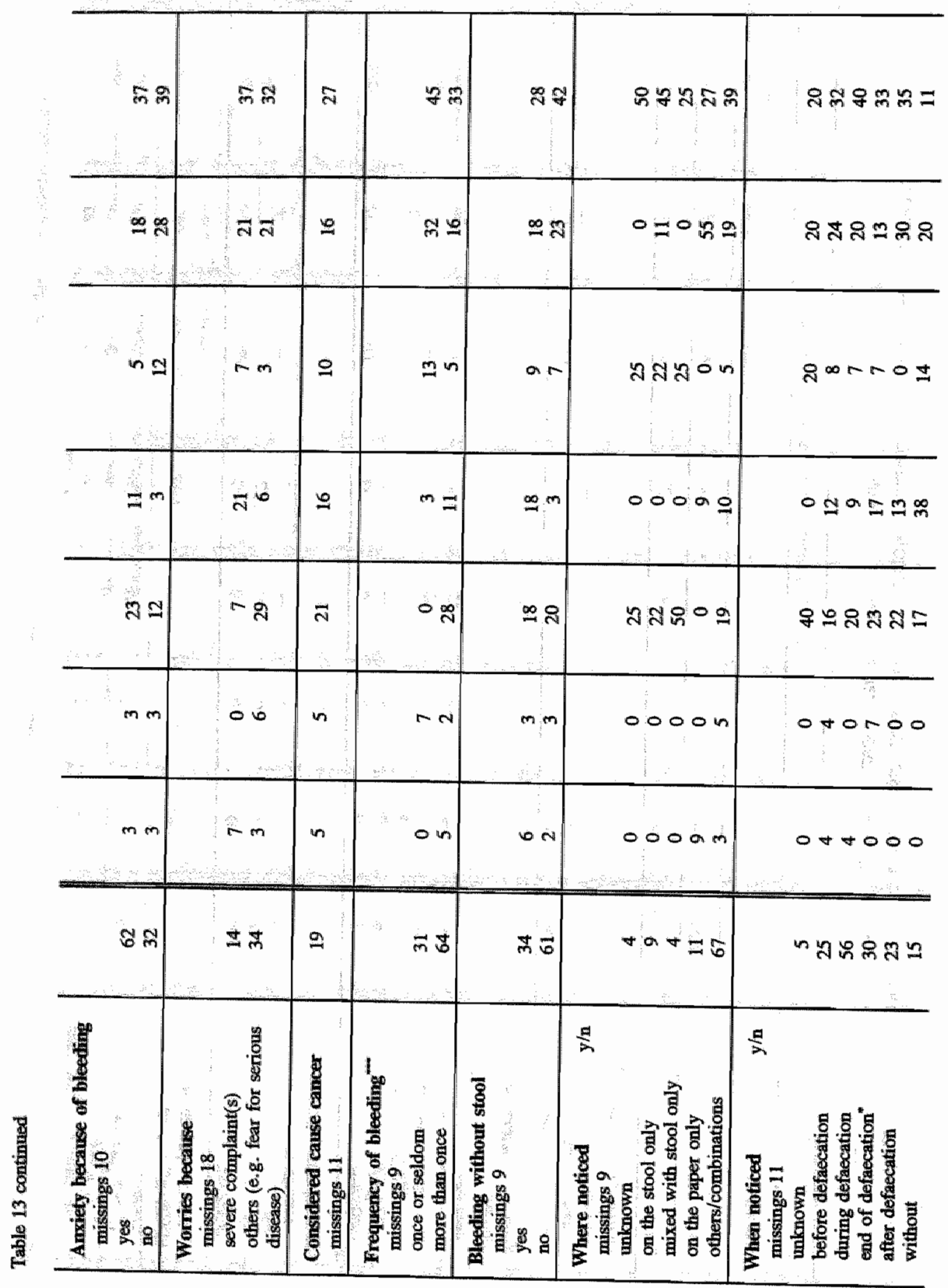




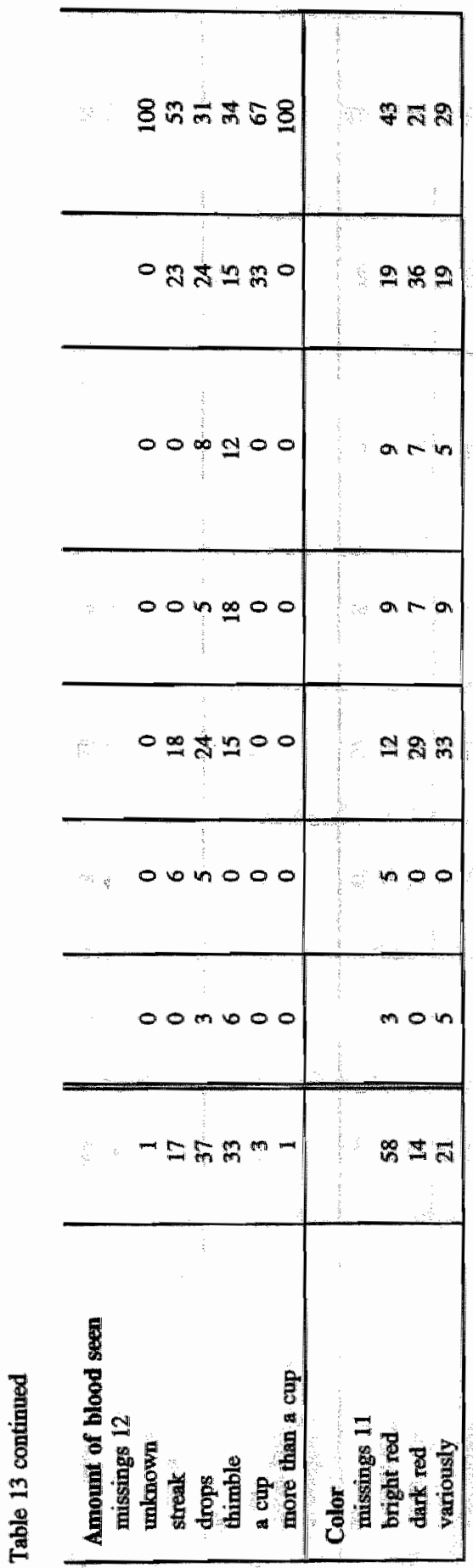




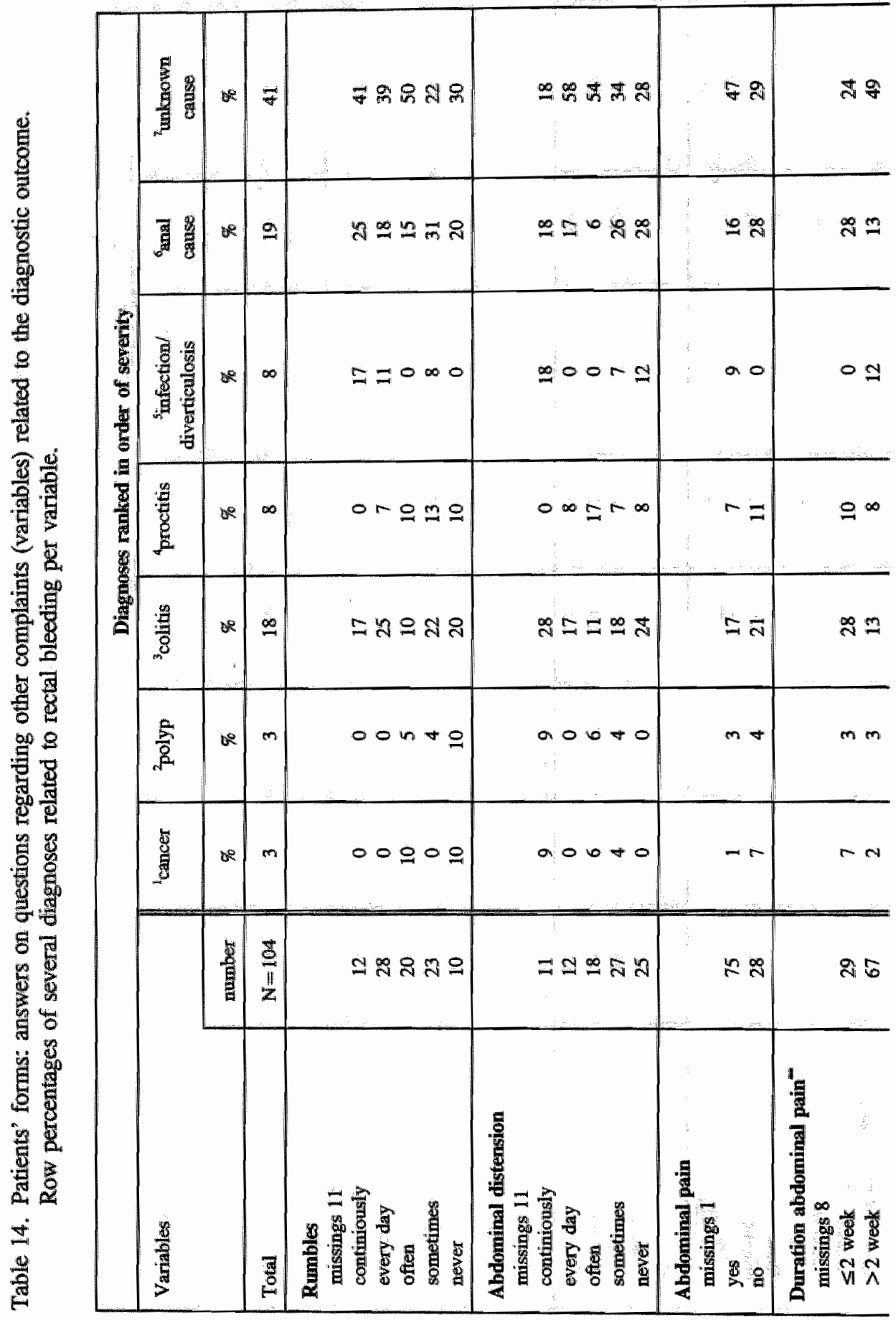




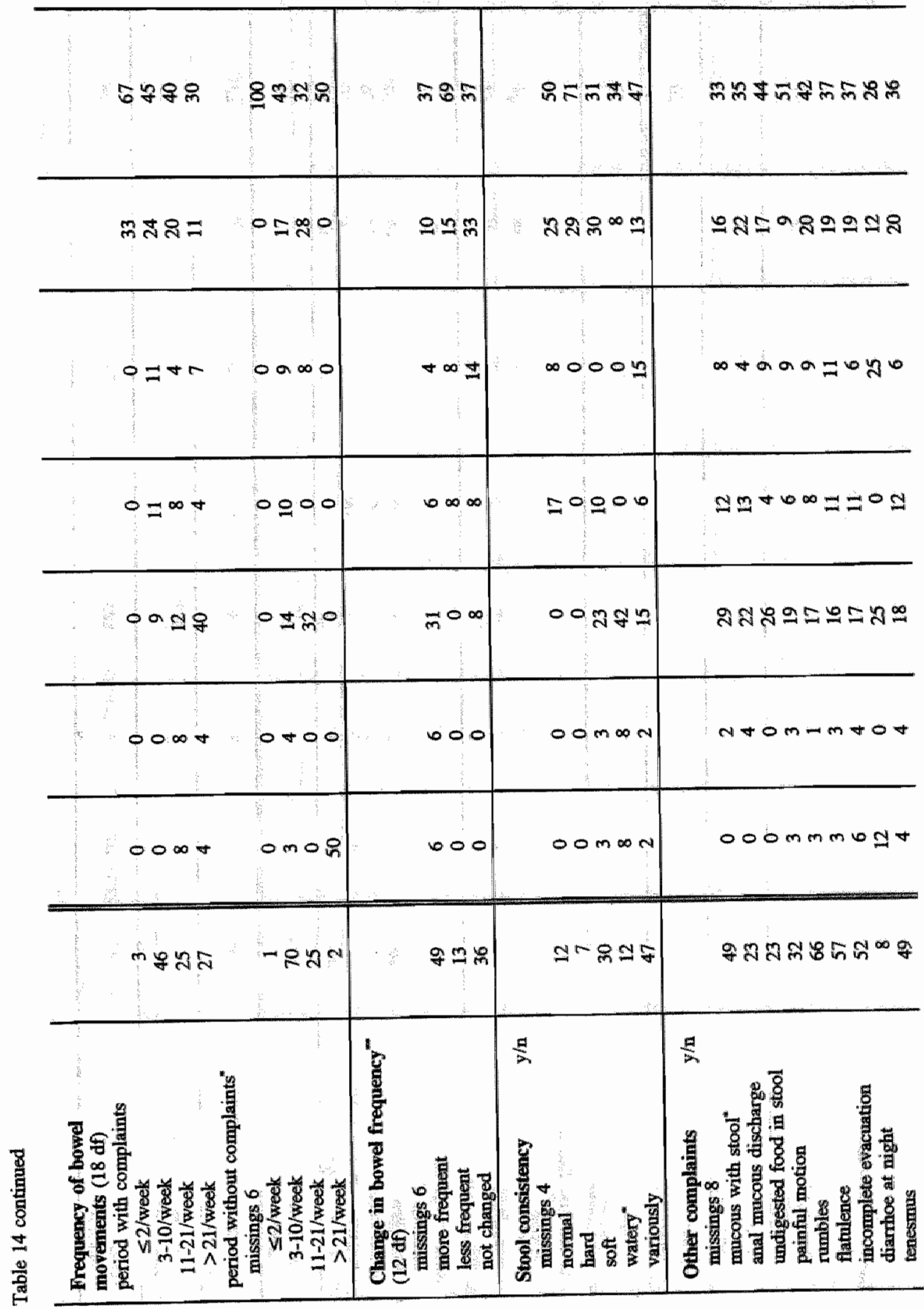




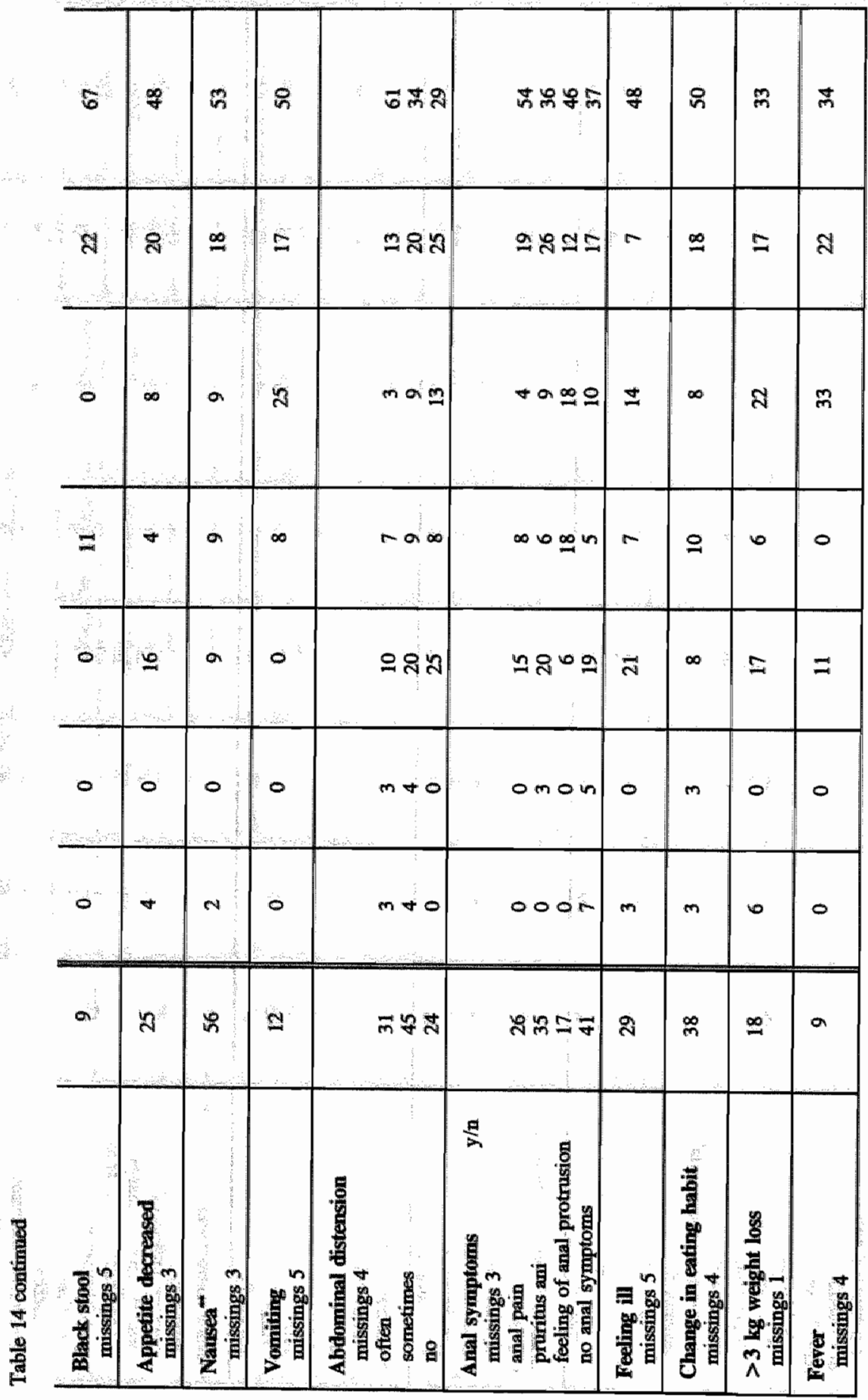




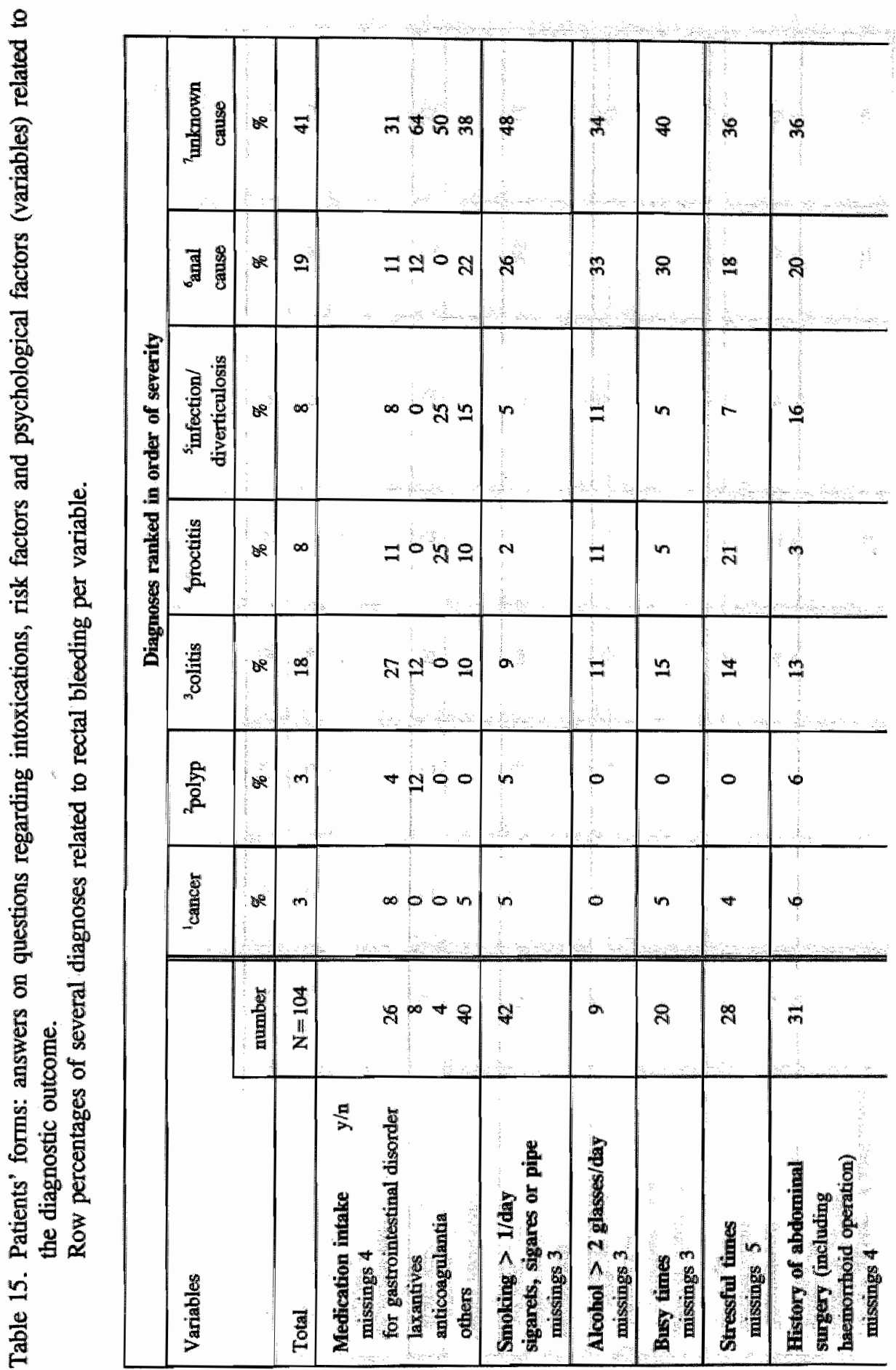




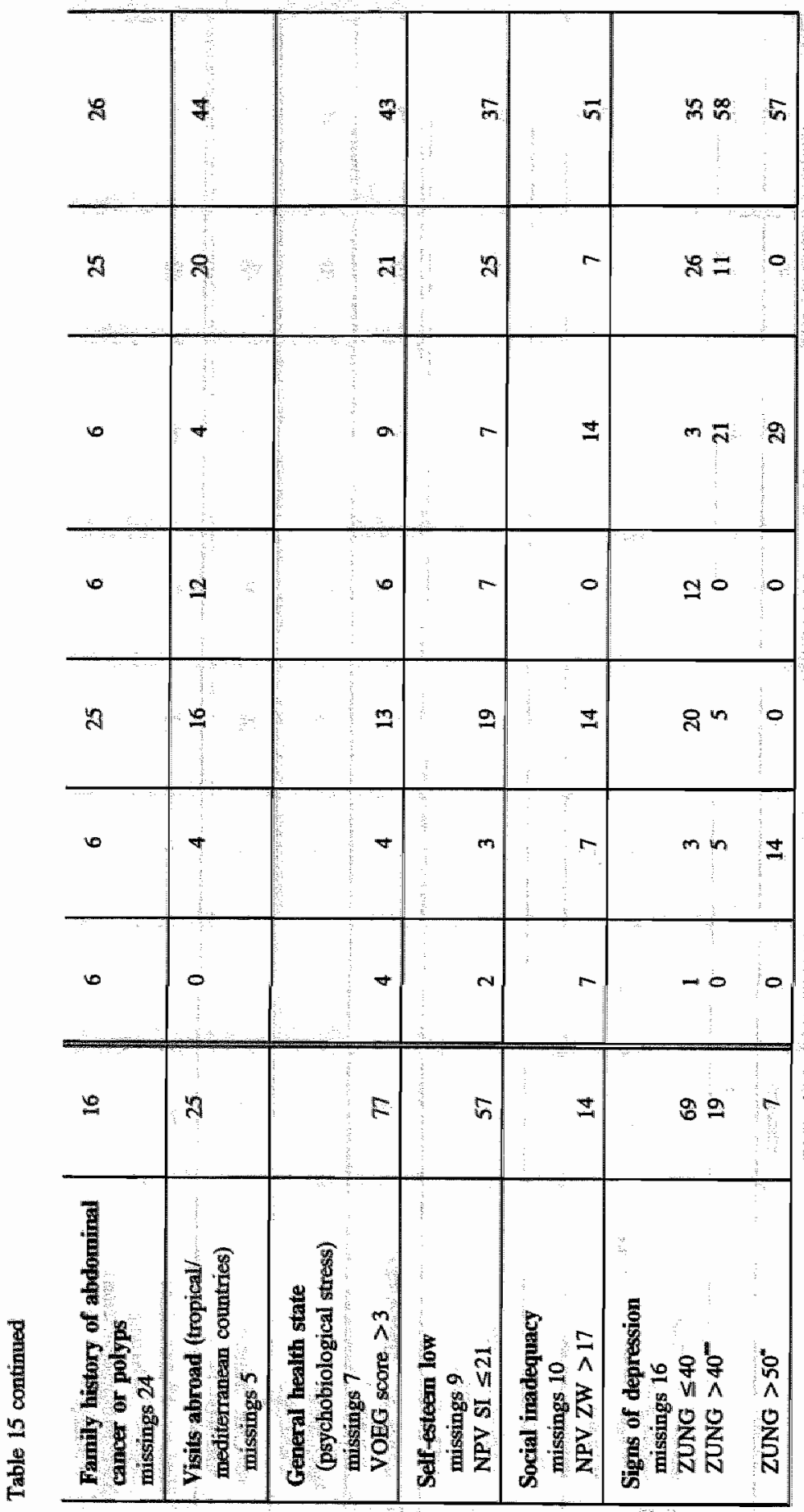




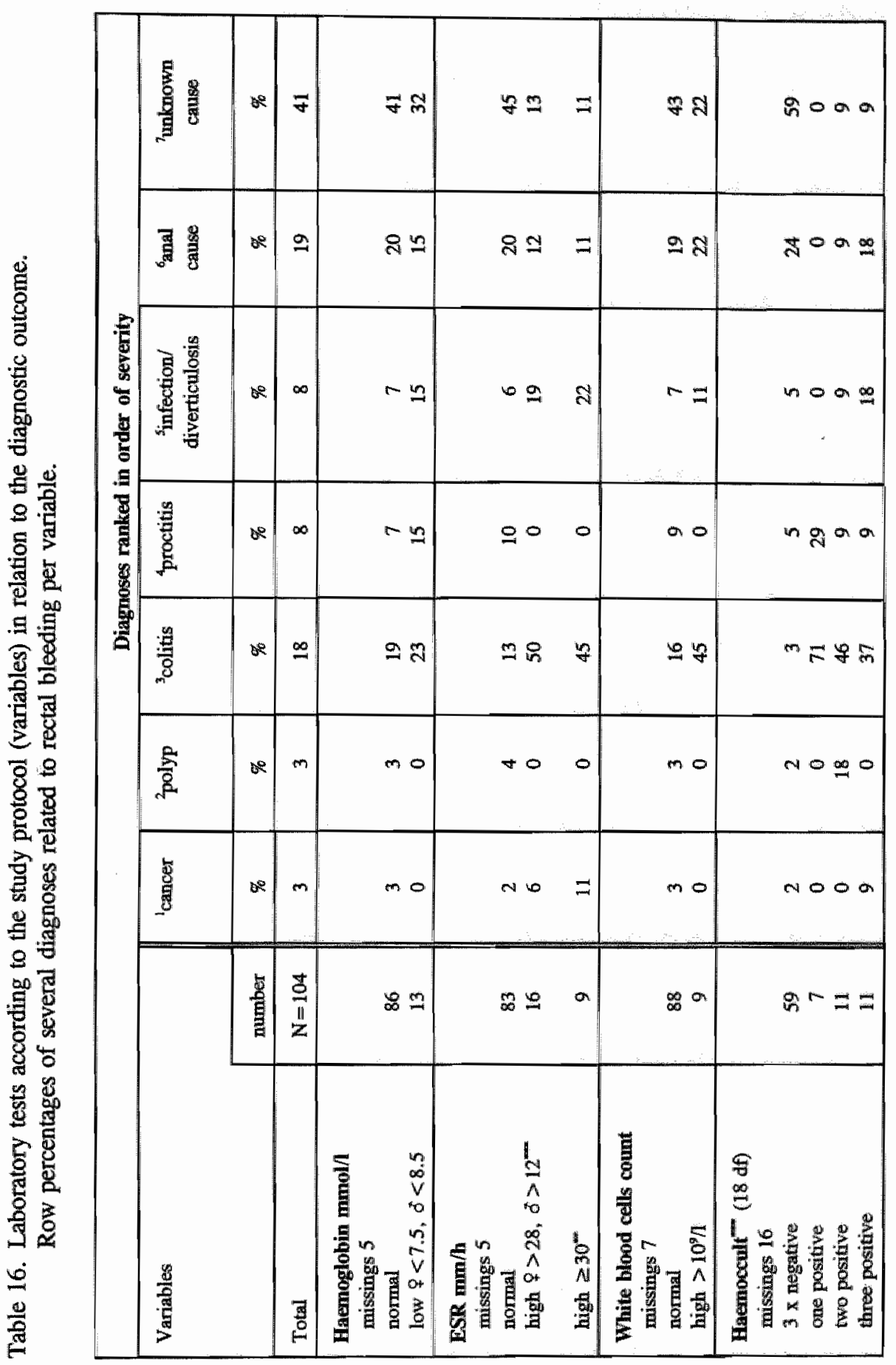

